Sand 80-7013

Unlimited Release

UC-63a Distribution
RECORD COPY

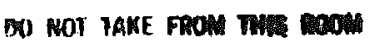

\title{
Simulation and Simplified Design Studies of Photovoltaic Systems
}

\author{
D. L. Evans, W. A. Facinelli, and L. P. Koehler
}

Arizona State University 
Issued by Sandia Laboratories, operated for the United States Department of Energy by Sandia Corporation.

\section{NOTICE}

This report was prepared as an account of work sponsored by the United States Government. Neither the United States nor the Department of Energy, nor any of their employees, nor any of their contractors, subcontractors, or their employees, makes any warranty, express or implied, or assumes any legal liability or responsibility for the accuracy, completeness or usefulness of any information, apporatus, product or process disclosed, or represents that its use would not infringe privately ownest rights.

Printed in the United States of America

Available from

National Technical Information Servica U. S. Department of Commerce

5285 Port Royal Road Springfield, VA 22161

Price: Printed Copy $\$ 8.00$; Microfiche $\$ 3.00$ 
date: December 3, 1980
to: Distribution

from: K. L. Biringer

Organization 4718

\section{Sanclia Laboratories}

Albuquerque. New Mexico Livermore. Calıfornia

\footnotetext{
subject: $\frac{\text { Simulation and Simplified Design Studies of Photovolteic Systems, }}{\text { SAND80-7013: ERRATA }}$

Please enter the enclosed corrections to subject report:
}

page line

$1-4 \quad 4$

2-12 last

" $\sigma$ " should be replaced with "PV"

"optional" should be replaced with "optimal"

2-36 Fig. 2.7

Caption should read "Effect of Location and Weather Patterns"

$\begin{array}{ll}\text { 3-14 } & \text { last } \\ 3-36 & \text { Fig. } 3.8 \\ 4-24 & \text { Fig. } 4.3 \\ 5-14 & \text { 2nd para. 1st line } \\ 5-15 & \text { Ref. } 5.5\end{array}$

$"=0.88 "$ should be $", \alpha=0.88 "$

Change equation in figure to

$\log _{10} Q_{S}=-0.640+0.732 \bar{K}_{\mathrm{T}}$

Vertical ris is " $\overline{\mathrm{H}} / \overline{\mathrm{H}}_{\text {long term }}$ "; Horizontal

Axis should have " $\overline{\mathrm{H}}$ " after $\leq$

Fig. 6" should be replaced with "Fig. 5.8"

should be E.A. Hyman, "Phenomenological

Cell Modeling: A Tool for Planning and

Analyzing Battery Testing at the BEST

Facility," Report RD77-1, Public Service

Electric and Gas company and PSE and $G$

Research Corporation, Newark, NJ (1977). 
SAND 80-7013

Unlinited Release

\title{
SIMULATION AND SIMPLIFIED DESIGN STUDIES OF PHOTOVOLTAIC SYSTEMS
}

\author{
D.L. Evarns \\ W.A. Facinelli \\ L.P. Boehler \\ Mechanical Engineering Department \\ Arizona State University \\ Tempe, Arizona 85281
}

\begin{abstract}
Results of TRNSYS simulations of photovoltaic systens with electrical storage are described. Studies of the sensitivity of system performance, in terms of the fraction of the electrical load supplied by the solar energy system, to variables sach as array size, battery size, location, time of year, and load shape are reported.

An accurate simplified method for predicting array output of max-power photovoltaic systems is presented. A second simplified method, which estimates the overall performance of max-power systems, is develoged. Finally, a preliminary technique for predicting clamped-voltage system performance is discussed.
\end{abstract}




\section{ACENOWLEDGEMENTS}

The work embodied in this report entitled 'Simulation and Simplified Design Studies of Photovoltaic Systems' was conducted by Arizona State Dniversity with Dr. D.L. Evans of the Mechanical Engineering Department serving as Principal Investigator.

Special thanks is due to Kent Biringer of Sandia Laboratories for his assistance, advice and comments.

The assistance of Renee Overbeck, Katty McIntosh, and Jeanette Heschke in preparing the manuscript is deeply appreciated. 
Tit10

$\underline{\text { Page }}$

List of Symbols

\section{Chapter}

1.0 Introduction $\ldots \ldots \ldots \ldots \ldots \ldots \ldots \ldots \ldots \ldots \ldots \ldots \ldots \ldots \ldots \ldots \ldots$

1.1 Background $\ldots \ldots \ldots \ldots \ldots \ldots \ldots \ldots \ldots \ldots \ldots \ldots \ldots \ldots \ldots$

1.2 This stndy $\ldots \ldots \ldots \ldots \ldots \ldots \ldots \ldots \ldots \ldots \ldots \ldots \ldots \ldots \ldots \ldots \ldots$

1.3 Sumary of this Study $\ldots \ldots \ldots \ldots \ldots \ldots \ldots \ldots \ldots \ldots \ldots \ldots \ldots \ldots$

2.0 System Simnlation Stadies $\ldots \ldots \ldots \ldots \ldots \ldots \ldots \ldots \ldots \ldots \ldots \ldots \ldots$

2.1 The system $\ldots \ldots \ldots \ldots \ldots \ldots \ldots \ldots \ldots \ldots \ldots \ldots \ldots \ldots \ldots \ldots \ldots \ldots 2.1$

2.1.1 The Sinulation Program .................2.2

2.1.2 The Solar and Heteorological Data Base .......2.2

2.1.3 The Geographical Location .................2.2

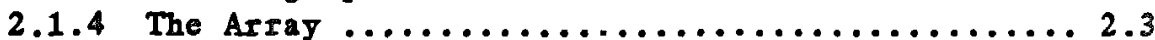

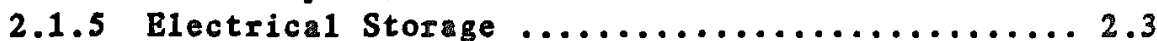

2.1 .6 The Regulator/Inverter ................ 2.4

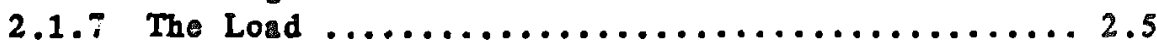

2.2 The Simulations $\ldots \ldots \ldots \ldots \ldots \ldots \ldots \ldots \ldots \ldots \ldots \ldots \ldots . \ldots . \ldots$

2.2.1 Baseline Load/A1buquerque/Equinox Months ...... 2.8

2.2.2 Base1ine Load/A1buquerque/Seasonal Variations .. 2.10

2.2.3 Baseline Load/Effect of Location or Weather Patterns ................................. 2.1

2.2.4 Vaxiation of Load Shape/Albuquerque/Equinox

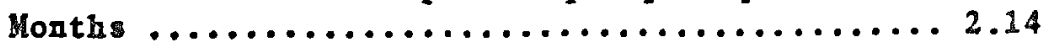

2.2.5 Effect of Rardon Fluctuations in the Load .....2.2.16

2.3 Battery Mode1 Sensitivity .................. 2.18

2.3.1 Choice of Battery Mode1 .................2.18

2.3.2 Energy Losses in the Battery .............. 2.21

2.3.3 Range of State of Charge $\ldots \ldots \ldots \ldots \ldots \ldots \ldots \ldots 2.22$

3.0 Predicting Array Outpat $\ldots \ldots \ldots \ldots \ldots \ldots \ldots \ldots \ldots \ldots \ldots \ldots \ldots . \ldots \ldots$

3.1 The Assumptions $\ldots \ldots \ldots \ldots \ldots \ldots \ldots \ldots \ldots \ldots \ldots \ldots \ldots . \ldots . \ldots$

3.2 The Analgsis $\ldots \ldots \ldots \ldots \ldots \ldots \ldots \ldots \ldots \ldots \ldots \ldots \ldots \ldots \ldots . . \ldots . \ldots . \ldots$

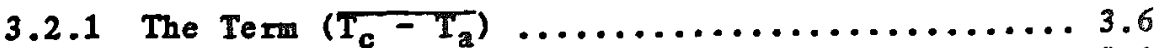

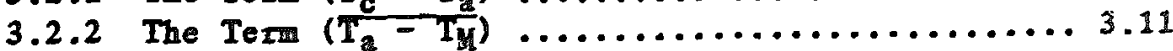

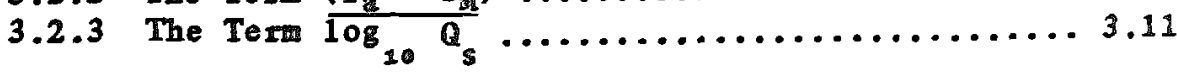

3.3 The Use of the Procednre $\ldots \ldots \ldots \ldots \ldots \ldots \ldots \ldots \ldots \ldots \ldots . .12$ 
3.4 Problems with the Procedare $\ldots \ldots \ldots \ldots \ldots \ldots \ldots \ldots \ldots \ldots \ldots . . \ldots .17$

4.0 Simp1ified Method for Max-Power Tracked System

Performance ................................4.1

4.1 Introdnction $\ldots \ldots \ldots \ldots \ldots \ldots \ldots \ldots \ldots \ldots \ldots \ldots \ldots \ldots \ldots . . . . \ldots$

4.2 System Parameters $\ldots \ldots \ldots \ldots \ldots \ldots \ldots \ldots \ldots \ldots \ldots \ldots \ldots \ldots \ldots . . \ldots$

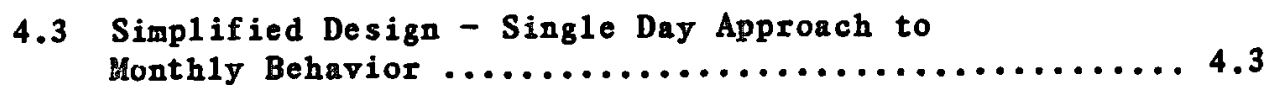

4.3.1 Energy Allocation - Single Day .............4.3

4.3.2 Monthly Distribution ...................4 4.4

4.3.3 The Design Procedure ................... 4.6

4.4 Example $\ldots \ldots \ldots \ldots \ldots \ldots \ldots \ldots \ldots \ldots \ldots \ldots \ldots \ldots \ldots \ldots \ldots \ldots \ldots .4 .8$

4.5 Discussion $\ldots \ldots \ldots \ldots \ldots \ldots \ldots \ldots \ldots \ldots \ldots \ldots \ldots \ldots \ldots \ldots \ldots . \ldots \ldots$

4.5 .1 Comparison of Results .................. 4.13

4.5.2 Interaction on Successive Days ............4.14

4.5 .3 High $\mathrm{K}_{\mathrm{T}}$ Months ....................... 4.15

4.5 .4 Varying Load Profiles ...................4.16

4.5 .5 Utility Sellback ..................... 4.16

4.5.6 A1 ternative Procedures .................. 4.16

4.6 Summary $\ldots \ldots \ldots \ldots \ldots \ldots \ldots \ldots \ldots \ldots \ldots \ldots \ldots \ldots \ldots \ldots \ldots . \ldots \ldots \ldots$

5.0 Simplified Method for Clamped-Voltage System Performance ... 5.1

5.1 Photoroltaic Cell and Battery Mode1s ............. 5.1

5.1 .1 Photovoltaic Ce11 Mode1 .................. 5.1

5.1 .2 Battery Mode1 ........................ 5.3

5.2 Dependence of Array Output npon Ratio of Solar

Cells to Battery Cells ....................... 5.3

5.3 Non-Computer-Based Prediction Method ............. 5.6

5.3.1 Prediction of Performance as a Function

of $S R$ for a Given $S R * \ldots \ldots \ldots \ldots \ldots \ldots \ldots \ldots \ldots \ldots .6$

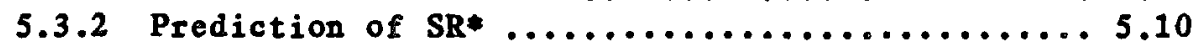

5.4 Computer-Based Prediction Method ............... 5.11

6.0 Discussion, Conclusions and Summary ................6.1

6.1 Simulation Results $\ldots \ldots \ldots \ldots \ldots \ldots \ldots \ldots \ldots \ldots \ldots \ldots \ldots \ldots . . \ldots$

6.2 Simplified Procedure for Predicting Array Output ..... 6.2

6.3 Mar-Power Tracked $S_{y} s t e m$ Results $\ldots \ldots \ldots \ldots \ldots \ldots \ldots \ldots 6.3$

6.4 Battery or Voltage Clamped System Results ..........6.4 


c
$c_{f}$
$c_{i}(i=1, \cdots 6)$
$c_{s}$

CV1, CV2

F

F $_{\text {B }}$

$F_{\text {C }}$

$F_{D}$

f

B

$\mathbb{I}$

I

$I_{\mathbf{m p}}$

$I_{\text {sc }}$

$\mathrm{K}$

$\overline{\mathbf{K}}_{\mathbf{T}}$

Array area

Daylength correction term [eq. (4.6)]

Correction factor to convert $\mathbb{R}_{e}\left(\overline{T_{c}-T_{a}}\right) /(\rho \alpha)$ for non-optimum tilts

Constants in equations used to define the $I-V$ carve of ce11s or arrays [eqs. (5.1)]

Correction factor to convert average day insolation to good, mediocre or poor day insolation (see Fig. 4.4)

Symbols used to denote cells of different I-V curve shape (see page 5-2 and Table 5.1)

Battery fractional state of charge

If $F_{p}$ is reached and if $F_{B}>F_{D}$, first priority is given to ICcharging the battery ( $\beta_{\text {rom }} D_{\text {the array) to } F=F_{B}}$

Maximum fractional state of cherge permitted for the batteries

Minimum fractional state of charge permitted for the batteries

Fraction (or percent) of load that is met by a photovoltaic system

Daily total solar energy received on a horizontal surface. Includes direct and diffuse components of insolation

Electrical Current

Photoroltaic cell or array current

Photovoltaic cell or array current at maximum power output

Ce11 or array short circuit current

Thermal conductance for energy transfer as heat from the cells to the final heat sink (usnally the atmosphere)

Monthly average ratio of total radiation on a horizontal surface to radiation that would be received by this same surface if it vere located above the atmosphere (the ertraterrestrial radiation). This is sometimes referred

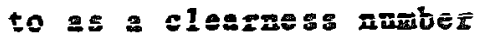




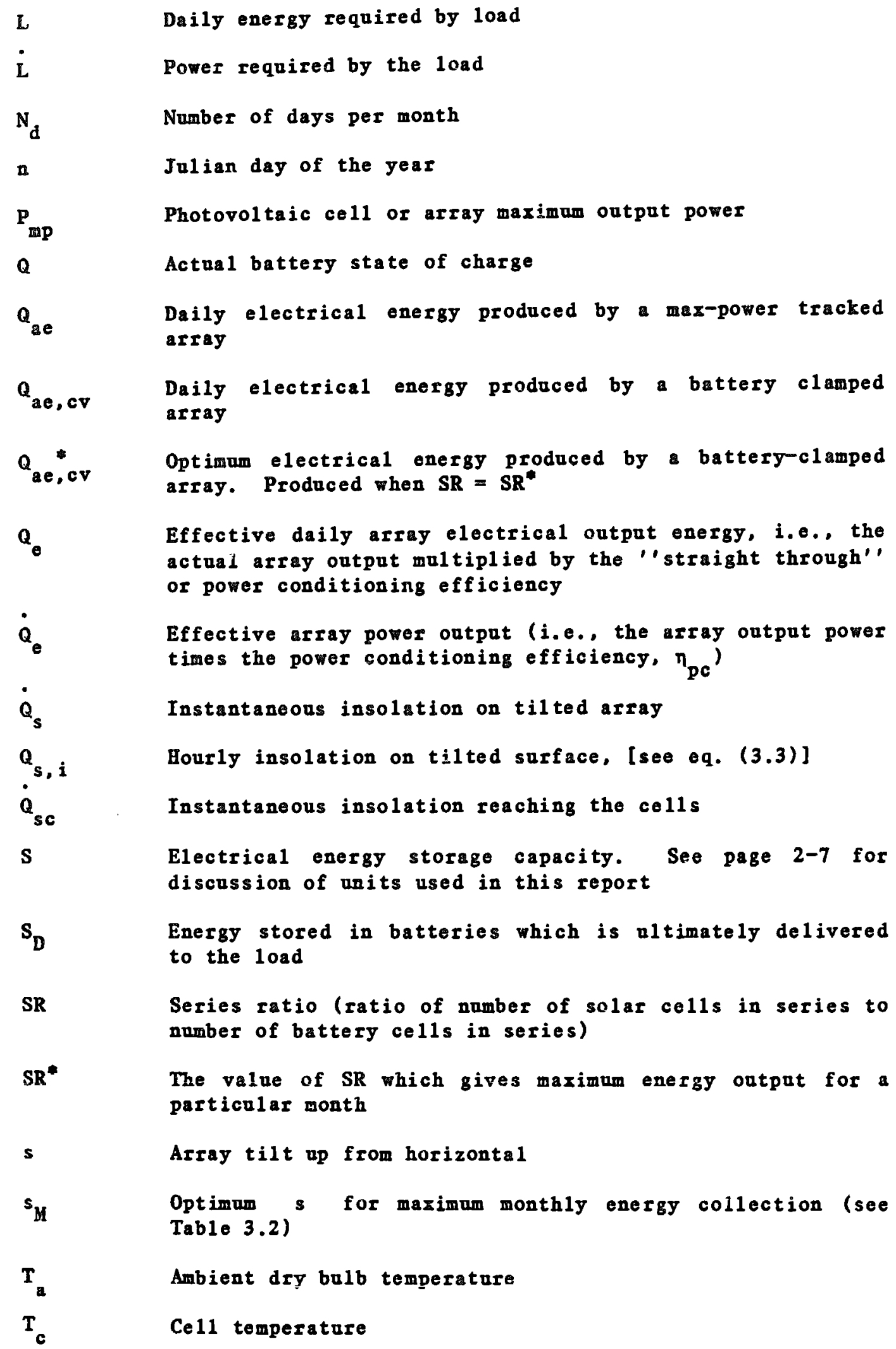




\begin{tabular}{|c|c|}
\hline $\mathbf{T}_{\mathbf{M}}$ & $\begin{array}{l}\text { Mean monthly temperature as compiled by the Natioral } \\
\text { Weather Service }\end{array}$ \\
\hline $\mathrm{T}_{\mathrm{NOCT}}$ & NOCT (Nominal operating cell temperature) \\
\hline$T_{p}$ & Time of day at which peak of sinusoidal load occurs \\
\hline $\mathbf{T}_{\mathbf{5}}$ & A reference temperature for cell efficiency (see $\eta_{I}$ ) \\
\hline$T_{I i}(i=1,2)$ & $\begin{array}{l}\text { Constants in equations used to define the } I-V \text { curves of } \\
\text { ce11s or arrays [eqs. }(5.1) \text { ] }\end{array}$ \\
\hline $\mathbf{t}$ & Time \\
\hline $\mathbf{t}_{\mathbf{D}}$ & Daylight daylezgth [see eq. (4.9)] \\
\hline $\mathbf{V}$ & Voltage \\
\hline $\mathbf{v}_{\mathrm{b}}$ & Battery cell voltage \\
\hline $\mathbf{v}_{\mathrm{c}}$ & Photovoltaic cell or array voltage \\
\hline$v_{\text {mg }}$ & Cell or array voltage for maximum power output \\
\hline $\mathbf{v}_{0}$ & Thermal voltage [eq. (5.1)] \\
\hline$v_{\text {oc }}$ & Ce11 or array open circuit voltage \\
\hline $\mathbf{X S}$ & $\begin{array}{l}\text { That portion of the daily effective array output energy } \\
\text { which cannot be used imediately by the load }\end{array}$ \\
\hline xs & $\begin{array}{l}\text { Instantaneous excess energy (i.e., the amount by which the } \\
\text { array power exceeds the load demand) }\end{array}$ \\
\hline
\end{tabular}




\section{GREER SYMBOLS}

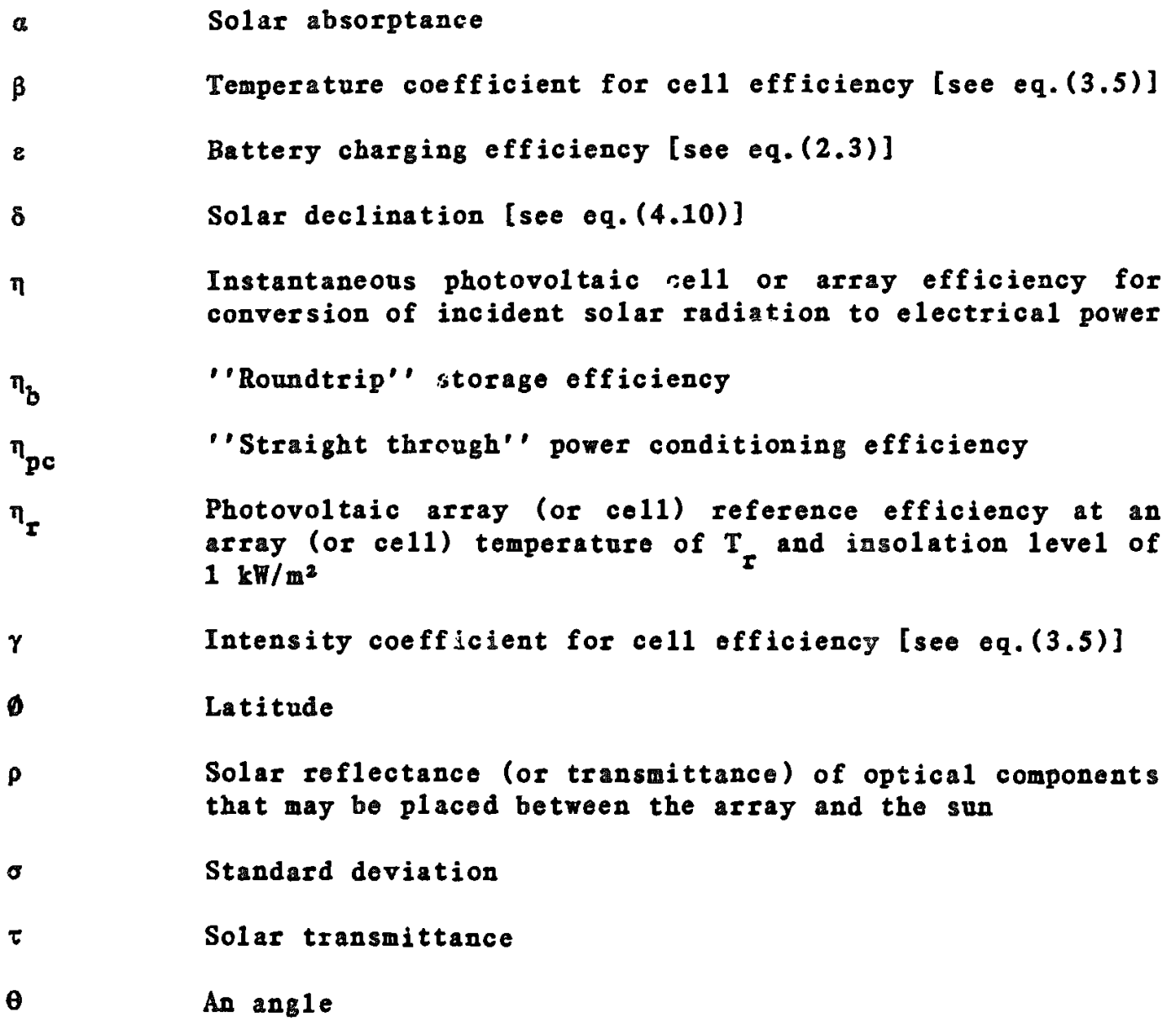

\section{SUBSCRIPTS}

a

e

i

n

$\mathbf{I}$

s
Array

Effective or electrical

Hourly value

Daily valuo

Reference value

Solar 


\section{SPECIAL SYMBOLS}

as, e.g., in $\bar{Q}_{e}$, means monthly average value

pos symbol used before integral sign to indicate only positive values of the integral should be considered

(12) as used, e.g.. in $\bar{Q}_{s}(12)$ denotes midday (mear solar noon)
values 


\section{LIST OF TABLES}

Table

2.1 Hours of Storage for Discharging at $L$ for Various Times of the Year at Three Locations

2.2 Jtility Sellback Results

2.3 Effect of Battery Mode1

2.4 Storage Losses as a Percent of Load

3.1 SOLMET Sites and Years of Data Used in this Study

3.2 Optimam Tilts

3.3a Comparison of Simplified Procedure for Predicting Array Output with Hourly Simulation; Albuquerque

3.3b Comparison of Simplified Procedure for Predicting Array Output with Hourly Simulation; Madison

3.3c Comparison of Simplified Procedure for Predicting Array Output with Hourly Simulation; Medford

3.4 Essence of the NOCT Test Requirements

4.1 Sumary of Procedure for Estimating System Performance

4.2 Comparison of Results from Simplified Procedure with Simulation Results

5.1 Constants Used in Eqs. 5.1 for Determining I-V Curves 5-16

6.1 Example of Manufacturer's Data 6-11 


\section{LIST OFF FIGUKES}

Figure

Srbject

$\underline{\text { Page }}$

2.1 Schematic of Photovoltaic Electric System 2-30

2.2 Diurna1 Load Shape 2-31

2.3 System Performance Predictions of TRNSYS Simulations 2-32

2.4 Storage Battery Otilization for Various Size Systems $F=$ Fractional State of Charge of Battery

2.5 Seasonal Variation in System Performance 2-34

2.6 Seasona1 Differences Between Daily Load Shape and Insolation Profiles for the Same $Q_{e} / L$ 2-35

2.7 Effect of Location or Weather Patterns 2-36

2.8 Combined Effect of Seasonal Variations and Local

$\begin{array}{ll}\text { Weather Patterns 2-37 } & \text { 20 }\end{array}$

2.9 Effect of Load Shape on System Performance 2-38

2.10 Energy F1ow Diagram for Dtility-Feedback 2-39

2.11 Typica1 Daily Interactions Between Array Output_and Fluctuating Load for (a) $Q_{e} / L=0.6$ and $(b) Q_{e} / \bar{L}=0.4 \quad 2-40$

2.12 Charge $(I>0)$ and Discharge (I $(0)$ Characteristics of Three Models for a Lead-Acid Battery Cell of 250 Amp-hr Capacity

2.13 Effect of Battery "Vo1tage Difference"' and Charging Losses on System Performance

2.14 Effect of Different Ranges of Battery State of Charge 2-43

3.1 Energy Balance Schematic for an Array 3-28

3.2 Long Term Monthly Results for $K_{e}\left(T_{c}-T_{a}\right) /(\rho \alpha)$ vs. $\bar{K}_{T}$ 3-29

3.3 Distribation of Individual Monthly $\overline{\mathrm{B}}_{\mathrm{T}}$ about the Long Term $\bar{K}_{\mathrm{T}}$ for the Same Honth and Location. The Sever Cities Listed in Iig. 3.2 were Used

3.4 Distribution of Individual Monthly $\mathbb{K}_{e}\left(T_{c}-T_{a}\right) /(\rho a)$ about the Straight Line Fit Shown in Fig. 3.2

3.5 Correction Factor for Converting to Non-Optimun Tilts 3-32 
3.6a Midday Values of $\mathrm{K}_{\mathrm{e}}\left(\mathrm{T}_{\mathrm{c}}-\mathrm{T}_{\mathrm{a}}\right) /(\rho a)$ vs. Long TeIm Monthly $\bar{K}_{T}$. These Data are for Total Radiation on the Optimum Tilt. Adjustment to Non-optimum Tilts can be Made by a Cosine Correction. The Direct Normal Data (DN) are Shown in Figure $3.6 \mathrm{~b}$

3.6b Midday Values of $\mathrm{K}_{\mathrm{e}}\left(\mathrm{T}_{\mathrm{c}}-\mathrm{T}_{\mathrm{a}}\right) /(\rho a)$ vs. Long Term Monthly $\overline{\mathrm{B}}_{\mathrm{T}}$. These Data are for Direct Normal Radiation. The Total Radiation on the Tilt (TT) Data are Shown in Fig. 3.68

3.7 TMY Monthly Results for $\left(T_{a}-T_{M I}\right)$ for Seven Cities

3.8 Long Term Monthly Results for $\log _{10} Q_{S}$ vs $\bar{B}_{T}$ for Seven Cities Using Optimum Tilts Each Month

3.9 SOLMET Derived $\overline{\mathbf{x}}_{\mathrm{T}}$ 's for Albuquerque, $\mathrm{NM}$

3.10 SOLMET Derived $\overline{\mathrm{K}}_{\mathrm{T}}^{\prime}$ s for Bismarck, ND 3-38

3.11 SOLMET Derived $\overline{\mathrm{K}}_{\mathrm{T}}$ 's for Madison, WI 3-39

3.12 SOLWET Derived $\overline{\mathrm{B}}_{\mathrm{T}}$ 's for Medford, OR 3-40

3.13 SOLUET Derived $\overline{\mathrm{K}}_{\mathrm{T}}$ 's for Phoenir, $\mathrm{AZ} \quad 3-41$

3.14 SOLMET Derived $\overline{\mathrm{K}}_{\mathrm{T}}$ 's for Santa Maria, CA 3-42

3.15 SOLAET Derived $\overline{\mathrm{K}}_{\mathrm{T}}$ 's for Washington D.C./Sterling, VA 3-43

3.16 Long Term Monthly Average Daily Total Radiation on Monthly Optimally Tilted (TT) Array for Seven Cities

3.17 Long Term Monthly Average Daily Direct Normal Radiation (DN) for Seven Cities

3.18 Long Term Average Midday Total Insolation on Optimally Tilted Array for Seven Cities. For Legend see Fig. 3.2 3-46

3.19 Long Term Average Midday Direct Normal Insolation for Seven Cities. For Legend see Fig. 3.2

3.20 Energy Balance Schematic for NOCT Test

3.21 Fig. 3.2 Converted for Use with NOCT Data. The Solid Curve is for NOCT Data Taken at $1.0 \mathrm{~km} / \mathrm{m}^{2}$ Insolation. The Dotted Curve is for NOCT Data Taken at $0.8 \mathrm{~kW} / \mathrm{m}^{2}$

$3.22 \Delta T$ Corrections to be Applied to NOCT Data to Adjust Wind Speed and Average Temperature to Local Conditions. (Modified from Ref. 3.19)

4.1 Pictoral Representation of the System Parameters $Q_{e}, L$, $X S$, and $S$ 
4.2 Apportionment of Effective Array Output on an Arbitrary Day

4.3 Generalized Distribution of Daily Total Radiation on a Horizontal Surface for Various $B_{T}$

4.4 Daily Effective Array Output as a Function of $\overline{\mathbb{K}}_{\mathrm{T}}$ (3-Dag Distribution)

4.5 Comparison of Simulated Monthly Average Effective Array Outpat with Cosine Approximation for Albuquerque in

(a) June and (b) December

4.6 Alternative Design Procedure. Linear Least Squares P1ots of Simulation Results Showing Total Losses as a Function of Monthly Mean XS and the Storage Parameter. $s / \eta A$

4.7 Alternative Design Procedure. Simulated Monthly Dumping Losses as a Function of Monthly Mean Values of $\mathrm{S} / \mathrm{XS}$ and $\mathbf{K}_{\mathrm{T}}$

5.1 Normalized_Monthly Performance vs. Series Ratio, CV1 Ce11s, $Q_{e} / \bar{L}=0.6, \mathrm{~S} / \mathrm{nA}=20 \mathrm{~W}-\mathrm{hrs} /\left(\mathrm{sm}^{2}\right)$

5.2 Normalized_Monthly Performance vs. Series Ratio, CV2 Ce11s, $\bar{Q}_{e} / \bar{L}=0.6, \mathrm{~S} / \bar{\eta} A=20 \mathrm{~W}-\mathrm{hrs} /\left(\mathrm{q}_{\mathrm{a}}^{2}\right)$

5.3 Power Output vs. Cell Voltage for a CV1 Cel1 at Miiday on an Average March Day in Albuquerque

5.4 Normalized Array Output or Cell Power vs. Series Ratio. Obtained by Rescaling Fig. 5.3 $\left(\mathrm{SR}^{*}=5.6\right)$

5.5 Normalized Array Ontput vs. Series Ratio, from TRNSYS Simulations and from Linearizing the Scale of Fig. 5.4. $Q_{e} / \bar{L}=0.8, S / \eta A=20.3 \mathrm{~W}-\mathrm{t} \Omega \mathrm{s} /\left(\mathrm{gan}^{2}\right)$

5.6 Optimum Clamped Voltage Array Output vs. Max-Power Array Ontput, CV1 Ce11s, Normalized by Maxiaum $\bar{Q}_{a e}$

5.7 Optimum C1amped Voltage Array Ontput vs. Max-Power Array Ontput, CV2 Ce11s, Normalized by Mazimum $\bar{Q}_{a e}$

5.8 Information Flow Diagram of Average-Day Simulation Program for Clamped-Voltage Systems

5.9 Comparison c $c$ TRNSYS and Average-Day Program Simulation Results 
4.2 Apportionment of Effective Array Outpot on an Arbitrary Dey

4.3 Generalized Distribution of Daily Total Radiation on a Horizontal Surface for Various $\mathrm{K}_{\mathrm{T}}$

4.4 Daily Effective Array Output as a Function of $\bar{K}_{T}$ (3-Day Distribution)

4.5 Comparison of Simulated Monthly Average Effective Array Output ith Cosine Approximation for Albuquerque in

(a) June and (b) December

4.6 Alternative Design Procedure. Linear Least Squares Plots of Simulation Results Showing Total Losses as a Function of Monthly Mean $\overline{X S}$ and the Storage Parameter, $S / n A$

4.7 Alternative Design Procedure. Simulated Jionthly Dumping Losses as a Fanction of Monthly Mean Values of $\mathrm{S} / \overline{\mathrm{XS}}$ and $\mathbf{K}_{\mathrm{T}}$

5.1 Normalized_Month1y Performance vs. Series Ratio, CV1 Ce11s, $Q_{e} / \bar{L}=0.6, \mathrm{~S} / \eta \mathrm{A}=20 \mathrm{~W}-\mathrm{hrs} /\left(\% \mathrm{~m}^{2}\right)$

5.2 Normalized_Month1y Performance vs. Series Ratio, CV2 Ce11s, $Q_{e} / \bar{L}=0.6, S / \eta A=20 \mathrm{~W}-\mathrm{hrs} /\left(\mathrm{mm}^{2}\right)$

5.3 Power Output vs. Ce11 Voltage for a CV1 Ce11 at Midday on an Average March Day in Albuquerque

5.4 Normalized Array Outprt or Cell Power vs. Series Ratio, Obtained by Rescaling Fig. $5.3\left(\mathrm{SR}^{*}=5.6\right)$

5.5 Normalized Array Output vs. Series Ratio, from TRNSYS Simulations and from Linearizing the Scale of Fig. 5.4. $\bar{Q}_{e} / \bar{L}=0.8, S / \eta \bar{A}=20.3 \mathrm{Whrs} /\left(\mathrm{m}_{\mathrm{m}}^{2}\right)$ 5-20

5.6 Optimum Clamped Vo1tage Array Ontput vs. Max-Porer Array Output, CV1 Cells, Normalizea by Maximum $\bar{Q}_{a e}$

5.7 Optimum Clamped Voltage Array Output vs. Max-Power Array Outpat, CV2 Cells, Normalized by Maximum $\bar{Q}_{a e}$

5.8 Information F1ow Diagram of Average-Day Simulation Program for Clamped-Voltage Systems

5.9 Comparison cf TRNSYS and Average-Day Program Simulation Results 


\subsection{INTRODUCTION}

\subsection{Background}

Widespread adoption of photovoltaic (PV) systems for terrestrial use relies on several factors. The most important are system cost and system performance. These two are not inseparable, however, since performance dictates the price that can be paid zor the system. For comparisons of PV systems with systems which use nonrenerable fuels, economic andyses requiro knowledge of fuel savings that wouid result should a PV system be used to meet part of the 1oad. If PV systems are to be compared with other renewable energy alternatives, system sizing (i.e., performance calculations) mast be done in order to compare the costs of each.

Detailed and sophisticated compoter programs corrently exist (Ref. 1.1, 1.2) which allow performance calculations to be made. These codes can be used to exploze trade-offs and problem areas that may arise, but they typically reguire access to fairly large computing facilities and some sophistication of use. They obviously do not replace the need for construction and testing of hardware prototypes although they can greatly reduce the number of prototype systems that need to be built.

Such detailed programs also will not satisfy the eventual neod for simplified design guidelines that ill be necessary to effectively implement large scale use of PV systems. The codes do, however, serve as useful tools in the development of such design guidelines. This fact has already been demonstrated in the national solar thermal program where the development of the University of Wisconsin's TRNSYS (Ref. 1.3) simulation program has led to the f-Chart method of thermal system design (Ref. 1.4). Thus certain types of thermal systems (space heating and domestic 
water heating) can now be reliably designed without resorting to computer calculations.

The terrestrial photovoltaic field has not yet reached that point of maturity where simplified design techniques are available. However, the rapid growth that this field is experiencing suggests that it is not too early to deal with such subjects.

\subsection{This Study}

The major thrust of the work documented in this report has been the investigation of the validity of certain simplified design procedures for photovoltaic system analysis. The gon has been to expiore system sensitivities and to lay the groundwork for possible simplified design methods. This document is not, therefure. a design mannal in the sense that it could be easily used for design purposes.

The systems addressed here are passively cooled and grid connected or have a non-photovoltaic back-up source. Both systems with and without dedicated battery storage are studied. Max-power tracked systems have received the most attention although inroads have been made in the clamped-voltage mode of operation.

Max-power tracked systems are easier to address in a simplified design procedure since the PV array can be uncoupled from the battery, power conditioning equipment, and the load. In the battery or voltage-clamped mode, the array roltage (and thus, power output) is determined by the battery and its interaction with the array and $10 a d$.

Computer simulation has been used to guide the development and validation of the simplified techniques discussed here. Such simulations have also been used to uncover some fairly general design "rules of thumb" concerning battery sizing and to study 
the sensitivity of the results to various system parmeters and load behavior.

This report is divided into five (5) main parts. They are:

Chapter 2: System Simulation Studies

Chapter 3: Simplified Method for Predicting Array

Output

Chapter 4: Simplified Method for Max-Power Tracked System Performance

Chapter 5: Simplified Method for Clamped-Voltage System Performance

Chapter 6: Discussion, Conclusions and Sumary

\subsection{Summery of this Study}

This section briefly sumarizes the results of this study. A slightly more detailed sumary of the complete results can be found in Chapter 6.

- $\bar{Q}_{e} / \bar{L}$, the ratio of monthly average daily array output (nultiplied by the power conversion efficiency) $\bar{Q}_{e}$ to the monthly average daily electrical load $\bar{L}$, and $s / \overline{n A}$, the ratio of storage capacity (S) to effective array area (monthly average array efficiency times the array area, $\bar{\eta} A$ are good parameters for correlating $f_{e}$ the fraction of $\bar{L}$ supplied by solar, for various locations for similarly tilted arrays.

- When $\bar{a}_{e} / \bar{L}$, is small, $f_{e}$ differs from $\bar{Q}_{e} / \bar{L}$ only by the storage losses which can be small if mach of the load occurs during daylight hours.

- When $\bar{Q}_{e} / \bar{L}$ is large, $f_{e}$ can be significantly different from $Q_{e} / \bar{L}$ due to storage losses and dumping (or not collecting) energy when storage is filled. 
- Load shape is important in determining $f_{e}$ for a given $\bar{Q}_{e} / \bar{L}$ and $s / \overline{\eta A}$, for $s / \overline{\eta A}<50 \mathrm{~W}-\mathrm{hrs} /\left(\% \cdot \mathrm{m}^{2}\right)$.

- $s / \overline{\eta A}>50 W-h r s /\left(\omega_{-1} m^{2}\right)$ of storage is seldom warranted for most load shapes that might be considered for ${ }^{\circ} \sigma$ app1ications.

- The knees of the $f_{e}$ versus $s / \bar{\eta} A$ curves are somewhat load shape and $Q_{e} / \bar{L}$ dependent bat typically occur in the region of $S / \overline{n A}=30 \mathrm{~W}-\mathrm{hrs} /\left(\mathrm{H}^{\circ} \mathrm{m}^{2}\right)$.

- In addition to the obvious conclusion that locations of poor insolation require more array area to meet a given fraction of the load, the results of this study show that battery size should scale with the effective array area in order to yield the same system performance (i.e.. $f_{e}$ ) in different locations.

- Predicted system performance does not appear to be strongly dependent on the frequency or magnitude of random fluctuations in the 1 oad.

- Predicted system performance does not appear to be strongly dependent on the battery model (at least for the three different battery models used) or on the range of battery state of charge. However, good representations of the charge and the discharge curves are necessary.

- The results of these simulation studies show that simplified design procedures should accont for diurnal load shape, daylength (or time of year), and, to a lesser extent, location. 
Simplified array output results:

- A method was developed whereby the monthly average array efficiency $(\eta)$ can be hand calculated from a minimas of inf ormation.

- This $\bar{\eta}$. when multiplied by the monthly average insolation on the array, gives the monthly average electrical output.

- The results are derived from long term ( 22 gear) average behavior.

- The method was developed for passively cooled, max-power tracked systeas.

- The results apply to ither flat arrays (of various tilts) or 2-D tracked concentrating systems.

- Results were also derived wich enable one to predict monthly average midday array temperature and elcctrical output.

- Statistics were compiled which permit an assessment of the expected departures from long term behavior.

Simplified Method for Max-Power Tracked System Performance:

- A simplified methodology was developed to predict the fraction of an electrical load that could be supplied by a passively cooled, flat array. PV system.

- The nethod was validated by comparison with computer simulation. 
- The method accomodates various diurnal load shapes, daylengths, and c1imatic locations.

- The method is applicable to systems with and withont dedicated storage.

- The method has potential for use with hand-held programable calculators. It certainly can be used easily on smal1 computers.

- The method makes use of Liv and Jordan (Ref. 1.5) type distributions of daily radiation on the horizontal to define a good, a mediocre, and a poor day to represent the monthly weather variations.

- Calculations are conducted for these three days and averaged to obtain a monthly value.

- Results for Albuquerque, NM, Madison, WI, and Medford, OR, show the method is within a standard deviation of $2.6 \%$ (absolute) of simulation results.

Clamped-Voltage Mode Results:

- Some representation for the solar cell I-V curve under various temperatures and insolation must be available in order to simolate or predict system performance.

- For a good choice of SR, the number of PV cells in series with each battery cell, the electrical output for c1amped-voltage operation is only 2 to $3 \%$ below that for max-power tracking, if no power loss is considered for the max-power tracker.

- The optimum value of SR varies from month to month for a given location. 
- A simplified design procedure akin to those described above appears to be infeasible.

- In preliminary comparisons, the results of a short compoter program for predicting clamped-voltage array outpat vs. SR agree with those from TRNSYS simulations. 
1.1 D.L. Evans, T.A. Facine11i, and R.T. Otterbein, 'Combined Photovoltaic/Thermal System Studies," Report SAND78-7031, Arizona State University, Tempe, AZ (1978).

1.2 E.R. Hoover, " SOLCEL II: An improved Photovoltaic System Analysis Program, ', SAND79-1785, Sandia 1aboratories, Albuquerque, NM (1979).

1.3 S.A. Klein, T.A. Beckman, P.I. Cooper, N.A. Duffie, T.L. Freeman, J.C. Mitche11, D.M. Beekman, R. L. Oonk, P.J. Hughes, M.B. Eberlein, J.A. Duffie, W.E. Buckles, V.D. Karman, M.J. Pawelski, D.M. Jtzinger, M.J. Brandemuehl, M.D. Arny, and J.C. Theilacker, TRNSYS - A Transient Simclation Program, Report 38, Solar Energy Laboratory, University of Wisconsin, Madison, WI (1979).

1.4 W.A. Bockman, S.A. Klein, and J.A. Duffie, Solar Heating Design, Wiley Interscience, New York, NY (1977). 


\subsection{SYSTEM SIMULATION STUDIES}

This chapter discusses the computer simulation studies of photovoltaic electric systems that were done in crder to assess the sensitivity of system performance results to various parameters. These studies then allowed the search for various correlations that might relate the important parmetis to system performance, a first step in establishing sinplified design procedures and ' rules of thumb.' '

\subsection{The Srsten}

The system modeled in these studies is illustrated in Fig. 2.1. It consists of a flat array "photovoltaic collector," regulator. inverter, and battery storage. These units are used to supply whatever fraction of the electrical load they are capable of meeting. Whenever this fraction is less than one (1), the balance of the load is met by some back-up system whether it be a utility grid or a stand-alone auxiliary power sousce. If the load is totally met and storage cannot accept excess solar-generated electricity, the excess may be considered to be fed back to the back-up (e.g. if the back-up were atility grid that would permit such operation) or "'duaped' in some non-useful (i.e., non-useful to the electrical load) way. Hence, duming would represent physically dissipating the energy as theral energy in a resistive network, disconnecting all or part of the array in order to aroid the collection of the excess power, or woving off the max-power point.

In these simolations, the errays were always assumed to be max-power tracked, i.e. the voltage on the array was continuwusly adjusted in order that the power out was the maximum possible. Deviations from this type of operation are discussed in Chapter 5 . 


\subsubsection{The Simulation Program}

A11 of the computer simulations reported in this chapter were performed using TRNSYS, a general simulation program for solar energy systems (Ref. 2.1) available from the University of Wisconsin. TRNSYS-compatible subroutines for the photovoltaic collector, regulator/inverter, and storage battery have been described previously (Ref. 2.2). Improved versions of these have been developed during the course of this study, along with an electrical subsystem whici combines the above three components. The new versions were used in this study: they may be requested from the authors.

Time steps of 0.5 hour or less were used to avoid convergence problems. Monthly sumaries of the results were from year-long simulations ( 8760 hours) were tabulated and analyzed.

\subsubsection{The Solar and Meteorological Data Base}

The data base used for these studies was the hourly Typical Meteorological Year (TMY) data (Ref. 2.3) in order to avoid the computation expenses involved in simulating multiple years of operation. The source of the solar information contained in the TMY data is the SOLMET data base (Ref. 2.4). This includes the standard year corrected total radiation on the horizontal and the direct normal (beam) radiation.

\subsubsection{The Geographical Locations}

Albuquerque, N data were chosen to drive the initial and most extensive set of simulations. Since the weather in Albuquerque is consistently good from month to month, some simulations were also run using weather data for other locations representing a range of weather patterns. They are: Bismarck, ND; Madison, MI; Medford, OR; Phoenix, AZ; Santa Maria, CA; and Washington D.C./Sterling, VA. Of these locations, Madison, WI merits the title of most uniformly poor weather (although Washizgton/Sterling is competitive). Medford, OR, on the 
other hand, spans the whole range of very poor (in the winter) to very good (in sumer). For these reasons, Madison and Medford (along with Albuquerque) receive more attention in this report than other cities.

\subsubsection{The Array}

For these simulations the photovoltaic flat array was considered to consist of cells having an efficiency of $15 \%$ at $28^{\circ} \mathrm{C}$. The array was south facing and $t i 1$ ted up from the horizontal at the local latitude angle (0). The encapsulant over the cells in the array was assumed to have a transmittance of $88 \%$. With the assumed cell pecking factor on the array of 1.0 , the resulting array reference efficiency was $13.2 \%$ at $28^{\circ} \mathrm{C}$.

For thermal considerations, the solar absorptance of the array was assumed to be $88 \%$ and the thermal loss coefficien was taken to be $20 \mathrm{~kW} /\left(\mathrm{m}^{2} \cdot \mathrm{C}\right)$ or $72 \mathrm{~kJ} /\left(\mathrm{hr} \cdot \mathrm{m}^{2} \cdot \mathrm{C}\right)$. The loss coefficient deperds in a complicated way on wind speed and direction and on secondary flow patterns in the array field. Since these factors are difficult to determine, a constant thermal loss coefficient was used.

However, the correlations that are used in presenting the results of the simulations in this chapter make the results independent of most of these choices and therefore much more versatile than the above array description would indicate. This will become more apparent in Section 2.2 .

\subsubsection{Electrical Storage}

The model for electrical storage used in these simulation studies is the modified-Shepherd Model for lead-acid batteries (Ref. 2.2). It is discussed in more detail in Section 2.3 where the sensitivity of the simulation results to the battery model is described.

In the resils of Section 2.2, the batteries were permitted to function over the fractional state of charge range of $0.4<F<0.95$. 
The sensitivity of the results to this range is also discussed in Section 2.3 .

The battery charging strategy adopted for the results of this chapter gives first priority to recharging the battery to $F=0.6$ with array ontput once the battery has reached its lowest permissible state of charge $(F=0.4)$; otherwise, first priority is given to satisfying the load. Compared to a strategy of always giving the load to be met first priority for array ontput, this gives a small reduction $(\sim 2 \%)$ of the solar fraction due to increased battery losses.

The battery is considered to be "dedicated storage" in that it was only charged by the array and never by the back-up cr auxiliary power. This mode of operation may not represent the most economic mode of operation.

\subsubsection{The Regu1ator/Inverter}

The regulator and power conditioning equipment simulated in these studies gave a constant ''straight through', efficiency (i.e., efficiency for converting d.c. array outpnt power directly to a.c. power) of 81\%. The assumption of a constant efficiency is not anressonable since equipment of this type typically has very flat efficiency versus load curves over a wide part of the intended operating range. The actual efficiency is not critical since the results are presented here in a way that is independent of the value.

The regulator in the simulations includes a max-power tracker. Therefore, it must match power taken from the array at one voltage, with some or all of that power (if storage is involved) delivered to the battery at another voltage level. This is not presently a common method of operation in systems involving battery storage, but such operation is quite possible and may become common in future large systems (Ref. 2.5 ). 
Results obtained for this max-power mode of operation may be useful in predicting results of battery-clamped operation (where the battery and photovoltaic array are wired directly in parallel). Chapter 5 discusses battery-clamped systems in more detail.

\subsubsection{The Load}

One of the difficult problems associated with developing simplified design procedures for photovoltaic systems is the wide diversity of electrical loads to which systems may be mated. Demand profiles or diurnal load shape can have a significant influence on system performance.

In the majority of the simulations described here, the diurnal load shape was assumed to consist of a cosine function of 24 hour period superposed on a constant background, as demonstrated in Fig. 2.2. The load shape was assumed to be repetitive frow day to day. The daily total load or energy for Fig. 2.2 is givea by

$$
L=\int_{0}^{24} \dot{L}(t) d t .=24 L_{0}
$$

Limited information (Ref. 2.6) suggests that for residential base load applications, an appropriate choice of parameters is $L_{1} / L_{0}=0.25$ and $T_{p}=17(5 \mathrm{pm})$ (where $T_{p}$ is the hour of maximum demand). These values were used as a baseline in the initial studies conducted under this program; the resulting load shape is referred to as the baseline load. The effect of load shape was then investigated by altering these parameters and redoing the simulation; these results are discussed in Section 2.2.4.

For applications such as residences and small comercial installations, the electrical demand is not continuous and "smooth" as shown in Fig. 2.2, although the monthly average daily profile may be. Particularly for systers with 1ittle or no storage, one might expect errors to arise in estimating the fraction of such "noisy" loads supplied by solar if the monthly average daily profile is used 
each day in the simulation. This has been studied and is discussod in Section 2.2.5.

\subsection{The Simulations}

The results of the computer simulations of the photovoltaic systems described in Section 2.1 are discussed in this section with the exception of battery sensitivity studies, which are reported in Section 2.3. The results of all the studies are correlated in terms of the quantities:

$$
\begin{aligned}
& f_{e}-\text { the fraction (or percent) of the electrical load that is } \\
& \text { actually supplied directly by the solar system, } \\
& \bar{a}_{e} / \bar{L} \text { - the ratio of the monthly average daily total solar } \\
& \text { electric availability to the monthly average daily total } \\
& \text { electrical load, } \\
& \text { s/nA - the ratio of storage size to the ' 'effective' area of }
\end{aligned}
$$
S/nA - the ratio of storage size to the "'effective"' area of photovoltaic array.

The first of these, $f_{e}$ is a non-dimensional quantity that is similar to the solar fraction commonly used in the solar thermal field (Ref. 2.7). Rnowledgo of this parameter allows the dosigner to conduct an economic analysis, since he can predict his auxiliary energy savings and the resulting net present porth of these savings realized over a period of time.

The second combination, $\bar{Q}_{e} / \bar{L}$, is also non-dimensional. It differs frow $f_{e}$ since $\bar{Q}_{e}$ represents the array output $\bar{a}_{a e}$ multiplied by the 'straight through', efficiency for power conditioning, $\eta_{p c}$. However, not all of $\overline{\vec{Q}}_{e}$ may actually be made available to the load since some way be irretrievably fed back to a utility. dumped or lost in storage. Only in the special case where the solar output is always less than the load should it be expected that $\overline{Q_{e}} / \bar{L}$ and $f_{e}$ would be equal to one another. A designer, of course, has to know the magnitude of his load $\bar{L}$. With knowledge of 
array output he can then select an array area that gives a desired $\overline{Q_{e}} / \bar{L}$. Chapter 3 presents a simplified method for predicting monthly average array operating efficiency and thus monthly average array outpat.

The third term, $\bar{S} / \overline{n A}$, is a dimensional parameter that has been found by this study to be useful in "collapsing" data from man types of weather patterns. This shouid become apparent in the sections that follow.

Battery capacity, $S$, is often given in terms of amp-irs where the battery is discharged over its useful capacity range at the $5 / 10$ rate (discharge current equal to the battery capacity divided by 10 hours). In some respects this is the least ambiguous method of stating capacity, but in other respects it is not explicit. Therefore, capacities have also been stated here in terms of energy (W-hrs). which are easier to use but less precise.

When amp-hr units are used in this stady, they refer to the total capacity of 11 sinde cells (i.e., all nominal two volt cel1s) that make up the battery. If, for example, one is making use of a 12 volt, 100 amp-hour battery consisting of 6 cells in series, each celi has necessarily a capacity of 100 amp-hrs. Total capacity of all single cells would then by 6 × 100 or 600 amp-hrs., Which is the namber that should be used with the results presented here.

These sane 6 cells could be connected in parallel to yield a 2 vo1t, 600 amp-hr battery which, for simulation of max-power tracked systems, would produce the same system performance as its 12 volt counterpart discussed above. However, in real systems, coordinating voltages among the array, the max-power tracker, and the battery is $3 n$ important design consideration.

To convert amp-hr capacities to energy values, one needs only to multiply them by an appropriate voltage. Perhaps the best value would be the average between the voltage at the beginning and at the end of 
an $S / 10$ ( $S$ in amp-hrs) discharge rate. These voltages depend on the construction of the battery and on the range of fractional state of charge that is permitted during operation.

The fine points of this voltage choice have been sidestepped here by choosing the nominal voltage of 2.0 volts per cell as the appropriate voltage. Thus, the 12 volt, 100 amp-hr battery discussed above is assumed to represent $1200 \mathbb{W}$-hrs of storage, as does the 2 vo1t, 600 anp-hr battery. The results which follow demonstrate that system performance is not strongly enough dependent on $s / \bar{\eta} A$ to merit more precise interpretations of $S$.

The $S$ that is used in tive results that follow represents the effective capacity that is ntilized in operation of the system. If a 500 amp-hr (1000 W-hr) cell is ased bat it is not permitted to discharge below a fractional state of charge of 0.5 , this represents an effective $S$ of 250 amp-hrs $(500 \mathrm{~W}-\mathrm{hr})$, if full charge is permitted.

The $\bar{\eta}$ in s/inA is the monthly efficiency for converting solar energy into array ontpat electrical energy. A simplified method for determining this is presented in Chapter 3. The $A$ in $s / \eta \bar{A}$ represents the array area.

\subsubsection{Baseline Load/Albuquerque/Eqninox Months}

Fig. 2.3 shows a map of system performance typical of the baseline load in Albuquerque, $N$, in the months of March and September. Resalts for other months can vary from those shown in Fig. 2.3, primarily because of the change in the daily insolation profile created by changing daylengths. This effect is discussed in more detail in the next section.

In systems with relatively small arrays $(\bar{Q} / \bar{L} \sim 0.2)$ the array output is always less than the inmediate baseline demand. Consequently, the output is always nsed directly by the load and there 
is no need for storage. System performance is then independent of the storage capacity.

As the array becomes larger (e.g., $\left.\bar{Q}_{e} / \bar{L}=0.6\right)$, there are periods when the power output of the array erceeds the imediate requireant of the baseline load. With no storage available, this extra or excess (XS) energy must be dumped. As battery capacity is increased, however, some of the extra energy can be stored for use 1ater when array ontput again satisfies less than the full 1oad. Dumping decreases further with increased battery capacity until, with a storage capacity corresponding to about $\mathrm{S} / \mathrm{\eta A}=20 \mathrm{amp}-\mathrm{hrs} /\left(\mathrm{w}^{\circ} \mathrm{m}^{2}\right)$ or $40 \mathrm{~W}-\mathrm{hrs} /\left(\% \cdot \mathrm{m}^{2}\right)$, duming is eliminated, and no further improvement in performance can be achieved with increased storage.

As the array becomes larger yet $\left(e . g ., \quad \bar{a}_{e} \bar{L}=1.0\right.$ ) its output increases, but virtually all of the increased production occurs during periods in which the full baseline load already is satisfied by a smaller array. Without storage, almost all of the increased output is merely dumped and does not significantly improve performance. The addition of storage, however, again permits the extra midday array output to be used in the afternoon and nightime when the system othorwise would be incapable of satisfying the load. As in the case of $\overrightarrow{Q_{e}} / \vec{L}=0.6$, a storage capacity erists for which dumping is minimized and any additional storage is not effectively utilized.

When the array size increases further, the monthly average daily output exceeds the daily load $\left(\vec{a}_{e} / \bar{L}=1.2\right)$. Without storage, little improvement in performance is noted. With sufficient battery capacity

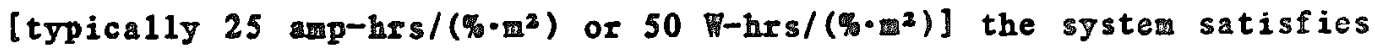
nearly the entire load, with excess array outpot being dumped. These larger storage sizes are what might be temed "intermediate size storage" in that they are depleted by several consecutive days of poor insolation and are replenished during the next good insolation period. The temptation of speaking of "number of hours" of storage will be aroided until the effect of geographic location is discussed in Section 2.2.3. 
Fig. 2.4 illustrates the use of the battery. The small diagrams superposed on this figure are frequency distributions of the battery state of charge. For example, these show that sma11 batteries [S/ $\overline{7 A}$ $\sim 20 \mathrm{~W}$-hrs/(\% $\left.\left.\mathrm{m}^{2}\right)\right]$ cover their entire permitted range of state of charge, since they typically charge completely during the day and then fully discharge overnight. For $\bar{Q}_{e} / \bar{L}=0.6$, photovoltaic array_output is insufficient to fill a large capacity battery [S/ $\bar{A}$ A 40 $\left[\right.$ H-hrs $\left./\left(\% \cdot m^{2}\right)\right]$. As a result, the state of charge is at or near its minimum permitted value most of the time. If this minimum happens to be near zero (i.e., if the battery were allowed to be fully discharged), such operation would not favor long battery 1 ifetimes. This situation reverses for large arrays $\left(e .8 ., \bar{Q}_{e} / \bar{L}-1.2\right)$ and 1 arge batteries. Here the array outpot maintains the batteries at full charge most of the time since there is more than enough energy to meet the average daily load. Such operation would favor long battery lifetime.

Note that a fired $S / \overline{\eta A}$ does not infer the same battery capacity at $\bar{Q}_{e} / \bar{L}=0.6$ as it does at $\bar{Q}_{e} / \bar{L}=1.2$. For the same $10 \mathrm{~d}$, it takes twice the array size for a $\bar{Q}_{e} / \bar{L}=1.2$ as it does for a $\bar{Q}_{e} / \bar{L}=0.6$. Equa1 $\underline{\mathrm{S} / \bar{H}}$ thus requires twice the battery capacity for $\bar{Q}_{e} / \bar{L}=1.2$ as for $\overline{Q_{e}} / \bar{L}=0.6$.

\subsubsection{Base1ine Load/Albuquerque/Seasonal Variations}

Fig. 2.5 demonstrates the seasonal variation in system performance. The figure considers four months in Albuquerque: March, June, September, and December. The effects of monthly average insolation differences again have been removed from the figure by comparing behavior at constant $\bar{a}_{e} / \vec{L}$ ratios. The figure indicates that, when little storage is provided, significantly better performance is achieved in summer. With additional storage, seasonal variations are minimized.

The major factor contributing to the seasonal variation shown is daylength. In inter months, a shorter daylength requires a greater 
peak array output in order to attin the same total output. The steeper noontime peak in array prodnction is more poorly matched to the given load profile. Hence, more energy is directed to storage in winter months and, if insefficient storage exists, more energy is damped. Thus, at the lower values of storage in Fig. 2.5 the December curve shows the worst performance. March and September exhibit improved behavior while Jane, with the longest daylength, generates an ontpat most closely matched to the load profile and consequentig has the best performance.

Fig. 2.6 demonstrates the above results through the use of typical load and output curves for June and December. The more peaked December array output profile is clearly illustrated.

\subsubsection{Baseline Load/Effect of Location or Weather Patterns}

Fig. 2.7 exhibits the variation in system performance typical of the wonths of March and September for seven cities for $\vec{Q}_{e} / \bar{L}=0.6$. Similar results are observod for other values of $\bar{Q}_{e} / \bar{L}$. Monthly average daily total radiation differences between the locations have been effectively removed by considering constant array outpat to load ratios (i.e.. fired $\bar{Q}_{e} / \bar{L}$ ratios). Differences in daylength due ro latitude differences in these equinos months are less than ten minutes for the range of latitudes considered. The major contributing factor is thus the difference in local weather traits, e.g.. the speed and frequency of storm fronts in a given area, the occurrence of mornigg or afternoon fog or clondiness, etc. According to Fig. 2.7 this effect is comparatively winor even in systems with no storage at all, when comparisons are made at a given $\bar{Q}_{\mathrm{e}} / \bar{L}$.

Fig. 2.8 demonstrates the combined effects of seasonal and weather differences. It shows performance during the year, again for seven cities, of systems equipped with two different storage capacities. The small storage cases portray clearly the periodicity which leads to daylength as an explanation for seasonal differences in performance. The larger storage cases once again demonstrate the 
effect of storage in diminishing losses caused by poor matching of the load to the array ontput.

Both Figs. 2.7 and 2.8 demonstrate the value of using $S / \overline{\eta A}$ along with $\bar{a}_{e} / \bar{L}$ as correlation parameters. No other combination of variables bas been found to serve as well in collapsing the data from such an assortment of climates into nearly single curves of fixed $\bar{Q}_{e} / \bar{L}$.

If the dimensionless group $S / \bar{\eta} A \vec{Q}_{S}$ were used in place of the dimensional group $\bar{S} / \overline{\eta A}$, the curves for different locations would not collapse as well onto a nearly single curve. For example, if the horizontal axis of Fig. 2.7 were changed to $S / \bar{\eta} \bar{Q}_{S}$, any data point for Madison would be moved farther to the right of a corresponding point for Albuquerque of equal $s / \overline{\eta A}$, since $\bar{Q}_{S}$ wonld be less for Madison than for Albuquerque. Obviously, neither $S / \bar{\eta} A$ nor $S / \bar{\eta} \bar{Q}_{S}$ have any effect on the vertical axis or at very large $S$, but each has different effects between those two extremes.

Admittedly, $\bar{\eta} \bar{Q}_{S}$ is intuitively more appropriate to use in the denominator of the storage parameter. For example, doubling the insolation and halving the array efficiency does not change the systen performance, yet this would donble the parameter $s / \bar{\eta} A$ and thus have the appearance of increasing $f_{e}$.

The most important point to be made regarding to the use of $\bar{s} / \bar{n}$ is that the results presented-here are for ''similarly tilted arrays."' For the same array configuration and 'similar' tilts, geographically dependent insolation variations are such that $\mathrm{S} / \overline{\eta A}$ happens to be useful in collapsing data.

\footnotetext{
1'Similarly tilted arrays"' means that array tilis in different locations either are optimally tilted for maximum energy collection in each location or are equal increments away from these optional tilts
} 
Thus, for comparing monthly results for two different locstions, say for "similar" tilts of $(\theta+\theta)$ where $\theta$ is independent of location, $\bar{s} \bar{n} A$ is a usefol parameter. It is not as useful for comparing monthly syster performance results for array tilts of $\left(\theta+\theta_{1}\right)$ with results for iilts of $\left(\theta+\theta_{2}\right)$ if $\theta_{1}$ is appreciably different from $\theta_{2}$. Then $S / \overline{\eta A Q}_{S}$ would be more useful. One can, however, introduce a modified $A$ for given location by multiplying it by the ratio of the insolation on the tilt $\left(0+\theta_{1}\right)$ to the insolation on the tilt $\left(0+\theta_{2}\right)$.

As an example, consider the same arrays operated in Juse in both Madison and in Albuquerque, neglecting for the moment the difference between the monthly operating efficiencies due to climate and tilt differences. If the tilt of the array in Madison is $\left(D+27=70^{\circ}\right)$ and that in Albequerque $\left(D-13=20^{\circ}\right)$, one bas to correct $S / \eta A$ in one of the two cities so as to obtain "similar" tilts in both locations before system comparisons can be made. Suppose the Madison results are chosen for correction. Then a modified area $A^{\prime}$ noeds to be calculated that would account for a change in tilt from $\left(0+27=70^{\circ}\right)$ to $\left(D-13=30^{\circ}\right)$ in Madison $\left(D=43^{\circ}\right)$. Thus,

$$
\begin{aligned}
A_{\text {Mad }}^{\prime} & =A_{\operatorname{Mad}} \bar{Q}_{S}\left(\text { for } 30^{\circ} \pm \text { tilt } ; / \bar{Q}_{S}\left(\text { for } 70^{\circ} \text { tilt }\right)\right. \\
& =A_{\operatorname{Mad}}(1.5)
\end{aligned}
$$

where 1.5 represents the June ratio for insolation on the two tilts. (Sources of this information will be discussed in Chapter 3.) Now $\mathrm{s}_{\mathrm{Alb}} / \tilde{\eta A}_{\mathrm{A} 1 \mathrm{~b}}$ can be compared with $\mathrm{s}_{\mathrm{Mad}} / \overline{\eta A}^{\prime}$ Mad since adjustments to similar tilts has been made (i.e., to tilts of $(0-13)$ ).

The usefulness of $S / \overline{n A}$ might appear questionable, but it should be remembered that usually only optimum or nearly optimum tiles are considered in design. In such applications, $\bar{S} / \bar{\eta} A$ is a mach more convenient parameter than $S / \overline{\pi n A Q}_{S}$. Its use forms the bssis for some "rales of thamb" to be discassed in Chapter 6. 
A significant result of this section is that for a given load, L, location which requires $n$ times as mach array area in order to attain the same $\bar{Q}_{e} / \bar{L}$ ratio as another location, also needs essentially $n$ times as much battery capacity, ignoring array efficiency differences, in order to provide a comparable solar fraction, $f_{e^{-}}$It is certainly no surprise that, for example, one needs more array area in Madison, Wr than in Albuquerque, NM to meet a given load. However, it is not widely known that the ratio of battery capacity to array area is the same in both locations for comparable performance.

Also, since different amounts of array may be required to operate at given $\bar{Q}_{e} / \bar{L}$ at different times of the year (due to the insolation behavior and $t i l t$ ), a fired $s / \bar{\eta}$ may pield different amounts of storage through the year. Table 2.1 demonstrates this point for three different locations. Here the storage has been expressed as "hours of storage"' or the time it would take to deplete the storage if it were discharged from full charge at the average daily demand $L_{0}$. Expressed in this fashion, the storage is independent of the actual.10ad size.

Presumably a designer would design (i.e., choose the array size. array tilt and battery size) for the month with the least favorable insolation to load ratio. He would then calculate the $\bar{Q}_{e} / \bar{L}$ and $s / \overline{n A}$ that his design would yield during the remaining months so that yearly performance could be estimated. Once storage size and array size are selected, only $\bar{\eta}$ in s/ $\bar{\lambda}$ would vary from month to month. However, considering the relative insensitivity of $f_{e}$ to $\overline{s / n A}$ (see Fig. 2.3), the variations in $\bar{\eta}$ could be ignored with little loss in accuracy.

2.2.4 Variation of Load Shape/Albuquerque/Equinox Months

Fig 2.9 exhibits the effects on system performance of variations in the load characteristics. These calculations were made for Albuqueruqe, NM and are typical of March or September behavior. The 
effects are shown as a function of storage capacity for two different $\bar{Q}_{e} / \bar{L}$ 's. The values $T_{p}=0$ (a peak demand at midnight) and $T_{p}=12$ (a peak dexand at noon) demonstrate the full effect of the phase of the load. $T_{p}=0$ represents a demand exactlo ont of phase with the array outpat, while $T_{\mathrm{g}}=12$ describes a der:and precisely in phase with the array. System behavior for cases of a constant load throughout the day (in which $T_{p}$ has no meaning) is described here by $L_{1} / L_{0}=0$.

With 1 imited storage, the matching of demand to array output is clearly important. The peak output of south facing arrays usually occurs at noon. Thus, when the minimum demand occurs at noon (as it does when $T_{p}=0$ ), a greater portion of the output must be dumped and poorer system performance results. Conversely, when the maximum demand occurs at noon $\left(T_{p}=12\right)$ a lerger part of the array production is used directly, thereby minimizing the quantity of energy which is dumped and yielding improved system performance.

Larger $L_{1} / L_{G}$ ratios mezely amplify the effect. An increase in $L_{1} / L_{0}$ from 0.25 to 0.50 results in improved performance in the case of $T_{p}=12$, while the same change causes reduced performance in the case of $\mathbf{T}_{\mathbf{p}}=0$.

With increased storage, less of the array output which exceeds. the immediate demand needs to be domped and in all cases, performance improves with increased storage. At large storage capacities [e.g.. $\mathrm{s} / \mathrm{nA} 25 \mathrm{amp}-\mathrm{hrs} /\left(\% \cdot \mathrm{m}^{2}\right)$ or $\left.50 \mathrm{~W}-\mathrm{hrs} /\left(\% \cdot \mathrm{H}^{2}\right)\right]$ nc dumping occurs, and system performance differs only slightly die to battery inefficiencies applied to differing quantities of energy floming through storage.

Fig. 2.9 thus demonstrates that the amplitude and the phase of the load can significantly affect system performance. However, this figure also shows that for reasonable load shapes, more than 25

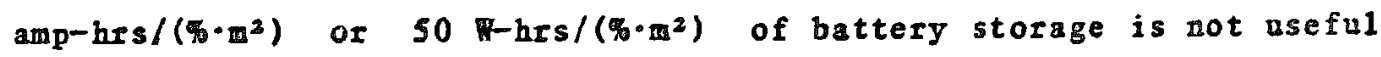
in improving system performance. This may be a useful 'rale of thomb" in preliminary design applications. 


\subsubsection{Effect of Randow Flactartions in the Load}

In iddition to rather continuous or monthly average diurnal variations, other largely random fluctuations in load are likely to occur as various electrical devices switch on and off daring a day. It is reasonable to expect that such fluctuations will have the greatest effect on performance (i.e., on the solar fraction, $f_{e}$ ) for systems with no storage since there will be no means of boffering the array output. Also, it can be shown that the effect of such fluctuations will be maximized when the array outpat power is nearly equal to the electrical demand. For the baseline load used here, this occurs for solar system sizes for which $\bar{Q}_{e} / \bar{L} \sim 0.4$. Simulations are described here which expiore the effect of fluctuation amplitide and frequency on system performance for systems with no storage.

One motivation for these studies was an apparent problem in predicting the actual energy flows in utility connected systems where se11-back of excess array generated power is permitted. If ratios of price-to-sell to price-to-bay (commonly called the se11-back ratio) are different from one (1.0) it would appear that short term fluctuations, although they may produce no net porer flows between the utility and the load, may produce a net monetary flow. If simulations were done using time periods longer than the periods typeial of the fluctuations, it would then seem that proper economic analyses conld not be accomplished since only net energy transfers conld be obtained. These net energy flows would not reveal anything about the actual bidirectional monetary flows.

The studies reported in this section were done by superposing on the baseline load at each time step a "'noise" component picked from a set of random numbers normally distributed about zero. The standard deviation of the random number set (expressed as a fraction of $L_{0}$ ) was used to characterize the magnitade of the fluctuations. In the cases where a large negative fluctuation would have produced a negative load, the load was set to zero. Variation of the simalation time step effectively changed the duration or period of the fluctuations. Both 
the power flows to the utility (when there was excess solar power) and from the utility were integrated as was the solar generated power going directly to the load.

Fig. 2.10 shows a simple energy flow diagram for reference. since under max-power tracking, the array output is fixed for given location, orientation, ard weather, any change in the solargenerated power that is fed back to the utility prodaces a change in the amount of solar-generated power that goes directly to the load. For a fixed load, this then produces a change in the solar fraction, $f_{e}$. Thus, changes in the bidirectional power flows to and from the utility due to fluctuations, produce changes in $f_{e^{*}}$ Once $f_{e}$ is known, proper economic analysis can be made.

Table 2.2 shows that monthly system performance is remarkably insensitive to such random fluctuations, even for standard deviations, $\sigma$, as $1 \mathrm{arge}$ as $50 \%$ of the mean demand. The results shown are for Albuquerque January TM data, but similar calculations for Medford, OR show comparable results.

In Table 2.2 the change in $f_{e}$ due to changing $\Delta t$ at $\sigma=0$ represents the numerical errors of the type encountered in any finite time-step calculation procedure of the type involved in TRNSYS. However, the problem of fluctuations elucidated above is best considered by examining the changes produced by increasing $\sigma$ at a fixed $\Delta t$. Although there is 1ittle effect of $\sigma$ on the monthly results, performance on individual days can be and are substantially affected.

These somewhat surprising results are explained by consideriag Fig. 2.11 which shows a typical daily interaction between array output and load. The region labeled $X S$ corresponds to the energy outpat of the array which, in the absence of storage, must be fed back to the utility. Only those fluctations from the average load which reselt in a change in $X S$ can cause a change in system performance. Thus, fluctuations during non-daylight hours have no impact whatsoever on performance. Also, only the largest of negative fluctuations affects 
performance during the early morning and late afternoon. In the period around noon, negative deviations from the average load result in increased dumping and thereby tend to decrease performanco. However, positive deviations daring this period are at least partially satisfied by the excess midday output of the array. This decreases the amount of energy dumped and tends to improve system performance. The net result over the period of a month is that the adverse effect of negative midday fluctuations is nearly compensated for by the favorable effect of positive fluctuations.

If the fluctuations become large enough (e.g., $\sigma=200 \%$ in Table 2.2), the negative fluctuations degrade performance much more than positive fluctuations improve it. This leads to a sizable reduction in the solar fraction, $f_{e^{*}}$

Load shape and size obviously play a role in system performance in the presence of fluctuations. For example, a load that tracked, on the average, the array power output (both in size and shape) would stffer in performance during periods of negative fluctuations but would aever realize any improvements daring positive fluctuations. No systematic investigation of load shape has been carried out here.

\subsection{Battery Mode 1 Sensitivity}

\subsubsection{Choice of Battery Mode1}

Section 2.2 presents results corrolated in a way that permits conclusions to be drawn concerning the sensitivity of $f_{\text {a }}$ to factors such as array size, battery storage capacity, and various system efficiencies. This section describes the results of battery sensitivity studies using three models of a lead-acid storage battery. and basically concludes that the results are nearly insensitive to the choice of battery model.

Details of battery modeling have been discussed in a previous report (Ref. 2.2). The key relationship for such a model is tho 
formula relating battery voltage to its current and stage of charge, i.e., $V_{b}=V_{b}(I, F)$. This function is shown graphically in Fig. 2.12 for a single lead-acid cell for the Shepherd (Ref. 2.8), Byman ${ }^{2}$ (Ref. 2.9), and GE (Ref. 2.6) models, the three versions tested in these simalations. The term "battery" refers to a collection of lead-acid cells connected in series and in parallel.

The major inefficiency in osing a storage battery is due to the higher voltages encountered when charging than when discharging. so that more power is necessary for charging than is available during subsequent discharge. As shown in Fig. 2.12, this difference in voltage is about the same for the Shepherd and Hyman models, and they should yield very similar simulation results. The voltage difference betwoen charge and discharge is less for the GE model than for the other two, and hence use of the GE model should give more efficient battery performance.

Since the inefficiency depends on both the typical charge and discharge rates at which the battery is operated, a valid sensitivity analysis of the battery models requires doing simulations in which the battery experiences an assortment of charge and discharge currents.

The battery currents in max-power systems vary at least as much as in comparable clamped-poltage systems. Hence, the sensitivity results reported here vere obtained asing only the former mode of operation. In the maz-power mode, it can be shown that the current into or out of each battery cell is independent of the series/parallel wiring of individual cells to form the battery.

In general, a small battery ( $\operatorname{sma11} S$ ) will see higher currents than will a large one (large $S$ ). The charge and discharge rates also depend ppon the sizes of the photovoltaic array and the load, relative to the battery size. Therefore the sensitivity stadies of this section include simulations having different combinations of battery.

${ }^{2}$ Also referred to as the modified-Shepherd Model 
solar cell array, and load sizes. Table 2.3 lists the eight combinations of component sizes used and the results of the simulations for the three battery models in terms of solar fraction, $f_{e}$, for equinox month: The differences in performance (from one mode1 to another) are less than an incrementa $12 \%$.

In two of the cases, reasons are apparent for the close agreement among the models in their estimation of system performance. In Case 6 , the battery is large relative to both the array and load, which means that it operates at $10 \mathrm{w}$ charge/dischrage rates. The voltage difference in each battery model is small for sma11 carrents, and thus one would expect that all three models will give nearly the same system performance.

On the other hand, the battery cells in systems with relatively small storage capacity will see large currents, leading to greater storage inefficiencies. But the small capacity 1 imits how much of the array ontput can be stored and how much of the load can then be supplied by the batteries, so they contribnte little to the overall system performance. This is the situation in Case 3 .

The combinations of components for which the performance is most difficult to anticipate are those in which the battery size is a good match to the array and load sizes, i.e., Cases 4 and 5 . In these circumstances it is hard to predict how the results using the different battery models will compare, but as indicated in Table 2.3, the differences in performance are negligible for these cases as well as for Cases 1 to 3 and 6 to 8 .

Besides giving essentially the same results, the simnlations using each of the three models require nearly the same amounts of computer time. However, the Shepherd and Hyman models are generally superior because they can be easily modified when better data on lead-acid batteries becomes available or when other kinds of batteries need to be modeled. Furthermore, the Byman model realistically represents the voltage as a continnous function of the carrent at any 
given state of charge, whereas the Shepherd model has a discontinuity at $I=0$. For these reasons, the Hymar model was used in the simulations reported earlier in this chapter.

\subsubsection{Energy Losses in the Battery}

Other losses, in addition to those associated with the difference between the charge and discharge voltage curves, mast be considered in an accurate battery mode1. In the lead-acid type of cell, these include electrolysis of water which occurs during an occasional 'equalizing" charge and various chemical losses. (For a complete discussion of energy dissipation in a battery see Refs. 2.9 or 2.10.)

These minor losses are most conveniently accomodated in a battery model by lumping them into a "charging efficiency factor." This parameter multiplies the charging current to yield the actual rate of change of battery state of charge (Ref. 2.2), i.e.. when $I>0$.

$$
\mathrm{dQ} / \mathrm{dt}=\mathrm{I} \cdot \mathbf{\varepsilon}
$$

The value of $\varepsilon$ to be used in singlations depends upon the manner in which the real electric system is operated, e.g., how of ten an equalizing charge is applied. The simulations under discussion in this chapter have $\varepsilon=0.95$, a value which is typical of actual battery operation (Ref, 2,10).

The effect of the "voltage difference"' losses and charging losses on system performance is exhibited in Fig. 2.13. The lowest set of curves are for the Hyman battery model with $\varepsilon=0.95$. In these cases both kinds of losses occur. The middle set of curves are again for the Hyman mode1, but with $\varepsilon=1.0$. The difference between the two curves thus represents the charging losses.

The uppermost set of curves in Fig. 2.13 are from simulations using a model of an ideal lossless battery. (This is the "Mode 1 "' 
battery model with $\varepsilon=1.0$, Ref. 2.2.) The upper gap is thas dae to the "voltage difference" losses.

These storage "'voltage difference"' losses are clearly more important than are the charging losses, particularly for the cases with the 1 arger $\bar{Q}_{e} / \bar{L}$, and bring about a significant degradation in overall system performance. These results imply that: (1) accurate modeling of photovoltaic systems with storage batteries requires a good representation of $V_{b}=V_{b}(I, F)$, and (2) the choice of the value of $\varepsilon$, at least within the range of 0.95 to 1.0 , is only of minor importance.

\subsubsection{Range of State of Charge}

The appearance of the Hyman model's charge/discharge curves in Fig. 2.12 suggests that battery (and, hence, system) performance may depend upon where the battery tends to operate in its state of charge range. That is, "voltage difference"' losses will be less when the battery charges and discharges near the middle range of $F$, compared with its operating at either high or 1 ow values of F. This section compares the results of simulations having different state of charge imits on the battery $\left(F_{C}, F_{B^{\prime}}\right.$ and $F_{D}$ ) which restrict it to different ranges of state of charge.

In the systems discussed in Sections 2.1 and 2.2 , the battery was inherentiy restricted to operate between $F_{D}=0.4$ and $F_{C}=0.95$ with $F_{B}=0.6$. Battery losses and therefore system performance would be somewhat different if lower values of $F_{D}$ and $F_{C}$ were used, although the frequency distributions shown in Fig. 2.4 would remain essentially unchanged. This was confirmed by rernnning the simulations with $F_{D}=0.05, \quad F_{C}=0.6$, aná $F_{B}=0.25$. Battery losses and overall system performance are compared in Table 2.4 and Fig. 2.14. Results in Fig. 2.14, when viewed in light of the state of charge histograms, clearly reveal the following trends: 
(1) When $F$ is usaa11y low $\left[\bar{Q}_{e} / \bar{L}=0.6, \quad s / \overline{n A}=50\right.$ $\mathbb{W}$-hrs/(\%) $\left.\left.\mathbb{m}^{2}\right)\right]$, the 0.40 to 0.95 range gives more efficient battery performance.

(2) When $F$ is usually high $\left[\overline{\mathrm{Q}}_{\mathrm{e}} / \overline{\mathrm{L}}=1.2, \mathrm{~s} / \overline{\eta A}=50\right.$ $\left.W-h r s /\left(\% \cdot m^{2}\right)\right]$, the 0.05 to 0.60 renge gives more efficient battery performance.

These results are consistent with the spacing between the charge and discharge curves in the Hyman model at various battery states of charge. Yet, the differences between the two sets of simulations, both in terms of the battery losses (Table 2.4) and solar fraction (Fig. 2.13) are $\sin 211$.

The system performance results depicted in Fig. 2.14 diffex primarily because of additional dumping of excess aray ontput in the $0.05<F<0.60$ cases. In these simulations, a lower perwitted voltage 1 imit kept the battery from discharging over the entire allowed range of $\Delta F=0.55 ;$ i.e., no constant voltage, taper discharge was permitted. No such limitation eristed in the $0.40<F<0.95$ cases as a constant $\nabla 01$ tage, taper charge was permitted at an upper voltage 1 init. Thus, the simulations with $F$ confined to a lower range have an effective battery capacity less than in those with a higher range of $F$. With less storage capacity, nore dumping occars and the system performance is poorer.

Since these simulations were done, a more sophisticated regulator/inverter model has been developed which permits a tapered discharge at constant voltage. Simulations with $0.05<F<0.60$ incorporating this scheme would have an effective battery capacity larger than the set of simulations ith the same range of $F$ described above. This mould lead to results which agree even more closely with those from the $0.40<F<0.95$ simulations. 


\section{CHAPTER 2 REFERENCES}

2.1 S.A. K1ein, T.A. Beckman, P.I. Cooper, N.A. Duffie, T.L. Freeman, J.C. Mithce11, D.M. Beekman, R.L. Oonk, P.J. Hughes, M.B. Eberlein, J.A. Duffie, W.E. Buckles, V.D. Karman, M.J. Pawe1ski, D.M. Utyinger, M.J. Brandemueh1, M.D. Arny, and J.C. Theil acker, TRNSYS - A Transient Simulation Program, Report 38, Solar Energy Laboratory, University of Wisconsin, Madison (1979).

2.2 D.L. Evans, T.A. Facine11i, and R.T. Otterbein, 'Combined Photovoltaic/Thermal System Studies," Report SAND78-7031, Arizona State University, Tempe, AZ (1978).

2.3 I.J. Ha11, R.R. Prairie, H.E. Anderson, and E.C. Boes, "Generation of a Typical Meteorological Year," Proc. 1978 Annua 1 Meet. Amer. Sec. of ISES, Denver, CO (1978).

2.4 'SOLMET Usex's Manual, Hourly Surface Radiation - Surface Meteorological Observations," National Oceanic and Atmospheric Administration, Environmental Data Service, Asheville, NC (1979).

2.5 L. L. Bacciarel1i, B.L. Grossman, E.F. Lyon, and N.E. Rasmussen, - The Energy Balance Associated with the Dse of a Maximum Power Tracker in a 100-KH-Peak Power System," Proc. Fonrteenth IEEE PV Specialists' Conference, San Diego, CA (1980).

2.6 'Conceptual Design and Systems Analysis of Photovoltaic Systems," Report No. AL0-3686-14, General Electric Co., Space Division, Philadelphia, PA (1977).

2.7 W.A. Beckman, S.A. Klein, and J.A, Duffie, Solar Heating Design, Tiley Interscience, New York, NY (1977). 
2.8 C.M. Shepherd, 'Design of Primary and Secondary Cells II. An Equation Describing Battery Discharge," J.Electrochem. Soc.. 112, 657 (1965).

2.9 E.A. Hyman, 'Phenomenological Cell Modeling: A Tool for Planning and Analyzing Battery Testing at the BEST Facility,.' Report RD77-1, Public Service Electric and Gas Company and PSE and G Research Corporation, Newark, NJ (1977).

2.10 G.W. Vinal, Storage Batteries, John Wileg and Sons, New York, NY (1955). 


\section{Table 2.1}

Hours of Storage for Discharging at $L_{0}$ for Various Times of the Year at Three Locations

For al1 Locations and Times, $f_{e} \simeq 55 \%$

\begin{tabular}{|l|c|c|c|c|c|}
\hline Month & $\mathrm{Q}_{\mathrm{e}} / \mathrm{L}$ & $\begin{array}{c}\mathrm{S} / \bar{\eta} A \\
\frac{W-h r s}{\left(\% \cdot \mathrm{m}^{2}\right)}\end{array}$ & $\begin{array}{c}\text { A1 buquerque } \\
\text { (Hours) }\end{array}$ & $\begin{array}{c}\text { Madison } \\
\text { (Hours) }\end{array}$ & $\begin{array}{c}\text { Medford } \\
\text { (Hours) }\end{array}$ \\
\hline March & .6 & 30 & 9.8 & 12.7 & 14.4 \\
June & .6 & 30 & 8.7 & 12.1 & 9.7 \\
Sept. & .6 & 30 & 9.8 & 13.6 & 11.5 \\
Dec. & .6 & 30 & 11.9 & 29.5 & 47.0 \\
\hline
\end{tabular}

These Hours of Storage numbers are based on supplying a power equal to the average load, $L_{0}$. To determine the hours of storage based on average solar system output power (i.e. $\bar{Q}_{e} / 24$ ), divide these numbers by 0.6 . 
Table 2.2

Utility Sellback Results

Albuquerque TMY, January

Random Load (of std. dev. o) Superposed on Baseline Load $\Delta t=$ Time Step in Hours

\begin{tabular}{|c|c|c|c|c|c|c|}
\hline \multirow[b]{2}{*}{ Qe/L } & \multirow[b]{2}{*}{$\begin{array}{l}\text { XS } \\
(\% \text { of } L)\end{array}$} & \multirow[b]{2}{*}{ 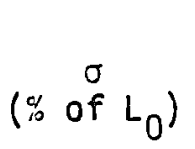 } & \multicolumn{4}{|c|}{$f_{e}(\%)$} \\
\hline & & & $\Delta t=0.05$ & $\Delta t=0.10$ & $\Delta t=0.50$ & $\Delta t=1.0$ \\
\hline \multirow{7}{*}{$40 \%$} & \multirow{7}{*}{9.0} & 0 & 31.01 & 31.03 & 30.98 & 30.69 \\
\hline & & 10 & 31.01 & 31.02 & 31.04 & 30.51 \\
\hline & & 20 & 30.76 & 30.77 & 30.91 & 30.21 \\
\hline & & 30 & 30.31 & 30.33 & 30.60 & 29.75 \\
\hline & & 40 & 29.64 & 29.65 & 30.03 & 28.93 \\
\hline & & 50 & 23.78 & 28.80 & 29.25 & 27.86 \\
\hline & & 200 & N/A & 16.43 & 16.94 & 15.60 \\
\hline \multirow{6}{*}{$60 \%$} & \multirow{6}{*}{24.9} & 0 & 34.94 & 34.96 & 34.87 & 34.42 \\
\hline & & 10 & 34.99 & 35.01 & 34.93 & 34.30 \\
\hline & & 20 & 34.81 & 34.85 & 34.84 & 34.02 \\
\hline & & 30 & 34.50 & 34.55 & 34.59 & 33.57 \\
\hline & & 40 & 34.04 & 34.11 & 34.16 & 32.91 \\
\hline & & 50 & 33.44 & 33.52 & 33.61 & 32.34 \\
\hline \multirow{7}{*}{$100 \%$} & \multirow{7}{*}{61.3} & 0 & 38.74 & 38.77 & 38.63 & 37.97 \\
\hline & & 10 & 38.82 & 38.86 & 38.77 & 37.80 \\
\hline & & 20 & 38.67 & 38.73 & 38.73 & 37.54 \\
\hline & & 30 & 38.42 & 38.53 & 38.59 & 34.19 \\
\hline & & 40 & 38.06 & 38.22 & 38.32 & 36.65 \\
\hline & & 50 & 37.59 & 37.80 & 37.97 & 36.02 \\
\hline & & 200 & $N / A$ & 28.93 & 29.99 & 27.26 \\
\hline
\end{tabular}




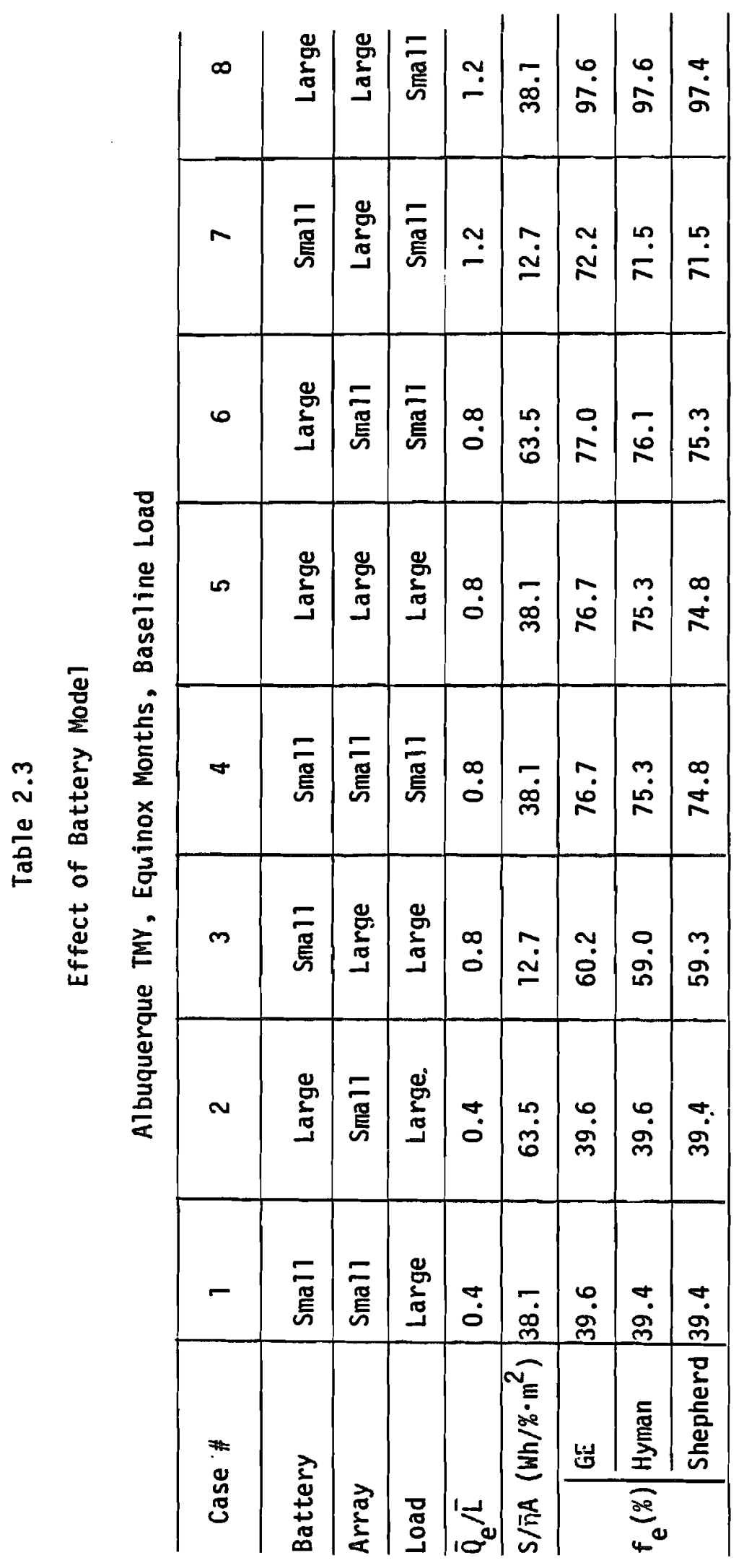


Table 2.4

Storage Losses as a Percentage of Load

Albuquerque TMY, Equinox Months, Baseline Load

\begin{tabular}{|c|c|c|c|c|c|c|c|c|c|c|}
\hline \multirow[b]{2}{*}{$\begin{array}{l}\text { Range of } \\
\text { State of Charge }\end{array}$} & \multicolumn{5}{|c|}{$\overline{\mathrm{Q}}_{\mathrm{e}} / \overline{\mathrm{L}}=0.6$} & \multicolumn{5}{|c|}{$\vec{Q}_{e} /[\bar{L}=1.2$} \\
\hline & 12.7 & 25.4 & 38.1 & 50.8 & 63.5 & 12.7 & 25.4 & 38.1 & 50.8 & 63.5 \\
\hline $.05<F<.60$ & 3.0 & 5.5 & 5.6 & 5.5 & 5.5 & 7.2 & 9.9 & 8.5 & 7.5 & 6.9 \\
\hline $.40<F<.95$ & 3.4 & 5.1 & 5.0 & 4.9 & 4.8 & 6.5 & 9.8 & 8.6 & 7.7 & 7.1 \\
\hline
\end{tabular}




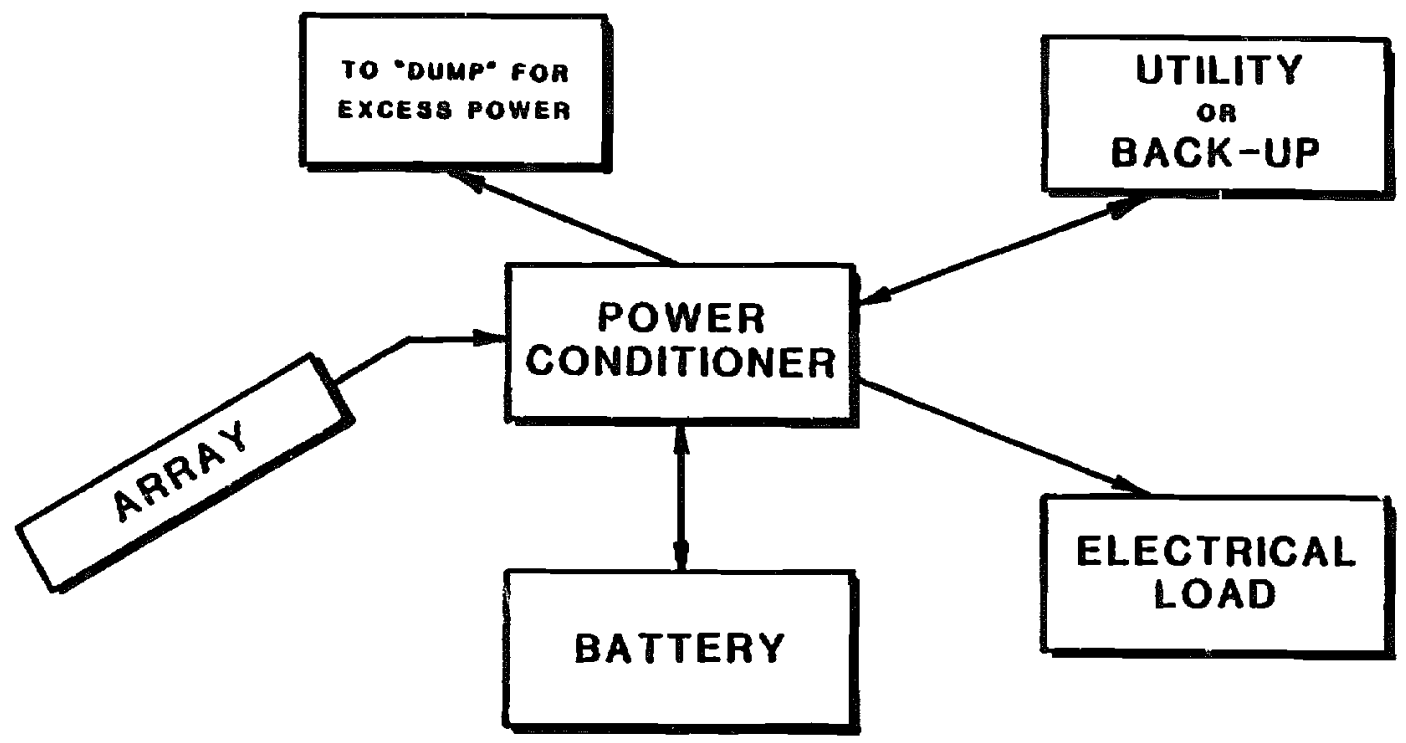

Figure 2.1 Schematic of Photovoltaic Electric System 


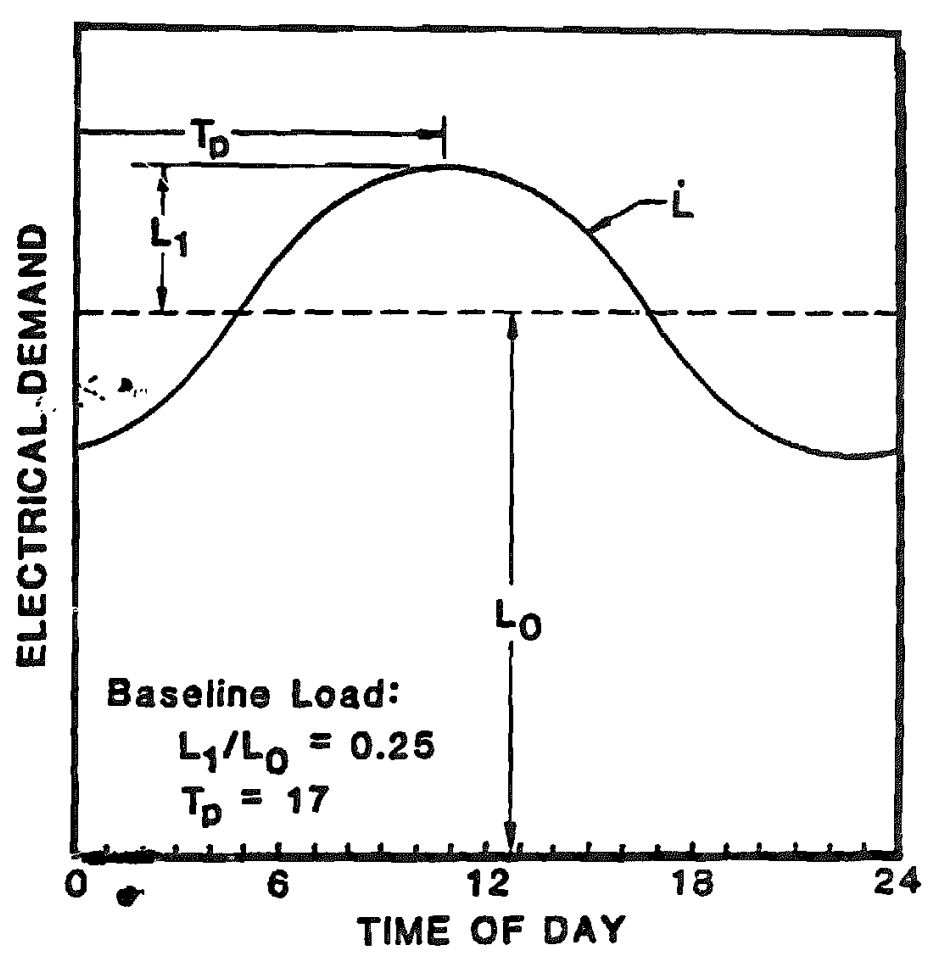

Figure 2.2 Diurnal Load Shape

$\because \sim_{i} \cdot$ 


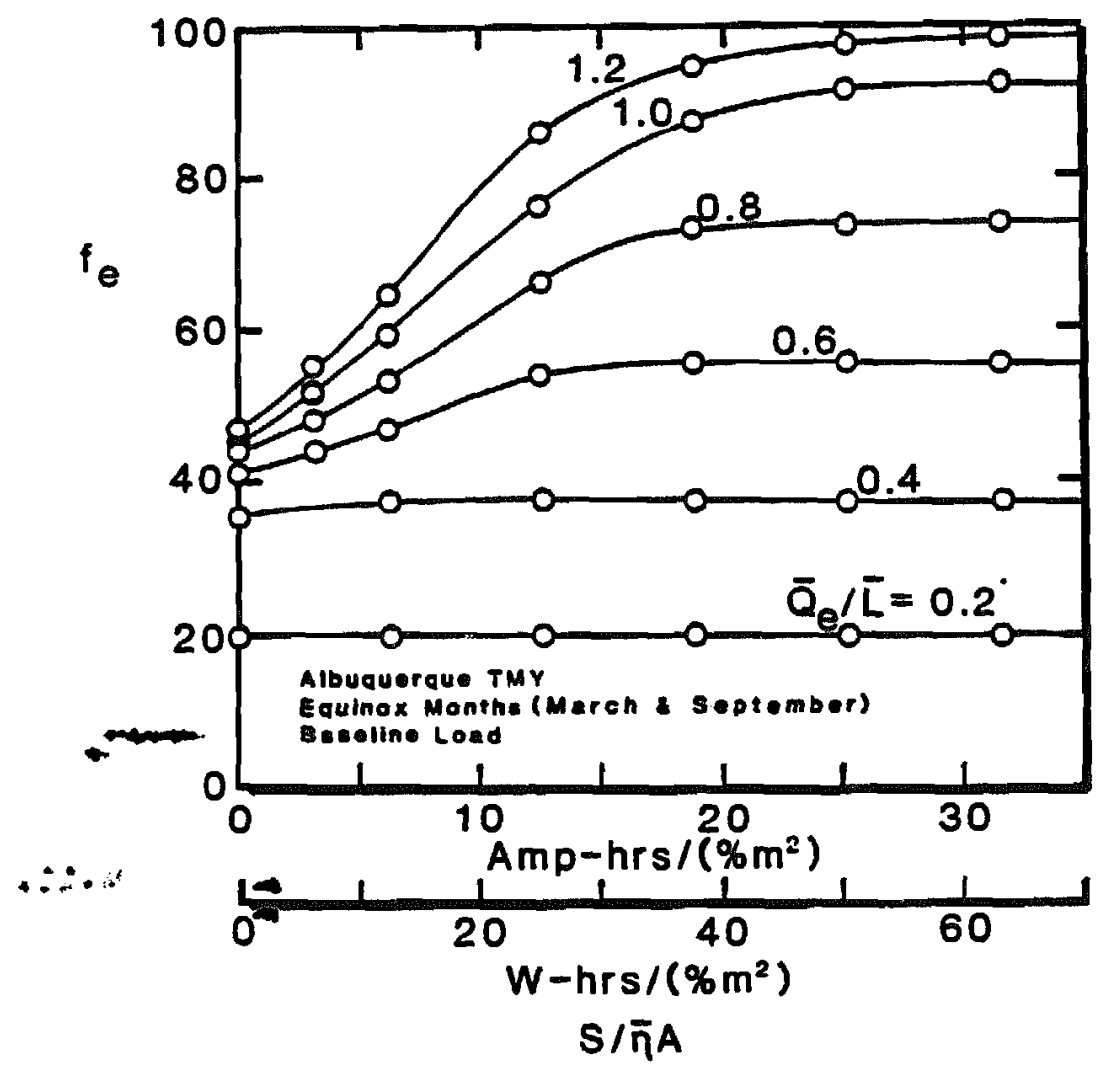

Figure 2.3 System Perance Predictions of TRNSYS Simulations 


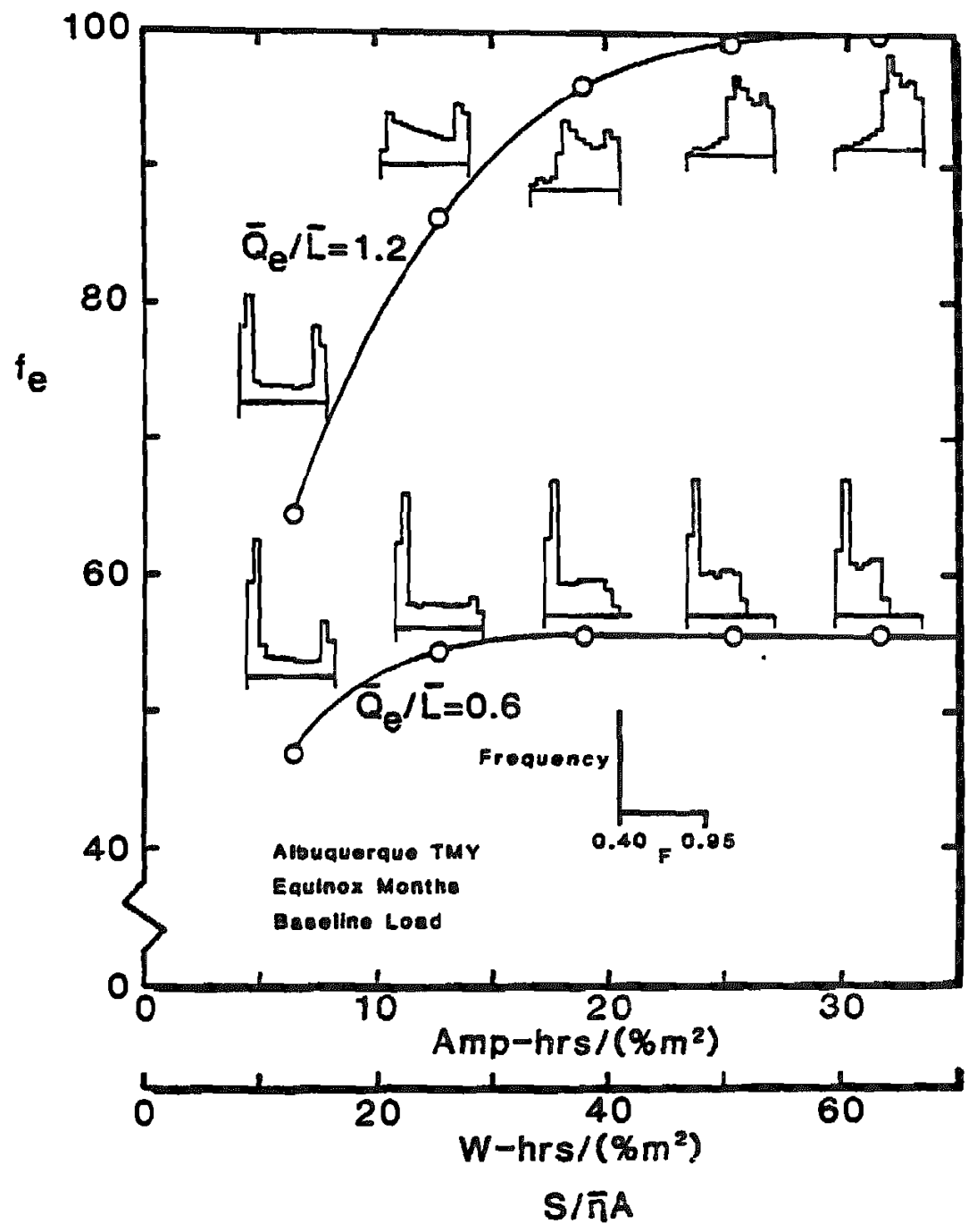

Figure 2.4 Storage Battery Utilization for Various Size Systems $F=$ Fractional state of Charge of Battery. 


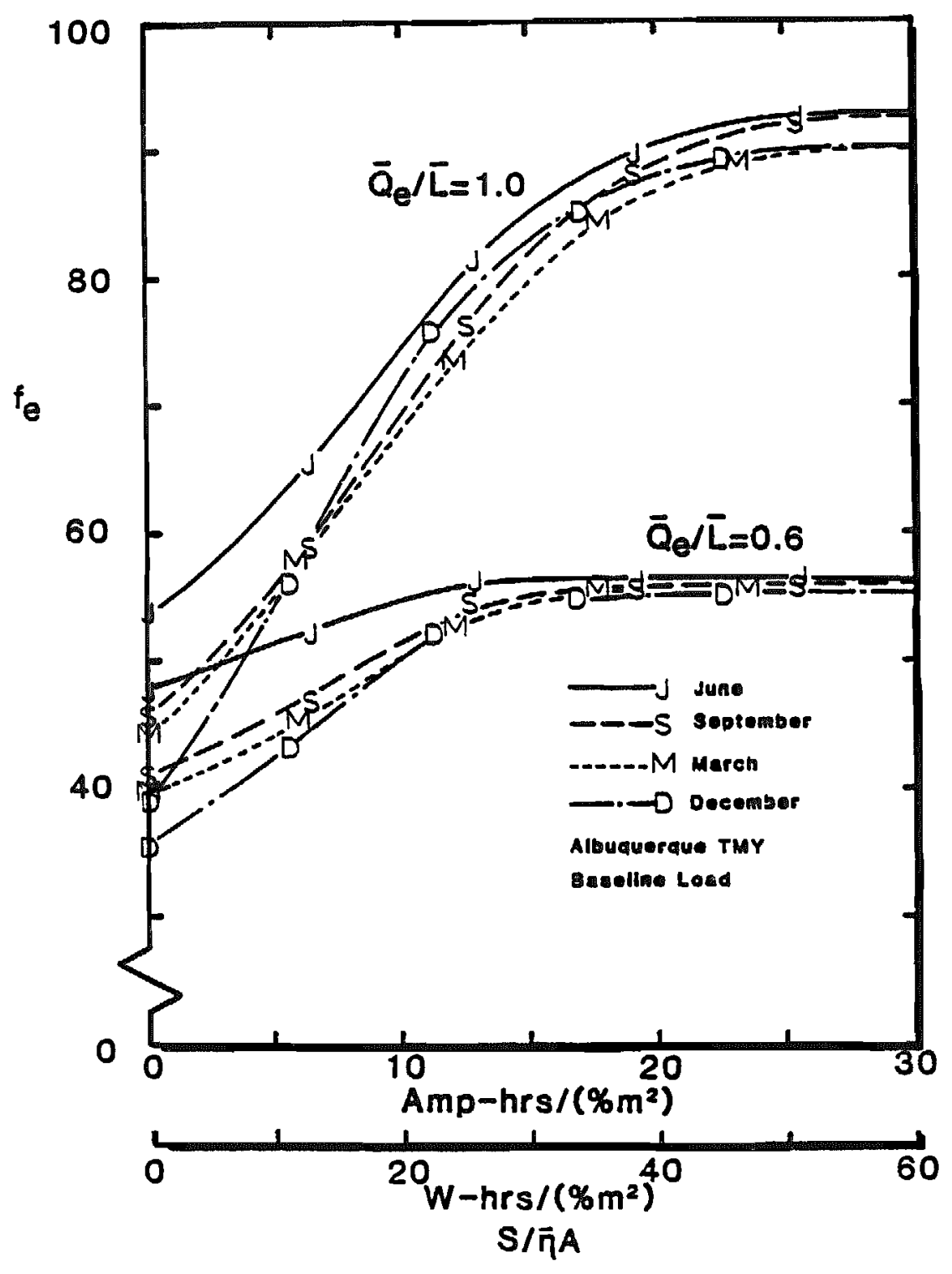

Figure 2.5 Seasonal Variation in System Performance. 

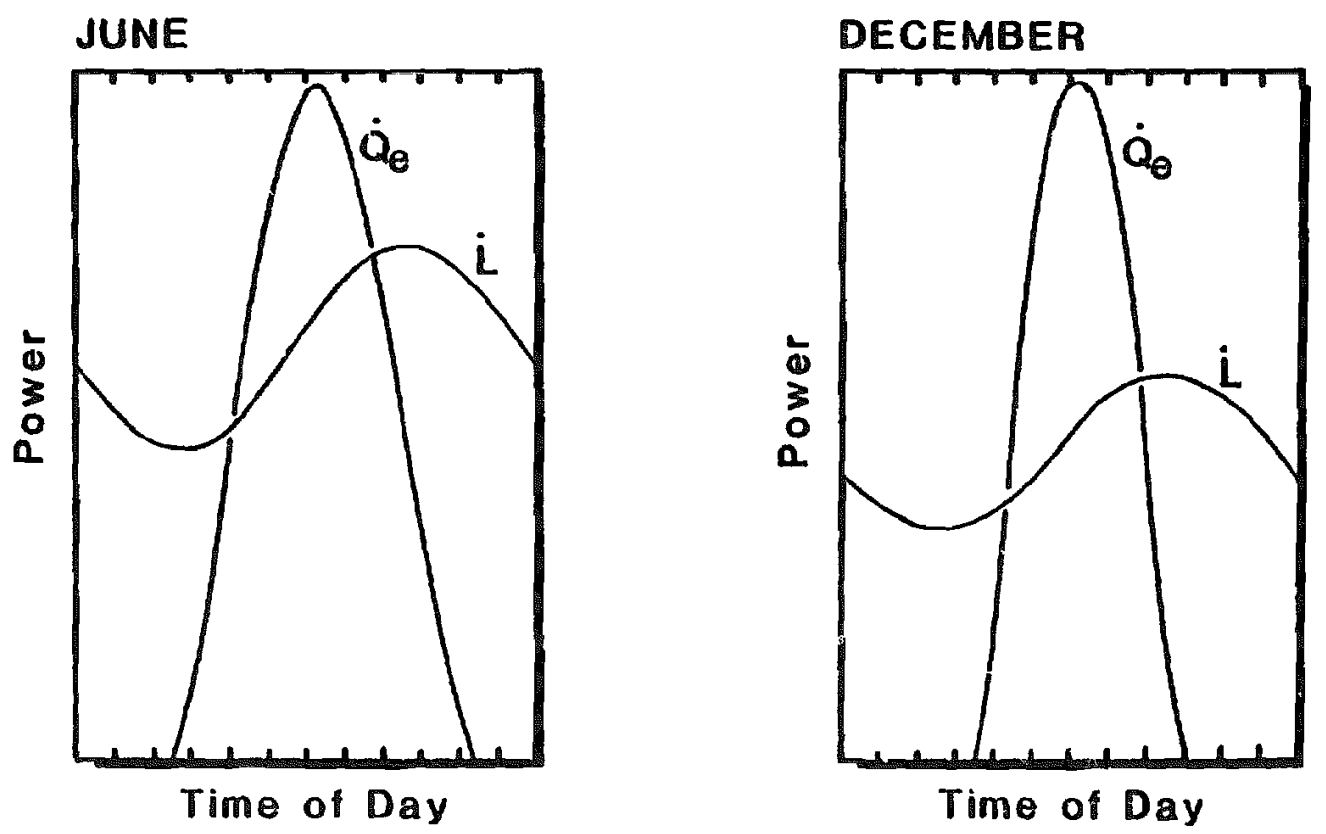

Figure 2.6. Seasonal Differences Between Daily Load Shape and Insolation Profiles for the Same $\bar{Q}_{e} / \bar{L}$. Curves are Normalized to the Maximum $\dot{Q}_{e}$ Each Month. 


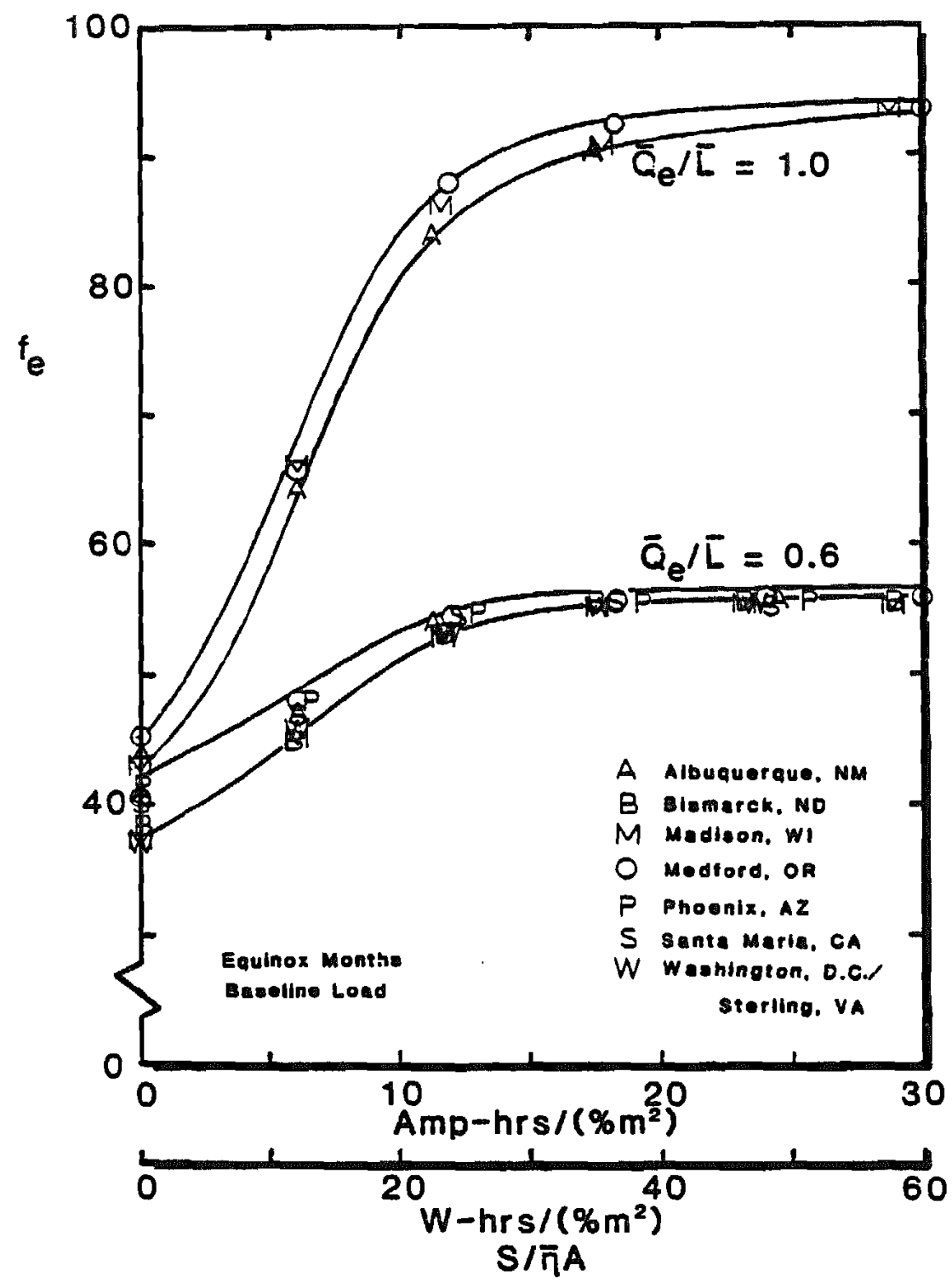

Figure 2.7 Effect of Location on Weather Patterns. 

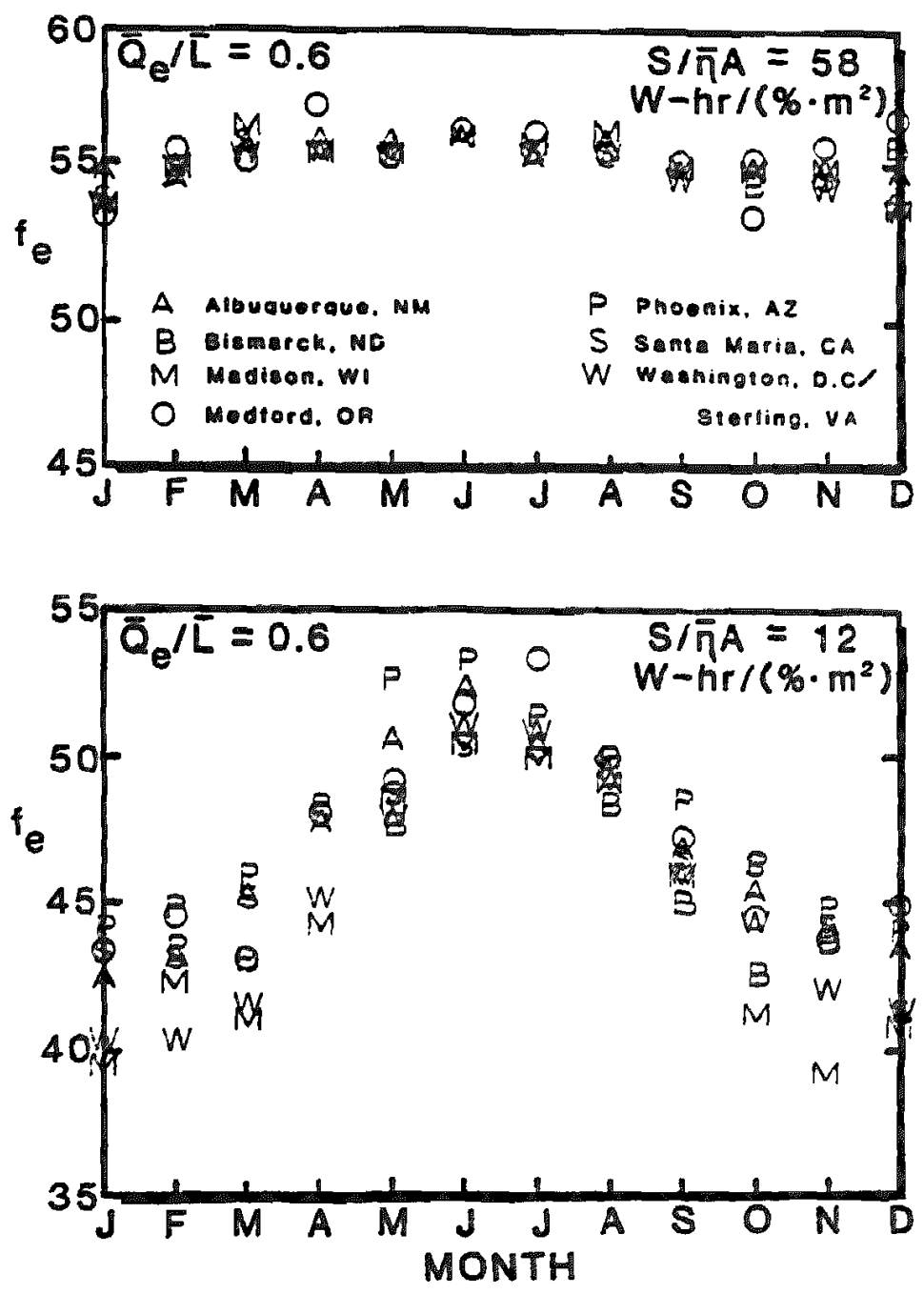

Figure 2.8 Combined Effect of Seasonal Variations and Local Weather Patterns. 


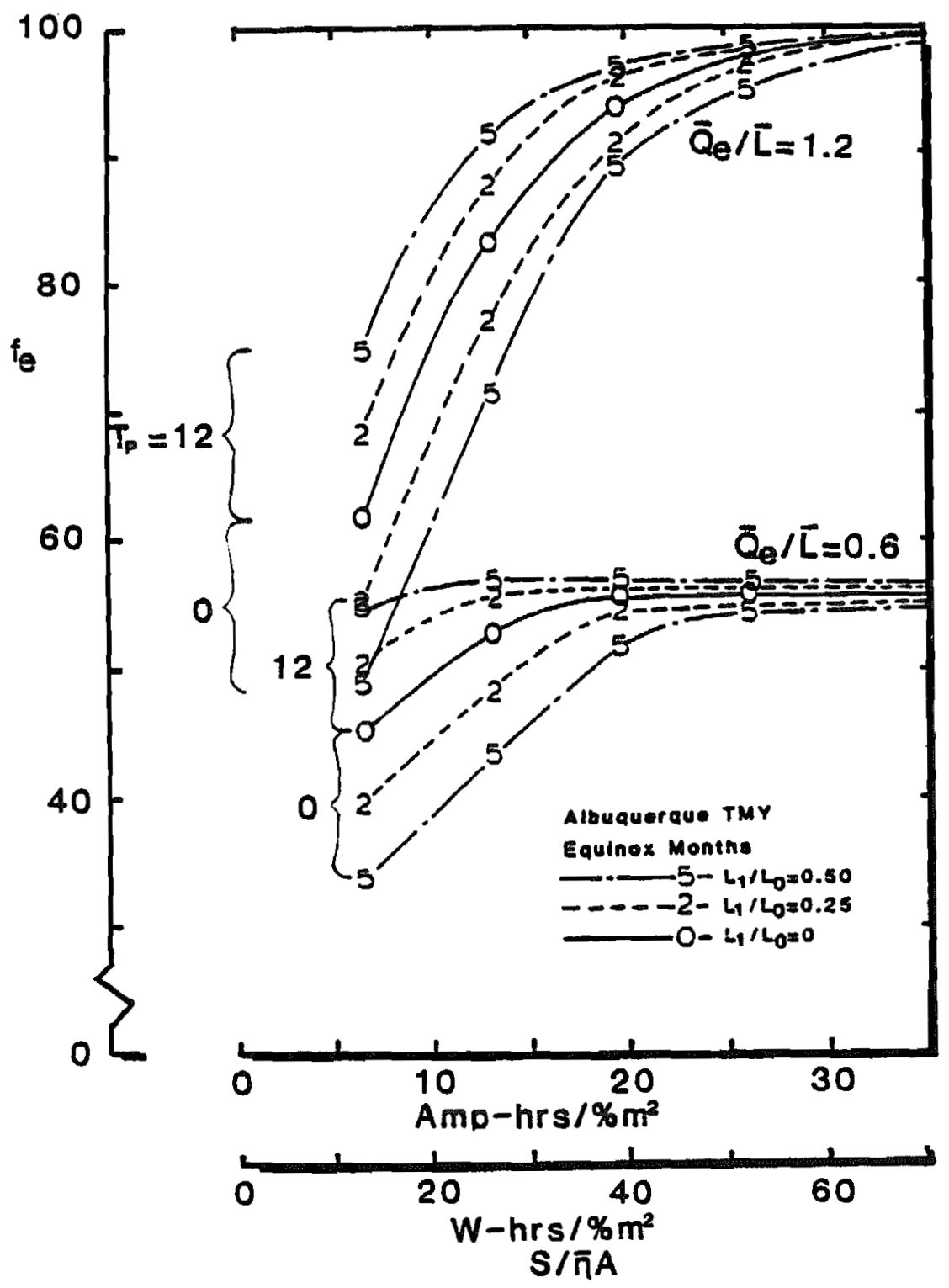

Figure 2.9 Effect of Load Shape on System Performance. 


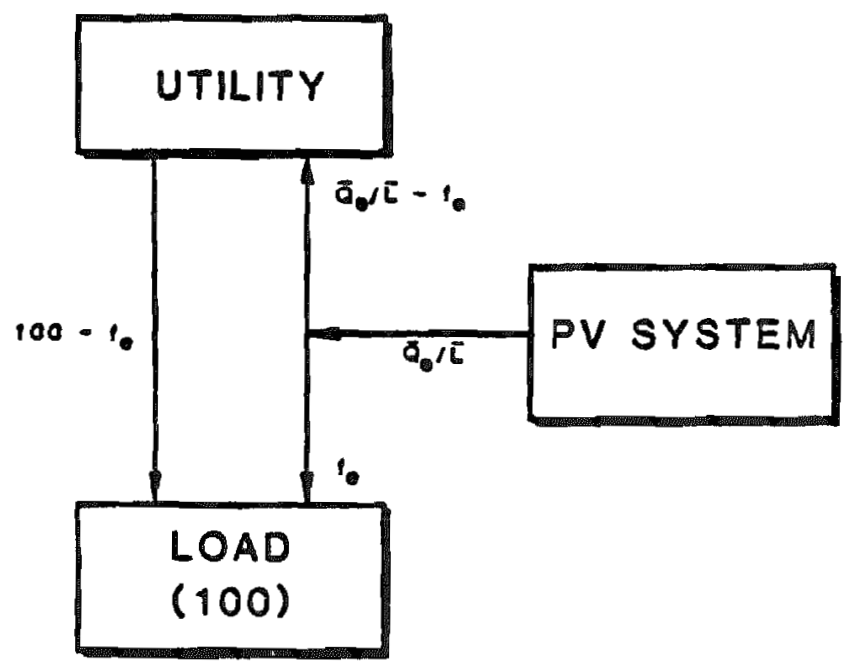

Figure 2.10 Energy Flow Diagram for Utility-Feedback. 


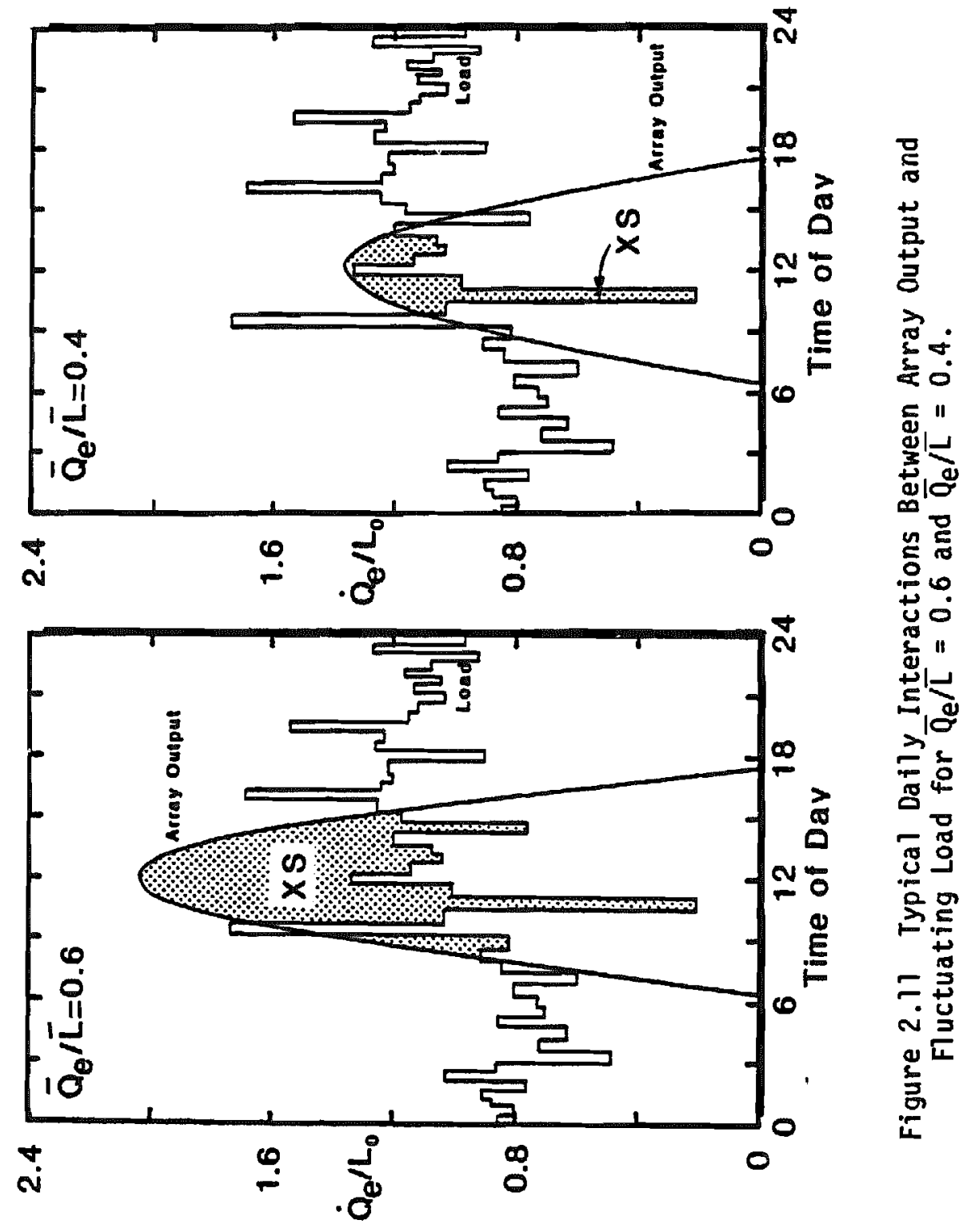




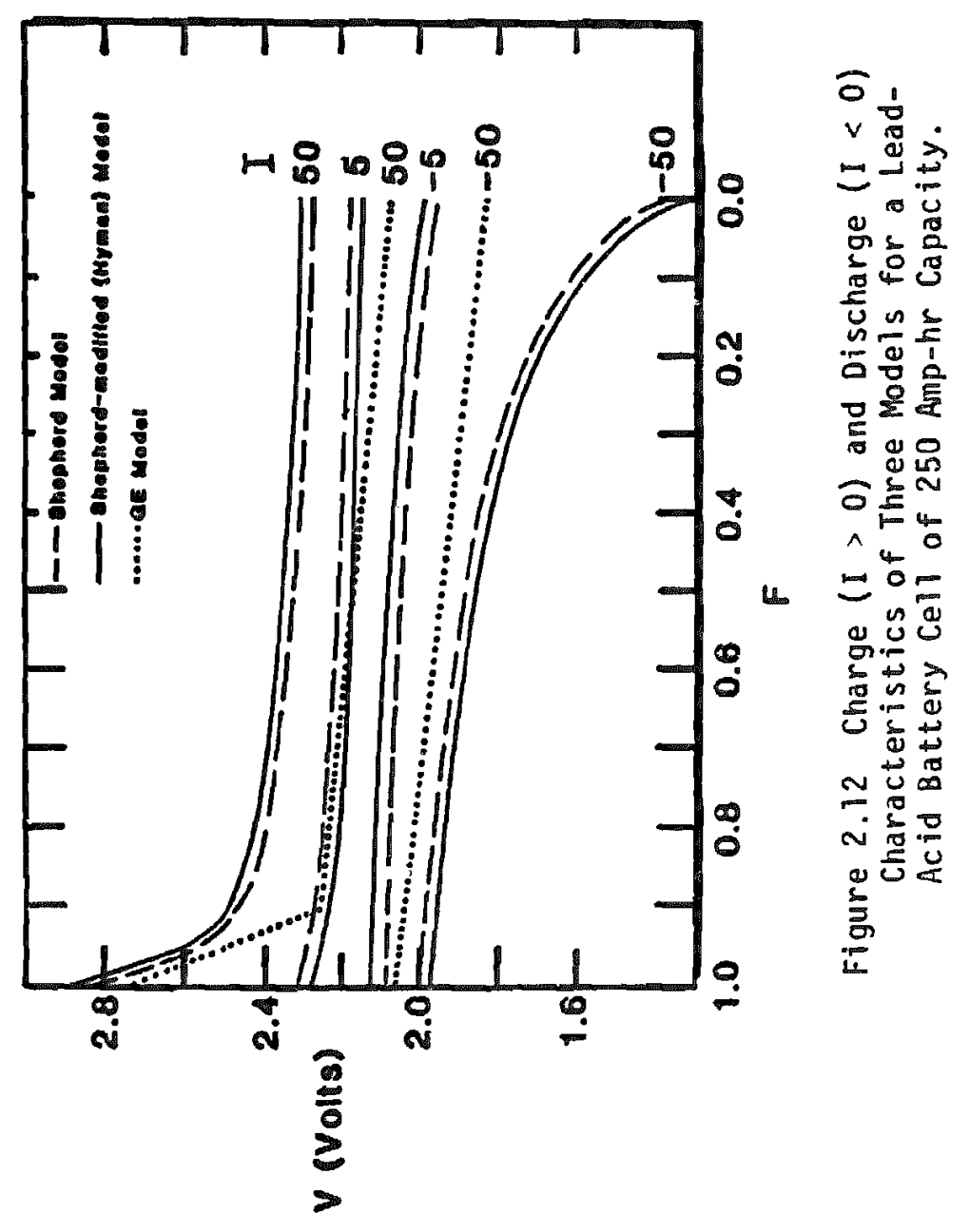




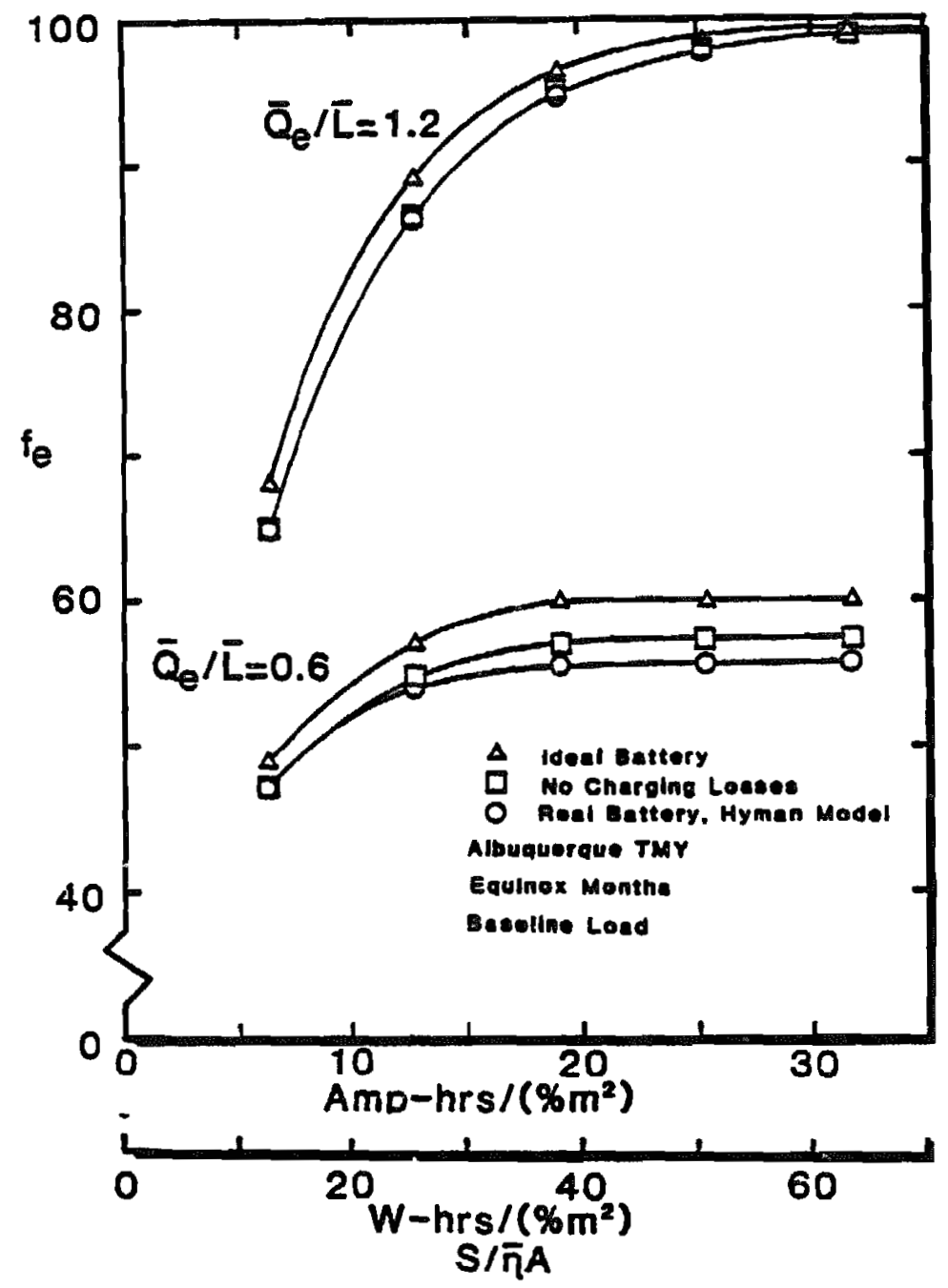

Figure 2.13 Effect of Battery "Voltage Difference" and Charging Losses on System Performá ie. 


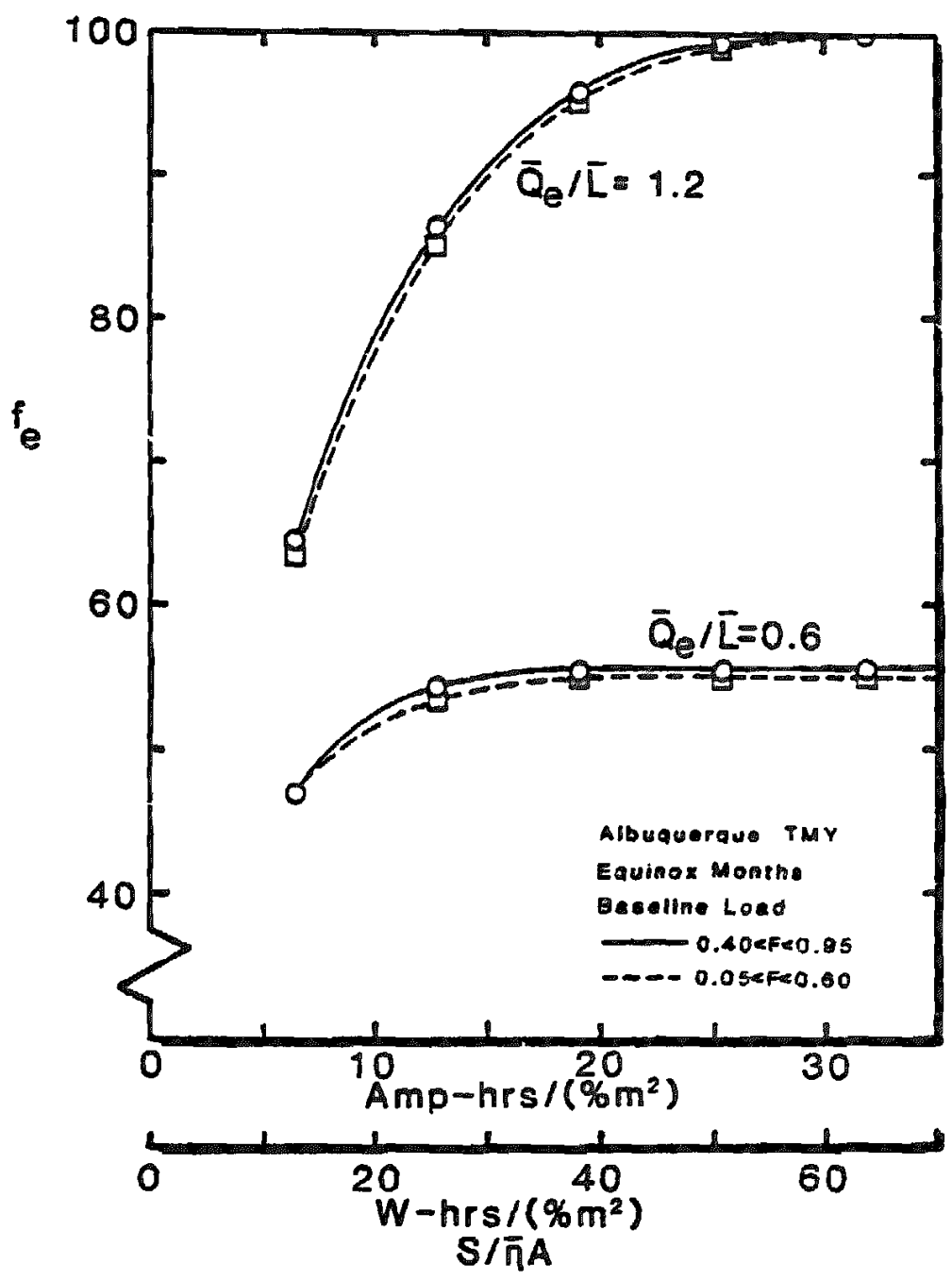

Figure 2.14 Effect of Different Ranges of Battery State of Charge. 


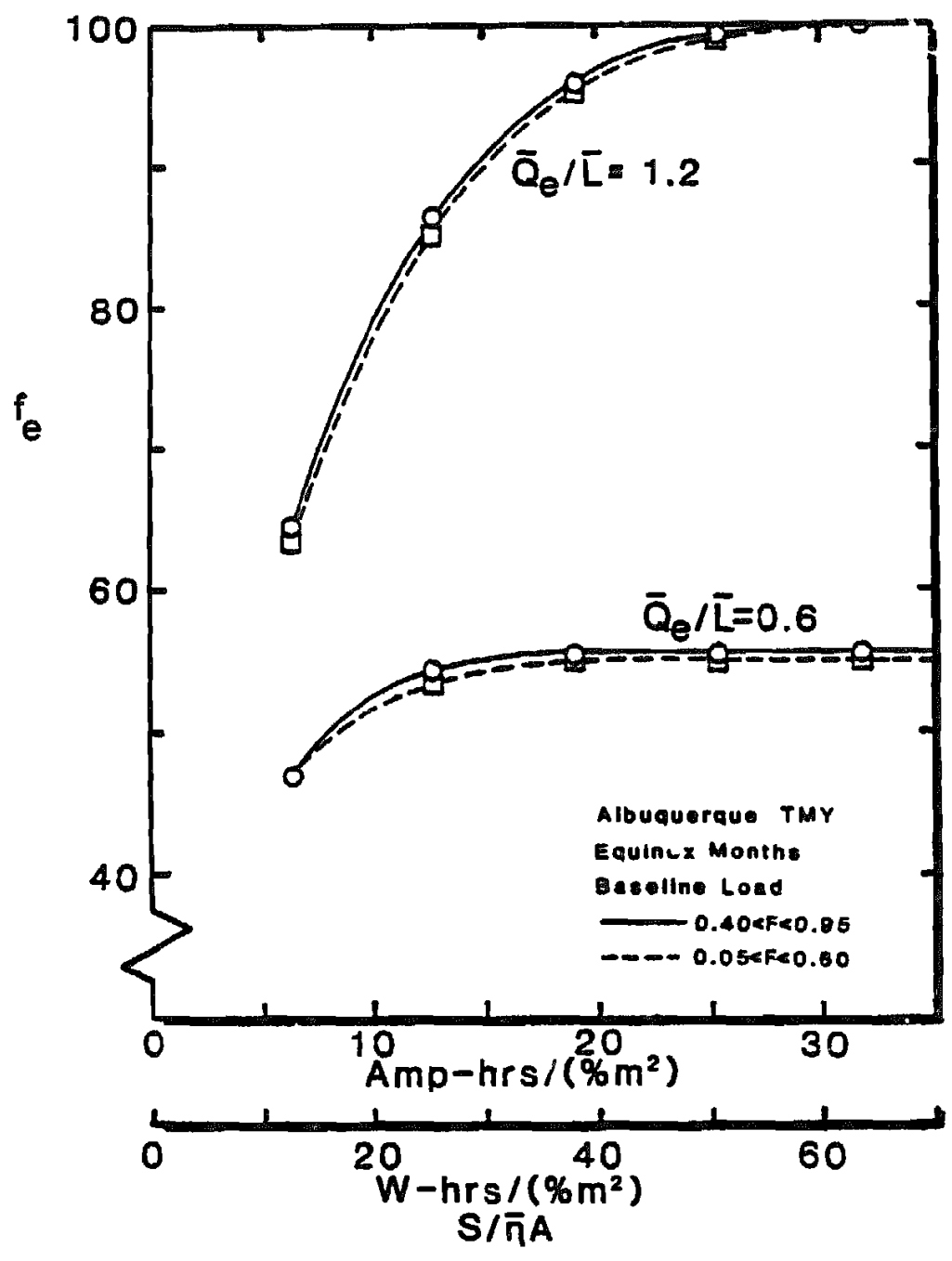

Figure 2.14 Effect of Different Ranges of Battery State of Charge. 


\subsection{PREDICTING ARRAY OUTPUT}

\subsection{The Assumptions}

In photovoltaic system design it is necessary to predict the output of a given solar cell array under various conditions. As shown in Chapter 2, if the output is swall enough and coincides timewise with the load to be met, the solar contributios to the load can of ter be easily estimated from the calculated array output. If the output is large and/or does not coincide timewise with the load, then predicting the solar contribution to the load is not as easy since not all of the array output may be used. However, in this case, the calcnlation of array ontput is desirable since it may play an important role in correlating system performance results.

The present chapter is devoted to a simplified procedure for calcolating array ontput starting with minimum of input information. The time periods of interest are monthly intervals since there exists a rather good data base on weather and insolation for such periods.

The analysis and results that follow strictly apply to only passively cooled arrays since these types of systems are most strongly tied to ambient weather conditions. The results may, with care, be useful for actively cooled arrays where the heat sink for the thermal energy deposited in the array is ultimately the ambient outdoor weather although this has not been studied extensively. The results definitely do not apply to combined systems that make use of the thermal energy, since in such systems, cell temperature is often determined by non-weather related conditions.

It is also assumed here that the solar cell arrays are mar-power tracked; i.e., the voltage imposed on the array is always such that the electrical power produced is a maxim. This assumption is not quite as restrictive as it first appears since it can be shown (Ref. 3.2) that, under the proper conditions, other modes of operation 
can produce nearly the same amount of energy as max-power tracked arrays do over some comon period of time. For example, arrays that operate in a battery clamped mode (i.e., the battery voltage determines the array voltage) may operate on a nearly comparable basis with max-power tracked systems if the ratio of solar cells to battery cells is properiy chosen (see Chapter 5).

The approach adopted here is to find a mean monthly array efficiency that when multiplied by the mean monthly solar irradiation of the array, yields essentially the same electrical energy production as the integration of the instantaneous ontputs over the month. This latter quantity can be obtained hy use of a sophisticated computer simulation program, but this in itself is not regarded as a simplified technique. It is used here only as an artifice in the determination of the mean monthly array efficiency.

The mean monthly solar irradiation on the array has, of course, been the subject of much work, particularly in the solar thermal field. There are several accepted methods for estimating its value; these will be referenced later in this chapter.

\subsection{The Analysis}

In terms of the instantaneous solar irradiation, $\dot{Q}_{s}(t)$ on a photovoltaic array, the monthly average daily array electrical outpat energy, $\bar{a}_{a e}$ is given by

$$
\bar{Q}_{a e}=A \int \eta \dot{Q}_{s}(t) d t / N_{d}
$$

where $\eta$ is the instantaneous array efficiency and the integration is carried out over monthly periods. $\vec{Q}_{e}$, the electrical energy potentially availaule to the load introduced in Chapter 2 , is related to $\bar{Q}_{\text {ae }}$ by:

$$
\vec{Q}_{e}=\eta_{p c} \vec{Q}_{a e}
$$


where $\eta_{p c}$ is the "straight through" power conditioning efficiercy of the system.

Instantaneous insolation data required in eq. (2.1) is very seldom available. Many times hourly data are the best which are available; i.e. instantaneous insolation data integrated over one hour time intervals. If the insolation for hour $i$, defined as $a_{s, i}$ is given by

$$
\overline{\mathbf{Q}}_{s, i}=\int_{i} \dot{Q}_{s} d t
$$

where the integration is over the ith hour, then eq. (3.1) can be approximated by

$$
\bar{Q}_{a e}=\Sigma \Sigma \eta_{i} Q_{s, i} / N_{d}
$$

Here the sumation goes over all hourly intervals in the month and $\eta_{i}$ is the "hour1y" efficiency. Equation (3.4) is an approzimation to eq. (3.1) since it is impossible to reconstruct the instantaneous insolation from the hourly insolation. Hence, it is impossible to tell what fraction of each hour was characterized by ''high'" insolation (and thus lower efficiency due to the higher teaperature of the array) and what part by ''low'" insolation (and thrs a lower efficiency). Although this has not been explored in detail, the difference between eqs. (3.1) and (3.4) should be small for low concentration ratio collectors (e.g. flat plate arrays). This difference undeubtediy increases with concentration.

The array efficiencies $\eta$ and $\eta_{i}$, for maz-power operation, are furctions of array (and cell) design, cell temperature and array irradiation. Axray design is typically characterized by stating a reference efficiency $\eta_{I}$, for the array when the cell temperature is at reference $T_{r}$ (often 28C), and array illumination is at some reference level $Q_{s, r}$ (often assumed to be 1 kllow or one sun). For the purposes of this work $\eta_{i}$ will be assumed to be related to 
cell tempereture, $T_{c, i}$ and array insolation, $Q_{s, i}\left(\right.$ in $\left.\mathrm{kW} / \mathrm{m}^{2}\right)$, through (Ref. 3.1)

$$
\eta_{i}=\eta_{I}\left[1-\beta\left(T_{c, i}-T_{I}\right)+\gamma \log _{10} Q_{s, i}\right]
$$

Here $\beta$ and $\gamma$ are primarily cell material dependent coefficients that relate most closely to the open circuit voltage behavior of the cells (and thus to the max-power voltage). Equation (3.5) generally ignores the dependence of the max-power current on cell temperature, an effect which is often small. Most often this equation is seen without the last term $(y=0)$ (e.g. Ref. 3.2) although it can bo important in low insolation locations. In high irradiation situations, such as in concentrator systems, where series resistance effects become important, the insolation cependent term in eq. (2.4) does not provide the proper behavior especially above the irradiation levels that produce the maximum efficiency (Ref. 3.3).

Thus, to the accuracy that most insolation data are known, the monthly average daily array electrical energy production for max-power operation is given by

$$
\begin{aligned}
\bar{Q}_{a e} & =A \Sigma \eta_{i} Q_{s, i} / N_{d} \\
& =A \Sigma \eta_{I}\left[1-\beta\left(T_{c, i}-T_{r}\right)+\gamma \log _{10} Q_{s, i}\right] Q_{s, i} / N_{d}
\end{aligned}
$$

Where the summations go over all the hours of the month. Adding and subtracting the hourly ambient (dry bulb) temperatnre $T_{a, i}$ and the mean monthly temperature $T_{M}$ to the terms in parentheses and recollecting pields:

$$
\begin{aligned}
\bar{Q}_{a e}= & \left(\eta_{r} A / N_{d}\right)\left[\Sigma Q_{s, i}-\beta \Sigma\left(T_{c, i}-T_{a, i}\right) Q_{s, i}\right. \\
& -\beta \Sigma\left(T_{a, i}-T_{M}\right) Q_{s, i}-\beta\left(T_{M}-T_{r}\right) \Sigma Q_{s}, i \\
& \left.+\gamma \Sigma Q_{s, i} \log _{10} Q_{s, i}\right]
\end{aligned}
$$


The ase of eq. (3.6) in any simplified design procedure is, of course, inappropriate because of the occurrence of the hourly quantities, $T_{a, i}, T_{c, i}$ and $Q_{s, i}$. From a simplified standpoint, it world be preferable to calculate $Q_{a e}$ from:

$$
\bar{Q}_{\mathrm{ae}}=\overline{\eta q A} \Sigma Q_{s, i} / N_{d}
$$

where $\bar{\eta}$ is a monthly average conversion efficiency and the sumation is just the monthly average daily insolation on the array. This latter quantity can be estimated from procedures comonly used in solar thermal related work.

$$
\begin{aligned}
& \text { An expression similar to eq. (3.5) can be used to regresent } \bar{n} \text { : }
\end{aligned}
$$

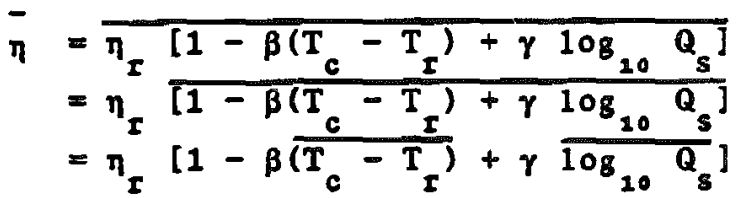

where the terms now lacking an $i$ subscript are left to be defined. With this, eq. (3.8) becomes

$$
Q_{a e}=\eta_{I} A\left[1-\beta \overline{\left(T_{c}-T_{I}\right)}+\gamma \overline{\log _{10} Q_{s}}\right] \Sigma Q_{s, i} / N_{d}
$$

Adding and subtracting $T_{a}$ and the mean monthly temperature $T_{Y}$ to eq. (3.10) yie1ds

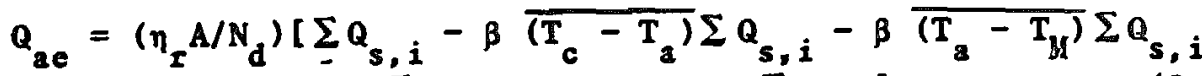

$$
\begin{aligned}
& \left.-\beta\left(T_{H}-T_{I}\right) \sum Q_{s, i}+\gamma \log _{10} Q_{s} \sum Q_{s, i}\right]
\end{aligned}
$$

where it has been noted that

$$
\overline{\left(T_{Y}-T_{r}\right)}=\left(T_{M}-T_{r}\right)
$$


Comparison of eqs. (3.7) and (3.11) shows that they yield the same result for $Q_{a e}$ if $^{2}$

$$
\begin{aligned}
& \overline{\left(T_{c}-T_{a}\right)} \Sigma Q_{s, i}=\sum\left(T_{c, i}-T_{a, i}\right) Q_{s, i} \\
& \overline{\left(T_{a}-T_{M}\right)} \Sigma Q_{s, i}=\Sigma\left(T_{a, i}-T_{M}\right) Q_{s, i} \\
& \overline{\log _{20} Q_{s}} \Sigma Q_{s, i}=\Sigma Q_{s, i} \log _{10} Q_{s, i}
\end{aligned}
$$

These three equations serve to define the quantities $\overline{\left(T_{c}-T_{a}\right)}$, $\overline{\left(T_{a}-T_{M}\right)}$, and $\overline{\log _{20} Q_{s}}$.

\subsubsection{The Term $\overline{\left(T_{c}-T_{a}\right)}$}

Intuitively, $\overline{\left(T_{c}-T_{a}\right)}$ that appears in eq. (3.13) represents the monthly average difference between the cell temperature and the ambient temperature during daylight hours. The $\left(T_{c, i}-T_{a, i}\right)$ term, to which it is related, should bo driven by the relationship between the insolation on the array and the thermal losses from the array to the environment. Indeed, an hourly energy balance on an array yields (see Fig. 3.1).

$$
K_{e}\left(T_{c, i}-T_{a, i}\right)=Q_{s, i} \text { ap }-Q_{s, i} \eta_{i} p
$$

where the left hand side represents the thermal losses from the cells to the surroundings, the first term on the right hand side represents the energy absorbed from the solar irradiation and the second term on the right hand side is the electrical energy produced by the array. ${ }$ is the thermal conductance (per aperture area) for heat transfer from the cells to the surroundings (Ref. 3.4) and is a complicated function of array design, ambient temperature, local wind conditions,

\footnotetext{
${ }^{2}$ The choices made in eqs. (3.13), (3.14) and (3.15) are not nnique but they seem to be natural in that they will allow reasonable physical interpretation
} 
and geometry. Since a designer usmally has little information on which extensive calculations can be based, it will be assumed that an adequate average value of $B_{e}$ can be defined.

Fortunately, $\eta_{i}$ is usually small in comparison to $a$ in eq. (3.16); therefore, the second term on the right hand side will be neglected in the analysis that follows. An iterative procedare for correcting for non-negligible $\eta_{i}$ will be shown later.

Thus, eq. (3.16) yie1ds

$$
\left(T_{c, i}-T_{a, i}\right)=\operatorname{ap} Q_{s, i} / \mathbb{R}_{e}
$$

Using this in eq. (3.13) yields

or

$$
\overline{\left(T_{r}-T_{a}\right)}=\Sigma\left[Q_{s, i}{ }^{2} \operatorname{ep} / \mathbb{R}_{e}\right] / \Sigma Q_{s, i}
$$

$$
K_{e}\left(T_{c}-\overline{T_{Q}}\right) T a p=\Sigma Q_{s, i}{ }^{2} / \Sigma Q_{s, i}
$$

The quantity $\mathrm{K}_{e}\left(T_{c}-T_{a}\right) /(\alpha p)$ was computed monthly using eq. (3.19) for seven widely varying clinatic locations in the Dnited States for which SOLMET (Ref. 3.5) data vere available. The locations and number of years of data used are shown in Table 3.1 .

The SOLMET data used consisted of the hourly standard year corrected total radiation on the horizontal (TH) and the direct normal (DN) or beam radiation. For flat arrays, optimus tilts chosen for each month were used. Each hour the DN contribution to the TR was removed from the latter in order to recover the diffuse component on the horizontal (DH). DH was then adjuted to yield diffuse radiation on the tilt (DT) by multiplying $D H$ by $(1+\cos s) / 2$, which assumes a uniform sky. DT was then combined with the ground reflected radiation (a ground reflectance of 0.2 was used) and the appropriate DN component on the tilt to gield total radiation (TI) on the tilt.

The quantity $\mathrm{K}_{\mathrm{e}} \overline{\left(\mathrm{T}_{\mathrm{c}}-\mathrm{T}_{\mathrm{a}}\right) /(\alpha \rho)}$ was also calculated for concentrating collectors assuming they were capable of two-dinemsional 
(2-D) tracking. For this type of tracking, $Q_{s, i}$ was $j u s t$ the $D N$ radiation from the soLMET data.

For each location, long term average $K_{e} \overline{\left(T_{c}-T_{a}\right) /(a p)}$ was then computed for each month from the multiple years of data. Various correlations relating these quantities to other long term average weather and solar data were attempted. The simplest and most effective correlation that was discovered is shown in Fig. 3.2, which relates long term $K_{e} \overline{\left(T_{c}-T_{q}\right) /(\alpha \rho)}$ to the long term average $\bar{K}_{T^{\prime}}$ the ratio of TH to the value of TH in the absence of the atmosphere (the extraterrestrial radiation) (Ref. 3.6). Long term $\bar{z}_{\mathrm{T}}$ 's were also obtained from the solMET data. Each data point shown in Fig. 3.2 represents the average of at least 16 years of SOLMET data and in most cases, 22 years.

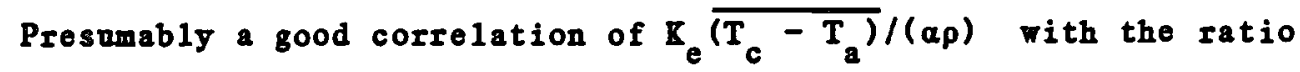
of TT to the extraterrestrial radiation on the tilt world also exist. However, if any radiation data exist for a site, it is usul1y either $T H$ or the ratio $\bar{K}_{T}$. Therefore, it is much more convenient from a designer's standpoint to use $\bar{K}_{T}$ than any other ratio.

TH by itself is not a good correlation parameter since it involves daylength. For example, in the sumer months when ihe days are long, a region of cloudy weather and relatively low average hourly insolation might have as much average daily radiation as a less cloudy period in the winter (shorter days) having higher average hourly insolation. The cell temperature rise above ambient [to which $\overline{\left(T_{c}-T_{a}\right)}$ is related] would be larger in the winter than in the sumer for this hypothetical example. Dividing the total radiation by the extraterrestrial radiation, as is done in obtaining $\overline{\mathbf{r}}_{\mathrm{T}}$, normalizes out the daylength and allows a more direct comparison of average hourly insolation.

Althoogh only the data for monthly optimum tilted flat arrays are shown in Fig. 3.1, there is 1 ittle detectable difference in the data 
for 2-D tracked concentrators as long as $F_{e}$ is the thermal conductance based on the aperture area and not the cell or absorber area. Again, this analysis assumes $Q_{s, i}$ is uniformly distributed in time over the hour i. Such would be the case for steady cloud cover. Broken and scattered clouds could cause significant deviations in areas of $10 \mathrm{r} \overline{\mathrm{R}}_{\mathrm{T}}$.

That there is little if any difference between the flat array data and the data for concentrators is not too surprising since the quantity $\Sigma Q_{s, i}{ }^{2} / \Sigma Q_{s, i}$ most heavily weights high insolation periods. Thus, the high incidence angle morning and evening periods for flat plates which are characterized by low irradiation are not important in dotermining the average monthly efficiency.

The solid line shown in Fig.3.2 is the best fit straight 1 ine characterizing the data. It can, with good accuracy, be used to

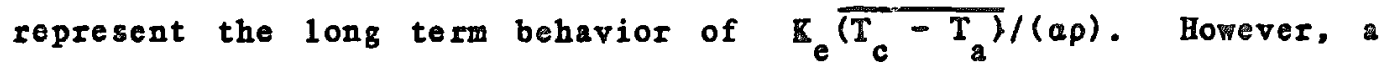
designer often would like to know what variations might be expected from the long term averages. Therefore, two deviations have been considered here. First, the scatter that could be anticipated in the monthly $\overline{\mathrm{K}}_{\mathrm{T}}$ at a particular location about the long term average $\overline{\mathrm{B}}_{\mathrm{T}}$ for that same month and same location is shown in Fig. 3.3. A11 months have been ircluded here, independent of the relative size of $\overline{\mathrm{K}}_{\mathrm{T}}$. The distribution of the irdividual monthly $\overline{\mathrm{F}}_{\mathrm{T}}$ 's about the long term average $\overline{\mathrm{K}}_{\mathrm{T}}$ is nearly Gaussian with a standard deviation, $\sigma$, of 0.042. If one considered only the months and locations of high $\vec{k}_{T}$ this distribution would be characterized by a somewhat smaller standard deviation. Likewise, lower $\overline{\mathrm{K}}_{\mathrm{T}}$ 's vould be characterized by somewhat 1 arger standard deviations.

Second, the scatter that would be represented about the straight line shown in Fig. 3.3 if data from every month and every location were shown, is represented in Fig. 3.4. Here $A_{0}$ and $A_{1}$ take on the values of the appropriate coefficients shown in the lirear equations on Fig. 3.2. Again, the distribution is nearly Gaessian with a standard deviation as shown (typically $0.043 \mathrm{~km} / \mathrm{m}^{2}$ ). 
Thile a designer using flat plates may choose an optimum tilt to maximize energy production for some one month of the year, it may be neither desirable nor necessary to adjust the tilt each month. However, even though the tilt may be non-optimum during many months, a designer may still need to predict array output. Therefore, calculations have been made to determine $\mathrm{K}_{\mathrm{e}} \overline{\left(\mathrm{T}_{\mathrm{c}}-\mathrm{T}_{\mathrm{a}}\right) /(\alpha \rho)}$ for non-optimum tilts. The results of these calculations were expressed as a correction factor, $C_{f}$, that when multiplied by the $K_{e} \overline{\left(T_{c}-T_{a}\right) /(a \rho)}$ for the optimun tilt yields the $K_{e} \overline{\left(T_{c}-T_{a}\right) /(\alpha \rho)}$ for non-optimu tilt. Such a multiplicitive factor is possible since, as discussed previously, $K_{e} \overline{\left(T_{c}-T_{a}\right) /(\alpha \rho)}$ is most strongly influenced by high insolatin values that occur near midday. Thus, one would expect $C_{f}$ to be dependent (nearly) on the cosine of the absolute value of the difference between the actual tilt (s) and the monthly optimum tilt ( $s^{\prime}$ ) (both tilts are assumed to be up from horizontal and the arrays are assumed to be south facing).

The optimum tilts were found to be almost totally latitude dependent. They can be calculated from the information found in Table 3.2.

Fig. 3.5 shows data on the correction factor $c_{f}$ as a function of $\left(s_{M}-s\right)$. The data there are for sumer and winter months for Albuquerque, NM and Madison, WI. These two locations have $\bar{K}_{\mathrm{T}}$ 's that are at the high and low ends, respectively, of the typical range of $\overline{\mathrm{K}}_{\mathrm{T}}$ 's found in most locations. Although the data in Fig. 3.5 show a nearly cosine dependence on $\left(s_{M}-s\right)$, the quadratic equation given there fits the data somewhat better.

For some types of design information it may be desirable to be able to predict $\overline{\left(T_{c}-T_{a}\right)}$ at midday or solar noon. This was evaluated by restricting the summations in eq. (3.19) to just the two hour period centered about solar noon each day. The same cities and years considered previously were used. Figures $3.6 \mathrm{a}$ and $3.6 \mathrm{~b}$ show the long term results as a function of the long term $\bar{K}_{T}$ as defined previously. Unlike the results shown in Fig. 3.2 , there is now a 
distinct difference between optimally tilted flat plate results (Fig. 3.6a) and 2-D tracking results (Fig. $3.6 b$ ).

\subsubsection{The Term $\overline{\left(T_{\mathrm{a}}-\mathrm{T}_{\mathrm{M}}\right)}$}

Next consider the term $\overline{\left(T_{a}-T_{M}\right)}$ defined by eq. (3.14). This term, in essence, is a measure of the difference between the average temperature during high insolation hours of the day and the mean monthly temperatare. Manipulation of eq. (3.4) yields

$$
\overline{\left(T_{a}-T_{M}\right)}=\Sigma T_{a, i} Q_{s, i} / \Sigma Q_{s, i}-T_{M}
$$

Typically, daily minimu temperatures are reached between 4 and 5 a.m. and masimum temperatures are reached between 4 and 5 p.m. Therefore, temperatures around 10 to 11 a.m. are usually close to the daily mean temperature. One roold expect, then, that $\overline{\left(T_{a}-T_{M}\right)}$ would be only slightly larger than zero. This indeed is the case as is shown in Fig. 3.7. Here the Typical Meteorological Yuar (MT) (Ref. 3.7) data for the seven sites noted previously (see Table 3.1), were used in order to save computation expenses.

For the purposes of this simplified design methodology it is sufficiently accurate to take

$$
\overline{\left(T_{a}-T_{M}\right)}=3 C
$$

\subsubsection{The Term $\overline{\log _{10} Q_{s}}$}

Next, eq. (3.16) can be manipulated to give

$$
\overline{\log _{10} Q_{s}}=\sum Q_{s, i} \log _{10} Q_{s, i} / \sum Q_{s, i}
$$

which now serves to define $\overline{\log _{10} Q_{s}}$. As was done for the term $K_{e} \overline{\left(T_{c}-T_{a}\right) /(\alpha \rho), ~ a ~ v a l u e ~ o f ~} \frac{10 Q}{\log _{20} Q_{s}}$ was calculated each wonth for the locations and number of years shom in Table 3.1. The long term 
monthly average values of $\overline{\log _{10} Q_{S}}$ vs. the long term monthly $\bar{K}_{T}$ are shom in Fig. 3.8. Also given is a best fit linear equation representing the data displayed and the standard deviation, $\sigma$, of all the data (all months for all seven sites) about the linear fit.

The results shown in Fig. 3.8 are for optimally tilted flat arrays although there is little discernible difference for 2-D tracking surfaces. Non-optimamally tilted flat plates pose a problem, however.

Examination of eq. (3.22) shows that values of $Q_{s, i}$ near 0.368 $\mathrm{kW} / \mathrm{m}^{2}$ most heavily weight the result for $\frac{\log _{10} Q_{s}}{s i n c e}$ $Q_{s, i} \log _{10} Q_{s, i}$ is maximum at that value. For flat arrays, such insolation levels occur at time intervals away from solar noon that depend upon latitode, time of year, and radiation patterns. These complications have so far precluded the establishment of a simple correction factor which condd convert the results of Fig. 3.8 into more nseful results for non-optimum tilts.

\subsection{The Use of the Procedure}

The task of calculating the monthly electrical energy output from max-power tracked photovoltaic arrays has been reduced to evaluating the terms that apper in the following equations:

$$
\begin{aligned}
\bar{\eta}= & \eta_{I}\left[1-\beta \overline{\left(T_{c}-T_{a}\right)}-\beta \overline{\left(T_{a}-T_{M}\right)}-\beta\left(T_{M}-T_{I}\right)\right. \\
& \left.+\gamma \log _{10} Q_{s}\right] \\
Q_{a e} & =\bar{\eta} A \Sigma Q_{s, i} / N_{d}=\overline{\eta A Q} \bar{Q}_{s}
\end{aligned}
$$

In order to ase these equations, a designer must supply:

a) $\eta_{I}, T_{I}$ - these are determined by the array design and should be obtained from the array mannfacturer. (See Section 6.5) 
b) B, $\gamma$ - properties that are primarily dependent on the cell composition. These should be obtained, where possible, from the cell manufacturer's data. Valnes for silicon cells should be close to $\beta=0.005 \mathrm{C}^{-1}$, $\gamma=0.12$. (See Section 6.5)

c) $a$

- This should be obtained, if possible from the manfacturer. Absorptance data for cells are difficnlt to find: values used in the literature range from 0.8 to 0.96 (Ref. 3.8 through 3.13). Lack of knowledge of the exact value of this parameter car be somewhat compensated for by knowing NOCT as discossed in Section 3.4, below.

d) $p$

- this will be deterwined by the opticel elements that may be present between the array and the sun. For flat plates, $p=1$; for concentrators, $\rho<1$.

e) $T_{M}$

- the wonthly mean temperature can be obtained frow weather station data if such a station exists in the vicinity of the installation site. If weacher data are taken at all, values of $T_{M}$ are nsually available. Ref. 3.14 contains values for 171 locations in the U.S. and Canada. Ref. 3.15 contains data for 261 sites in the U.S. and Canada. If data on daylight temperatures are available, these should be used for the $\left(T_{a}-T_{M}\right)+T_{M}$ that appears in eq. $(3.23 \mathrm{a})$.

f) $\overline{\mathbf{K}}_{\mathrm{T}} \quad-$ this ratio can be obtained from Ref. 3.14 for 171 locations or Ref. 3.15 for 261 locations 
in the U.S. and Canada. For other locations where total radiation date on the horizontal exist, $\bar{K}_{T}$ can be obtained by dividing it by the extraterrestrial radiation, this latter quantity being an easily calculable amount (See Ref. 3.16).

g) $\mathrm{I}_{\mathrm{e}}$

- this depends on the thermal design of the arrey, the wind speed, wind direction and to a lesser extent on the temperatures of both the array and the ambient. Thus, this parameter is determined by both the array design and the local microclimate. For flat arrays, $R_{e}$ can be estimated from Nominal Operating Cel1 Temperature (NOCT) results if they are available. This is discussed in Section 3.4.

h) $\overline{\left(T_{c}-T_{a}\right)}-$ is obtained from Fig. 3.2, with knowledge of $K_{e}, \rho$, and $\alpha$.

i) $\overline{\left(T_{a}-\right.} \overline{\left.T_{u}\right)}-=3^{\circ} \mathrm{C}$

j) $\overline{\log _{10} Q_{s}}$ - is determined from Fig. 3.8 .

k) $\Sigma Q_{s, i} / N_{d}$ - can be determined from procedures established in the solar thermal field (see Ref. 3.14, 3.16) or from tables or charts that exist (Refs. 3.15, 3.16). Further discussion can be found in Section 3.4 .

The following example is provided to illustrate the ose of this simplified method. Consider a max-power tracked flat array facing south, tilted up from horizontal at the local latitude $(s=0)$ in Albuquerque, N.M. Assume $K_{e}=0.02 \mathrm{~kW} /\left(\mathrm{m}^{2} \mathrm{C}\right)=0.88, p=1.0$, 
$\eta_{r}=0.15(15 \%), T_{r}=0 C, \beta=0.005 C^{-1}$, and $\gamma=0$. The comparison of the simplified technique with bourly simalation ill be made for the MY month of January $\left(\overline{\mathrm{B}}_{\mathrm{T}}=014, \mathrm{~T}_{\mathrm{M}}=1.1 \mathrm{C}.\right)$ Thus, from Fig. 3.2 for the optimum tilt during a month when $\overline{\mathrm{K}}_{\mathrm{T}}=0.614$,

$$
E_{e} \overline{\left(T_{c}-T_{a}\right) /(\alpha p)_{\text {opt }}}=0.73 \mathrm{kV} / \mathrm{m}^{2}
$$

From Table 3.2, the optiau tilt for Janary in Albuquerque (1atitude. $0=35.05^{\circ}$ ) is $s_{0}=0+29=64^{\circ}$. Therefore,

$$
\left(s_{m}-s\right)=64-35.05=29^{\circ} \text {. }
$$

which gives correction factor from Fig. 3.5 of

$$
c_{f}=0.90
$$

For this non-optimun tilt

$$
\begin{aligned}
\mathrm{R}_{\mathrm{e}} \overline{\left(\mathrm{T}_{\mathrm{c}}-\mathrm{T}_{\mathrm{a}}\right) /(a \rho)} & =0.90(0.73) \\
& =0.66 \mathrm{~kW} / \mathrm{m}^{2}
\end{aligned}
$$

For the assumed $K_{e}, \rho$, and $a$

$$
\overline{\left(T_{c}-T_{a}\right)}=(0.66)(0.88) / 0.02=29^{\circ} \mathrm{C}
$$

Then eq. (3.23a) jields

$$
\begin{aligned}
\bar{\eta} & =0.15[1-0.005(29)-0.005(3)-0.005(1.1-0)] \\
& =.125=12.55
\end{aligned}
$$

The above result strictly applies only when there is a balance between the solar energy absorbed by the array and the thermal losses to the surroundings; electrical output fro the array has been neglected. 
For many purposes this efficiency is sufficiently accurate, particularly when compared with the uncertainties that are usualy involved in knowing or calculating $\Sigma Q_{s, i}$ for use in eq. (3.23b). However, when a more accurate $\vec{\eta}$ is required, an iterative procedure can be invoked in the following way. First, the above $\bar{\eta}$ (now referred to as $\bar{\eta}_{1}$ is used as a first approximation to $\eta_{i}$ in eq. (3.16). Equation (3.19) then becomes:

$$
K_{e} \overline{\left(T_{c}-T_{a}\right) / \rho\left(\alpha-\bar{\eta}_{1}\right)=\Sigma Q_{s, i}{ }^{2} / \Sigma Q_{s, i}}
$$

Equation (3.28) becomes

$$
\overline{\left(T_{c}-T_{a}\right)}=0.66(0.88-.125) / 0.02=25^{\circ} \mathrm{C}
$$

and eq. (3.23a) yie1ds:

$$
\begin{aligned}
\bar{\eta} & =0.15[1-0.005(25)-0.005(3)-0.005(1.1-0)] \\
& =0.128=12.8 \%
\end{aligned}
$$

Incressed accuracy gained by further iteration in this manner is usually never warranted.

Simulation using the hourly January TMY data as outlined in Ref. 3.2 yields a monthly average efficiency of $12.6 \%$. Also, using the simplified procedure, twolve monthly calculations weighted with montliy insolation were used to obtain a yearly efficiency of 11.4\%. Hourly simulation showed a yearly efficiency of $11.3 \%$. A month by month comparison is shown in Table $3.3 \mathrm{a}$.

The persatility of the procedure is shown by other results in Table 3.3 for (a) a poorly tilted array in Medford, OR, and (b) a 2-D tracking concentrator in Madison, WI. TMY data were used for these locations. Although monthly discrepancies as large as 5\% (relative) may occur, yearly efficiencies are, typically, exceptionally close. 


\subsection{Problems with the Procedure}

One of the 1argest problems with the simplified method developed in this Chapter is that in order to convert the monthly average efficiencies, $\bar{\eta}$, into electrical energy production, a designer mast be able to calculate the monthly solar irradiation of the array. although methods have been developed to do this from a minimus of information, nome of the ways is entirely satisfactory.

However, this is not a problem that is aniune to this procedure but instead is one that plagues all solar design efforts, including those that make use of hourly simulation. Many of the data bases (Ref. 3.6, 3.14) make use of existing $10 \mathrm{ong}$ term data of very questionable quality. Some more recent works (Ref. 3.17, 3.18) arke nse of data that, in various ways, have been rehabilitated frow this same originel data base. Although the rehabilitated data are probably superior to the original set, there are still uncertainties about the accuracy.

Figures $3.9,3.10,3.11,3.12,3.13,3.14$, and 3.15 compare the SOLET data base derived $\bar{K}_{T}^{\prime s}$ for all months for the seven sites used at length in this study with the $\bar{B}_{T}$ 's from the early Liu and Jordan rork (Ref. 3.6). Genera11y, good agreement exists for sumer months but during the winter the Lin and Jordan values are consistently above the SOLMET average values.

Generally, a designer should use the most accurate data that is arailable to him. If good measurements are available, they should be used with the realization that they usually represent only short tera trends. If a photovoltaic system is to be installed in one of the SOLMET sites, the SOLJET data base is probably the best choice.

Figures 3.16 and 3.17 were prepared for use in preliminary design work or in areas where little or questionable insolation data exist. These are based on SOLET data for the seven sites nsed in this work. 
These show that there is some correlation between the long term monthly average daily total radiation on the monthly optimum tilt vs $\overline{\mathbb{K}}_{\mathrm{T}}$ (Fig. 3.16) and the long term monthly average daily direct normal radiation vs $\overline{\mathrm{K}}_{\mathrm{T}}$ (Fig. 3.17). Due to the significant amounts of scatter of these data, these should be used only as last resorts. Daylength differences are of the most significant contribators to this scatter.

Less scatter is inherent in such plots if insolation is averaged for some given hourly period of the day. For exanple, Figs. 3.18 and 3.19 show long term hourly insolation data averaged during the two hour period around solar noon for the seven SOLMET sites. The data are correlated with the long term average monthly $\bar{K}_{\mathrm{T}}$ Fig. 3.18 displays average widday intensity of the total radiation on the optimum tilt, while Fig. 3.19 is for the midday direct normal intensity. These data are used in the clamped-voltage mode of system operation discussed in Chapter 5.

Another problem confronting the designer is the choice of $\mathrm{K}_{\mathrm{e}}$. the therwal conductance for heat rejection from the cells. As mentioned in the previons section, this problem is compounded since it involves both the array design and the local weather conditions. For flat arrays a link between these two variables is provided by the Nominal Operating Cell Temperature (NOCT) (Ref. 3.19) if the application under study uses the array mounted in a configuration similar to that specified in the NOCT testing. Fignre 3.20 shows that an energy balance requires:

where

$$
\mathrm{K}_{\mathrm{e}}\left(\mathrm{T}_{\mathrm{NOCT}}-\mathrm{T}_{\mathrm{a}, \mathrm{NOCT}}\right)=a Q_{\mathrm{s}, \mathrm{I}}\left(\mathrm{kW} / \mathrm{m}^{2}\right)
$$

Thus

$$
Q_{s, I}=1.0 \text { or } 0.8 \mathrm{~kW} / \mathrm{m}^{2}(\text { See Table } 3.4)
$$

$$
\mathrm{K}_{\mathrm{e}} / \alpha=Q_{\mathrm{s}, \mathrm{r}} /\left(\mathrm{T}_{\mathrm{NOCT}}-\mathrm{T}_{\mathrm{a}, \mathrm{NOCT}}\right) \quad\left(\mathrm{kW} / \mathrm{m}^{2} \cdot \mathrm{C}\right)
$$


Traditionally, $T_{a, N O C T}=20^{\circ} \mathrm{C}$. If monthly wind speeds during daylight hours average near $1 \mathrm{~m} / \mathrm{s}$ and temperatures average near $20 \mathrm{C}$ (the test conditions for NOCT weasurements) in the area where an array is $i o$ be located, then it would be reasonable to ase this ratio in conjunction with Fig. 3.2 to obtain a monthy $\overline{\left(T_{c}-T_{a}\right)}$. This obviously solves the problem of requiring independent information on a. However, Fig. 3.21 has been prepared to simplify the calculation of $\overline{\left(T_{c}-T_{a}\right)}$ for such conditions. A designer simply multiplies the ordinate of this figure by $\left(T_{N O C T}-T_{a, N O C T}\right)$ and by $C_{f}$ to get $\overline{\left(T_{c}-T_{a}\right)}$ for his application.

If wind speeds differ from $1 \mathrm{~m} / \mathrm{s}$ or temperatures differ from 20C, the correction term $\Delta T$ shown in Fig. 3.22 can be added to the standard NOCT value of an array to correct it for local conditions. For example, if wind speeds average about $1.5 \mathrm{~m} / \mathrm{s}$ and ambient temperatures about $32 \mathrm{C}$ the NOCT to be used in eq.(3.34) or with Fig. 3.21 should be 3C smaller than the standard NOCT value.

Several uncertainties should be kept in mind when choosing a representative $\mathbb{z}_{e}$ for either fiat plates or concentrators. These inclade uncertainties involved in the prediction of the thermal resistance of the array itself during the design stage (cell placement, thermal contact resistance, voids, cover material, etc.), wind direction, and secondary flow effects created by elements meking up the array field.

For concentrators, $\mathbb{R}_{e}$ is often expressed on an absorber area or heat sink area basis. For use in the procedure presented here, $\mathrm{s}_{\mathrm{e}}$ has to be based on the aperture area. The concentrator example in Table 3.3 has been specified to have a $\mathbb{K}_{e}$ of $0.01 \mathrm{EW} /\left(\mathrm{m}^{2} \cdot \mathrm{C}\right)$ based on apertire area but would have a $\mathbb{E}_{e}$ of $0.2 \mathrm{kp} /\left(\mathrm{m}^{2} \cdot \mathrm{C}\right)$ based on absorber area (concentration ratio or aperture to absorber area ratio of 20 ). 
3.1 'Photoroltaic Systems Concept Study," Report ALO-2748-1 Spectrolab, Inc., Sylmar, CA (1977).

3.2 D.L. Evans and L.W. Florschuetz, "Cost Studies on Terrestrial Photovoltaic Power Systems ith Sunlight Concentration," Solar Energy 19, 255 (1977).

3.3 'Terrestrial Photovoltaic Power Systems with Sunlight Concentration'', Report \#ERC-R-77006, Arizona State University, Tempe, AZ (1977).

3.4 L. W. Florschuetz, "On Heat Rejection from Terrestrial Solar Ce11 Arrays with Sunlight Concentration," Proc. Eleventh IEEE pV Specialists' Conference, Scottsdale, AZ (1975).

3.5 'SOLdET User's Manual, Hourly Surface Radiation - Surface Meteorological Observations," National Oceanic and Atmosphezic Administration Environmental Data Service, Asheville, NC (1979).

3.6 B.Y.H. Lin and R.C. Jordan, 'The Long-Term Average Performance of F1at-P1ate Solar-Energy Collectors," Solar Energy 2, 53 (1963).

3.7 I.J. Hall, R.R. Prairie, H.E. Anderson, and E.C. Boes, 'Generation of a Typical Meteorological Year,' Proc. 1978 Annual Meet. Amer. Sec. of ISES, Denver, CO (1978).

3.8 R.A. Arndt, J.F. Allison, J.G. Eaynos and A. Meulenberg, Jr., 'Optical Properties of the Comsat Non-Reflective Ce11," Proc. Eleventh IEEE PV Specialists' Conference, Scottsdale, AZ (1975). 
3.9 C.R. Baraona and H.W. Brandhorst, 'V-Grooved Silicon Solar Cel1s," Proc. Eleventh IEEE PV Specialists' Conference, Scottsdale, AZ (1975).

3.10 F. Restrepo and C.E. Backus, 'On Black Solar Cel1s or the Tetrahedra1 Textoring of a Silicon Surface,' IEEE Transactions on E1ectron Devices ED-23, 1193 (1976).

3.11 L.W. Florschuetz, 'Extension of the Hotte1-Whillier Model to the Analysis of Combined Photoroltaic/Thermal Flat Plate Collectors.' Solar Energy 22, 361 (1979). A1so see Proc. Sharing the Sun Joint Conference, U.S. and Canadian Sections of International Solar Energy Society, Vo1. 6, pg. 79, Hinnipeg, (1976).

3.12 L.W. Florschuetz, "On Heat Rejection from Terrestrial Solar Cell Arrays with Sunlight Concentration," Proc. Eleventh IEEE PV Specialists' Conference, Scottsdale, AZ (1975).

3.13 'Terrestrial Photovoltaic Power Systems with Sulight Concentration," Proc. Eleventh IEEE PV Specialists' Conference, Scottsdale, AZ (1975).

3.14 W.A. Beckman, S.A. Klein, and J.A. duffie, Solar Heating Design, Wiley Interscience, New York, NY (1977).

3.15 S.A. Blein, W.A. Beckman and J.A. Duffie, 'Monthly Average Solar Radiation on Inclined Surfaces for 261 North Aferican Cities"' Report \#44, Solar Energy Laboratory, University of Wisconsin, Madison (1978).

3.16 J.A. Duffie and W.A. Beckman, Solar Energy Thermal Processes. John iley and Sons, New York, NP (1974). 
3.17 W.H. Hoecker, G.F. Cotton and W.A. Hass, 'Solar Radiation and C1imate Data for Quasi-Homogeneous Climate Regions of the United States'" Report \#ERC ARL-77, Air Resources Laboratories, National Oceanic and Atmospheric Administration, Silver Springs (1979).

3.18 E.C. Boes, H.A. Anderson, I.J. Ha11, R.R. Prairie, R.T. Stromberg, 'Availability of Direct, Total and Diffuse Solar Radiation to Fixed and Tracking Collectors in the O.S.A.', Report \#SAND77-0885 (with Addendum), Sandia Laboratories, Albuquerque (1977).

3.19 J.W. Stultz and L.C. Wen, 'Low-Cost Silicon Solar Array Project," Report \#5101-31, Jet Propalsion Laboratory, Pasadena (1977). 


\section{SOLMET Sites and Years of Data Used in this Study}

Site

Albuquerque, NM

Bismarck, ND

Madison, WI

Medford, $O R$

Phoenix, AZ

Santa Maria, CA

Washington D.C./Sterling, VA
Years

22

22

22

22

22

16

21

Table 3.2

-Optimum Tilts-

Tilt Angle $\left(s_{M}\right)$ between the Plane of the Flat Array and Horizontal* for Maximum Monthly Average $K_{e}\left(\bar{T}_{c}-T_{a}\right) /(\alpha p)$

Month

$$
\mathrm{s}_{\mathrm{M}} \text { (Degrees) }
$$

1
2
3
4
5
6
7
8
9
10
17
12

$\phi+29$

$\phi+18$

$\phi+3$

$\phi-10$

$\phi-22$

$\phi-25$

$\phi-24$

$\phi-10$

$\phi-2$

$\phi+10$

$\phi+23$

$\phi+30$

*Array is assumed to be South facing

it is Latitude (Degrees) 
Table 3.3a

Comparison of

Simplified Procedure for Predicting Array Output with Hourly Simulation

\begin{tabular}{|lr|}
\hline Location & Al buquerque \\
Collector & Flat Plate \\
Concentration & 1 \\
Ratio & \\
Tilt (Degrees) & 35 \\
$K_{e} \mathrm{~kW} /\left(\mathrm{m}^{2} \cdot \mathrm{C}\right)$ & 0.02 \\
$\alpha$ & 0.88 \\
$\rho$ & 1 \\
$\eta_{r}(\%)$ & 15 \\
$T_{r}(C)$ & 0 \\
$\beta\left(C^{-1}\right)$ & 0.005 \\
$\gamma$ & 0 \\
\hline
\end{tabular}

\begin{tabular}{|c|c|c|c|c|}
\hline Month & TMY $\bar{K}_{T}$ & $\begin{array}{c}\text { TMY } \\
(C)\end{array}$ & $\begin{array}{c}n_{\text {est }}{ }^{\dagger} \\
(\%)\end{array}$ & $\begin{array}{c}\bar{n}_{\text {simu }}{ }^{*} \\
(\%)\end{array}$ \\
\hline 1 & 0.614 & 2 & 12.8 & 12.6 \\
2 & 0.654 & 4 & 12.4 & 12.2 \\
3 & 0.664 & 7 & 12.0 & 11.9 \\
4 & 0.727 & 13 & 11.4 & 11.3 \\
5 & 0.739 & 19 & 11.1 & 10.9 \\
6 & 0.732 & 23 & 10.8 & 10.7 \\
7 & 0.701 & 26 & 10.7 & 10.4 \\
8 & 0.707 & 25 & 10.6 & 10.5 \\
9 & 0.697 & 20 & 11.0 & 10.8 \\
10 & 0.713 & 15 & 11.3 & 12.2 \\
11 & 0.679 & 7 & 12.2 & 12.2 \\
12 & 0.645 & 3 & 12.6 & 12.6 \\
$y r$. & & & 11.5 & 11.3 \\
\hline
\end{tabular}

† Estimated by Chapter 3 simplified methods

* Simulated by hourly computer calculations 
Table 3.3b

Comparison of

Simplified Procedure for Predicting Array Output with Hourly Simulation

\begin{tabular}{|lr|}
\hline Location & Madison \\
Collector & $2-D$ Tracked \\
Concentration & 20 \\
Ratio & \\
Tilt (Degrees) & - \\
$K_{e} \mathrm{~kW} /\left(\mathrm{m}^{2} \cdot \mathrm{C}\right)$ & 0.01 \\
$\alpha$ & 0.88 \\
$\rho$ & 0.88 \\
$\eta_{r}(\%)$ & 15 \\
$T_{r}(c)$ & $c$ \\
$B\left(c^{-1}\right)$ & 0.005 \\
$\gamma$ & 0 \\
\hline
\end{tabular}

\begin{tabular}{|c|l|r|c|c|}
\hline Month & TMY $_{T}$ & $\begin{array}{c}\text { TMY } \\
(C)\end{array}$ & $\begin{array}{c}\bar{n}_{\text {est }}^{\dagger} \\
(\%)\end{array}$ & $\begin{array}{c}\bar{n}_{\text {simu1 }} \\
(\%)\end{array}$ \\
\hline 1 & 0.448 & -8 & 12.4 & 12.8 \\
2. & 0.497 & -6 & 12.0 & 12.3 \\
3 & 0.524 & -2 & 11.8 & 11.4 \\
4 & 0465 & 9 & 11.0 & 10.8 \\
5 & 0.494 & 15 & 10.4 & 10.2 \\
6 & 0.514 & 20 & 9.9 & 10.2 \\
7 & 0.542 & 22 & 9.6 & 9.8 \\
8 & 0.558 & 20 & 9.7 & 10.1 \\
9 & 0.525 & 17 & 10.1 & 10.4 \\
10 & 0.461 & 10 & 10.9 & 10.8 \\
11 & 0.393 & 2 & 11.9 & 11.6 \\
12 & 0.364 & -4 & 12.5 & 12.2 \\
yr. & & & 11.2 & 10.8 \\
\hline
\end{tabular}

$\div$ Estimated by Chapter 3 simplified methods

* Simulated by hourly computer calculations 
Table 3.3c

Comparison of

Simplified Procedure for Predicting Array Output with Hourly Simulation

\begin{tabular}{|lr|}
\hline Location & Medford \\
Collector & Flat Plate \\
Concentration & 1 \\
Ratio & 10 \\
Tilt (Degrees) & 0.02 \\
$K_{e} \mathrm{~kW} /\left(\mathrm{m}^{2} \cdot \mathrm{C}\right)$ & 0.88 \\
$\alpha$ & 1.0 \\
$\rho$ & 15 \\
$\eta_{r}(\%)$ & 0 \\
$T_{r}(C)$ & 0.005 \\
$\beta\left(C^{-1}\right)$ & 0 \\
$\gamma$ & \\
\hline
\end{tabular}

\begin{tabular}{|c|c|c|c|c|}
\hline Month & TMY $\mathrm{K}_{\mathrm{T}}$ & $\begin{array}{l}\text { TMY } T_{M} \\
\text { (C) }\end{array}$ & $\begin{array}{c}\bar{n}_{\text {est }}{ }^{\dagger} \\
(\%)\end{array}$ & $\bar{n}_{\text {simul }}{ }_{(\%)}^{*}$ \\
\hline 1 & 0.331 & 4 & 13.7 & 13.8 \\
\hline 2 & 0.423 & 5 & 13.3 & 13.8 \\
\hline 3 & 0.484 & 8 & 12.7 & 13.1 \\
\hline 4 & 0.532 & 10 & 12.3 & 12.3 \\
\hline 5 & 0.590 & 13 & 11.8 & 11.8 \\
\hline 6 & 0.639 & 19 & 11.2 & 11.1 \\
\hline 7 & 0.715 & 23 & 10.7 & 11.3 \\
\hline 8 & 0.679 & 22 & 11.0 & 11.4 \\
\hline 9 & 0.623 & 19 & 11.5 & 11.7 \\
\hline 10 & 0.513 & 13 & 12.3 & 12.3 \\
\hline 11 & 0.385 & 7 & 13.3 & 13.3 \\
\hline 12 & 0.262 & 2 & 14.1 & 13.9 \\
\hline$y r$. & & & 11.9 & 11.7 \\
\hline
\end{tabular}

† Estimated by Chapter 3 simplified methods

* Simulated by hourly computer calculations 
Table 3.4

Essence of the NOCT Test Requirements (Ref. 3.19$)^{\dagger}$

Insolation $^{\dagger} \quad=0.8$ or $1.0 \mathrm{~kW} / \mathrm{m}^{2}$

Ambient Air Temperature $=20^{\circ} \mathrm{C}$

Wind Average Velocity $=1 \mathrm{~m} / \mathrm{s}$. "not predominantly parallel to the array"

Mounting

- Tilted so that it is normal to the sun $\left( \pm 5^{\circ}\right)$ at solar noon with the bottom edge of the array two feet or more above the local ground level.

Electrical Configuration- Open Circuit Condition

tTwo values of insolation are currently used for NOCT specification. Early work used $0.8 \mathrm{~kW} / \mathrm{m}^{2}$ recommended in Ref. 3.19. Recent work has tended to use $1.0 \mathrm{~kW} / \mathrm{m}^{2}$. 


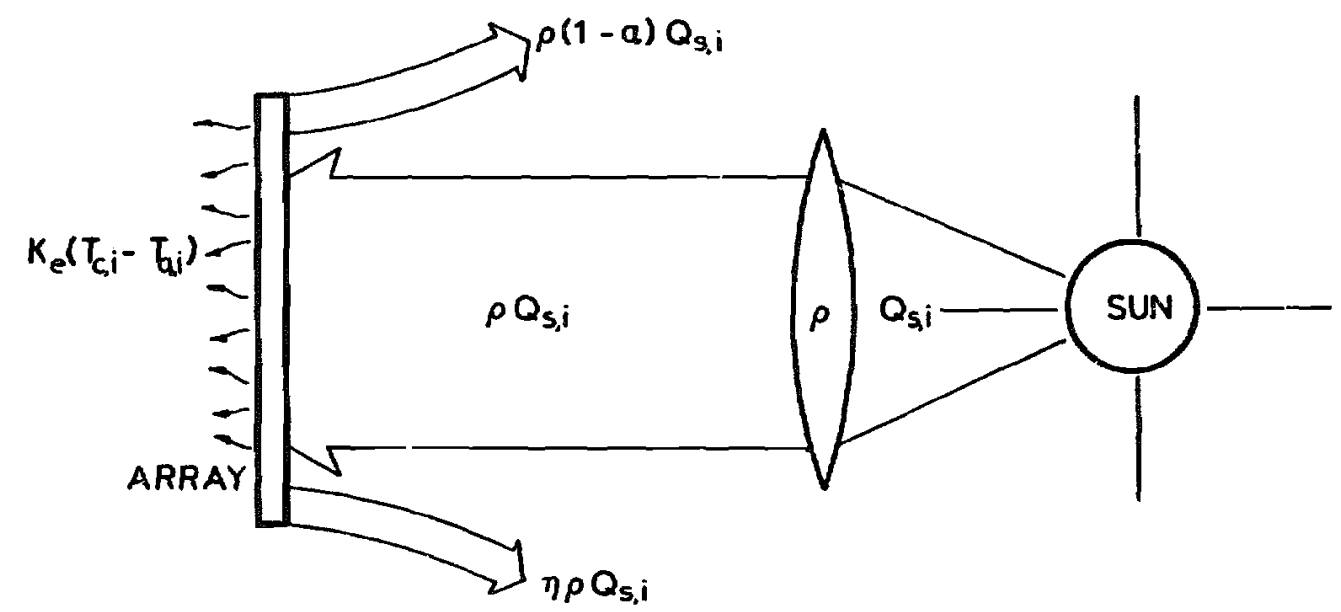

Figure 3.1 Energy Balance Schematic for an Array 


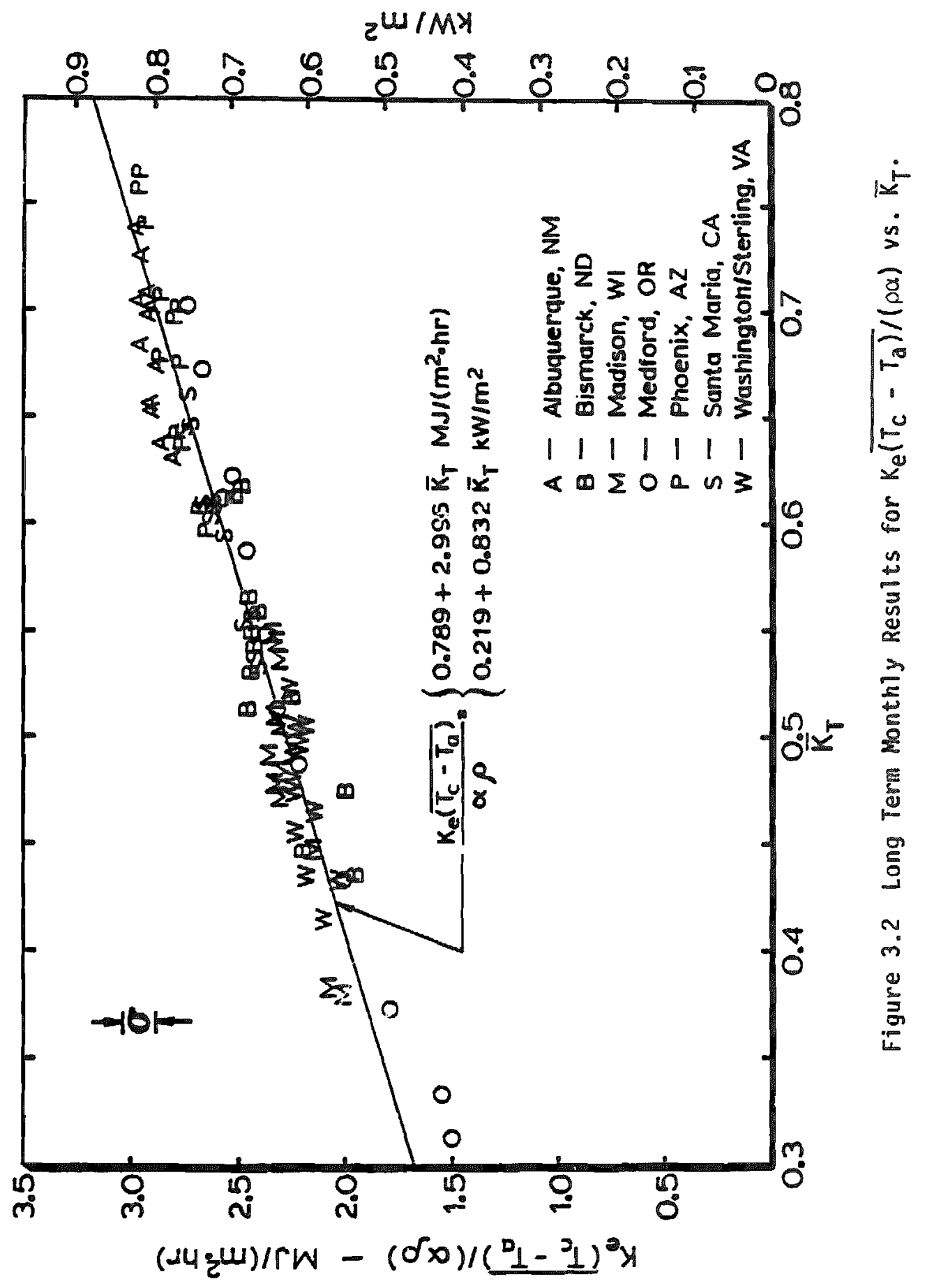




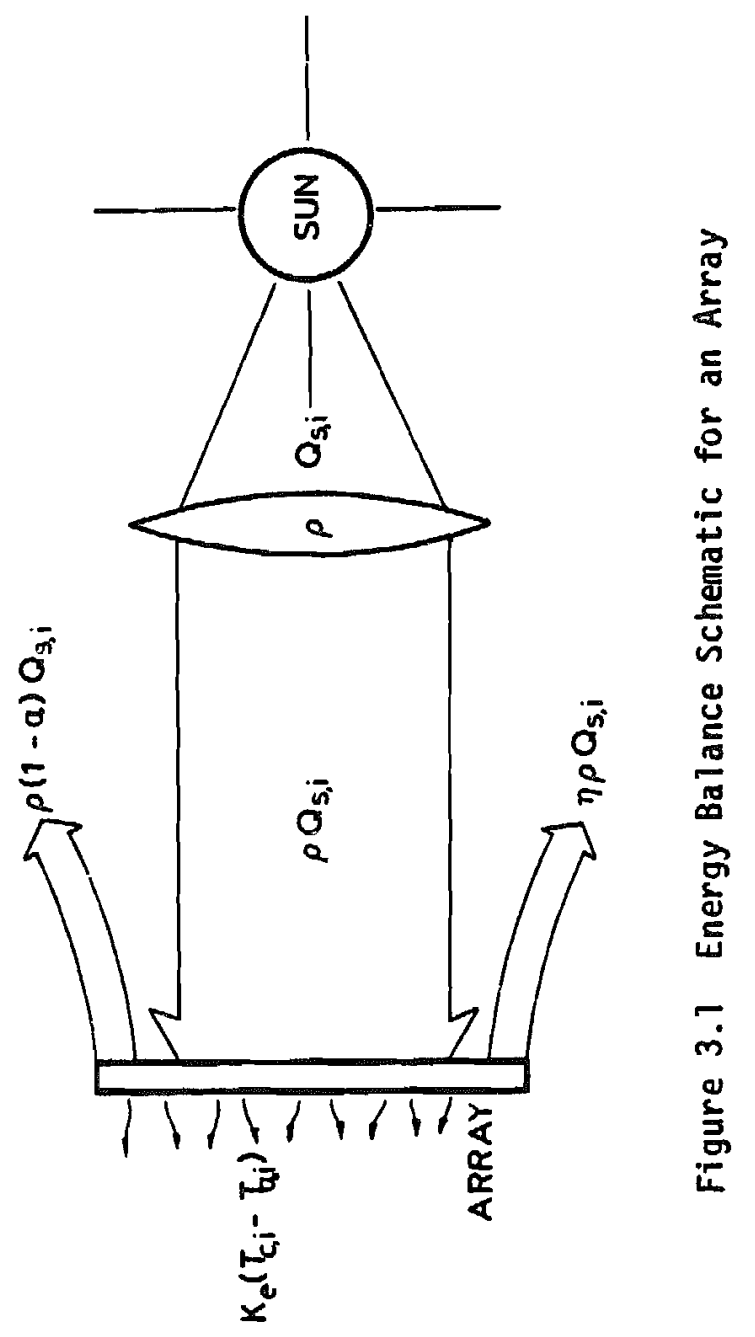




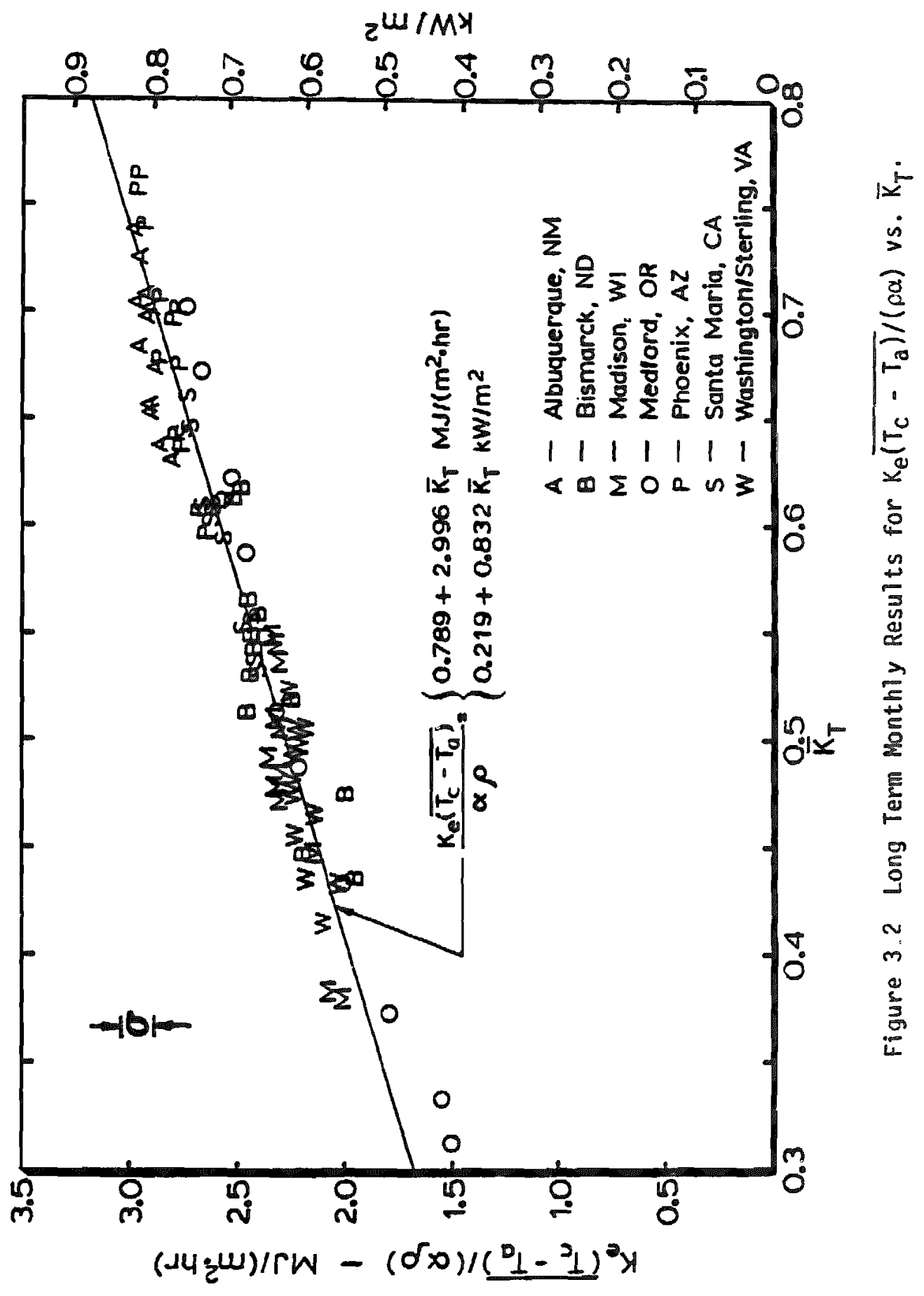




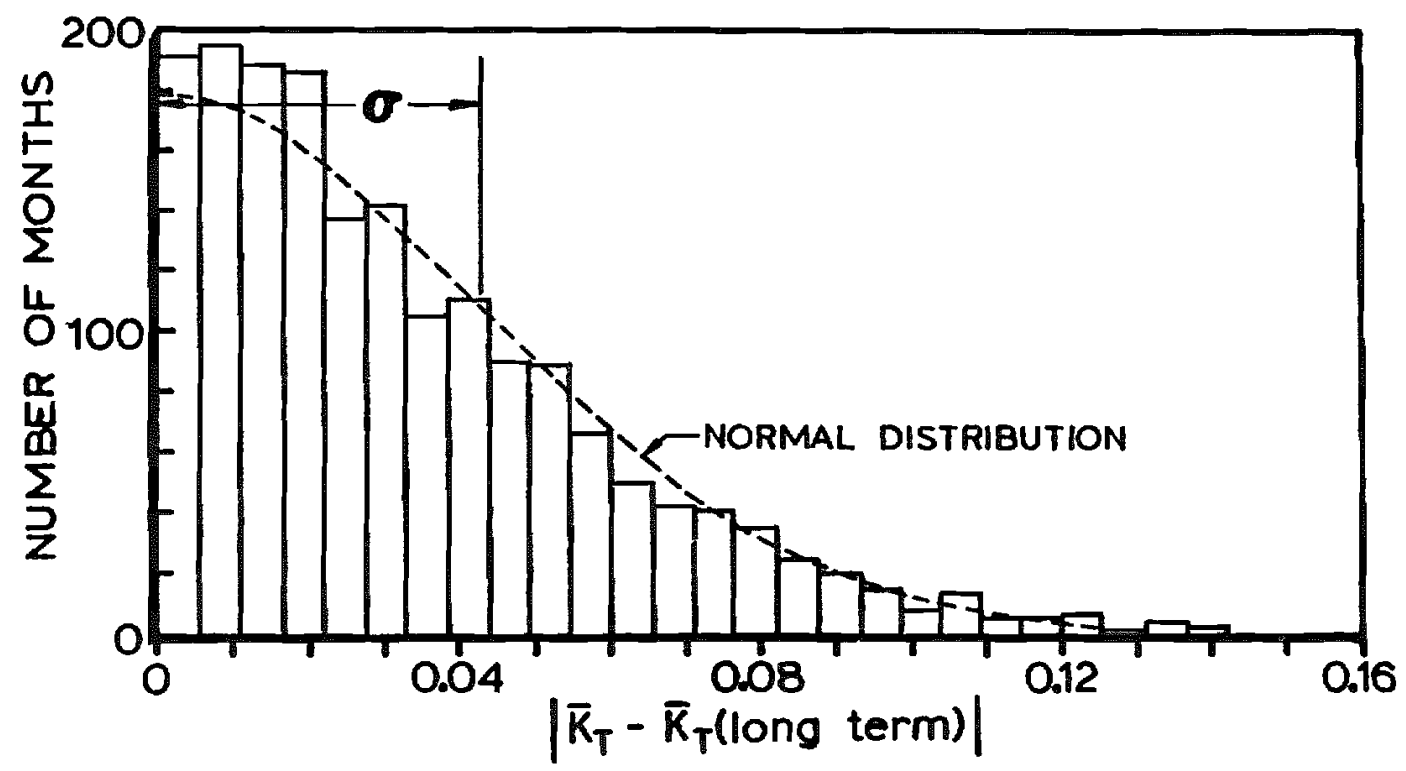

Figure 3.3 Distribution of Individual Monthly $\bar{K}_{T}$ about the Long Term $\bar{K}_{T}$ for the Same Month and Location. The Seven Cities Listed in Fig. 3.2 were Used. 


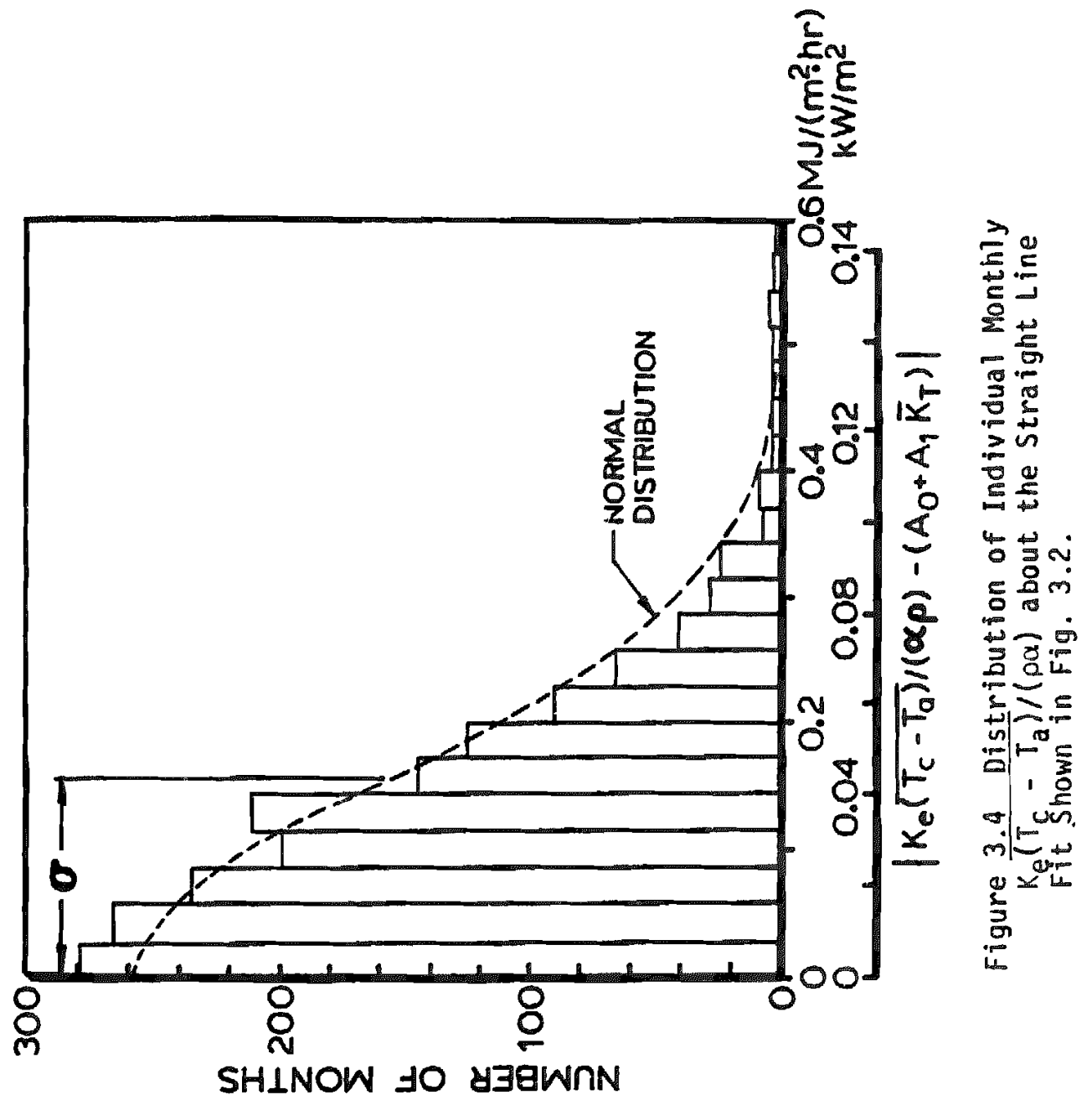




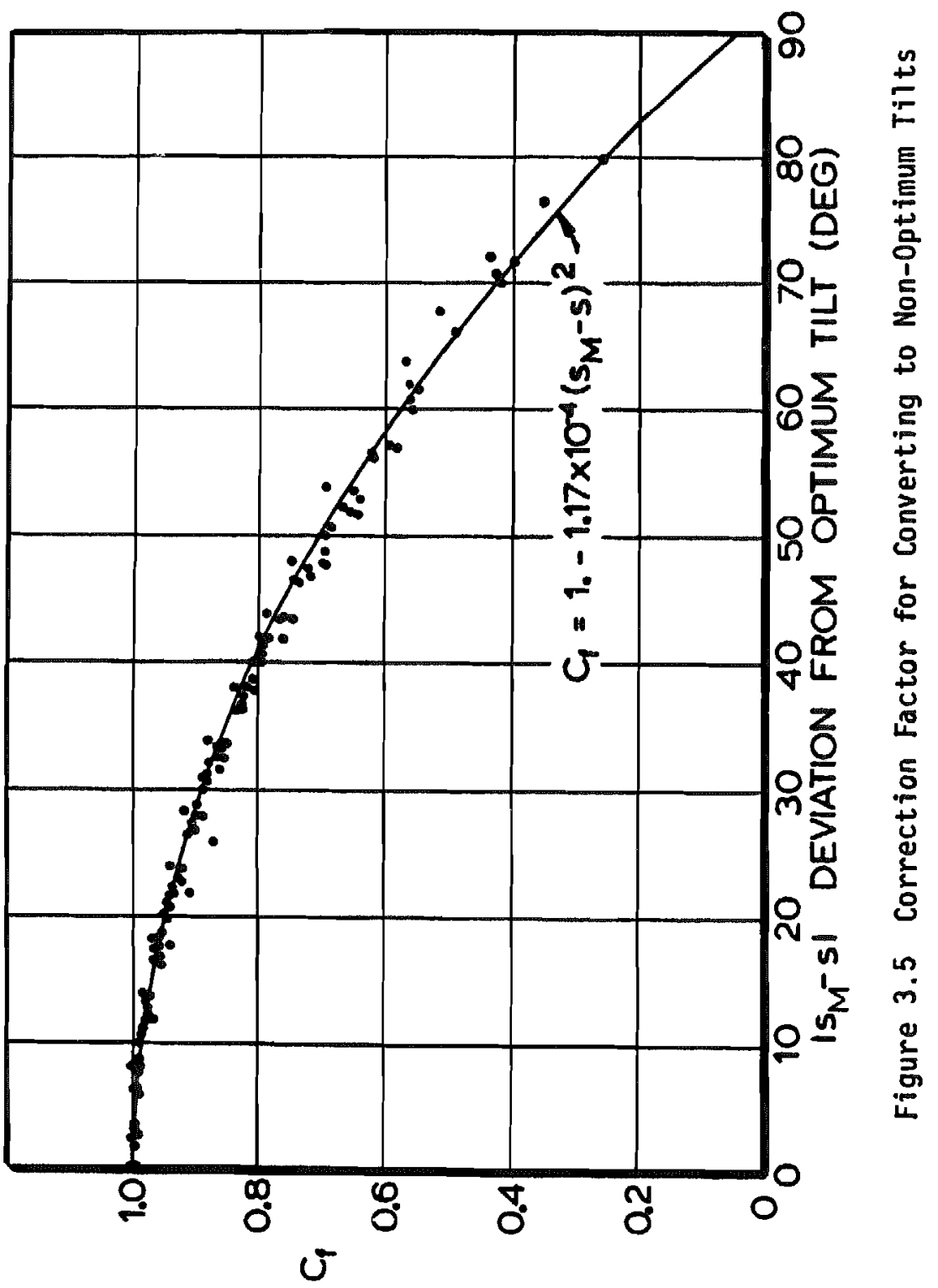




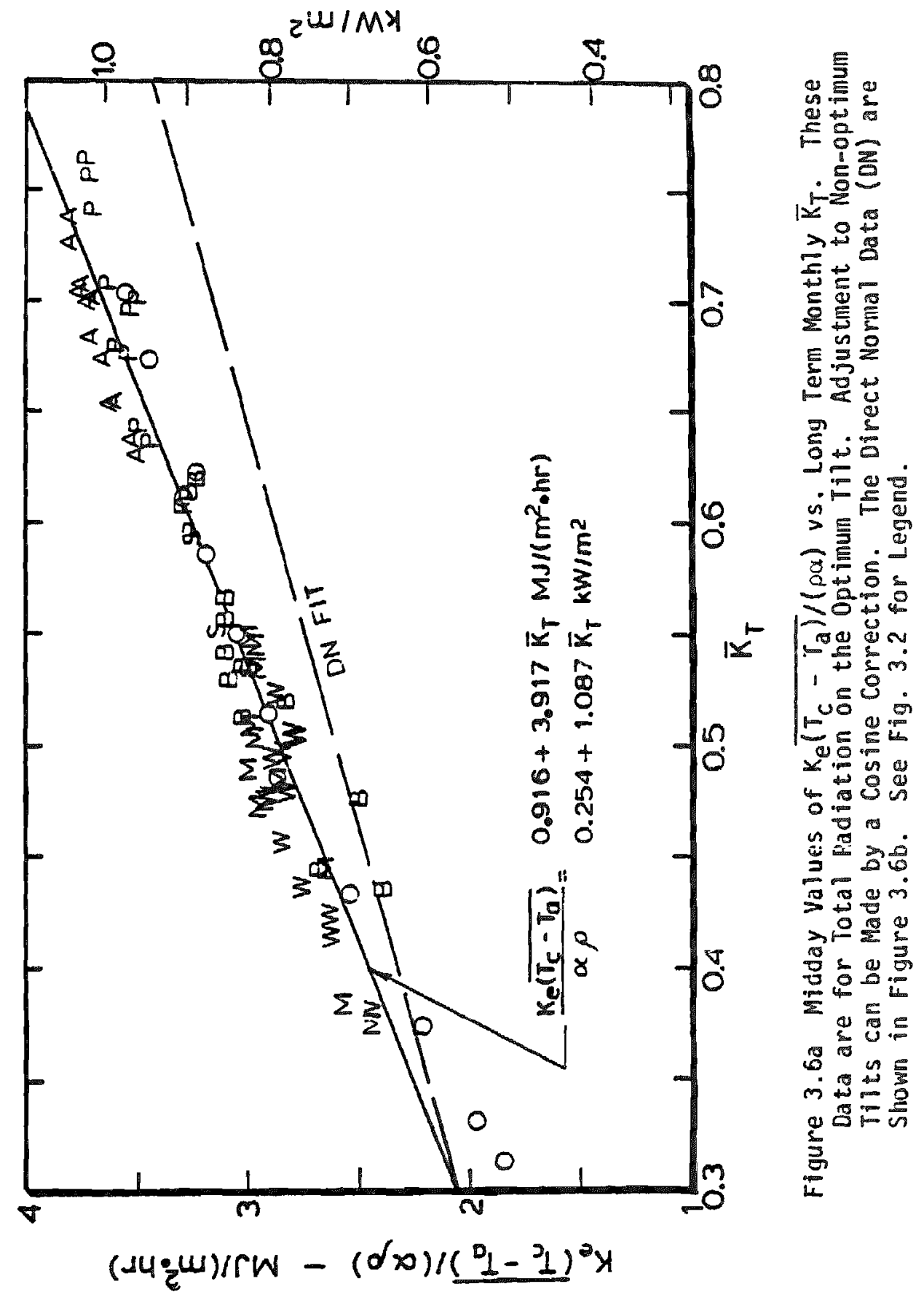




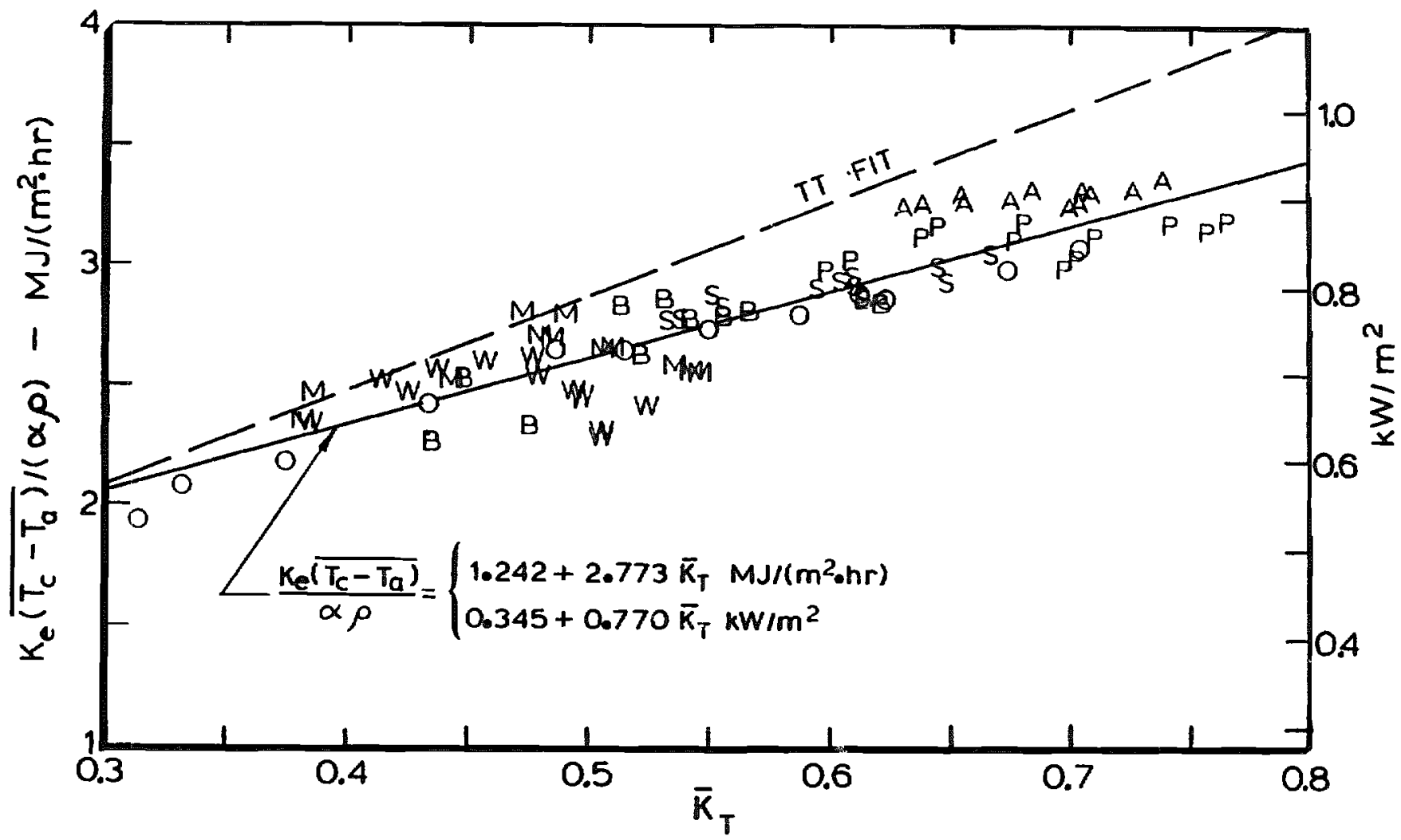

Figure 3.6b Midday Values of $K_{e} \overline{\left(T_{G}-T_{a}\right)} /(\rho \alpha)$ vs. Long Term Monthly $\bar{K}_{T}$. These Data are for Direct Nomal Radiation. The Total Radiation on the Tilt

(TT) Data are Shown in Fig. 3.6a. See Fig. 3.2 foplegend. 


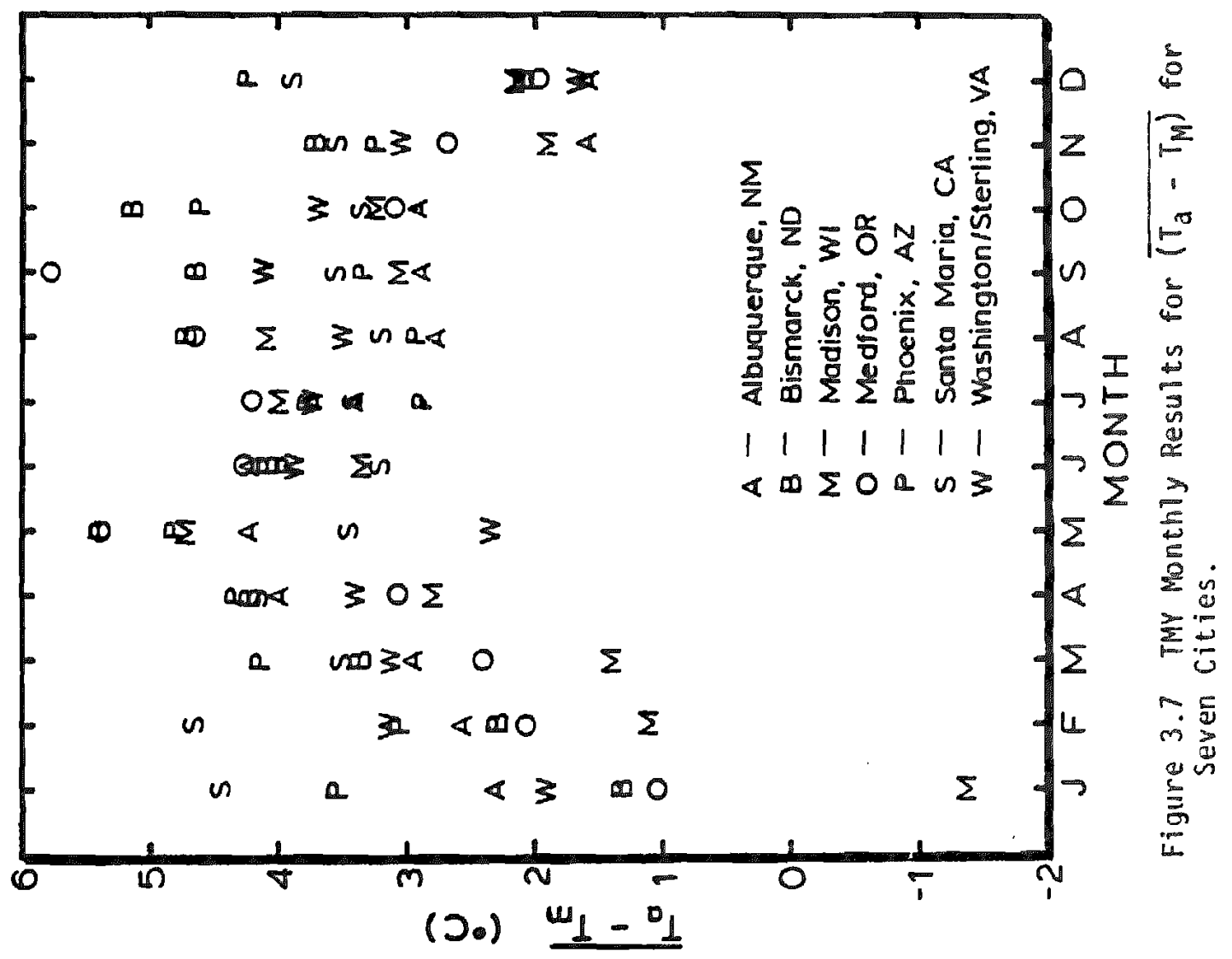




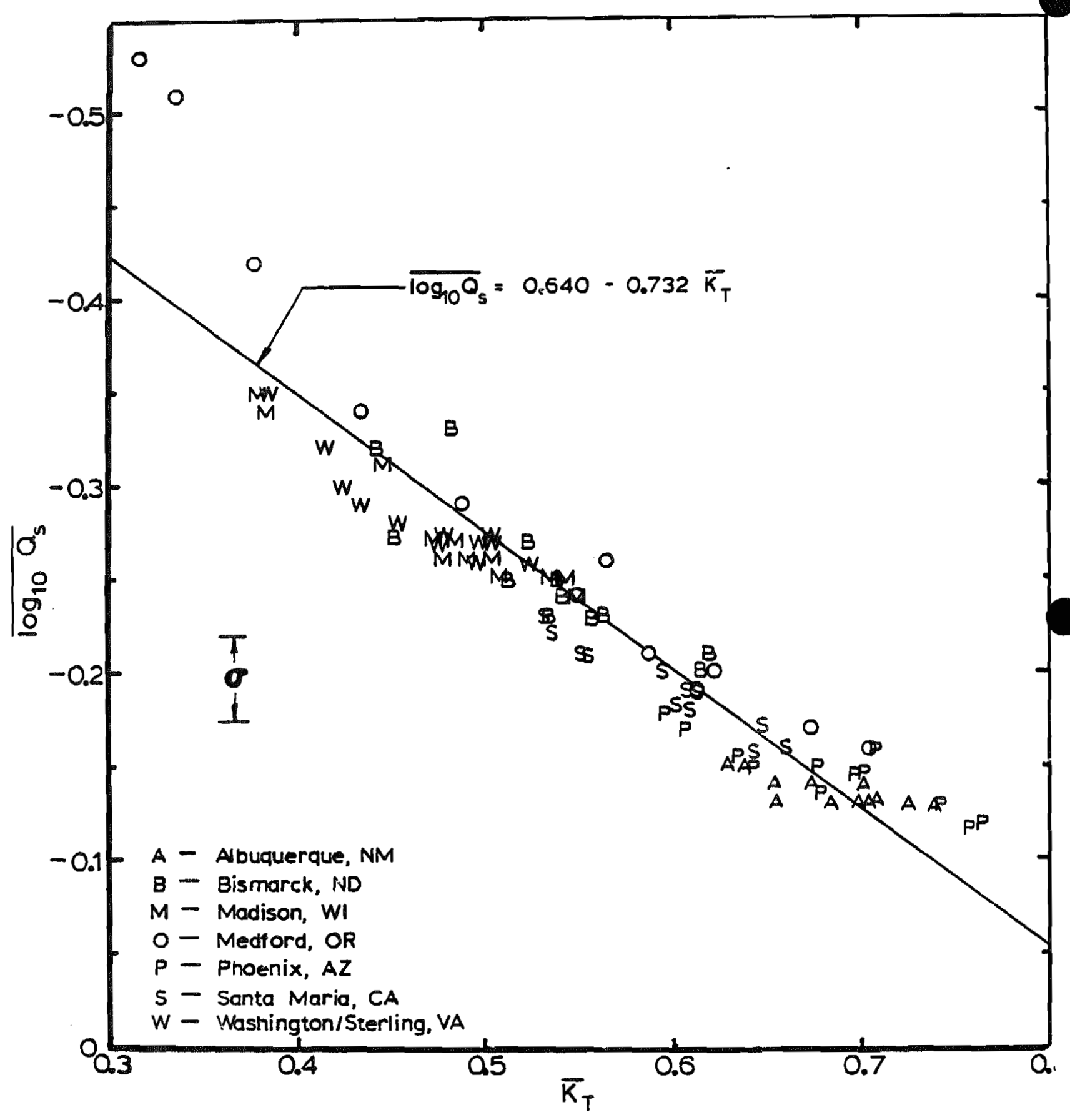
Figure 3.8 Long Term Monthly Results for $\overline{\log _{10} a_{S}}$ vs. $\bar{K}_{T}$ for Seven Cities
Using Optimum Tilts Each Month. 


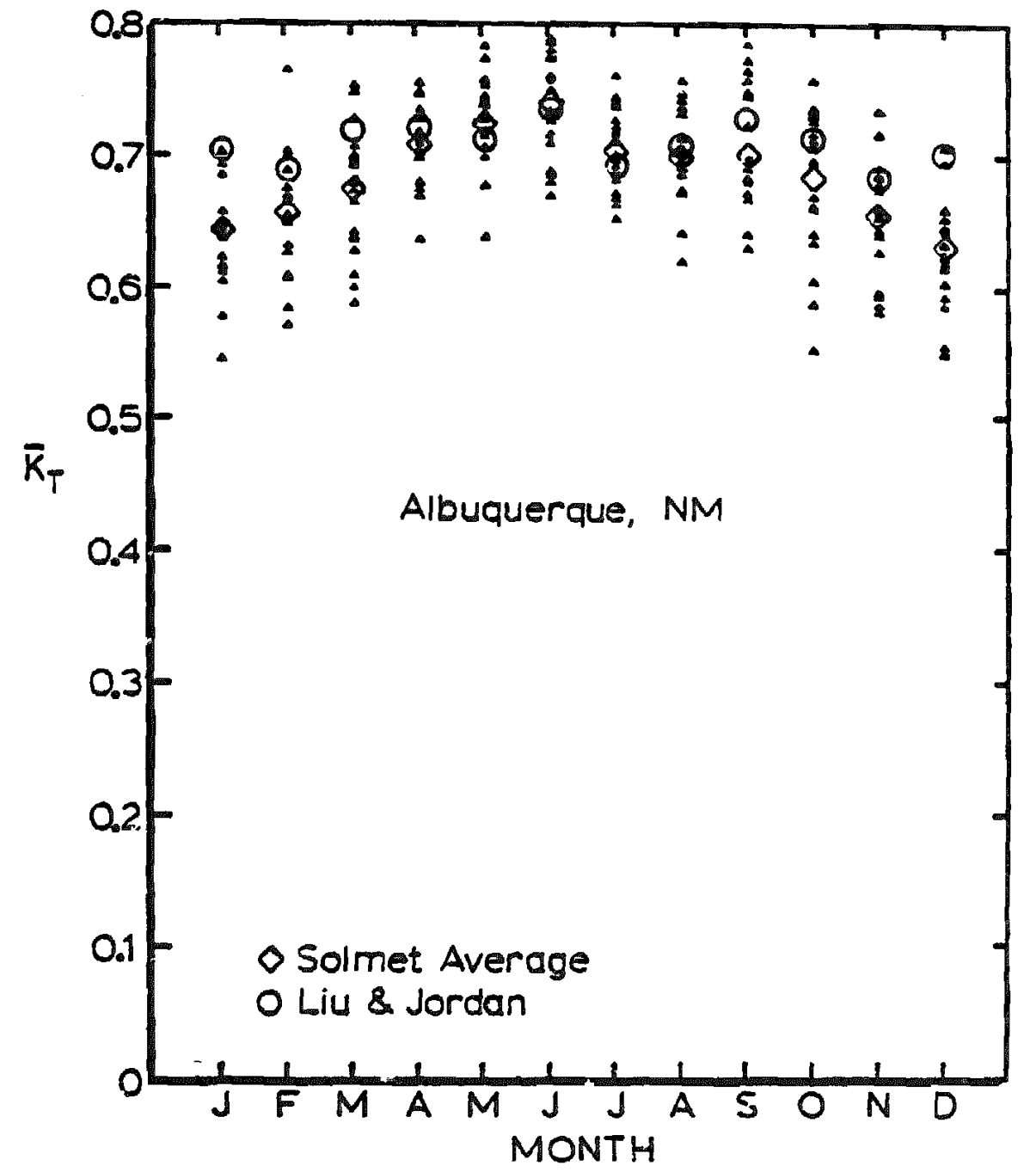

Figure 3.9 SOLMET Derived $\bar{K}_{T}$ 's for Albuquerque, NM. The Solid Triangle Data Points are SOLMET Data. 


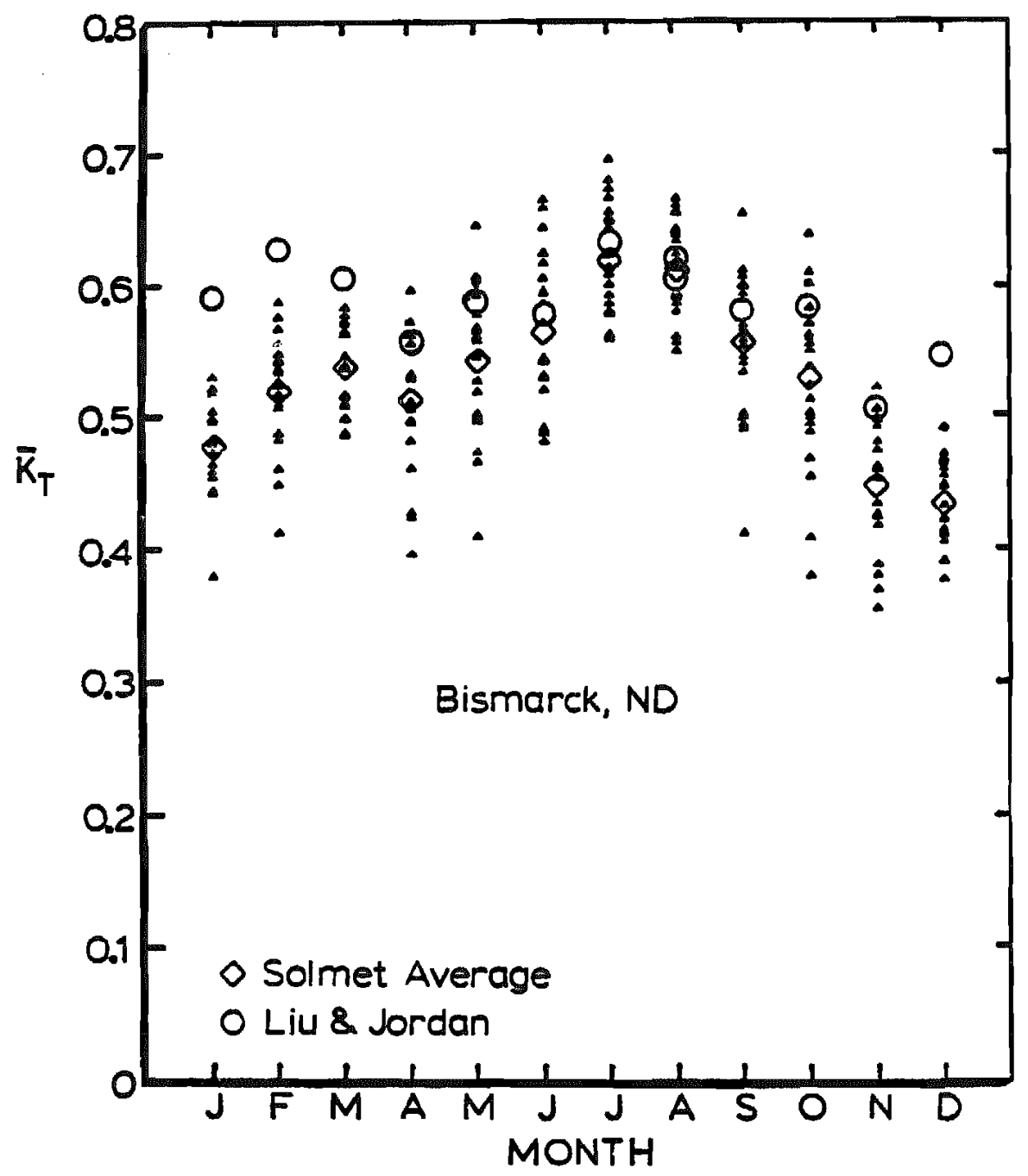

Figure 3.10 SOLMET Derived $\bar{K}_{T}$ 's for Bismarck, ND. Solid Triangle Data Points are SOLMET Data. 


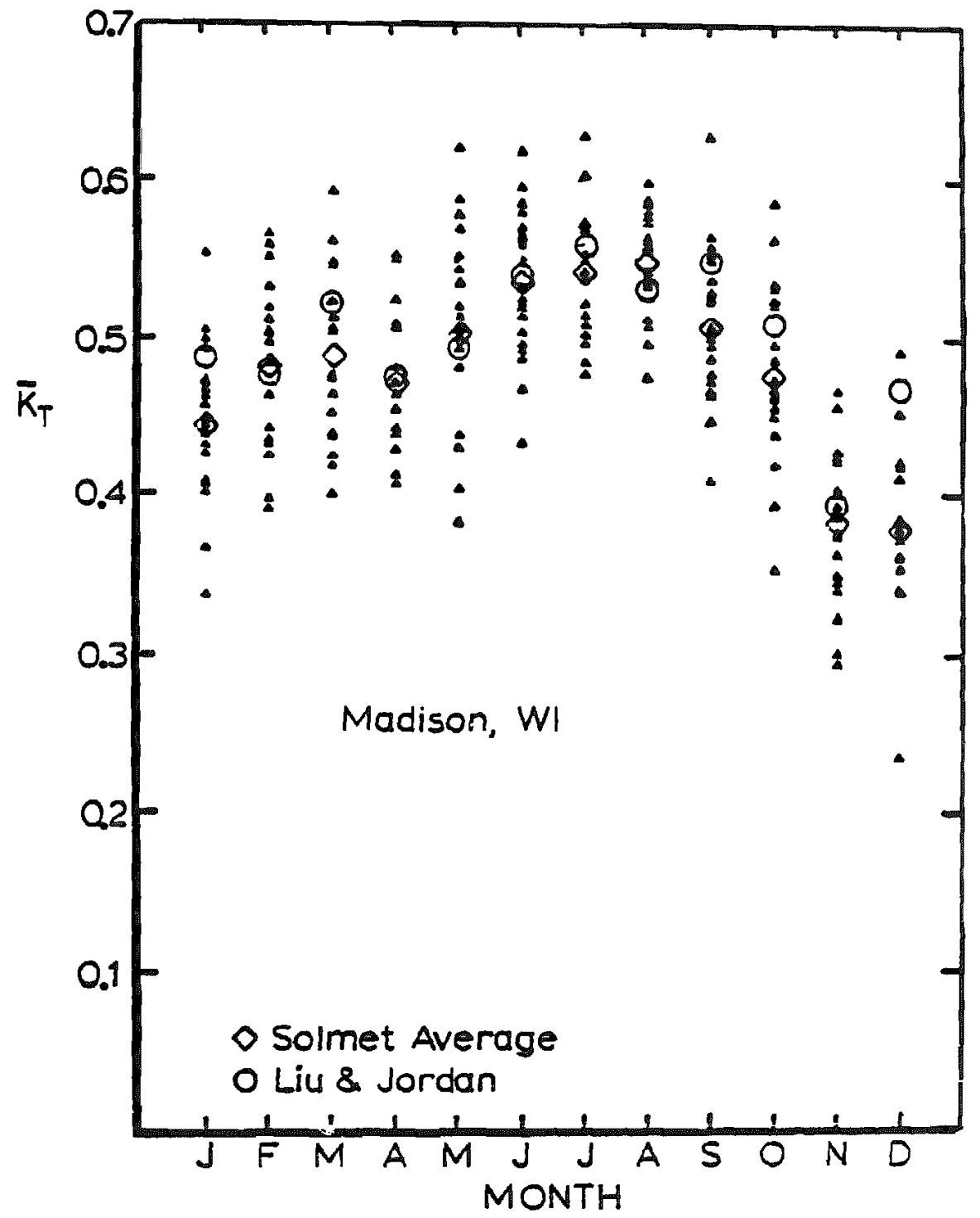

Figure 3.11 SOLMET Derived $\bar{K}_{T}^{\prime}$ 's for Madison, WI. The Solid Triangle Data Points are SOLMET Data. 


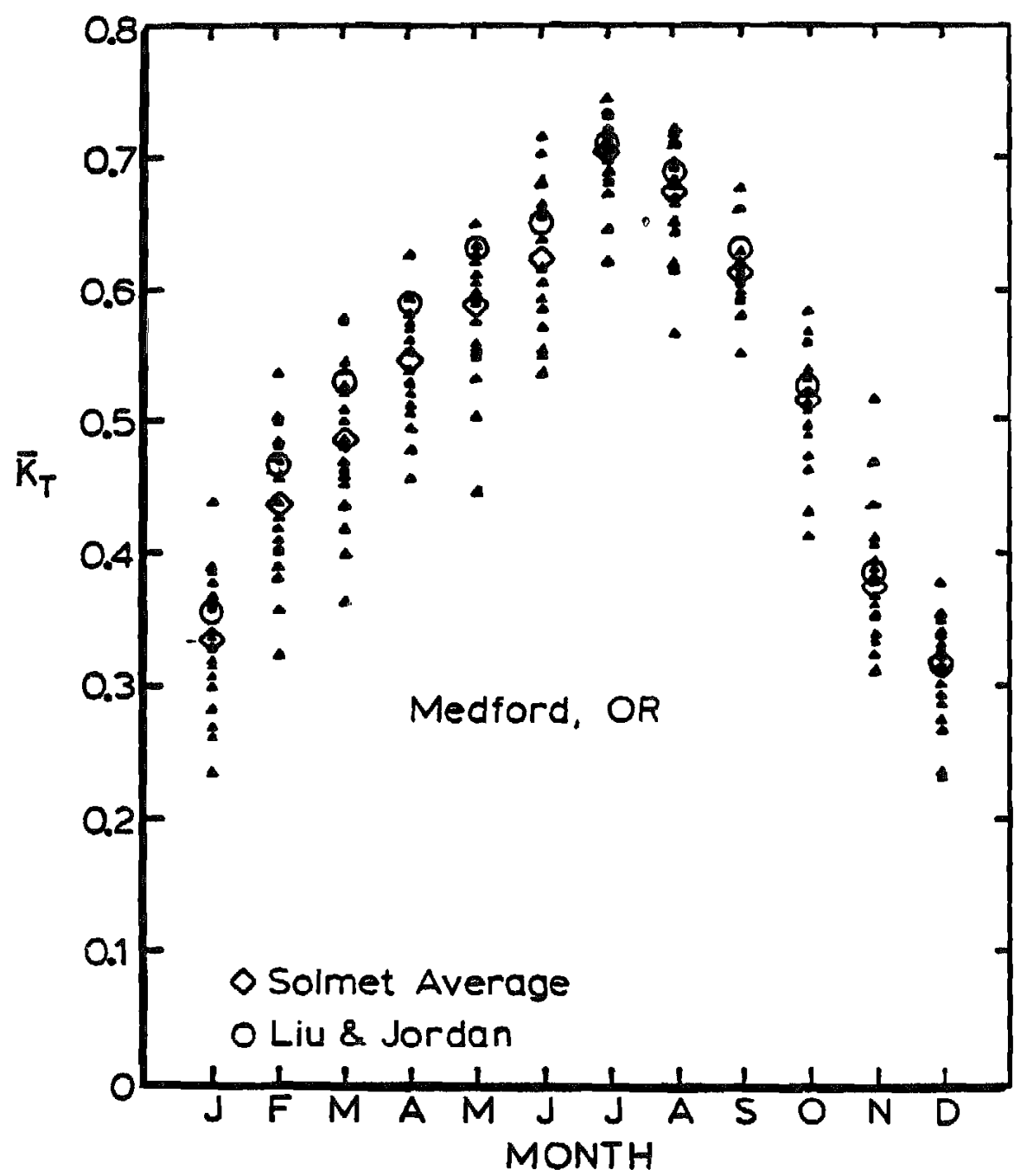

Figure 3.12 SOLMET Derived $\bar{K}_{T}$ 's for Medford, $O R$. The Solid Triangle Data Points are SOLMET Data. 


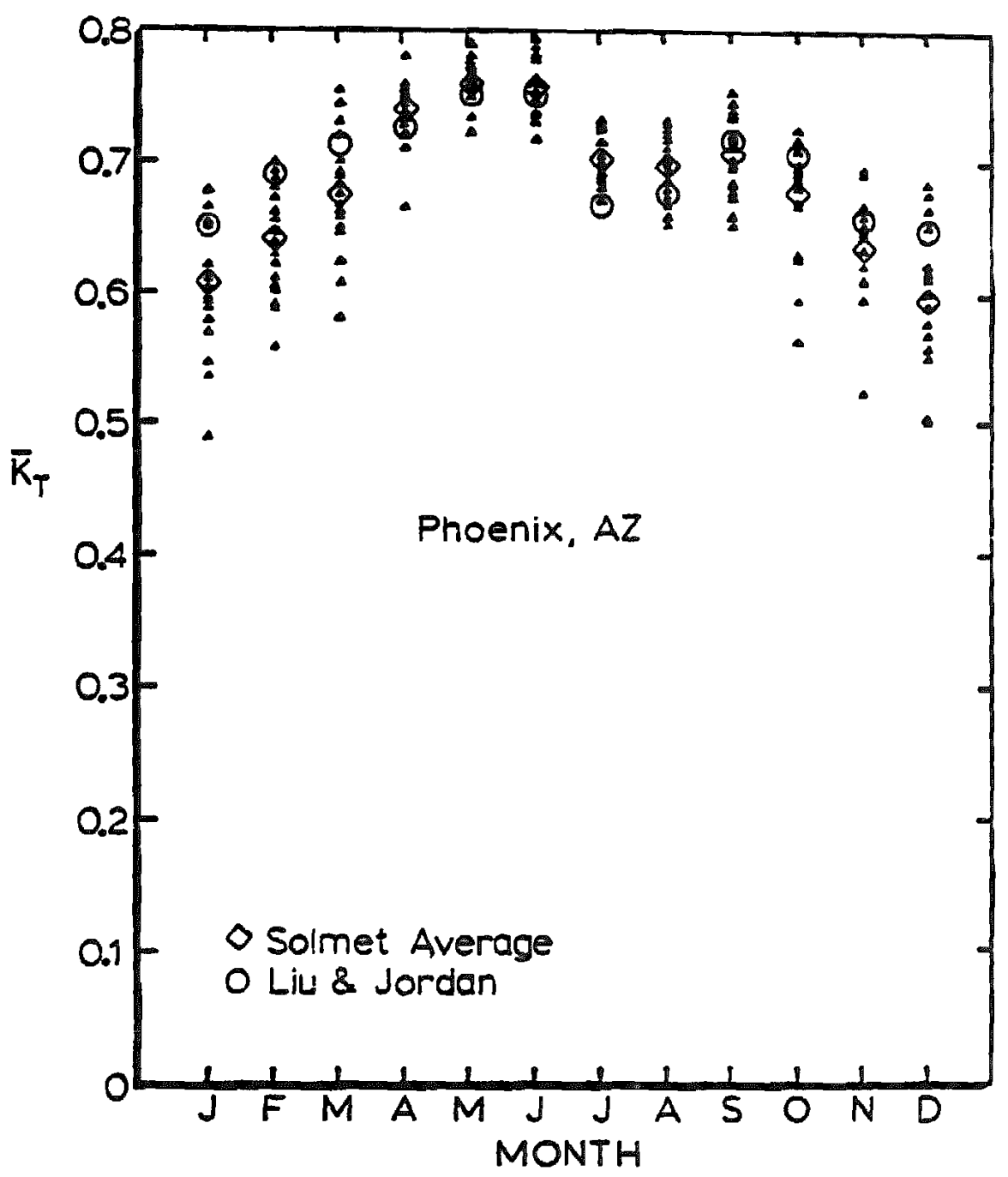

Figure 3.13 SOLMET Derived $\bar{K}_{T}$ 's for Phoenix, $A Z$. The Solid Triangle Data Points =re SOLMET Data. 


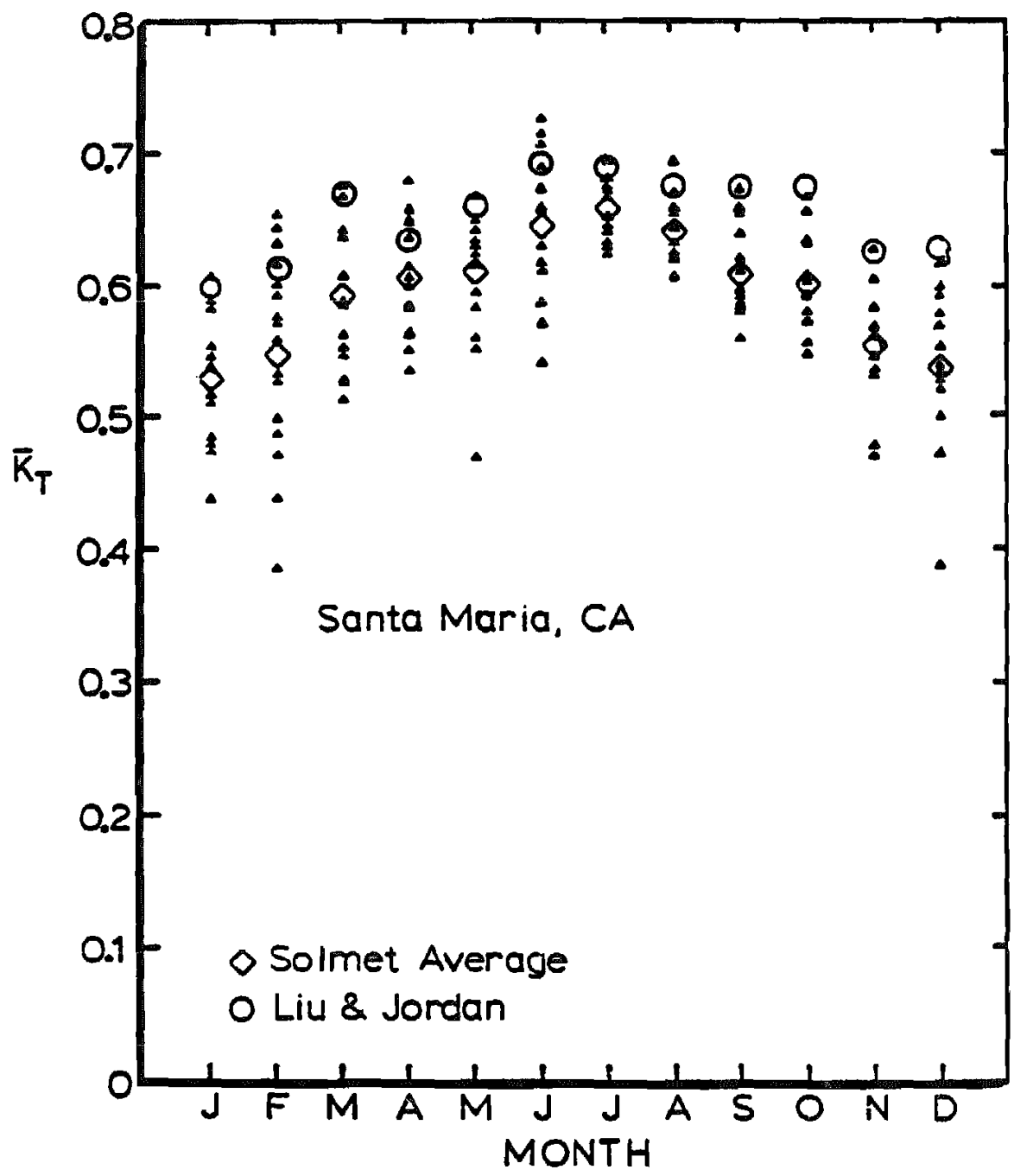

Figure 3.14 SOLMET Derived $\bar{K}_{T}$ 's for Santa Maria, CA. The Solid Triangle Data Points are SOLMET Data. 


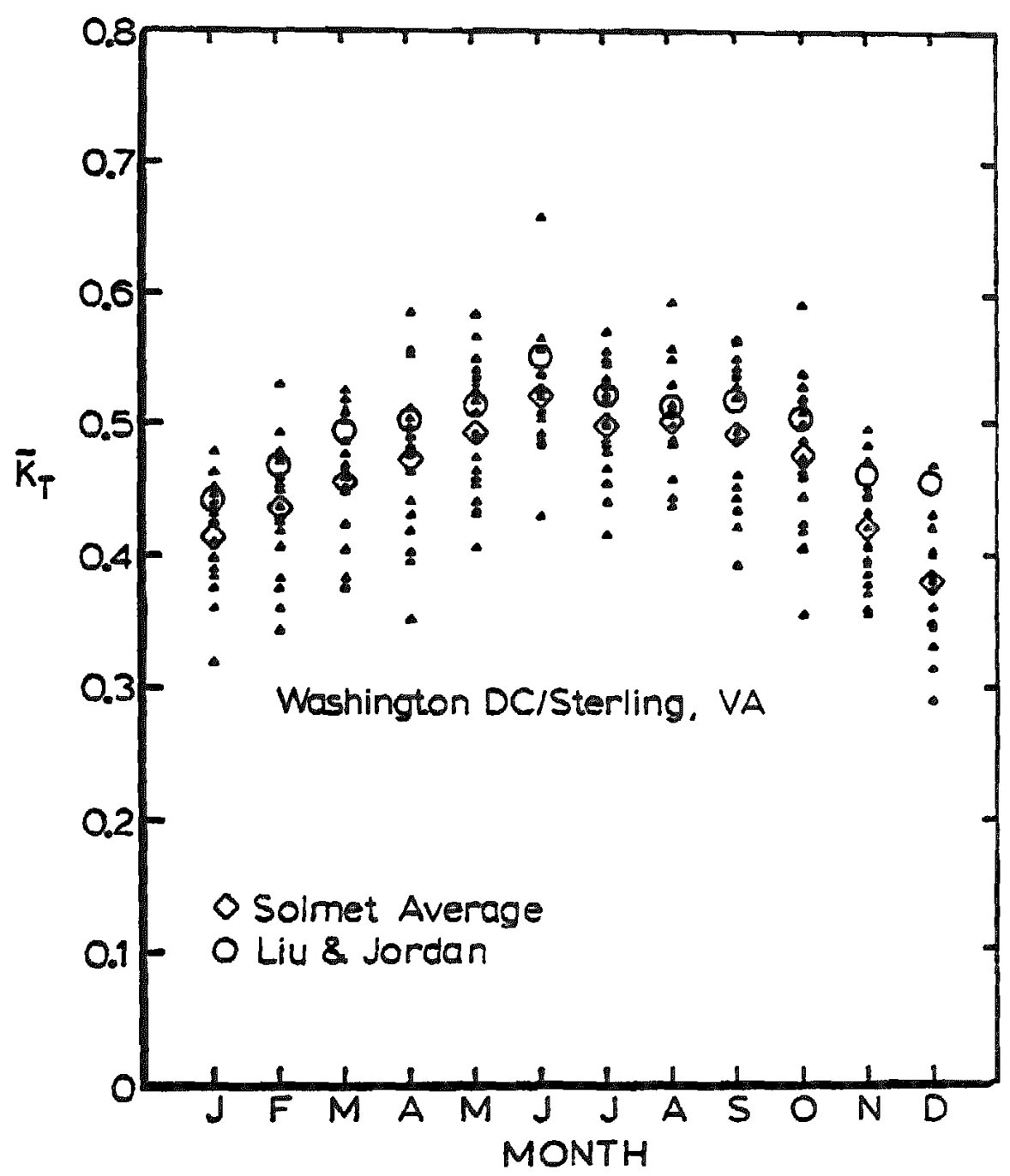

Figure 3:15 SOLMET Derived $\bar{K}_{T}$ 's for Washington D.C./ Sterling, VA. The Solid Triangle Data Points are SOLMET Data. 


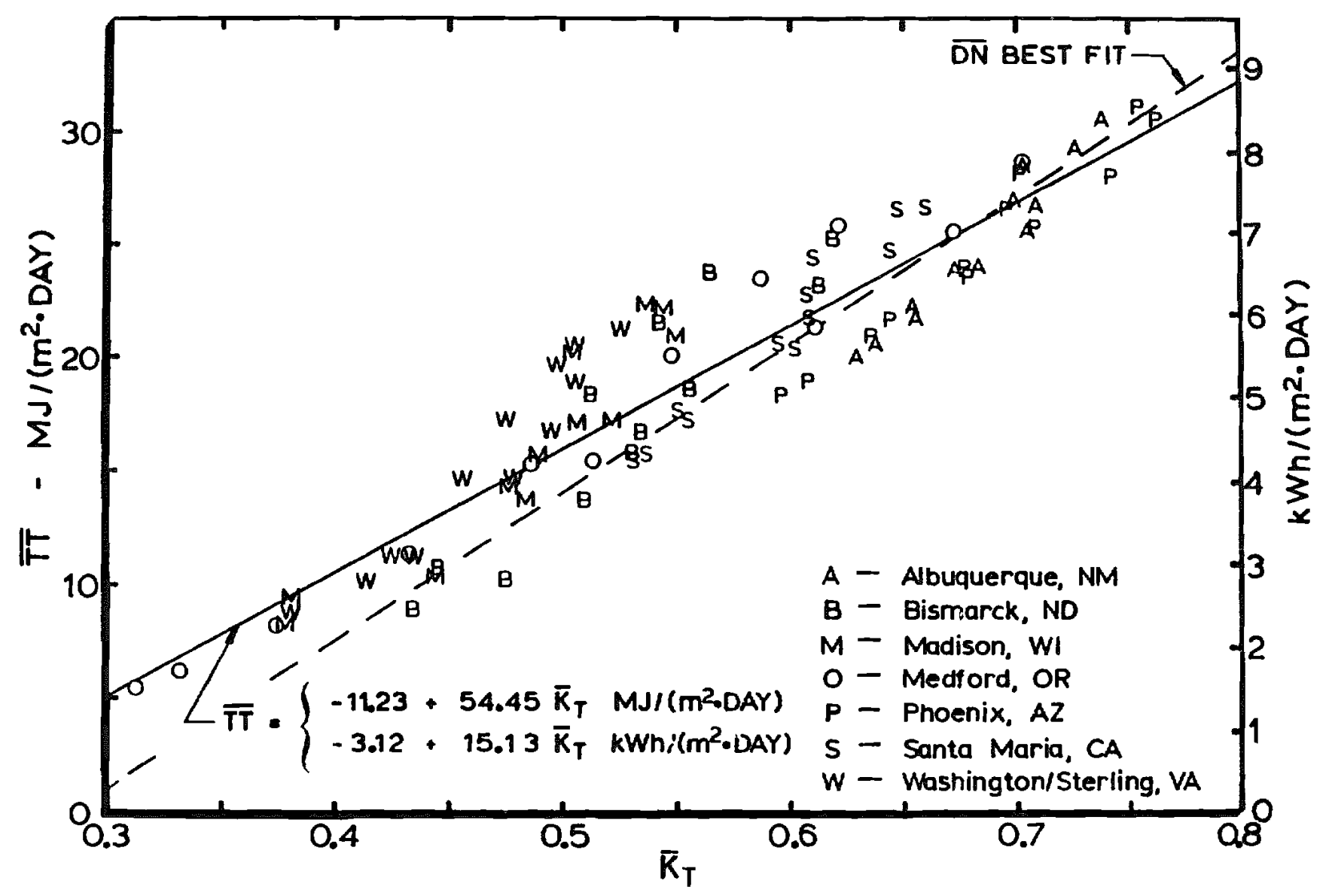

Figure 3.16 Long Term Monthly Average Maily Total Radiation on Monthly Optimally Tilted (TT) Array for Seven Cities. The Direct Normal (DN) Data are Shown in Fig. 3.17. 


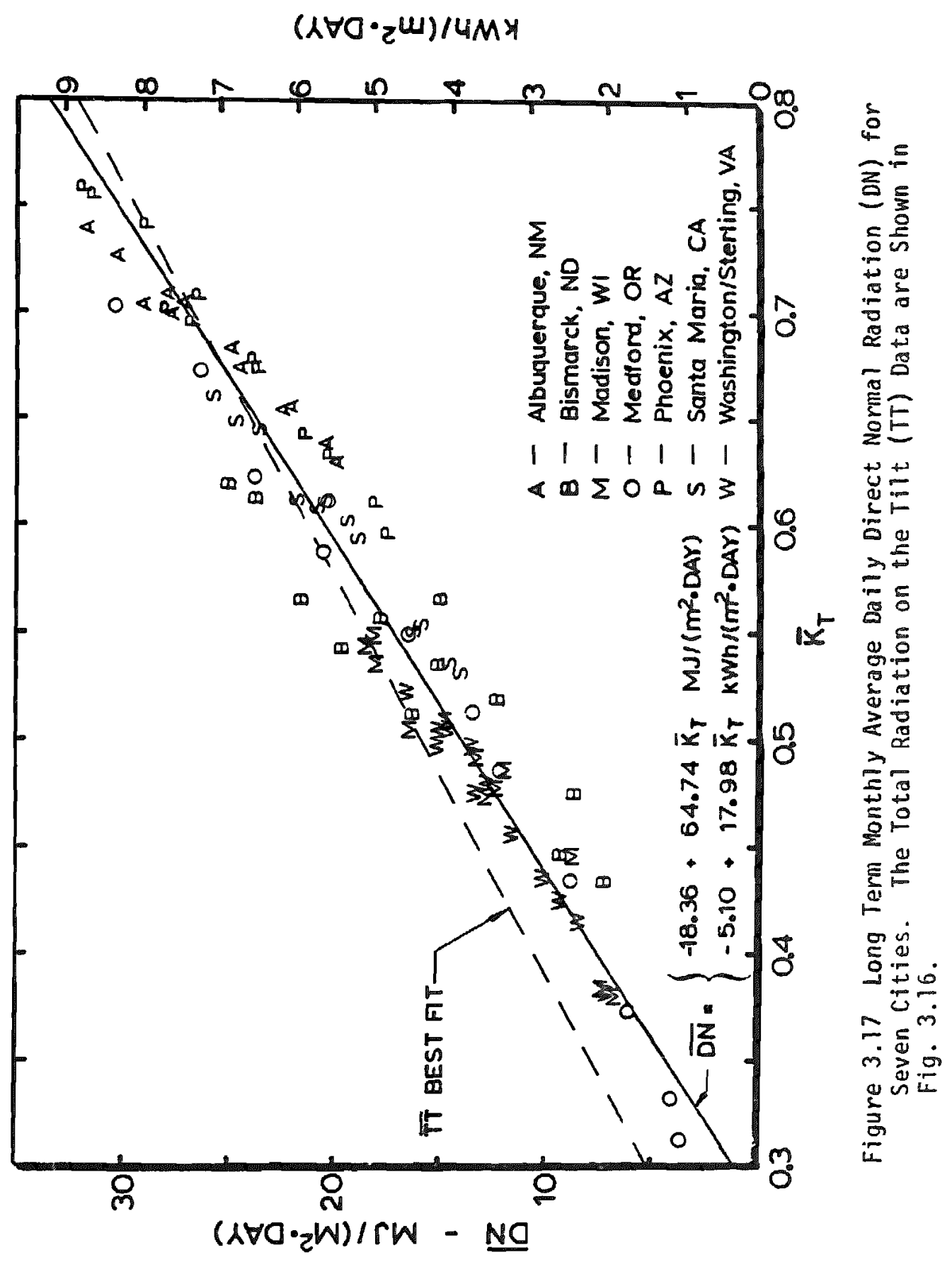




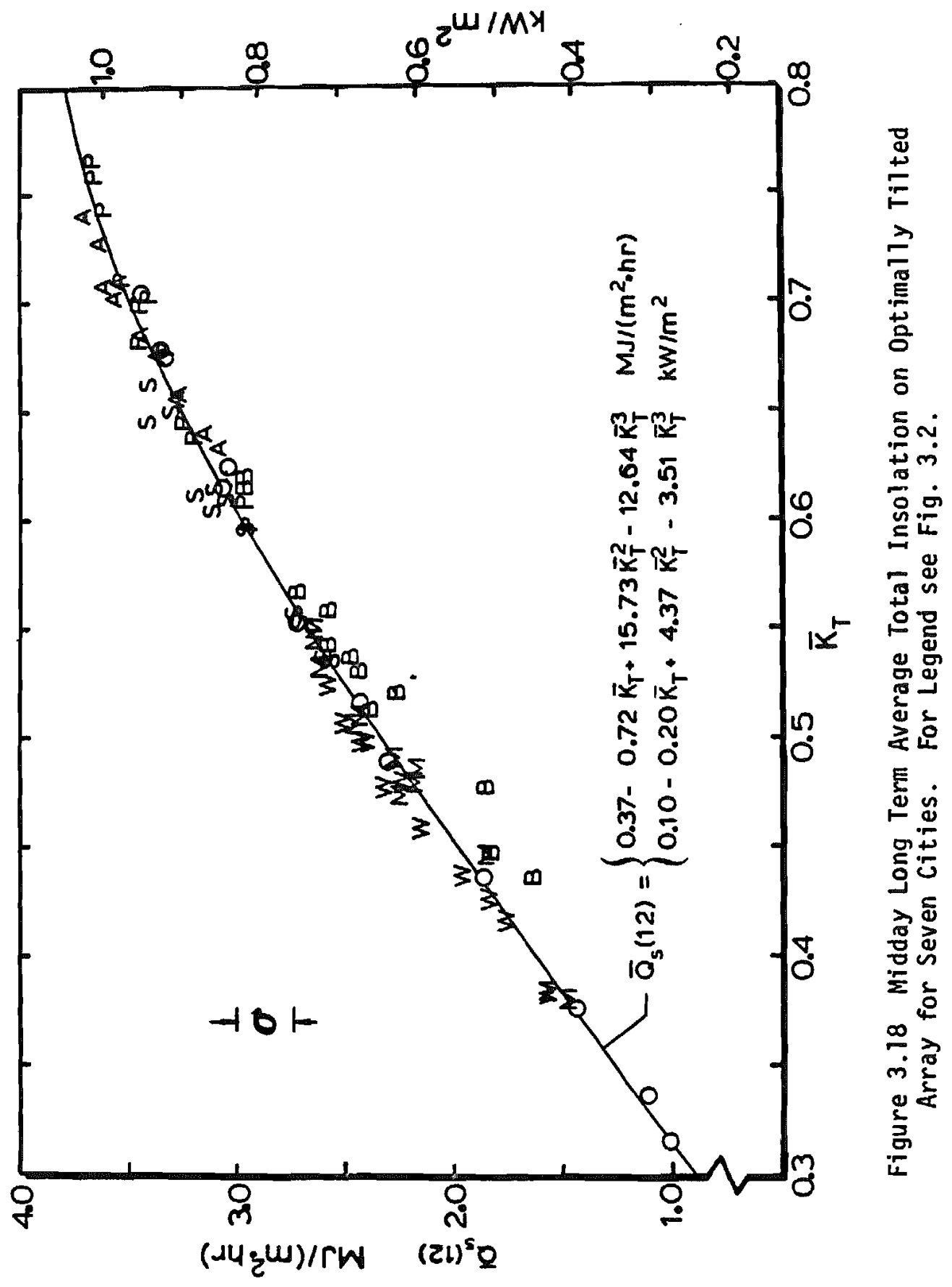




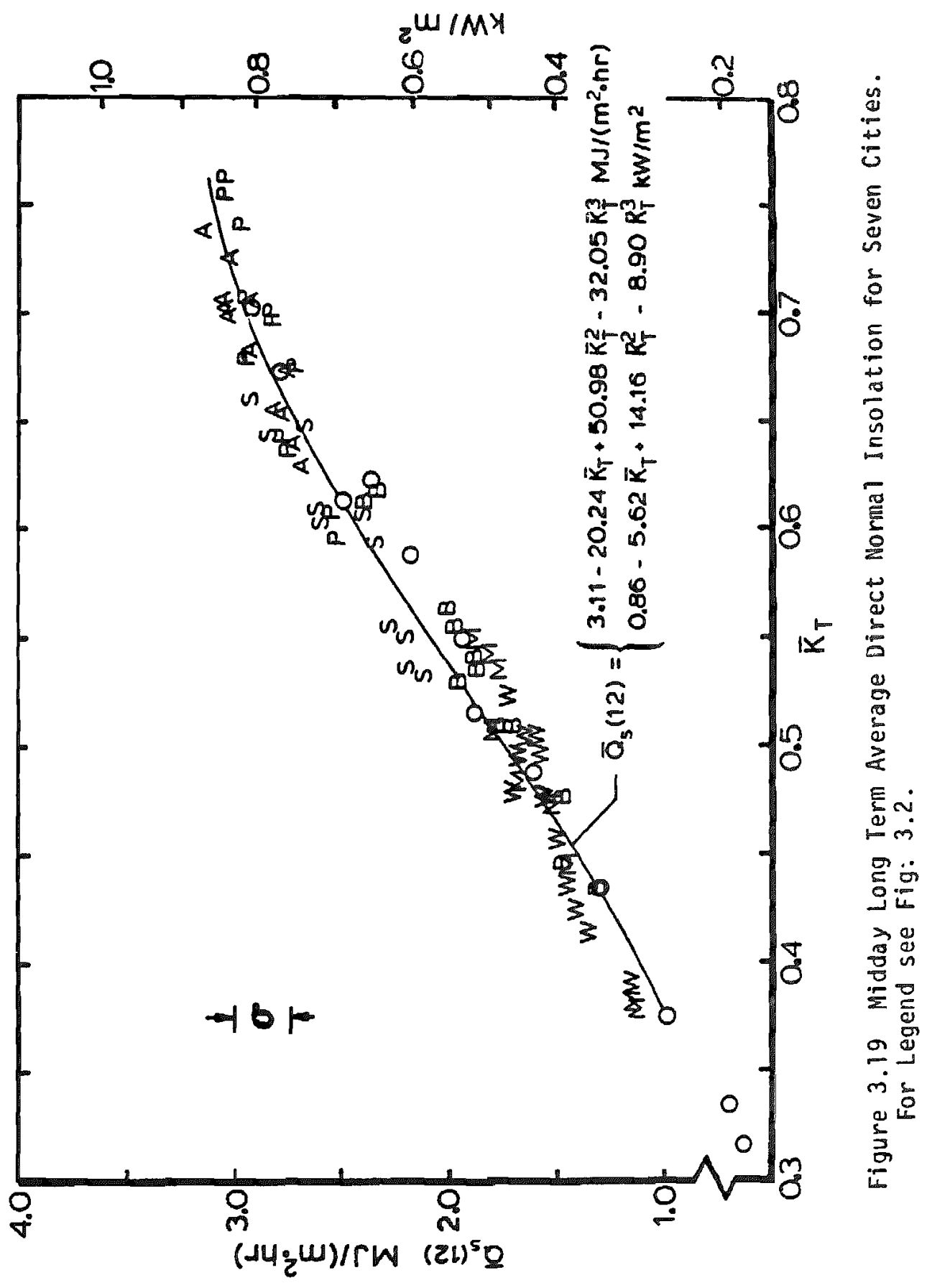




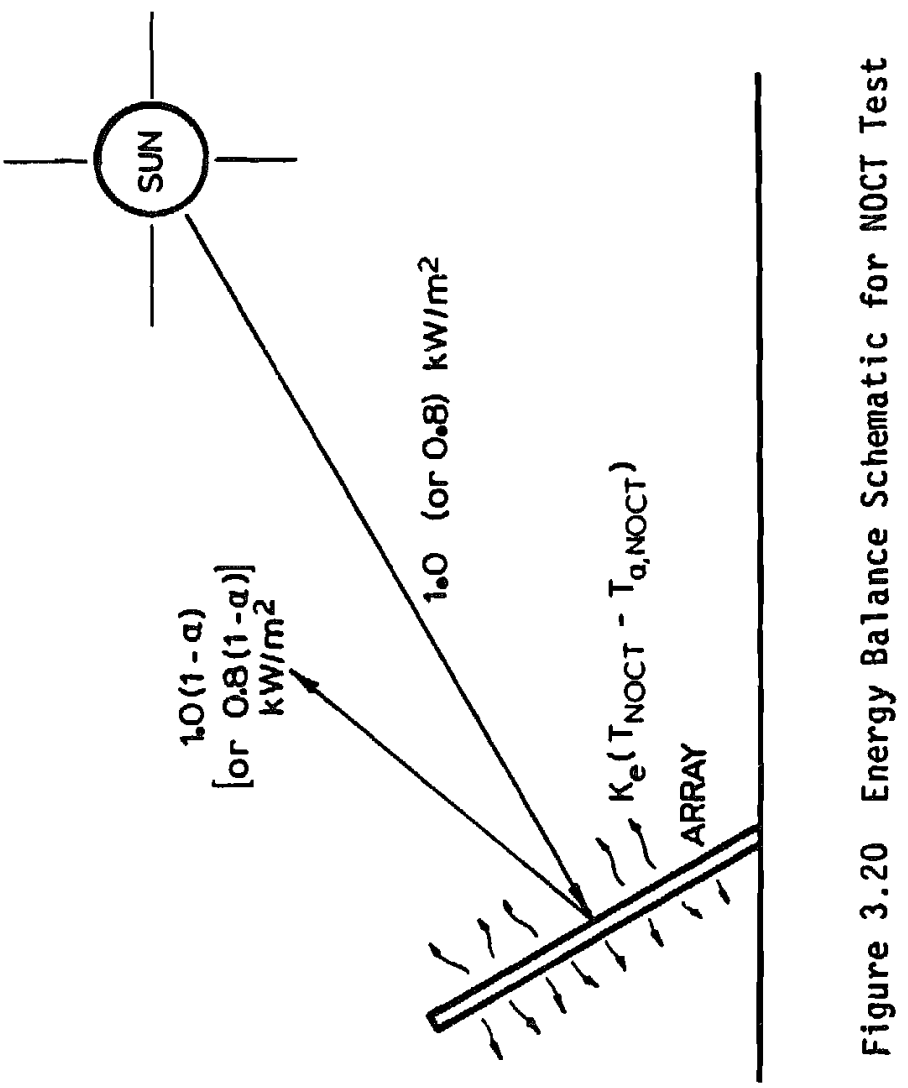




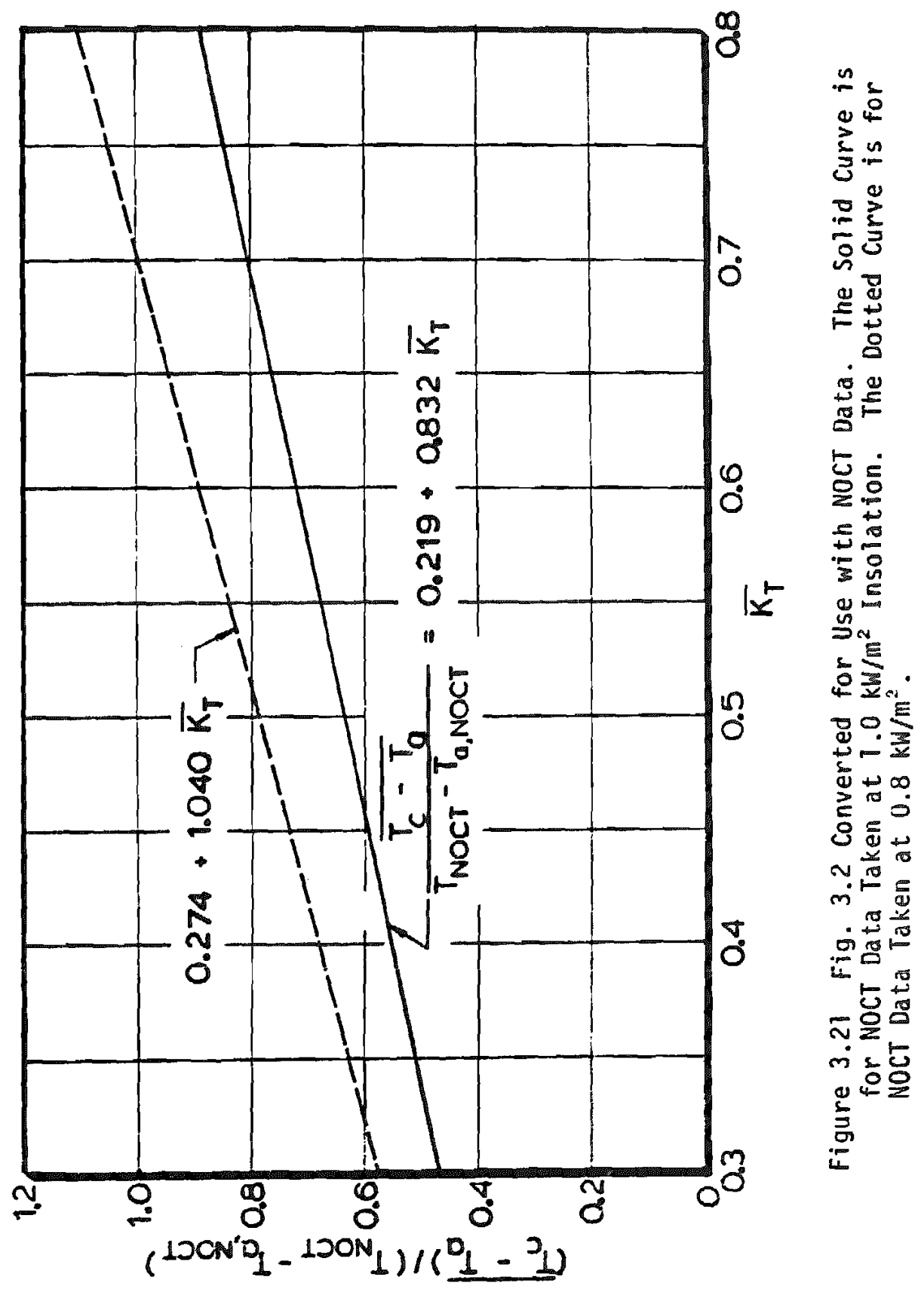




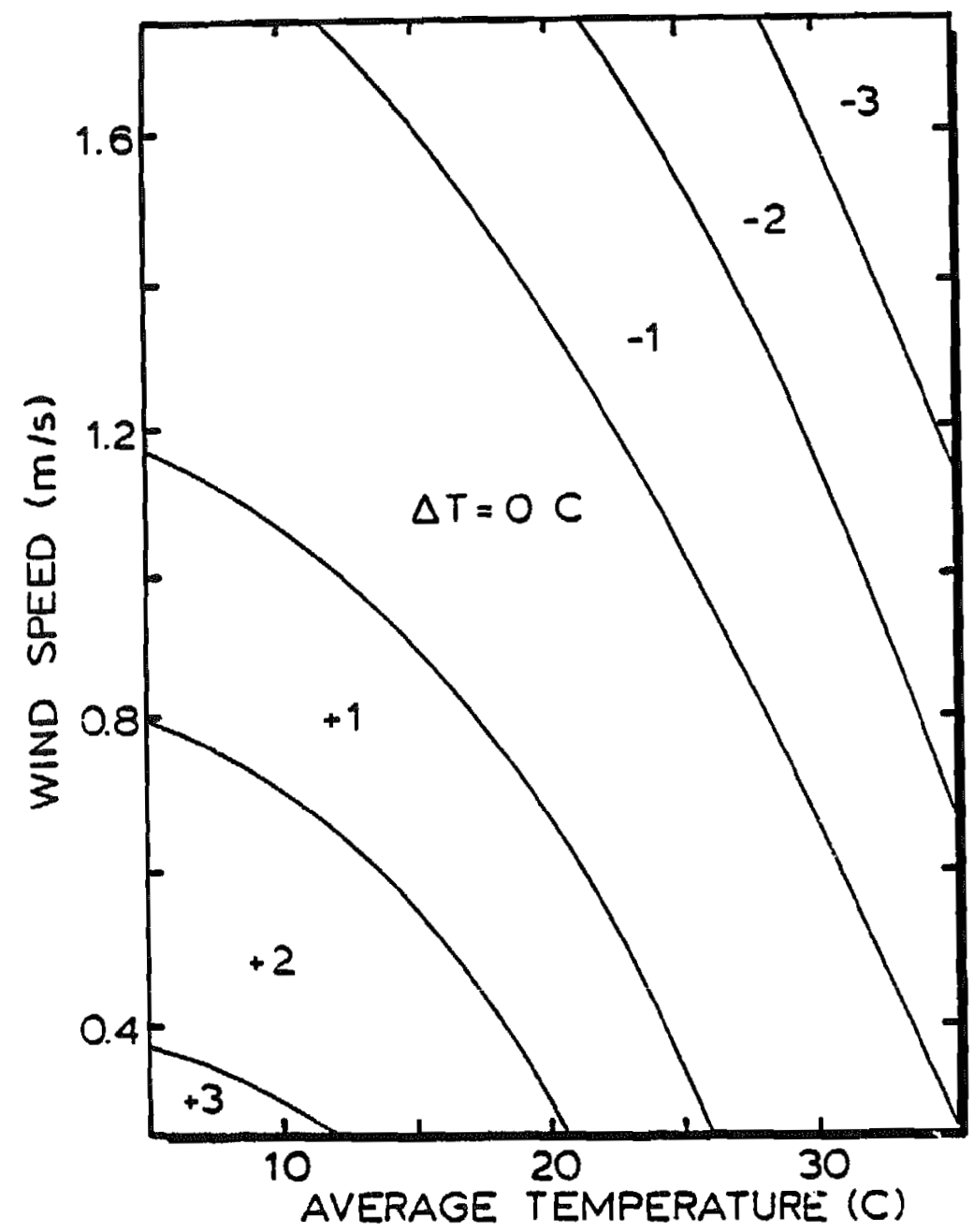

Figure $3.22 \Delta T$ corrections to be Applied to NOCT Data to Adjust Wind Speed and Average Temperature to Local Conditions. (Modified from Ref. 3.19) 
4.0 SIMPLIFIEI METHOD FOR MAX-POWER TRACEED STSTEM PERFORMANCE

\subsection{Introduction}

In this chapter, a fairly general simplified procedure for estinating the performance of PV systems of the type described in Fig. 2-1 is developed. This procedure is for mar-power tracked, passively cooled, flat plate arrays with battery storage and a back-up energy source. The special case of zero storage is also considered. Results from this procedure are compared with those from detailed compter simalations and shown to agree to within a standard deviation of $2.6 \%$ (absolute) for the cases considered. Limitations to the procedure are discussed and an example is included.

\subsection{System Parameters}

The simulation studies described in Chapter 2 are presented ia terms of the groups $s / \bar{\eta} A$ and $\bar{Q}_{e} / \bar{L}$. These arose through an empirical1y based effort to collapse different families of curves and axe largely successful in doing so. However, the results of Chapter 2 also indicate that several additional variables (viz., losd characteristics, time of year, and, to a lesser extent, location) need to be considered in order to accurately estimate system performance. Only when the time of gear and expected lo3d match those used in the simulions can the Chapter 2 figures be used to predict performance. In order to predict performance for more general situations then, one needs additional or alternative parameters, genoral in mature, to characterize system behavior. Ideally these garameters involve only monthly mean values since the object here is to cbtain monthly perforance estionas. 
One such set of parameters arises from considering the interaction of the monthly average daily array ontput and demand curves for an arbitrary wonth and location, as shown for example in Figs. 4.1a,b. The ordinate in both figures has units of power and the abscissa those of time, so the various areas indicated represent energies. The area under the demand curve is $\bar{L}$, the total daily energy load. The area under the output curve is $\bar{Q}_{e}$, the mean daily effective energy output from the array for the month in question. The area under the array output surve and above the demand curve will be referred to as excess (XS), the energy which must either be stored or dumped. Finally, the storage capacity (S) is also represented as an area which is shown in Fig. 4.1b superposed on part of the $X S$ energy.

The four energies ( $\left.\bar{L}, \bar{Q}_{e}, x S, S\right)$ constitute a set of dimensional parameters which may be normalized in different fashions. One such normalization scheme forms the basis for the design procednre described later in this chapter. The scheme results in three parameters, each of which is a dimensionless energy.

One dimensionless parameter is the same $\overline{Q_{e}} / \bar{L}$ used in Chapter 2. It represents the altimate fraction of the daily load which would be supplied by the system if the load were idealiy matched to the array output. A second group, $X S / \vec{Q}_{e}$, is the fraction of electrical output which cannot be used directly becanse of an insufficient immediate demand. $X S / \bar{Q}_{e}$ thus represents the fraction of array energy which must be either stored or dumped. A third parameter, S/XS, is the ratio of battery storage to the awount of energy available to be stored.

Mathematically, the three parameters are as follows:

$$
\begin{aligned}
& \bar{Q}_{e} / \bar{L}=\int \dot{Q}_{e}(t) d t / \int \dot{L}(t) d t \\
& \overline{X S / \bar{Q}_{e}}=\operatorname{pos} \int\left[\dot{Q}_{e}(t)-\dot{L}(t)\right] d t / \int \dot{Q}_{e}(t) d t
\end{aligned}
$$




$$
S / X S=S N_{d} /\left[\operatorname{pos} \int\left[\dot{Q}_{e}(t)-\dot{L}(t)\right] d t\right]
$$

The integrations in the above equations are carried ont orer monthly periods.

One additional parameter, not readily apparent in Figs. 4.1a,b, accounts for storage losses. A battery efficiezcy is defined by

$$
\eta_{b}=s_{D} / s
$$

where $S_{D}$ is the stored energy which is ultimately delivered to the load. The functional dependencies of $\eta_{b}$ were not investigated. Howerer, results from the Chapter 2 simulation studies indicated that, at least for the battery model and range of operation used here, storage efficiency is effectively constant with a value of 0.87 .

\subsection{Simplified Design - Single Dep Approach to Monthly Behavior}

\subsubsection{Energy Allocation - Sing1e Day}

The distribution of electrical energy produced by the PV array on a given day, denoted by the subscript $n$, is defined by parameters very similar to those of the previous section. However, the integrations in Eqs. (4.1-4.3) are now carried out over day n. The daily distribution is depicted by the flow chart of Fig. 4.2 as a series of binary branches with the division of energy flow at each branch determined by the value of one of the daily system parameters. Thus, of the total effective daily energy produced, $Q_{e, n^{\prime}}$ a fraction $\left(1-\mathrm{XS} / \mathrm{Q}_{\theta, n}\right)$ flows directly to the load. Of the remainder, a fraction $S / X S_{n}$ is stored, and the rest is dumped. Fina11y, of the stored energy, a fraction $\eta_{b}$ 
supplies the load, and the remainder is lost. The net fraction of load satisfied by the system is easily computed as

$$
f_{e, n}=\left\{1+x s_{n}\left[\eta_{b} s / x s_{n}-1\right] Q_{e, n}\right\} Q_{e, n} / L_{n}
$$

with

$$
\mathbf{s} / \mathbf{X S _ { n }}<1
$$

and

$$
\mathbf{f}_{\mathrm{e}, \mathrm{n}}<\mathbf{1}
$$

The constraints on $S / X S_{n}$ and $f_{e, n}$ simply indicate that the batteries cannot generate energy and the system cannot supply more of the load than exists. In systems with large $Q_{e, n} / \bar{L}$ and sufficient storage, the system output for one day in some cases (notably a clear day followed by a cloudy day) can supply a part of the day's load; in this case of day to day interaction the solar fraction is not subject to the constraint. However, the simplified design procedare will ignore this day to day interaction.

In eq. (4.5), the parameters $\eta_{b}$ and $S / X S_{n}$ occur as a product. For the purpose of estimating system performance, the two may thus be condensed into a single system storage parameter, $\eta_{b} s / s_{n}$.

\subsubsection{Monthly Distribution}

The single day energy distribution equation, eq. (4.5) using monthly mean ralues $\left(X S, \bar{Q}_{e}\right)$ for $X S_{n}$ and $Q_{e, n}$ is not generally valid for estimating monthly system performance. Array output is not uniform from day to day throughout a month because of differences in atmospheric conditions, and $Q_{e, n} / \bar{L}$ varies accordingly. Since $X S_{n}$ is strongly dependent on $Q_{e, n}$ it too varies and affects both $X S_{n} / Q_{e, n}$ and $S / X S_{n}$. Application of eq. (4.5) is therefore not useful without some consideration being given to the day to day variation within a month. 
This section, then, describes a method for representing such variation in array output from knowledge only of $\overline{\mathbf{K}}_{\mathrm{T}}$ and the mean daily ontput, $Q_{e} \cdot$ Knowledge of the variation permits eq. (4.5) to be used to compute a distribution of daily performances for the month which in turn may be used to obtain an estinate of monthly performance.

The results of Liv and Jordan (Ref. 4.1) on generalized radiation distribution curves are useful in describing the desired distribution of array outpat. As a part of the work on data for seven SOLMET sites described in Chapter 3 of this report, the generalized radiation distribution curves were redone. The new curves along aith comparison with the Lin and Jorian curves are shown in Fig. 4.3. While those results specifically apply to total horizontal radiation dats, they may be expected to be at least approximately correct for tilted array output as well. Combined with the mean daily effective array output, $Q_{e}$. detormined by the methods of Chapter 3 , the insolation distributions of Fig. 4.3 can be used to construct a pattern of daily outputs which yield the appropriate monthly mean value and which reflect the expected variability within the month. The distribution is based on long term results and in this sense is preferable to simelation results based on a single, typical month.

Using Fig. 4.3 it is possible to obtain 30 separate values of $Q_{e, n}$ (a 30-day distribution) corresponding to predicted array output for each day of the month. While this makes the most sense in terms of referring to eq. (4.5) as single day equation, it is equal1 possible to approximate monthly performance using $N$ values of $Q, n$ (an $N$-day distribution) where $N$ is arbitrary. Since application of eq. (4.5) is somewhat involved (as is seen 1ater). it is advantageous to choose the smallest $N$ which still approximates the variability of output during a month. The results of this work suggest that in most cases $\mathrm{N}=3$ is sufficient. This was established by taking successively smaller numbers for $N$ and noting the resulting solar fraction. The 
3-day distribution corresponds $t$. representing the monthly weather with typical "good," "mediocre," and "poor"' days.

Figure 4.4 is an abbreviated cross plot of Fig. 4.3. It shows the values of $Q_{e, n}$ appropriate for a 3-day distribution. At a fixed $\bar{K}_{T}$, the uppermost curve gives a value of $Q_{e, n}$ for the good day, the intermediate curve yields a value for the mediocre day, and the lowest curve yields a poor day value of $Q_{e, n}$. The upper and lower curves in Fig. 4.4 are obtained from the values of F/ $\tilde{I}$ corresponding to the $1 / 6$ and $5 / 6$ points on the cumulative frequency distribution axis in Fig. 4.3. These closely approximate the $5 \mathrm{th}$ best and 5 th worst days of a 30-day distribution. The middle curve is adjusted so that poirt on this third curve whe taken with points on the $1 / 6$ (poor day) and $5 / 6$ (good day) curves at the same $\bar{E}_{T}$, averages to 1.0 . That is, the mean array output for the 3-day distribution equals the actual monthly mean value.

\subsubsection{The Design Procedure}

The ideas of Sections 4.2 .1 and 4.2 .2 are now merged into a procedure for estimating system performance. The procedure is valid for systems with an arbitrary amount of storage and a known but arbitrary daily load profile. It treats a load which does not vary from day to day but is readily adapted to situations in which the load profile does change (e,g., cistinct weekend and weekday profiles). The method provides for consideration of both seasonal and geographic variations.

The technique presumes that the monthly average daily effective energy output from the array is already determined (e.g., through the procedure described in Chapter 3 ). The designer is required to specify the quantity of available storage, a daily load profile (shape and magnitude), and the average daylength of the month at the location for which he is designing. He must also know $\bar{K}_{\mathrm{T}}$ for the month and site involved. 
The method proceeds in four steps. First, 3-day distribution of array outputs is obtained using Fig. 4.3, and

three values of $Q_{e, n} / \bar{L}$ are determined. Nert, an $Z_{n} / Q_{e, n}$ is computed for each of three values of $Q_{e, n} / \bar{L}$. Then, the syster storage parameter $\eta_{b} S / X S_{n}$ is evaluated directly, again for each of the three representative days. Finally, eq. (4.5) is applied three times, and the resulting values of the solar fraction are averaged to give an estimate for the expected monthly syster performance.

The bulk of the procedure lies in computing ${ }_{-} S_{n} / Q_{e, n}$ from a given value of $Q_{e, n} / \bar{L}$. This is accomplished by curve-fitting a normalized effective array power output, $\dot{Q}_{e, n}(t) / \bar{L}$, using a cosine function centered at noon, with half-period related to the daylength and with the amplitude adjusted to obtain the specified $Q_{e, n^{*}}$ The resulting $f i t$ is

$$
\dot{Q}_{e}(t) / \bar{L}=\left\{Q_{e, n} / \bar{L}\right\}\left\{\pi /\left[2\left(t_{D}-c\right)\right]\right\} \cos \left[\pi(t-12) /\left(t_{D}-c\right)\right]
$$

for

$$
\left[12-\left(t_{D}-c\right) / 2\right]<t<\left[12+\left(t_{D}-c\right) / 2\right]
$$

and

$$
\dot{a}_{e, n} / \bar{L}=0
$$

for other values of $t$.

Experience suggests $c=1$ hour gives accurate estimates of $\mathrm{XS}_{\mathrm{n}}$. This constant truncates a sight Gaussian-like tail in the periods just following sunriso and preceding sunset and improves the curve-fit during the hours when interaction with the load curve is important. Figures $4.5 \mathrm{a}, \mathrm{b}$ show examples of the cosine crrve-fit for June and December in Albuquerque. 
With $\dot{Q}_{e, n}(t) / \bar{L}$ approximated by eq. (4.6), $X S_{n} / Q_{e, n}$ is conputed using the daily equivalent of eq. (4.2). This is accomplished analytically if $L(t)$ can be expressod analytically and numerically (or graphically) otherwise.

Using the calculated values of $X s_{n} / Q_{e, n}$ and $Q_{e, n} / \bar{L}$, the combined parameter $\eta_{b} s / X s_{n}$ is readily determined. With each of the system parameters now calculated, eq. (4.5) is applied. A separate solar fraction is computed for each of the three representative days. This introduces the effect of varying array performance within the month so that when the three fractions are averaged this effect is included in the final result.

Table 4.1 sumarizes the procedure, and an example in the ensuing section demonstrates it.

\subsection{Example}

As an example of the procedure described in Section 4.4, consider the estimation of the performance of a PV system to be operated in Albuquerque during March. The following is known from the month and location.

$$
\begin{aligned}
& \overline{\mathrm{K}}_{T}=0.64 \\
& \mathrm{t}_{D}=11.7 \mathrm{hrs}
\end{aligned}
$$

Sources for the first of these wero discussed in section 3.3. The second can be calcnlated from

$$
t_{D}=2[\operatorname{arc} \cos (-\tan \phi \cdot \tan \delta)] / 15
$$

The solar declination, $\delta$, is calcrlated from

$$
\delta=23.45 \sin [360(284+n) / 365]
$$

where $n$ is the Julian day of the year. 
Suppose that the expected load is constant,

$$
\begin{aligned}
& \dot{L}(t)=L_{0}=1985 \mathrm{~kJ} / \mathrm{hr}=-0.55 \mathrm{~kW} \\
& \vec{L}=24 \mathrm{~L}_{0}=4.76 \times 10^{4} \mathrm{~kJ}=13.2 \mathrm{~kW}-\mathrm{hr}
\end{aligned}
$$

Suppose further that the product of storage capacity and efficiency for the systea in question is chosen by a designer to be

$$
\eta_{b} s=5265 \mathrm{~kJ}=1.46 \mathrm{~kW}-\mathrm{hrs}
$$

Finally, supgose that using the procedure of Chapter 3, the monthly mean daily array output as it comes from the inverter is determined to be

$$
\bar{Q}_{e} / \bar{L}=0.6
$$

Estiantion of the syter performance now proceeds following Table 4.1 .

Step 1. Obtain a 3-day distribution of array outputs using Fig. 4.4 and $\overline{\mathrm{K}}_{\mathrm{T}}=0.64$. The figure gives

$$
Q_{e, 3} / \bar{Q}_{e}=1.16: Q_{e, 2} / \bar{Q}_{e}=1.00: Q_{e, 3} / \bar{Q}_{e}=0.84
$$

Thus

$$
\begin{aligned}
& a_{e, 1} / \bar{L}=1.16(0.6)=0.696: \\
& a_{e, 2} / \bar{L}=0.60 ; \\
& a_{e, 3} / \bar{L}=0.504
\end{aligned}
$$

Step 2 a) Approrimate the instantaneous array ontput. Consider the first of the three values from Step 1 . From eq. (4.6), 


$$
\begin{aligned}
\dot{Q}_{e_{11}} / \bar{L} & =0.696[\pi /[2(11.7-1)]\} \cos [\pi(t-12) /(11.7-1)] \\
& =0.102 \cos [\pi(t-12) / 10.7]
\end{aligned}
$$

b) Compote $X S_{n} / Q_{e, n}$ The load carve is expressed analytically, hence, $\quad X S_{n} / Q_{e, n}$ can be computed analytically. Again consider the first point in the distribution:

where

$$
X S_{1} / Q_{e, 1}=\left[\bar{L} / Q_{e, 1}\right]_{t_{1}} f_{2}^{t}\left[Q_{e, 1} / \bar{L}-L_{0} / \bar{L}\right] d t
$$

$t_{1}$ is the 1st time that the array output equals the load

and

$t_{2}$ is the 2 nd time that the array output equals the load.

To determine $t_{1}$ and $t_{2}$, set $\dot{Q}_{e, 1}=L_{0}$. Thus,

$$
(0.102)\left(24 L_{0}\right) \cos [\pi(t-12) / 10.7]=L_{0}
$$

which gives

$$
t_{1}=12-[10.7 / \pi\} \operatorname{arc} \cos [(0.102)(24)]^{-1}=8.1 \quad(4.20)
$$

and

$$
t_{2}=12+\{10.7 / \pi\} \text { arc cos }[(0.102)(24)]^{-1}=15.9(4.21)
$$

Use eq. (4.6) with eq. (4.18) to obtain 


$$
\begin{aligned}
\operatorname{LS}_{1} / Q_{e, 1} & =\pi / 2\left(t_{D}-1\right) t_{1} \int_{2}^{t} \cos \left[\pi(t-12) /\left(t_{D}-1\right)\right] d t \\
& -\int_{1}^{t_{2}} L_{0} / Q_{e, 1} d t \\
& =1 / 2\left\{\sin \left[\pi\left(t_{2}-12\right) /\left(t_{D}-1\right)\right]\right. \\
& \left.-\sin \left[\pi\left(t_{1}-12\right) /\left(t_{D}-1\right)\right]\right\} \\
& =0.44
\end{aligned}
$$

Repeating the procedure for the remaining two days yields

$$
{x s_{2} / 0_{e, 2}}=0.37
$$

and

$$
\mathrm{xS}_{3} / Q_{0,1}=0.28
$$

Step 3 Compute the effective storage fraction, $\eta_{b} S / I_{n}$.

Use

$$
\eta_{b} S / X s_{a}=\eta_{b} S /\left[\left(x s_{n} / Q_{e, a}\right)\left(Q_{e, n} / \bar{L}\right) \bar{L}\right]
$$

For the 1st day this gives

$$
\left.\eta_{b} S / X S=5265 /[(0.44)(0.696)(24) 1985)\right]=0.36
$$

Similarly,

$$
\eta_{b} S / X S_{2}=0.50 ; \eta_{b} S / X S_{3}=0.792
$$


Step 4 Compute the monthly solar fraction

a) apply eq. (4.5) using values for the 1 st day.

$$
\begin{aligned}
f_{e, 1} & =[1+0.442(0.36-1)](0.696) \\
& =0.50
\end{aligned}
$$

Similarly,

$$
f_{e, 2}=0.49
$$

and

$$
\begin{aligned}
& f_{e, j}=0.47 \\
& \text { b) Average the results } \\
& f_{e}=(0.50+0.49+0.47) / 3 \\
& =0.49
\end{aligned}
$$

Thus, the procedure predicts that $49 \%$ of the load will be satisfied by the system for the month of March. This compares with 46.7\% predicted by computer simulation using TMY weather data.

In this example, assuming uniform weather throughout the month does not significantly affect the final estimate of $f_{e}$. This is seen by observing that $f_{e}=f_{e, 2}$ in Step 4 above and recognizing that that $f_{e, 2}$ is obtained from the monthly average values, $\bar{Q}_{e}$ and XS. Such a uniform werther assumption is not always valid. For instance, for Madison in June with $\vec{Q}_{e} / \vec{L}=0.6$, the baseline load shape, and a storage capacity corresponding to $S / \vec{\pi} A=5$ Anp-hr/ $\left(\% \cdot m^{2}\right)$, the solar fraction obtained using only monthly average values is $f_{e}=.59$, while the 3-pt. procedure yields $f_{e}=.54$. The value from hourly simulation is $f_{e}=.538$; hence, the 3-pt procedure in this case is crucial. 


\subsubsection{Comparison of Results}

Table 4.2 shows aciditional comparisons of predictions using the simplified technique with those of computer simulations. The table displays cases for which the baseline load defined in Chapter 2 was specified. The examples without storage best indicate the accuracy in estimating $X S$. Those corresponding to

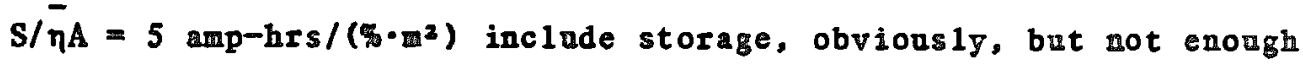
to 1 iminate damping. The $s / \bar{\eta} A=10$ amp-hrs/(\%/. $\left.{ }^{2}\right)$ cases for $Q_{e} / \bar{L}=0.6$ experience only minor aunts of dumping.

In virtuliy a11 instances, results from the simplified procedure are within $10 \%$ relative and $5 \%$ absolute of the simulated values. The standard deviation of the predicted values from the simulated values is $2.6 \%$ (absolute). Typically, results are very good for sumer months when weather patterns tend to be good (aore consistent). Poorest results occur in winter months. Also, results for larger storage sizes tend to be very good.

Several factors contribute to differences between simply predicted and computer simulated results. Simulation results are based on particular month which is likely to differ at least somewhat from the long term average which forms the basis for the simplified procedure. That is, insolation distributions for any one month can differ from the $10 n g$ term $(-22$ years) resilts shown in Fig. 4.3. This effect can readily be investigated by simulating the system over several years and comparing the corresponding estimate of the simplified procedure with the long term average of the simalations for any given month. Such a stady has not as get been performed.

Use of an insolation distribution to approxiate a distribution in array output also is not completely correct. In particular, temperature variation within a month cases changes in solar cell efficiency and so affects the distribution of array 
output. This effect is ignored by using strictly an insolation distribution.

Another obvious source of error in the simplified procedure lies in the cosine fit for the array power output. Individual poor days do not have cosine-like daily distributions although, averaging the poor days over the month, it may appear that they do. This is probably the largest source of error for winter months.

There is a1so an uncertainty in specifying storage capacity in energy units. Both the charging and discharging voltages enter into the determination of the energy capacity of the batteries. Since these voltages vary during the course of system operation, it is difficalt to precisely estimate the energy storage capacity from the rated capacity in amp-hrs. Two schemes have been used to estiate effective energy capacity. The first of these uses the storago efficiency value $\mathbf{0 . 8 7}$, determined from simulation results with a nominal 2.0 volt battery voltage for converting amp-hrs' to W-hrs. The second approach employs the well-defined ogen circuit battery voltage, 2.175 volts, with a nominal storage efficiency of 0.80. The two procedures yield equivalent estimates of the solar fraction and differ only in the apportionment of losses due to dumping and storage inefficiencies.

\subsubsection{Interaction on Successive Days}

One other phenomenon poses difficulties for the simplified procedure. Consider a system with $Q_{e} / \bar{L}=1$ and large storage capacity during a low $\bar{K}_{T}$ wonth. Cloudy days within the month result in generation which satisfies less than the full load, while clear days convert more than enough energy to meet the daily load. The load on a clear day then is completely satisfied and, in addition, storage may be filled to where it is not completely depleted by sunriso of the following day. if the following day is also clear, the system will again store energy. However, because 
storage is already partly filled, the available storage is less than on the previous day, and rore energy must be dumped.

This "end-of-the-day duming" is the situation presumed in the sinplified procedure. Constraining the solar fraction to not exceed unity effectively requires that no enerby produced on one day be used on the next. However, if the representative good day solar fraction (i,e., the largest $f_{e, n}$ of the 3-day distribation) is near unity, then some of the "better" good days contribute $f_{e, n}>1$ to its value. The procedure imposes the constraint only on the representative $f_{e, n}$ and not on the "better'" good dey $f_{e, n}$ 's: hence, the good day fraction is higher than if the constraint were strictly imposed. Including additional days in the distribution allows the constraint, on the solar fraction te be more completely enforced.

For the same system as above, if clear day is followed by a cloudy day, part of the production of the clear day contributes toward satisfying the cloury day load. When such iateraction on succossive days sccurs, the constraint on $f_{e}$ is not valid. Since enforcing the constraint tends toward conservative estimates of system performance, however, the recomended procedare is to enforce it as strictly as possible. Thas, predictions for which the good day fraction is greater than about 0.95 should be vieved as optimistic and consideration should be given to using more than - 3-day distribution in order to perait stricter enfercement of the constraint on solar fraction.

4.5.3 High $\bar{K}_{T}$ Months

In months with high $\overline{\mathbf{K}}_{T^{\prime}}$ the 3-day distribution offers 1 ittle advantage oves a uniform day assuaption. Hence, for $\overline{\mathbf{B}}_{T}>0.65$, eq. (4.5) applied once using $\bar{Q}_{e} / \bar{L}$ gives results essentially equivalent to those obtained with the 3-day distribution calculation. 


\subsubsection{Varying Load Profile}

The procedure developed here assumes that the load profile is uniform from day to day through a month. To estimate monthly performance in situations where the load profile varies (e.g., a weekend load which differs from that during the week) it is necessary to approxinate monthly performance for each load shape and weight the results appropriately (e.g., weight the weekend results by $2 / 7$ and those for the week days by $5 / 7$ ).

\subsubsection{Utility Se11back}

The situation in which the utility serves as system storage, purchasing power which is not immediately needed and selling power when the array alone cannot satisfy the load, is merely a special case of the procedure already discussed. Here, the single-day direct fraction, that supplied directly by the array, is

$$
f_{e, n}=\left[1-x s_{n} / Q_{e, n}\right] Q_{e, n} / \bar{L}
$$

The fraction of the ontput which is sold to the utility is just $\mathrm{XS}_{\mathrm{n}} / \bar{L}$ and that purchased from the utility is $\left(1-f_{e}\right)$. These sre readily computed on monthly basis using the same 3-day procedure described previously. As shown in the results of Chapter 2, random fluctuations in the load do not significantly affect the monthly two-way energy flow, hence neglecting such fluctuations in the simplified procedure should introduce little additional error.

\subsubsection{A1 ternative Procedures}

Two alternative design approaches investigated in the course of this study showed promise, but ultimately proved to be inadequate. Both are eapirical in that they rely strictly on simalation results. Both, also, arrive at estimates of system performance by approrimating losses. In the first procedure, the total monthly losses (dumping plus storage losses), expressed as a 
percentage of the monthly load, are plotted as a function of $\mathrm{XS} / \overline{\mathrm{L}}$, with the storage group $\mathrm{S} / \bar{\eta} \mathrm{A}$ retained from Chapter 2 as a parameter. Figure 4.6 shows such plot with linear least squares curves shown in lien of simulation points. (The lowermost line in Fig. 4.5 represents cases with negligible dumping losses and displays, with simple manipulation, the 0.87 storage efficiency cited earlier.) In the second approsch nonthly duming losses, normalized by $X S$, are plotted as function of the storage variable S/XS. The standard deviation, $\sigma_{\bar{H} / \overline{\mathbb{E}}}$, of daily total radiation on the horizontal from the wonthly mean value is included as a parameter. Figure 4.7 shows this second alternative approach.

Both of these empirical approaches work reasnnably well in predicting performance for months with large $\overline{\mathrm{K}}_{T}$ (i.e., for months where there is little weather variation). Neither, however, adequately accounts for weather variations in months of low $\mathrm{K}_{\mathrm{T}}$

The first scheme does not consider day to day variation at a11, but considers parameters based strictly on monthly mean values. This leads to errors in the solar fraction of as much as $25 \%$ (absolute) compared with the corresponding simulation results.

The second approach also uses monthly mean values but attempts to consider variations through the use of an additional monthly mean parameter, namely $\sigma_{H / \bar{H}}$. This, however, does not recognize that weather variations of given magnitade have a greater effect on the saaller of two systems even when the two systems have the same ratio of $S / X S$. As a result, the second approach for correlating simplation results can yield poor results for low $\overline{\mathbb{B}}_{T}$ months.

\subsection{Summary}

The results of Chapter 2 were used to discern parameters which characterize the interaction of PV system components. A practical 
simplified design procedare for predicting tine fraction of a given load supplied by solar was developed around these parameters and was shown to be adequate for most design parposes.

The technique, although perhaps laborious for hand calculations, has potential for adoption to hand-held pxogrammable calculators. It certainly can be instituted on any small corpater in a simple and computationally efficient manner.

The developed technique allows for assessing the impact of many design alternatives, such as array efficiency, array size, battery size, battery efficiency, power conversion efficiency. load shape and location. Since the technique uses cosine fits to the daily insolation profile it is restricted to flat arrays. However, other analytical shapes conld be used to represent 2-D tracking systems. 
CHAPTER 4 REFERENCES

\subsection{B.Y.H. Liu and R.C Jordan, "The Long-Ter Average Performance of Flat-P1ate Solar-Energy Collectors," Solar Energy 2, 53 (1963).}


Table 4.1

Summary of Procedure for

Estimating System Performance

1. Compute $\bar{Q}_{e, n} / \bar{L}$ :

Use $\overline{\mathrm{K}}_{\mathrm{T}}$ and Fig. 4.4 to obtain a distribution of effective array outputs:

$$
Q_{e, n} / \bar{Q}_{e}, \quad n=1,2,3
$$

Use these with known $\bar{Q}_{e}$ and $\bar{L}$ to obtain:

$$
Q_{e, n} / \bar{n} \quad n=1,2,3
$$

2. Compute $X S_{n} / Q_{e, n}$ :

a) Approximate the instantaneous array output using a cosine fit:

$$
\dot{Q}_{e, n} / \bar{L}=\frac{Q_{e, n}}{\Gamma} \cdot \frac{\pi}{2\left(t_{D}-l\right)} \cos \left[\frac{\pi(t-12)}{\left(t_{D}-1\right)}\right]
$$

b) Use the above output profile to compute $X S_{n} / Q_{e, n}$ analytically, numerically or graphically:

$$
X s_{n} / Q_{e, n}=\frac{1}{Q_{e, n} / L}\left\{\operatorname{pos} \int_{24}\left[\frac{Q_{e}, n}{L}-\frac{L}{L}\right] d t\right\}, \quad n=1,2,3
$$

3. Compute $\eta_{b} S / X S_{n}$ :

Use:

$$
n_{b} S / X s_{n}=\frac{n_{b} S}{\left(x s_{n} / Q_{e, n^{-}}\right) \cdot\left(Q_{e, n} / \bar{L}\right) \bar{L}}, \quad n=1,2,3
$$

4. Compute the monthly solar fraction:

a) Use:

$$
f_{e, n}=\left\{1+\left(x s_{n} / Q_{e, n}\right)\left[n_{b} S / x s_{n}-1\right]\right\} \cdot Q_{e, n} /[, n=1,2,3
$$

$$
f_{e}=\frac{1}{3} \sum_{n=1}^{3} f_{e, n}
$$




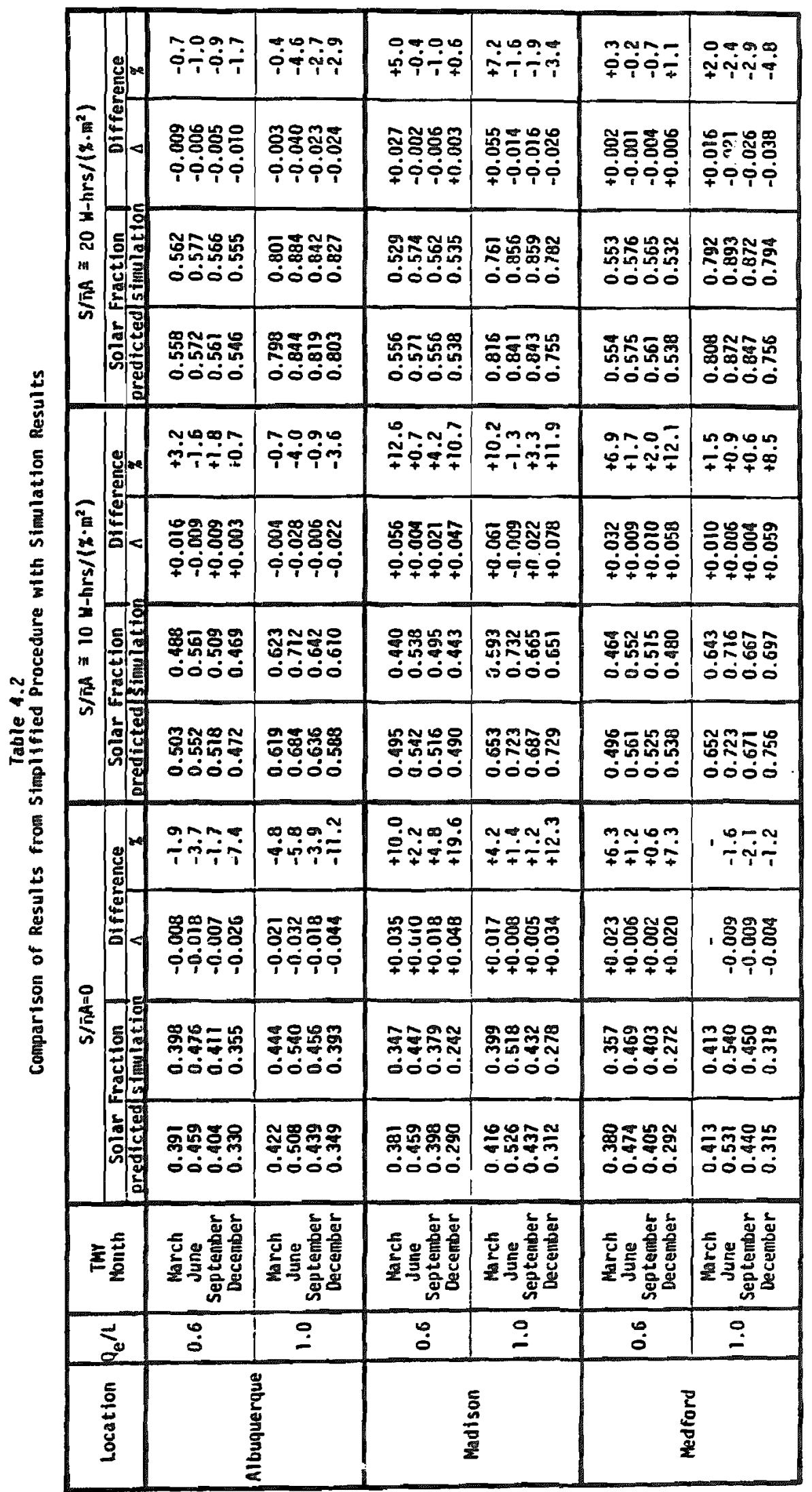




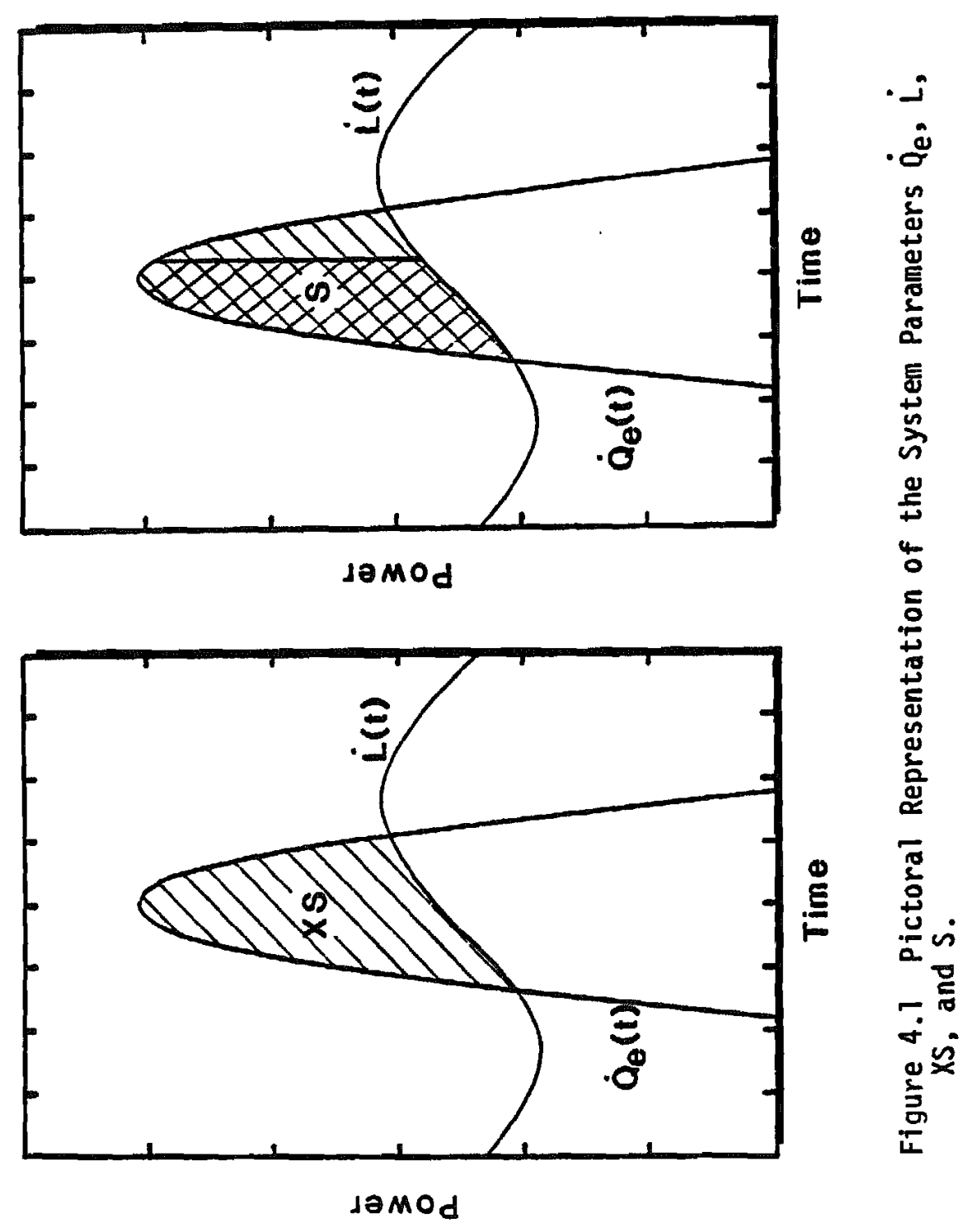




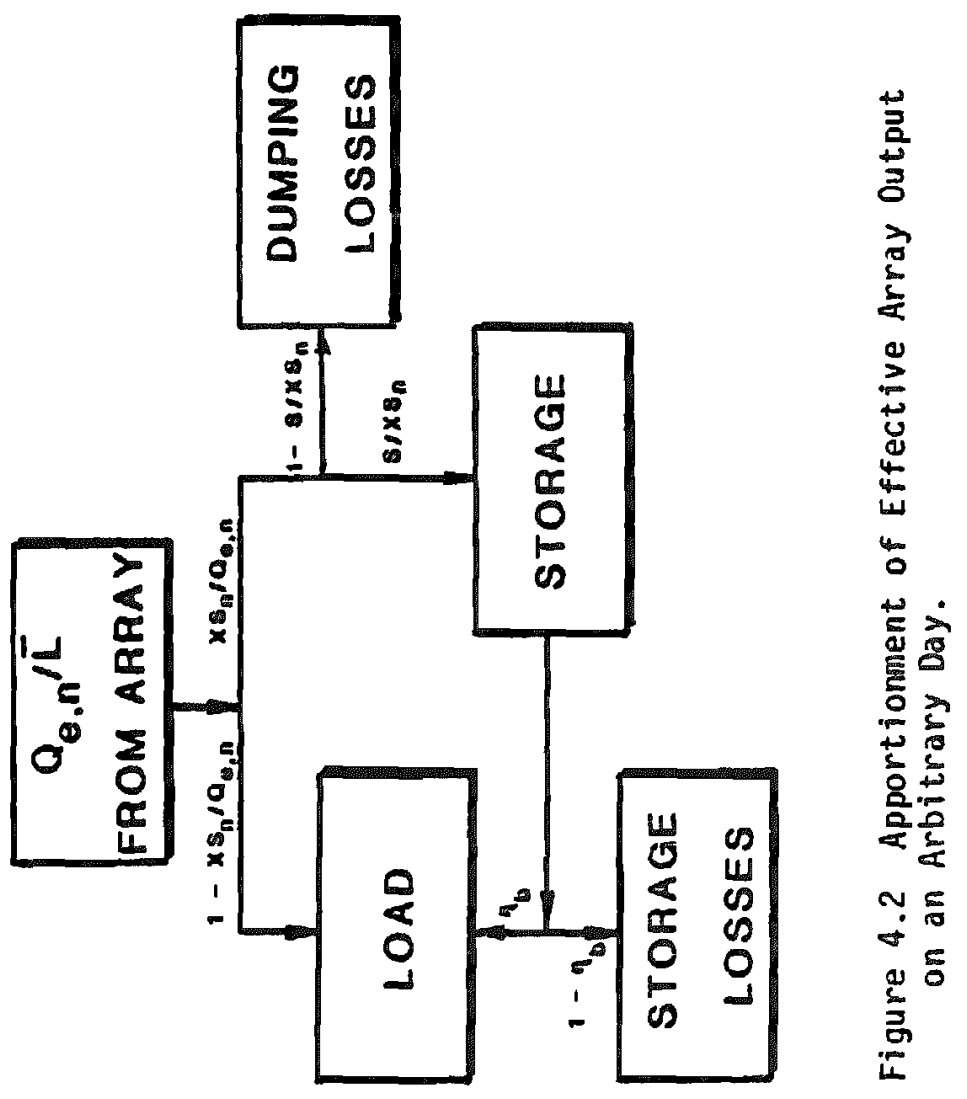




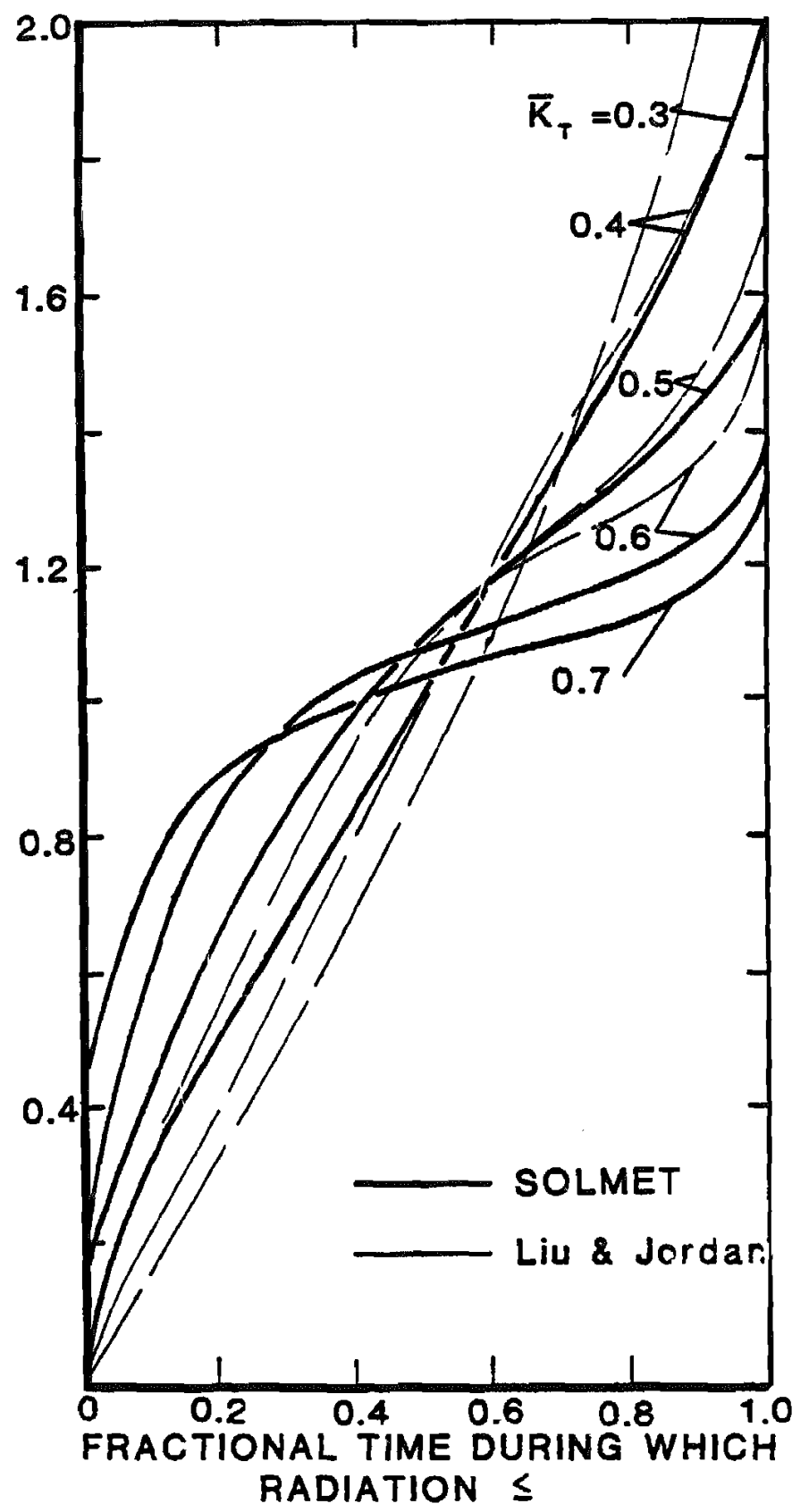

Figure 4.3 Generalized Distribution of Daily Total Radiation oin a Horizontal Surface for various $\bar{K}_{T}$. 


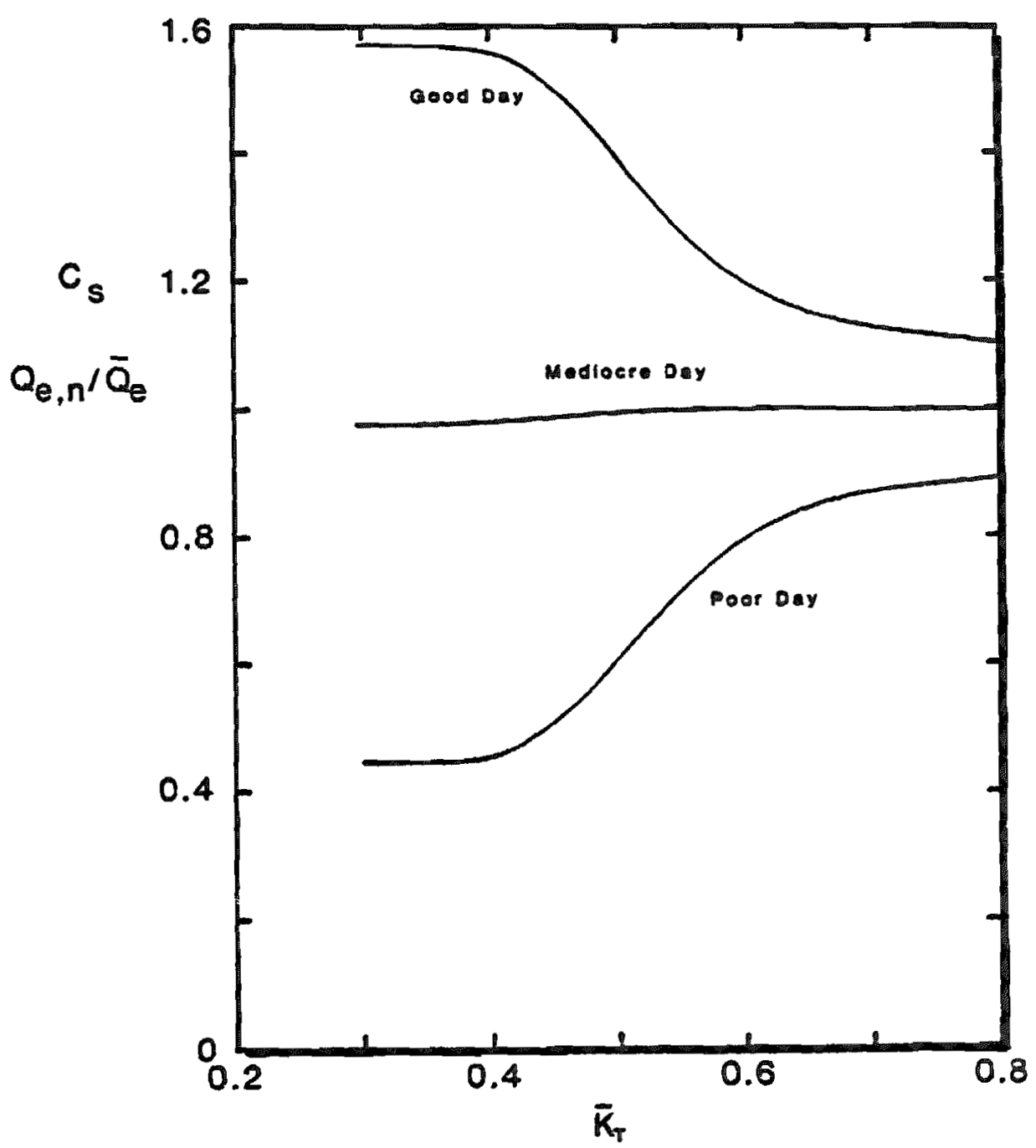

Figure 4.4 Daily Effective Array Output as a Function of $\bar{K}_{T}$ (3-Day Distribution). 


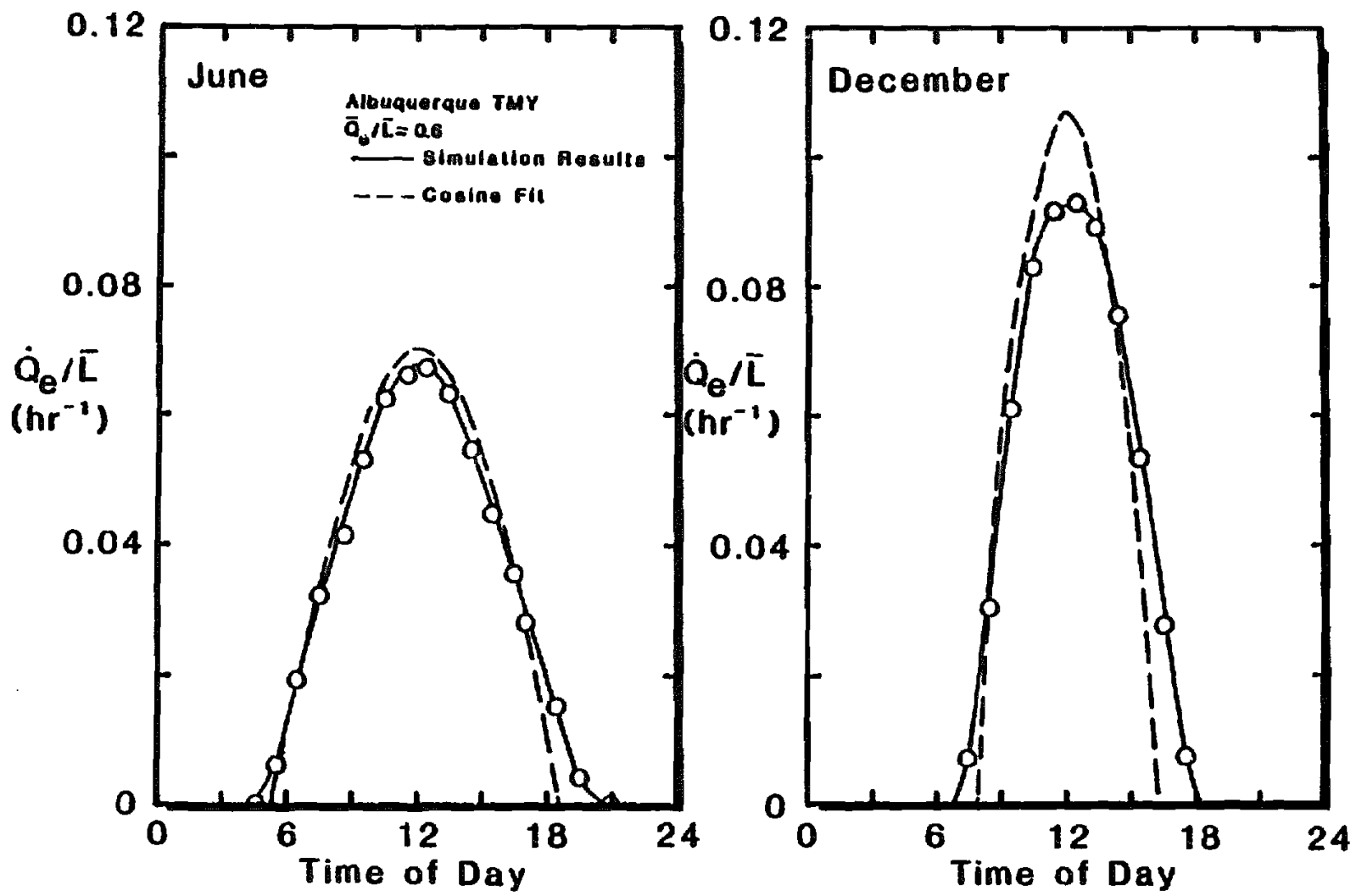

Figure 4.5 Comparison of Simulated Monthly Average Effective Array Output with Cosine Approximation for Albuquerque in June and December. 


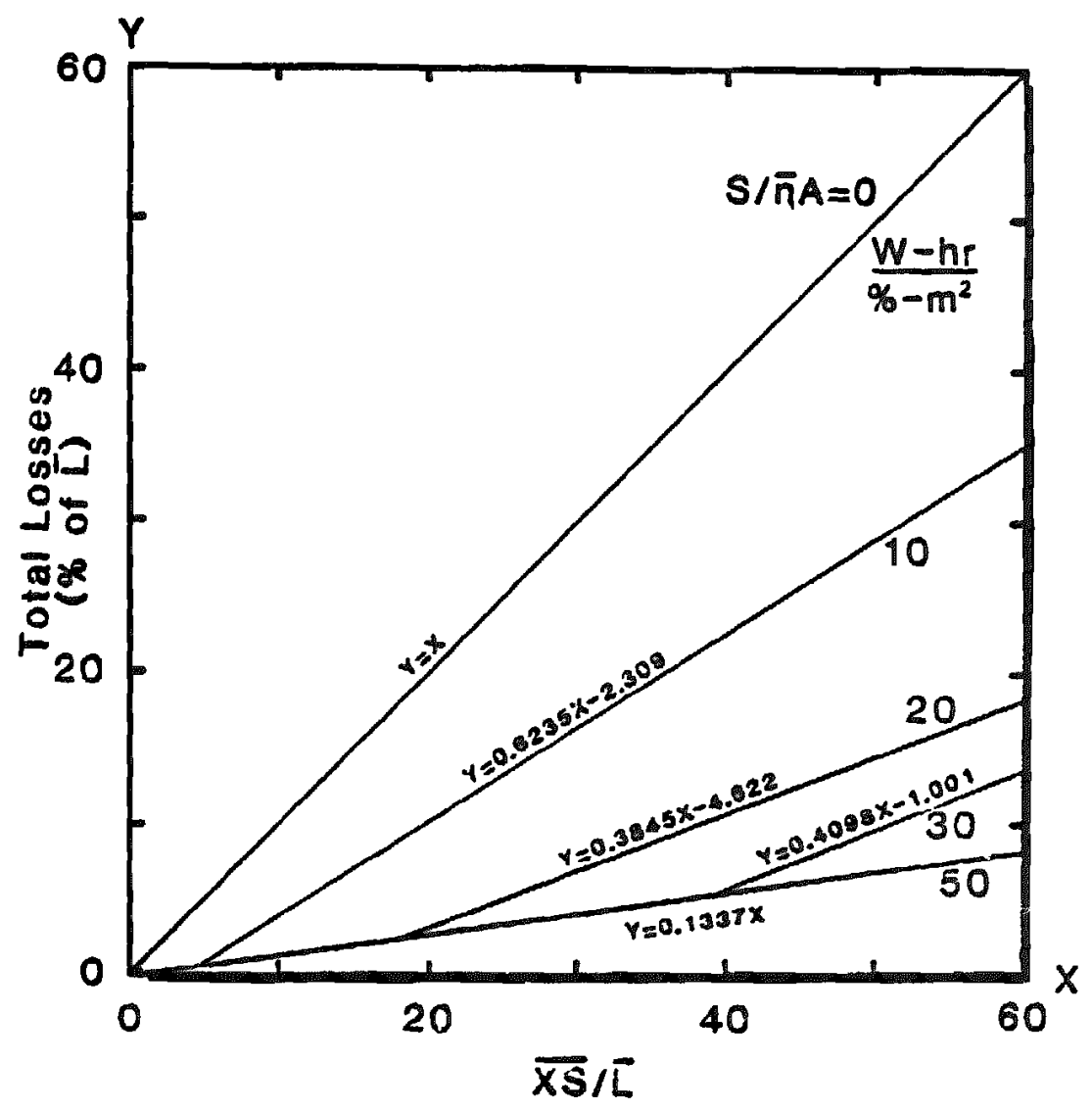

Figure 4.6 Alternative Design Procedure. Linear Least Squares Plots of Simulation Results Showing Total Losses as a Function of Monthly Mean $\overline{X S}$ and the Storage Parameter, S/ $\bar{n} A$. 


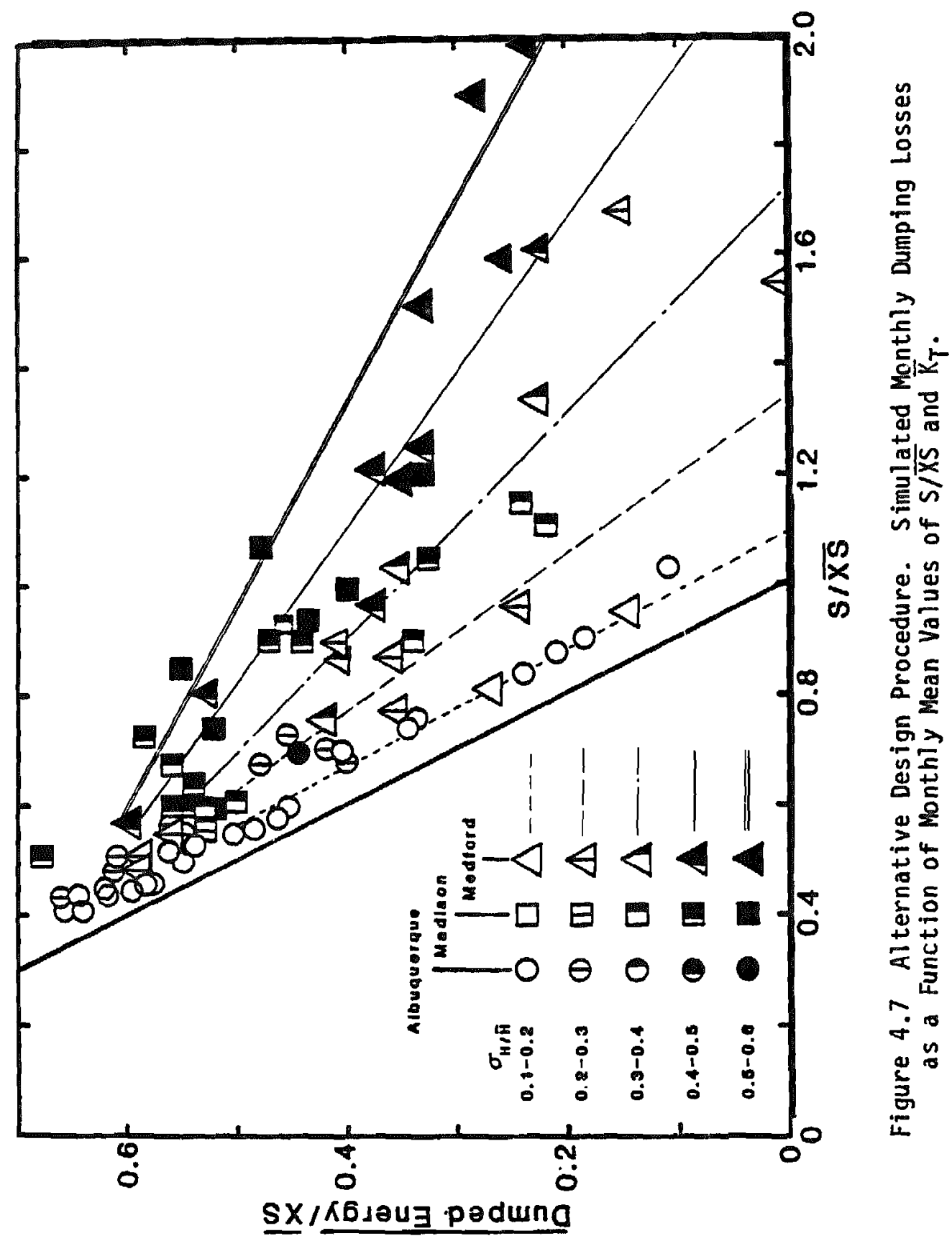


Al1 the simulations mentioned in the previous chapters are of systems operating in the max-power mode in which the voltage imposed on the photovoltaic arrey is dyramically adjusted to give the maximu power output t any given insolation and temperatare. The other mode of operation, to be discussed in this chapter, is called the "clamped-voltage" mode. For systems operating in this mode, the arzay is in parallel with the battery; their voltages are "clamped" to one another. The array voltage can no longer be varied independently of that of the battery in order to obtain the maximun power possible; therefore, the power output in this mode is less than in the max-power mode. Estimation of this reduced power output is the subject of this chapter.

\subsection{Photoroltaic Ce11 and Battery Mode1}

\subsubsection{Photovoltaic Co11 Mode1}

The difficulty eusountered in simulation of the clamped-voltage mode is that electrical power produced by the array is no longer related to the insclation by the simpl: max-power efficiency relationship of eq. (2.4). The conplete current-voltage $(I-V)$ curve and its dependence on insolation and temperature must be expressed in some functional form.

Perhaps the most comon method is to represent the cells as single or multiple diodes in parallel with direct current sources (Ref. 5.1). Although this method is suitable for computer simalation (Ref. 5.2), the equations which ast be solved are too cumbersone for any simplified design.

More reasomable and straightforvard is the set of equations given by: 


$$
\begin{aligned}
& v_{m p}=c_{1}-c_{2}\left(T_{c}-T_{I_{1}}\right)+c_{s} \cdot 10 g_{10} \dot{Q}_{s c} \\
& I_{m p}=c_{s} \cdot \dot{Q}_{s c}+c_{s}\left(T_{c}-T_{I I}\right) \\
& V_{0}=c_{b}\left(T_{c}+T_{I_{2}}\right) \\
& I_{s c}=I_{m p}\left(1+v_{0} / V_{m p}\right) \\
& V_{o c}=V_{m p}+V_{0} 1 n\left(1+V_{m p} / V_{0}\right) \\
& I_{c}=I_{s c}\left\{\left[1-\exp \left[\left(V_{c}-V_{o c}\right) / V_{0}\right]\right]\right.
\end{aligned}
$$

These allow the determination of cell current $\left(I_{c}\right)$, for a given cell voltage $\left(V_{c}\right)$, cell temperature $\left(T_{c}, C\right)$, and insolation $\left(Q_{s c}\right.$, $\left.k W / m^{2}\right)$. Here the constant values of the $C_{i}$ 's and $T_{r i}$ 's are chosen to fit the data for a particular cell. The first two equetions in (5.1) represent reasonable dependencies for the max-power voltage and current (Ref. 5.3), respectively, while the last three equations follow from the work of Lindmayer (Ref. 5.4). The third equation is merely an expression for what is commonly called the thermal voltage.

The work which follows presents some results for two different types of cell I-V carves distinguished as 'CV1'" and 'CV2''. These two cells differ primarily in their fill factor defined as

$$
f f=v_{m p} \cdot I_{m p} /\left(V_{o c} \cdot I_{s c}\right)
$$

The CV1 cell has a poorer fill factor than CV2 which means that it has a less "boxy" I-V curve. The power versus voltage curve is thus a less peaked curve for CV1 than for CV2. This will be apparent in the resnits that follow.

The values of the $C_{i}$ 's and $T_{r i}$ 's for CV1 and CV2 cells are given in Table 5.1. The CVI cells are intended to represent a parículer filat piate celi that may be comerciaily avaíabie. 
The eight parameters for CV2 were chosen by least-squares fitting to duplicate Spectrolab concentrator cells as they had been modeled by the subroutine SOLCEL in TRNSYS-compatible photovoltaic subroutines (Ref. 5.2). The value of $T_{r_{3}}$ so chosen, $291 \mathrm{C}$, is close to the expected theoretical value of 273 $c$, but the former gives a better fit to the empirical data for the Spectrolab/SOLCEL cel1s.

It should be pointed ont that often a designer is nct concernod with individual cell $I-V$ curves but rather array $I-V$ curves. This does not change the approach being described here. $V_{c^{\prime}} I_{c^{\prime}} V_{o c} I_{s c^{\prime}} V_{m p}$, and $I_{m p}$ are then interpreted as array voltages and currents, $Q_{s c}$ becomes insolation on the array and the $c_{i}^{\prime}$ 's take on new values in eqs. (5.1).

\subsubsection{Battery Mode1}

The Hyman or modified-Shepherd battery model has been used here. It is described briefly in Section 2.3 and in more detail in Refs. 5.2 and 5.5 .

\subsection{Dependence of Array Output upon Ratio of Solar Ce11s}

\section{to Battery Ce11s}

If the voltage difference across the terminals of a battery cell were constant, say $v_{b}$, and if the max-power voltage for each photovoltaic cell were fixed at $V_{\text {mp }}$, then the optimum number of solar cells in series per battery cell in series roold simply be

$$
\mathrm{SR}^{*}=\mathrm{V}_{\mathrm{b}} / \mathrm{V}_{\mathrm{mp}}
$$

where $S R$ is referred to as the series ratio and the asterisk denctes the optingm valué. 
In reality, variations with time of the insolation and solar cel1 temperature, upon which $V_{m p}$ depends, and battery state of charge and current, upon which the battery voltage depends, greatly complicate prediction of the optimum series ratio, $S R$. An optimum SR does exist under these conditions, but its deteraination can be difficult.

Selection of a solar cell to battery cell ratio, SR, different from $S R^{*}$ can lead to significant losses in array ontput. These 'mismatch'", losses are clearly depicted in Figs. 5.1 and 5.2 which give results of simnlations for arrays CV1 and CV2 for various values of SR. For these simulations the subrjutine SOLCEL has been altered to use eqs. (5.1).

The data shown in Figs. 5.1 and 5.2 represent monthly results for four months throughout the Albuquerque TMY using the baseline load (See Section 2.1.7 or Fig. 2.2). In these simulations, the array area is fixed, but $L_{0}$ is adjusted from month to month so that $\bar{Q}_{e} / \bar{L}$ is always equal to 0.6 , where $\vec{Q}_{e}$ is $\eta_{p c}$ times_array output for the same system run in the max-power mode. S/nA in these cases is $20 \mathrm{H}-\mathrm{hr} /\left(\mathrm{F}_{\mathrm{B}} \cdot \mathrm{m}^{2}\right)$.

The four short horizontal 1 ines in each of Figs. 5.1 and 5.2 represent the normalized $\bar{Q}_{a e}$ (max-power) values for the four months graphed. The $\vec{Q}_{a e}$ results are independent of the battery and load and consequently are independent of SR.

The axray, battery and load all interact in the battery-clamped mode. Thus, the results are system and load dependent, and the figures indicate the strong variation of $Q_{a e, c v}$ with SR. However, $Q_{a e, c v}{ }^{*}$, the maximum value of $\bar{Q}_{a e, c v^{\prime}}$ is within $2 \%$ of $\bar{Q}_{a e^{\circ}}$

\footnotetext{
The curves in Figs. 5.1 and 5.2 have been normalized with respect to the Inse $\bar{Q}_{a e}$
} 
Figs. 5.1 and 5.2 also show that $\mathrm{SR}^{*}$ (i.e., the $\mathrm{SR}$ corresponding to maximam electrical energy output) varies from month to month due to the different cell operating temperatures and different insolation levels from one ponth to another. Of these two effects, cell operating temperature is the nore significant.

If the system mere wired for best operation in Decerber (i.e., $\mathrm{SR}^{*}=5.3$ for $\mathrm{CV} 1$ or 4.6 for $\mathrm{CV} 2$ ), then mismatch losses would be non-negligible in June (i.e., 6\% loss for CV1 or 9\% loss for CV2). On the other hand, if the system wero arranged to give best performance in June, then mismatch losses would be stall for the other months, including December. This is because: (1) June has the highest value of $\mathrm{SR}^{*}$ (the cells are typically wargest in June and have the lowest $V_{m p}$ ) and (2) the $\bar{Q}_{a, . c v}$ vs $S R$ curves are asyetric, with the $S R>S R$ portions much less steep than tho segments for $S R<S R$.

The computer simulation required for the results in this section can involve considerable expense. For each syster configuration (i.e., array size, battery size, and load) simulations need to be run at a number of $\mathrm{SR}^{\prime} \mathrm{s}$ in order to define performance curves 1 ike those in Figs. 5.1 and 5.2 . in addition to the expense involved in design based upon computer simulation, the difficulty in assembling a TRNSYS data deck, particularly for the inexperienced programer, should not be underestimated.

Sections 5.3 and 5.4 discuss two approaches for estimating system performance which are easier to use than TRNSYS simulations. The non-computer-based approach of Section 5.3 was u1timate1y unsuccessful, but the method of Section 5.4, al though computer-based, yielded high accuracy in preliminarg validation study. 


\subsection{Non-Computer-Based Prediction Method}

5.3.1 Prediction of Performance as a Function of SR for Given $\mathrm{SR}^{*}$

The shapes of the perfozmance curves in Figs. 5.1 and 5.2 are a result of the solar cell I-V curves and their variation with cell temperature and insolation throughout the month. It is not unreasonable to expect, however, that the most important I-V curve is the one corresponding to average midday cell temperature and average midday insolation. Certainly electrical energy production is greatest near midday since that is typically the time of highest insolation. This period of the day would then contribute most significantly to the total electrical energy production for the month. This reasoning then forms the crux of the hypothesis on which the work described in this section is based. Simply stated, the hypothesis is that once $\mathrm{SR}^{*}$ and $\bar{Q}_{a e, c v}$ are known, monthly averago midday temperatures and insolation can be used to determine the performance curve of $Q_{\text {ae,cv }}$ vs SR.

This hypothesis has been validated for 8 different systems (various $\bar{Q}_{e} / \bar{L}, \bar{s} / \overline{\eta A}$ combinations) using CV1 cells and 4 different systems using CV2 cells. The monthly average midday temperature and insolation values are obtained from the results presented in Chapter 3. These are then used in eqs. (5.1) to obtain the midday $I-V$ curve. The following example is included to show both the validity of the hypothesis and all the steps required:

Example: Albuquerque, March TMY

$$
\begin{aligned}
& \mathrm{SR}^{*}=5.6 \text { assumed known (taken from TRNSYS simulations) } \\
& \overline{\mathrm{K}}_{\mathrm{T}}=0.664 \text { (from Harch TMY data) } \\
& \bar{D}=35^{\circ}
\end{aligned}
$$

CV1 ce11s 
Array: Flat-Plate (south facing)

$$
\begin{aligned}
s & =0=35^{\circ} \text { (array tilt equal to latitude) } \\
\tau & =0.88 \\
p & =1 \\
a & =0.77 \\
\mathbf{E}_{e} & =72 \mathrm{~kJ} /\left(\mathrm{hr} \cdot \mathrm{m}^{2} \cdot \mathrm{C}\right)=0.02 \mathrm{~kW} /\left(\mathrm{m}^{2} \cdot \mathrm{C}\right) \\
A_{c+11} & =0.007854 \mathrm{~m}^{2}
\end{aligned}
$$

Middar Insolation (Monthly Average)

Fron Fig. 3.18: $\dot{Q}_{\mathrm{g}}(12)=0.929 \mathrm{~kW} / \mathrm{m}^{2}$

From Table 3.2: $\left(s_{M}-s\right)=\left(s_{M}-0\right)=3^{0}$

Since Fig. 3.18 assumes an optimue tilt, a cosine correction is made to gield the insolation on this non-optimum tilt. The parameters shown in Table 5.1 for the CV1 cel1s produce cell I-V curve as opposed to an array I-V curve. Therefore, the insolation anst be mutiplied by the encapsulant trangmittance before it is used in egs. (5.1). If an array I-V were being studied, $\tau$ would be set to 1.0 .

$$
\dot{Q}_{s c}(12)=\dot{Q}_{S}(12) \cdot \tau \cdot \cos \left(s_{M}-0\right)=0.816 \mathrm{~kW} / \mathrm{m}^{2}
$$

Middsy Cell Tesperature, Voltage and Power (First Iteration) ${ }^{2}$

Frow Fig. 3.68

Then

$$
\mathrm{K}_{e} \overline{\left(\mathrm{T}_{c}-\mathrm{T}_{\mathrm{a}}\right.} /(\alpha \rho)=3.517 \mathrm{MJ} /\left(\mathrm{a}^{2} \cdot \mathrm{h}_{\mathrm{r}}\right)
$$

A1 so

$$
\overline{T_{c}-T_{a}}=3.517 \mathrm{ap} / \mathrm{K}_{e}=37.8 \mathrm{C}
$$

$$
\mathrm{C}_{\mathrm{f}}=\cos \left(\mathrm{s}_{\mathrm{H}}-\Phi\right)=1.0
$$

\footnotetext{
${ }^{2}$ The need for and purpose of iteration is described in Chapter 3
} 
For Albuquerque March TMY

$$
\mathrm{T}_{\mathrm{M}}=6.8 \mathrm{C} \text {. }
$$

Then the monthy average midday cell temperature, $\bar{T}_{c}$ is given by ${ }^{3}:$

$$
\bar{T}_{c}=C_{f} \overline{\left(T_{c}-T_{a}\right)}+T_{M}+3=47.6 \mathrm{C},
$$

For CV1 ce11s, eqs. (5.1) yie1d:

and

$$
\begin{aligned}
& V_{m p}=0.396 \mathrm{~V} \\
& P_{m p}=0.741 \mathrm{~W}
\end{aligned}
$$

$$
\eta=P_{\mathrm{mp}} /\left[\dot{\mathrm{Q}}_{\mathrm{sc}}(12) \cdot \mathrm{A}_{\mathrm{ce} 11}\right]=0.116
$$

Midday Ce11 Temperature, Voltage, and Power (Second Iteration)

$$
\begin{aligned}
& \quad \overline{T_{c}-T_{a}}=3.517 \cdot p(\alpha-\eta) / K_{e}=32.2{ }^{\circ} \mathrm{C} \\
& \bar{T}_{c}=C_{f} \overline{\left(T_{c}-T_{a}\right)}+T_{K}+3=42.0 \mathrm{C} \\
& V_{\text {mp }}=.410 \mathrm{~V} \\
& P_{\text {mp }}=.758 \mathrm{H} .
\end{aligned}
$$

These values of mialay cell temperature and insolation are then used in eqs. (5.1) to obtain the $P-V$ curve shown in Fig. 5.3 .

\footnotetext{
${ }^{3}$ It is assumed here that $\mathrm{T}_{M}+3$ is representative of monthly average midday ambient temperature.

0p. cit. 2 .
} 
The nert step in deriving a $\bar{Q}_{\mathrm{ae}, c v} \mathrm{vS}$. $S R$ curve is to rescale the vertical aris in Fig. 5.3 as is done in Fig. 5.4. Here it is assumed that $\vec{Q}_{a e, c v}$ is directiy proportional to the power output by a single cell at midday on an average day, or

$$
\bar{Q}_{e, c v} / \vec{Q}_{a e, c v} *=P / P_{\text {mp }}
$$

Thus the ordinate in Fig. 5.4 is both the dimensionless midday power ontput and the predicted dimensionless $\bar{Q}_{\mathrm{ae}, \mathrm{cv}}$.

With $V_{m p}$ calculated under average midday couditions, it is assumed that the typical cell voltage at noon is inversely proportional to the series ratio, i.e.

$$
\mathrm{V} / \mathrm{V}_{\mathrm{mp}}=\mathrm{SR} * \mathbf{S R}
$$

or

$$
S R=S R * V \cdot \operatorname{vip}
$$

Eq. (5.6) is used in going from voltage as the abscissa in Fig. 5.3 to SR on the horizontal axis in Fig. 5.4. SR is taken to be 5.6, which simulations found to be the optimum series ratio in March in Albuquerque, for system with $\bar{Q}_{e} / \bar{L}=0.8$ and $S / \eta \bar{A}=20.3$ Whrs $/\left(\% \cdot \mathrm{m}^{2}\right)$.

Replotting to restore a uniform scale on the horizontal aris for the data of Fig. 5.4 gives the dashed performance curve shown in Fig. 5.5. The results of TRSYS simulations are given by the solid curve in the same figure. The two curves are almost identical for $S R>5$.

The change of scale and replotting procedare used in going from Fig. 5.3 to 5.5 clearly shows that: (1) the steep side of the $\bar{Q}_{a e, c v}$ VS SR curve corresponds to the steep side of the $P-V$ soiar celi curve, and ( 2 ) the infiection on the right side of tae 
curve is due to the change of scale on the abscissa from $V$ units to SR units.

Finally, prediction of array output from the dimensionless ordinate in Fig. 5.5 requires knovledge of $\bar{Q}_{2 e, c v} *$ Figs. 5.6 and 5.7 indicate that

$$
\bar{Q}_{\mathrm{ae,cv}} * 0.98 \bar{Q}_{\mathrm{ae}}
$$

If an estimate of $\bar{Q}_{a e}$ is available (e.g, from the procedure of Chapter 3 ), then $\bar{Q}_{a e, c v}$ can be predicted.

The technique described in this section lumps clamped-voltage system considerations, particularly the photovoltaic arraybattery interactions, into the parameter $S^{*}$, the choice of which will be discussed in the next section.

\subsubsection{Prediction of $\mathrm{SR}^{*}$}

In this sub-section a method for predicting the monthly optimum $S R$ is described. It does rot rely on the use of computer calculations, but has been found to be erratic and thus, unreliable. A description of the approach is included here in order to show that a complete, non-computer-based method has been attempted and to justify use of the computer-based method of Section 5.4 .

A simple approach for determining $S^{*}$ would involve the use of eq. (5.3) if an appropriate battery voltage and solar cell max-power voltage could be determined. Since the procedure of Section 5.3.1 worked well using midday I-V curves, a similar approach was attempted here. $V_{m p}$ was chosen in the manner demonstrated in the example of that section. Attempts were then made to determine $V_{b}$ battery voltage, for the monthly average midday conditions. 
Battery voltage at any time of the day depends on the battery charging (or discharging) current and state of charge. (The systems and loads used here typically resulted in battery charging rather than discharging at midday.) $v_{b}$ can thus be determined from estimates of midday values of these quantities. Unfortunately, these are difficult to predict.

A fairly complicated procedure was developed to estimate battery current and state of charge. It first uses the prediction of $P_{m p}$ at noon to give a value of $\dot{Q}_{e}$ at noon and also to generate a cosine curve for $\dot{Q}_{e}(t)$, in a method resembling that of Chapter 4. From these values and $L(t)$, an $X S$ at noon and an integrated $X S$ from sunrise to noon vere determined. Division by the storage capacity and other factors yielded the midday current and state of charge, respectively.

For some systems this approach gave estimates of $\mathrm{V}_{b}$ and thus, $\mathrm{SR}^{*}$ [see eq. (5.3)] which are close to the values from simulation results. However, this is not generally the case: the method is highly erratic.

The difficulty is due to the basic problem of predicting photovoltaic array-battery interactions. Estimating battery behavior is difficult even in the max-power case, when array output is independent of battery fluctuations. In the clamped-voltage mode, prediction is further complicated by the "feedback"' from battery to array. A simplified design procedure akin to those described in Chapters 3 and 4 does not appear to be feasible for estimating performance of clamped-voltage system.

\subsection{Comprter-Based Prediction Method}

The results of the previous section indicate that: (1) a technique capable of handing array-battery interactions is necessary in order to predict clamped-voltage system performance, 
and 2) use of estimates of cell temperature and insolation at noon is justified to a certain extent. These conclusions suggested the development of the computer progran to be described in this section. The program accurately reproduces curves such as those in Figs. 5.1 and 5.2 , but with a rednction in computer time by a factor of about 25 in comparison with TRNSIS simulations. It shonld also be much easier to use in design applications than a detailed program 1 ike TRNSYS.

A flowchart for the new algorithm is given in Fig. 5.8. The program essentially simulates a given clamped-voltage system (fixed array size, battery size, and load) with a given SR during three representative days of a month. As indicated in the figure, the primary inputs are the quantitios $T_{M}, \bar{K}_{T}$, and $\bar{Q}_{s}$, along with the load profile $L(t)$. A listing of the program is not included here since the program is presently not in a state that would allow easy use by others.

The flowchart is explained from the bottom up (from the simple to complex) in the remainder of this section, emphasizing the four concepts embodied in the procedure: (1) sinulation of clamped-voltage system performance during a single day, (2) approximation of daily insolation and PV cell temperature profiles by cosine curves, (3) prediction of the peaks of each of these curves, and (4) representation of day-to-day variations in insolation daring a month by the insolation patterns on three statistically determined days.

Step 4 of the Fig. 5.8 flowchart simulates a day's operation of a clamped-roltage system by the same iterative procedure used in TRNSYS. At each time step, the inputs $T_{c}(t)$ and $\dot{Q}_{s c}()$ enter the CV1 or CV2 cell eqs. (1), thereby fixing a solar cell I-V curve. The program combines this information with value of $\dot{L}(t)$ and with the Hyman model for $V_{b}=V_{b}$ (I,F) to match the array and battery voltages. This process is repeated hourly. 
Because the program need only determine the array output. $Q_{\text {ae,c }}$, it only simulates the daylight, power-producing hours. Cither simplifications mate the program much more tractable and less expensive to ran than a general TRNSYS simulation. For example, it is assumed that the battery rare1y discharges during the daylight hours, so only the charging portion of the Hyman battery model is included in the program.

$T_{c}(t)$ and $\dot{Q}_{s c}(t)$, the functions input to step 4 of the program, are determined in step 3. Estimates of the peak of the insolation, $\dot{Q}_{s c}(12)$, and of the total daily insolation, $Q_{s c}$, specify an insolation cosine curve. An "effective daylength," $t_{D, e}$ is then found. This value plus a prediction of the noontine cell temperature, $T_{c}(12)$, yield a cosine approximation for $T_{c}(t)$.

The only location considered thes far with regard to clamped-voltage system performance is Albuquerque. Based upon TMY data for this city, IRNSYS-generated average daily insolation and temperature profiles for any month are shifted to the right, with their peaks occurring after 12:00 soon. In the case of the insolation, the shift is apparently due to cloud patterns in Albuquerque. The peak of cell temperatnre curves occurs at an even later time becanse of the rise in ambient teuperatare daring the early afternoon.

The phase shift in cell temperature is presently accounted for in the progran only by introduction of a time $1 \mathrm{ag}$ of one-half hour after solar noon in the $T_{c}(t)$ profile. This 30 minute interval approximates the delay found in the monthly outputs of several TRNSYS simulations. The insolation curves have not been shifted.

The peaks of the $T_{c}(t)$ and $Q_{s c}(t)$ profiles are determined in step 2 of the program by the aethod analogors to that of Chaptez 3 and described via the example in Section 5.3 .1 . 
Step 1 also uses previons results to select three values of the insolation multiplier, $C_{s}$. For a given $K_{T}$, the values are read directly off the vertical axis of the three-day insolation distribution, Fig. 4.4. $C_{s}$ then multiplies $\dot{Q}_{s c}(12)$ and $\bar{Q}_{s}$ to give estimated peak and total insolation values on each of three representative days from a given wonth.

The computer program which implements the flowchart of Fig. 6 is structured to ran three times in succession, once for each of the three values of $C_{s}$. The three resulting values of $Q_{a e, c p}$ are then averaged to give $Q_{a e, c v^{*}}$

The entire scheme is repeated for incremental SR to yield predictions of $\bar{Q}_{a e, c v}$ vs. SR such as those shown in Fig. 5.9. Comparison with TRNSYS results demonstrates the high accuracy of the simplified program. Depicted are the results for the months of June and December, but compurably close agreement holds for March and September data as well.

Becanse these studies are only for a certain size system, load profile, and location, the results are only preliminary validations of the simple progran. However, the high accuracy achieved thus far and the apparent adaptability of the program (e.g., for various load distributions) point toward continued atilization of the method and perhaps to its eventual use in actual clamped-roltage system design. 
5.1 H.J. Hove1, Semiconductors and Serimetals, Volume 11, Solar Ce11s, Acedemic Press, New York, NY (1975).

5.2 D.L. Evans, W.A. Facinelli and R.T. Otterbein, 'Combined Photovoltaic/Thermal Systean Studies." Report SAND78-7031. Arizons State University. Tempe, AZ (1978).

5.3 'Solar Ce11 Array Design Handbook, Volue 2," Jet Propulsion Laborntory, Pasadena, CA, (1976).

5.4 J. Lindmager, "Theoretical and Practical Fill Factors in Solar Ce11s," Comsat Technical Review, Vol. 1, No. 2 (1972).

5.5 G.W. Vinal, Storage Batteries, John wiley and Sons, New Iork, NY (1955). 


\section{Table 5.1}

Constants Used in Eqs. 5.1 for Determining I-V Curves

\begin{tabular}{|c|c|c|c|}
\hline \multirow{2}{*}{ CONSTANT } & \multicolumn{2}{|c|}{ Cells } & \multirow{2}{*}{ UNITS } \\
\cline { 2 - 4 } & $\mathrm{CV} 1$ & $\mathrm{CV} 2$ & \\
\hline$C_{1}$ & 0.452 & 0.459 & volts \\
$C_{2}$ & 0.00251 & 0.00236 & vol ts $/{ }^{\circ} \mathrm{C}$ \\
$C_{3}$ & 0.031 & 0.0246 & volts \\
$C_{4}$ & 2.200 & 0.104 & amps $\cdot \mathrm{m}^{2} / \mathrm{kW}$ \\
$C_{5}$ & 0.0038 & -0.00004 & amps $/{ }^{\circ} \mathrm{C}$ \\
$C_{6}$ & 0.0002 & $8.47 \times 10^{-5}$ & volts $/{ }^{\circ} \mathrm{C}$ \\
$T_{r_{1}}$ & 28. & 51.3 & ${ }^{\circ} \mathrm{C}$ \\
$T_{r_{2}}$ & 273. & 291. & ${ }^{\circ} \mathrm{C}$ \\
\hline
\end{tabular}




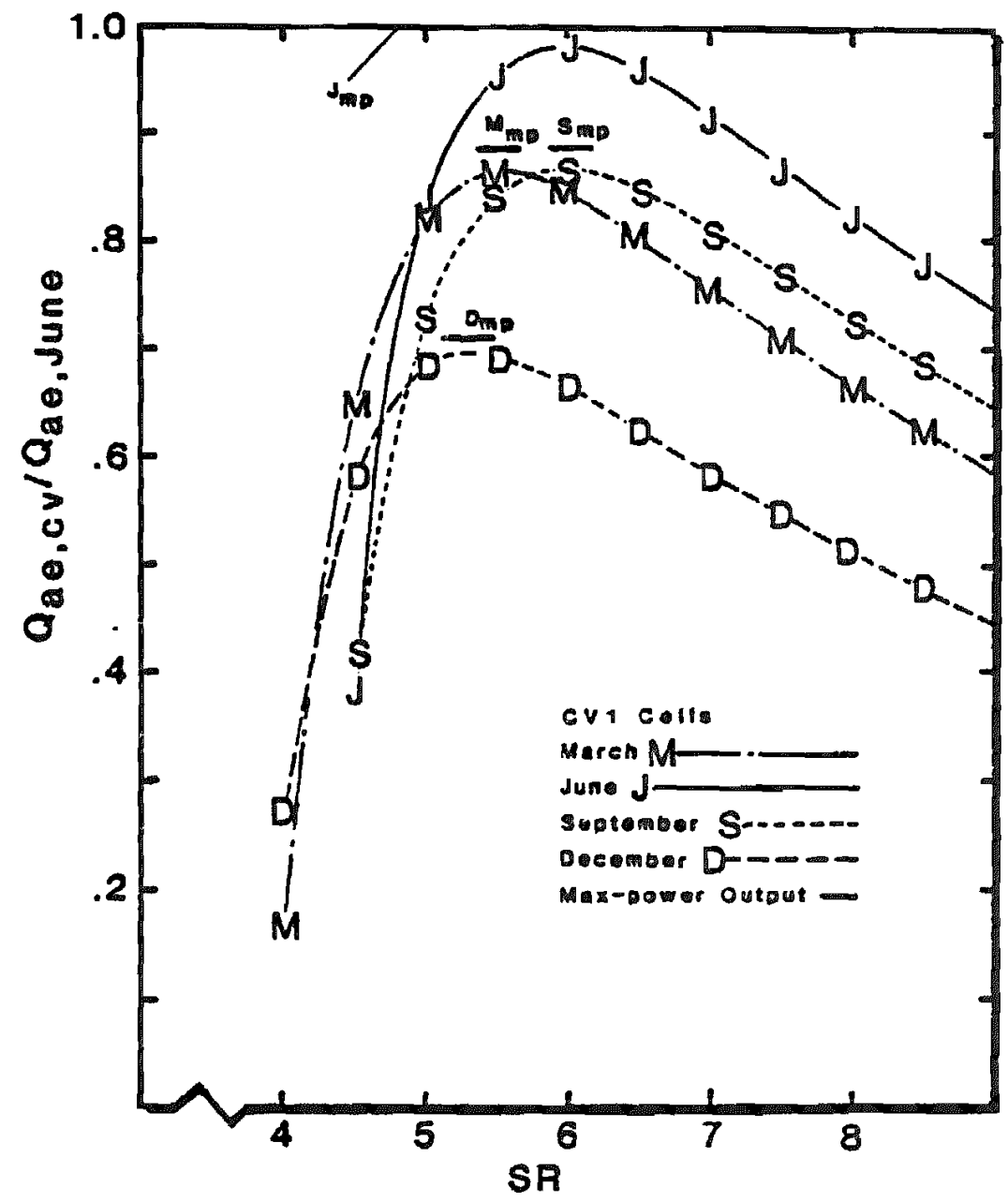

Figure 5.1 Normalized Monthly Performance vs. Series Ratio, CVI Ce1ls, $\bar{Q}_{e} / \bar{L}=0.6, S / \overline{n A}=20 \mathrm{~W}-\mathrm{hrs} /\left({ }^{\circ} \mathrm{m}^{2}\right)$. 


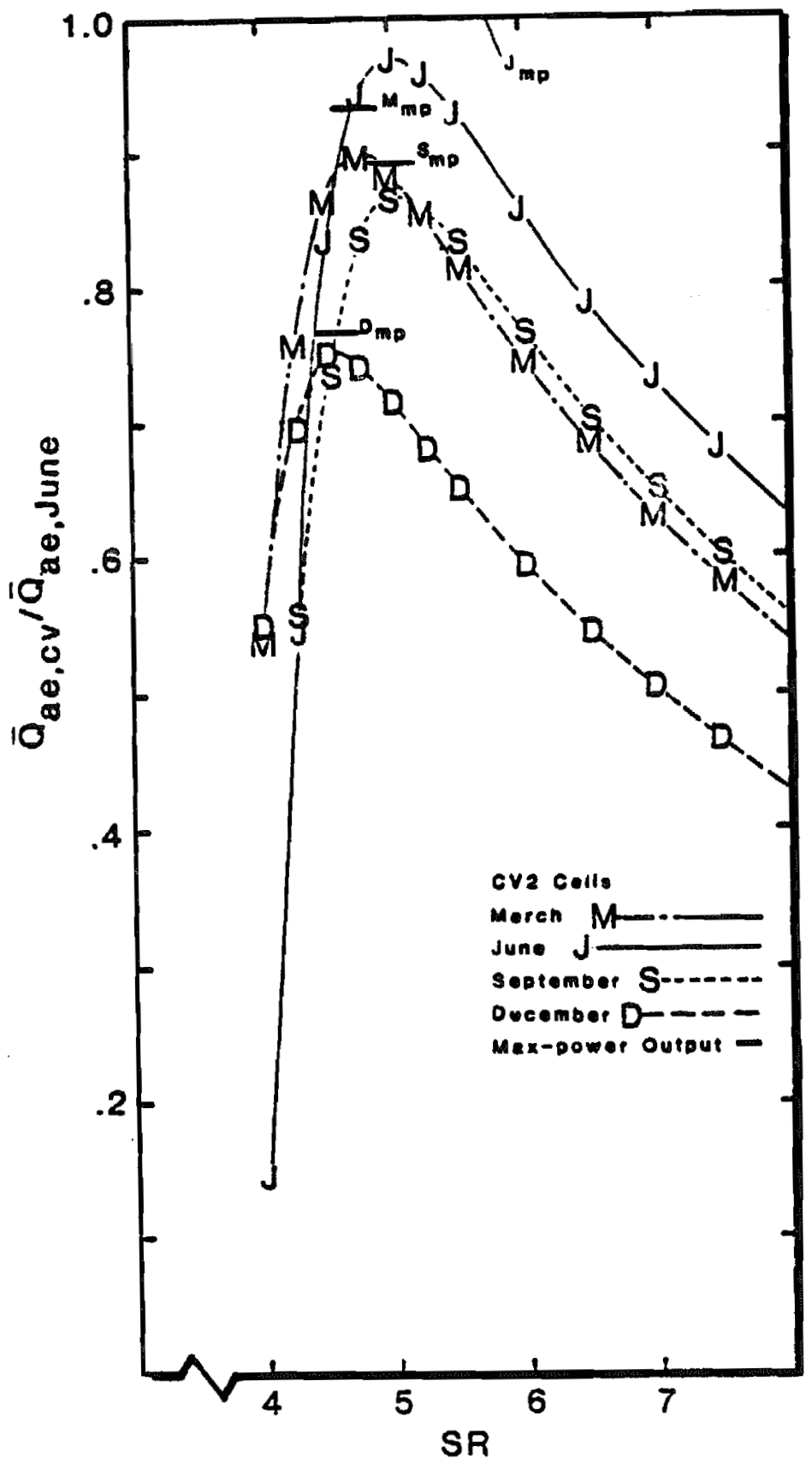

Figure 5.2 Normalized Monthly Performance vs.

Series Ratio, CV2 Cells, $\bar{Q}_{e} / \bar{L}=0.6$, $\mathrm{S} / \overline{\mathrm{n}} \mathrm{A}=20 \mathrm{~W}$-hrs $/\left(\% \mathrm{~m}^{2}\right)$. 


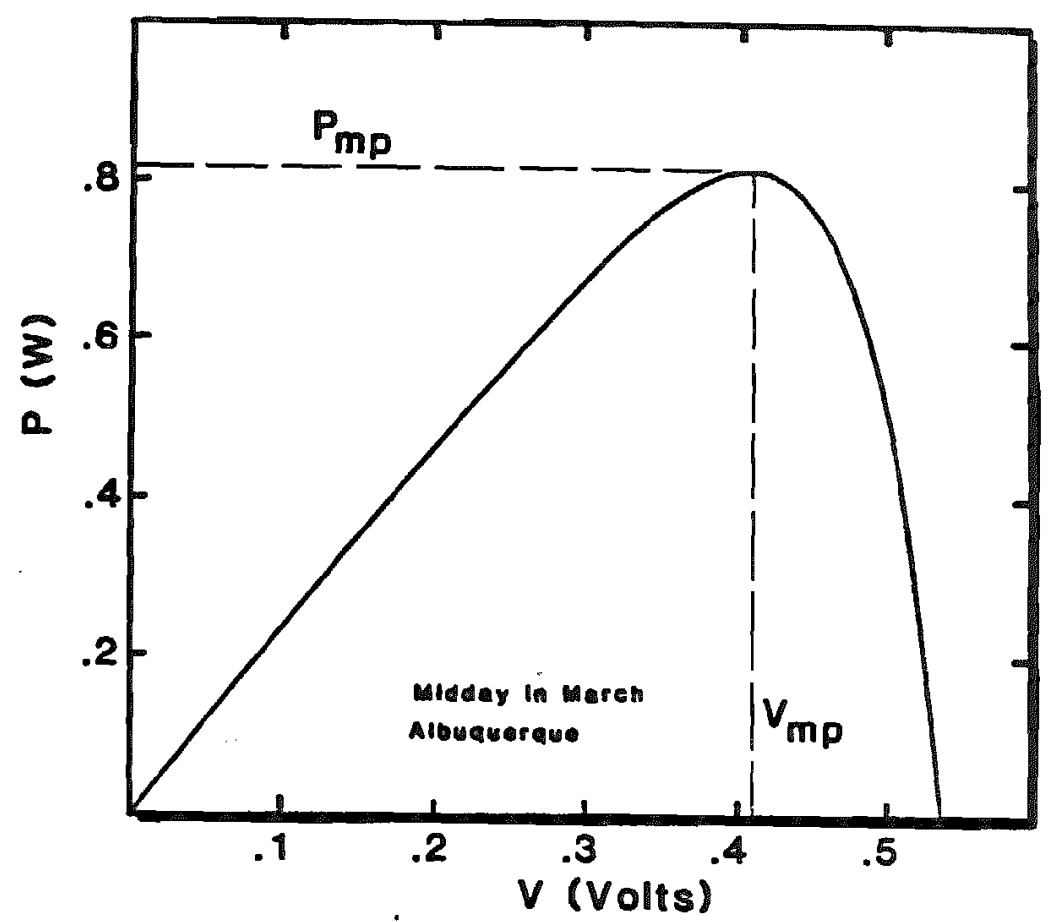

Figure 5.3 Power Output vs. Cell Voltage for a CVI Cell at Midday on an Average March Day in Albuquerque.

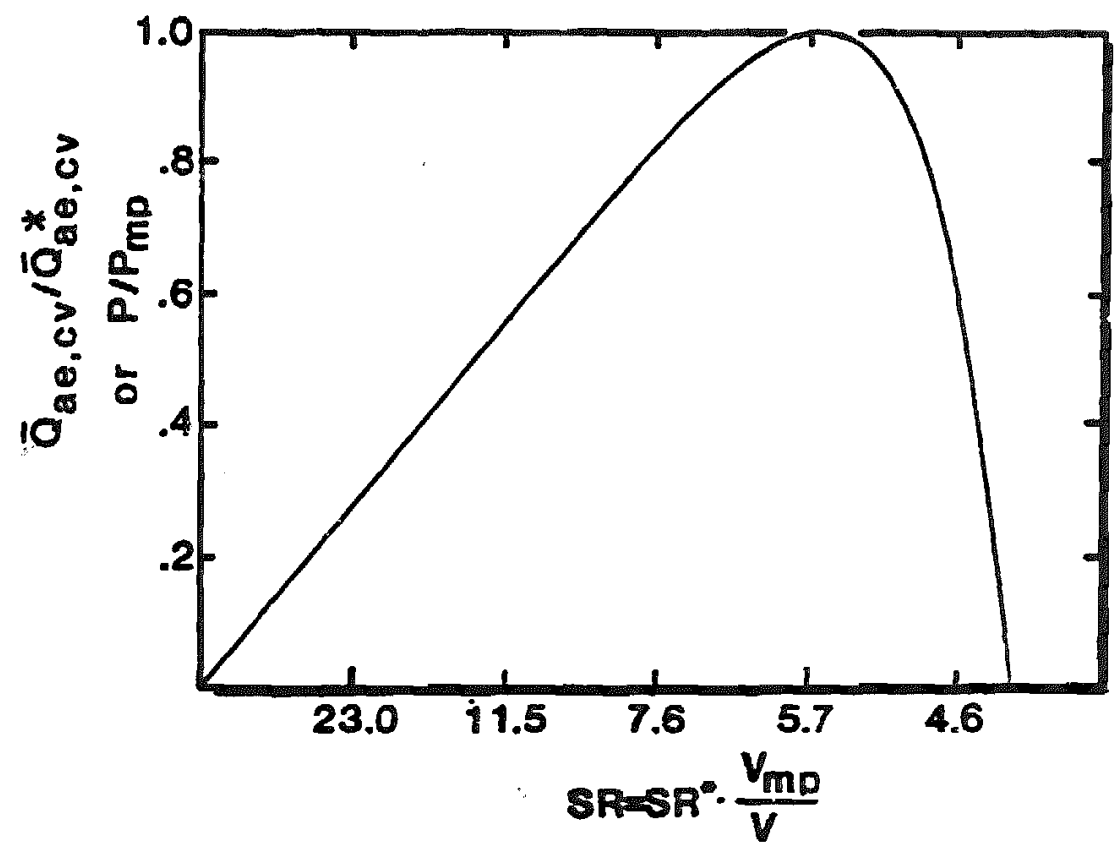

Figure 5.4 Normalized Array Output or Cell Power vs. Series Ratio, Obtained by Rescaling Fig. 5.3 $\left(S R^{*}=5.6\right)$. 


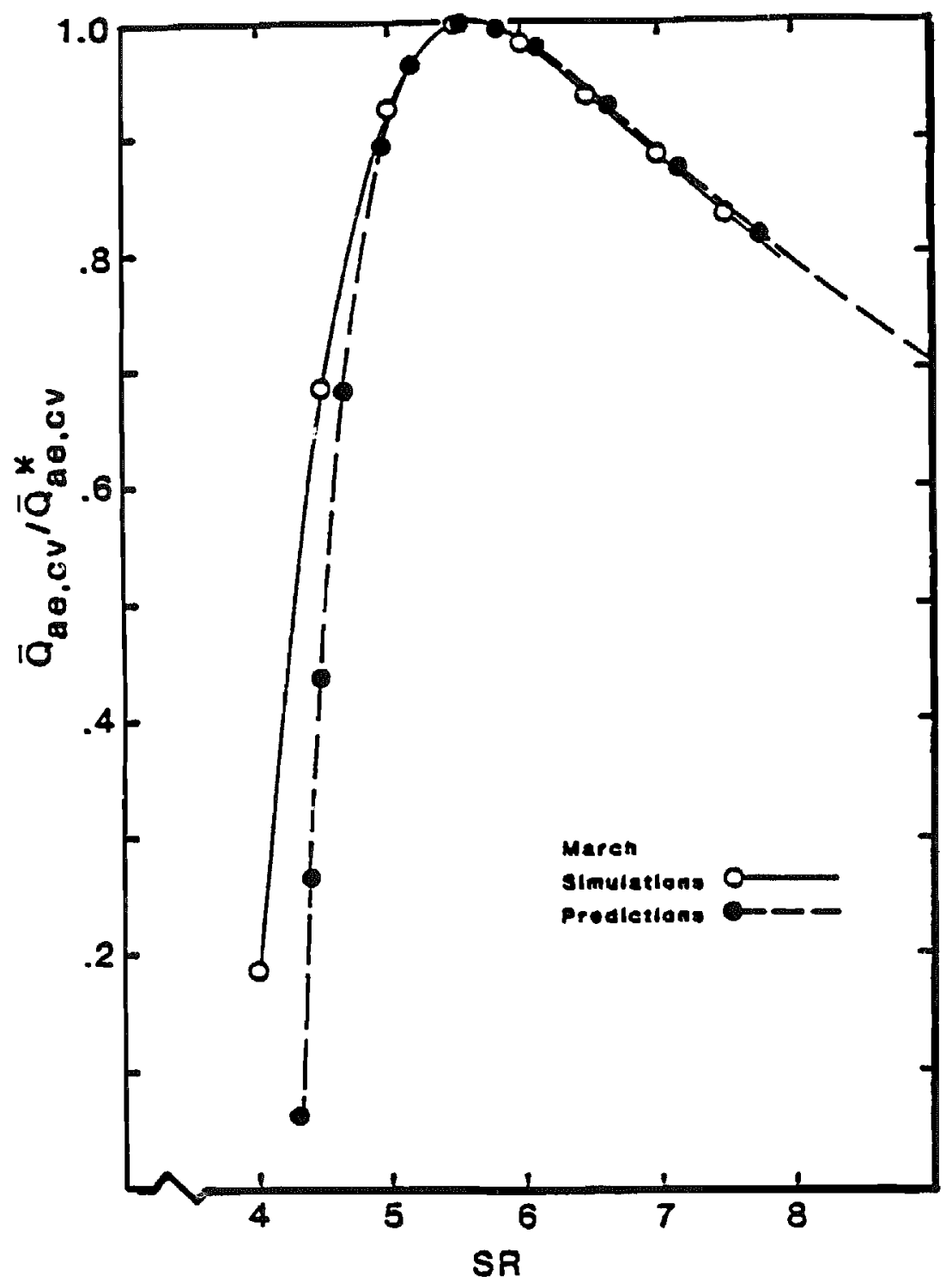

Figure 5.5 Normalized Array Output vs. Series Ratio, from TRNSYS Simulations and from Linearizing the Scale of Fig. 5.4. $\bar{Q}_{e} / \bar{L}=0.8, S / \bar{n} A=20.3$ $\mathrm{W}-\mathrm{hrs} /\left(\% \mathrm{~m}^{2}\right)$ 


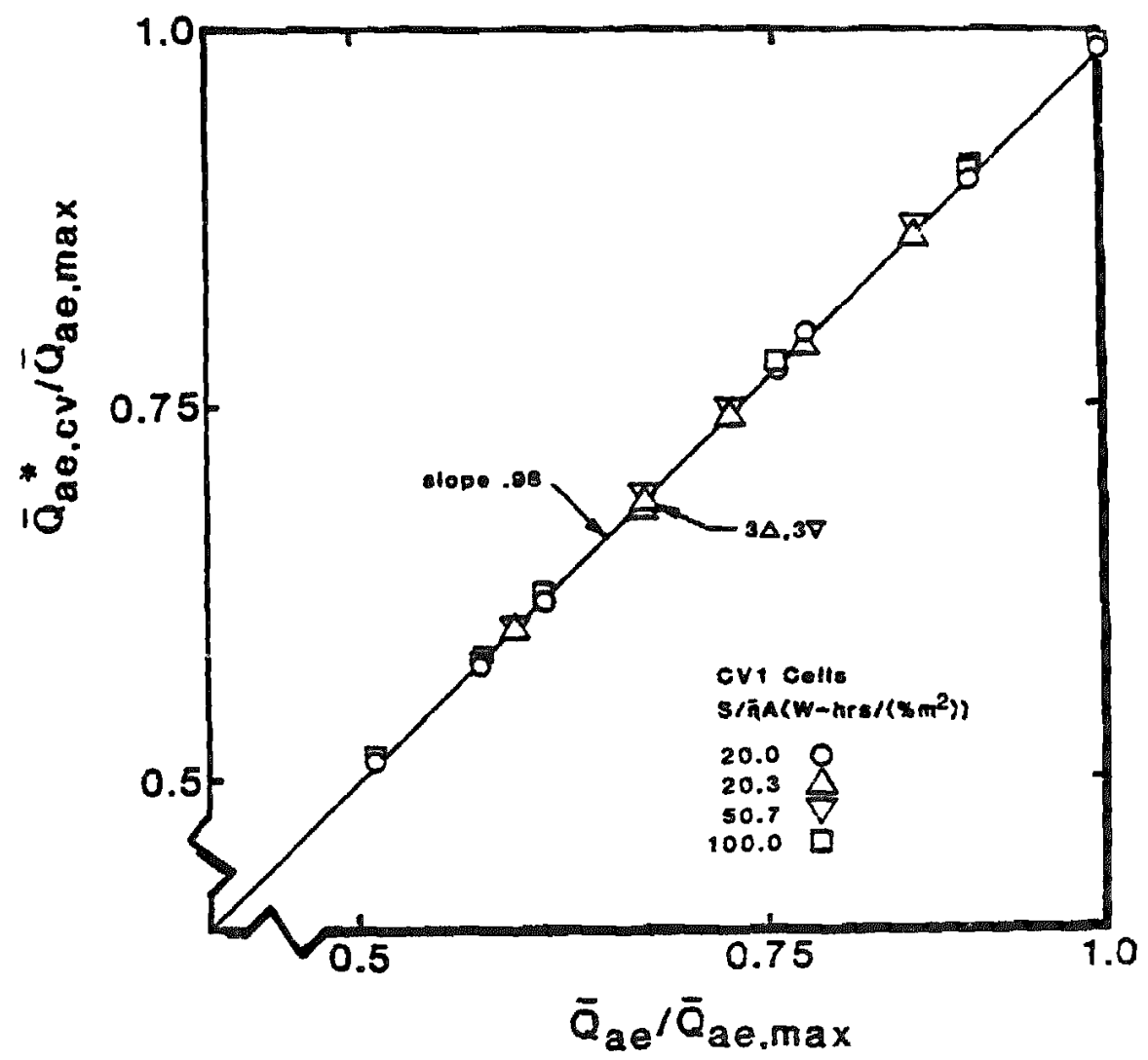

Figure 5.6 Optimum Clamped Voltage Array Output vs. Max-Power Array Output, CVI Cells, Normalized by Maximum $\overline{\mathrm{Q}}_{\mathrm{ae}}$. 


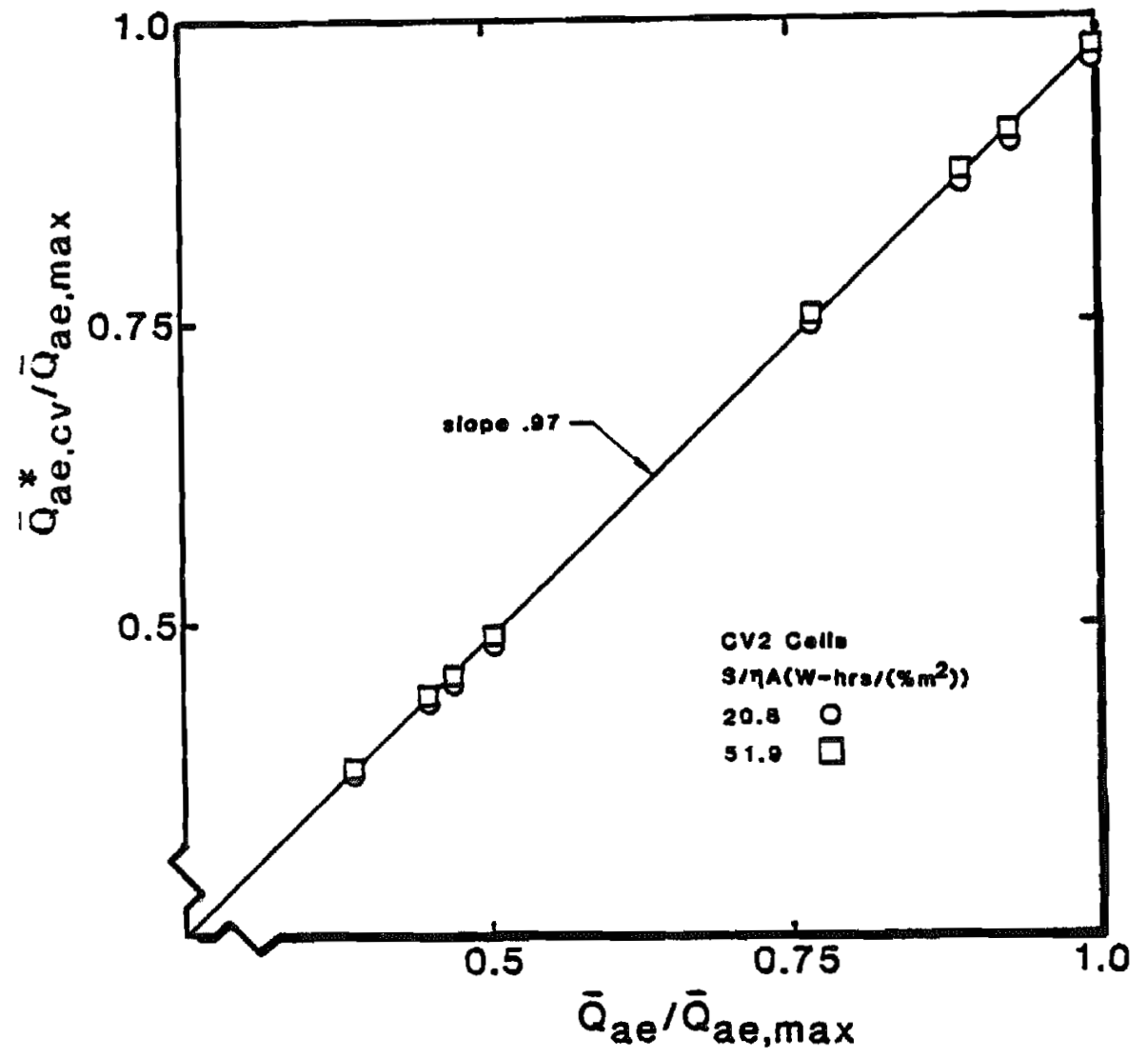

Figure 5.7 Optimum C1amped Voltage Array Output vs. Max-Power Array Output, CV2 Cells, Normalized by Maximum $\bar{Q}_{\mathrm{ae}}$. 


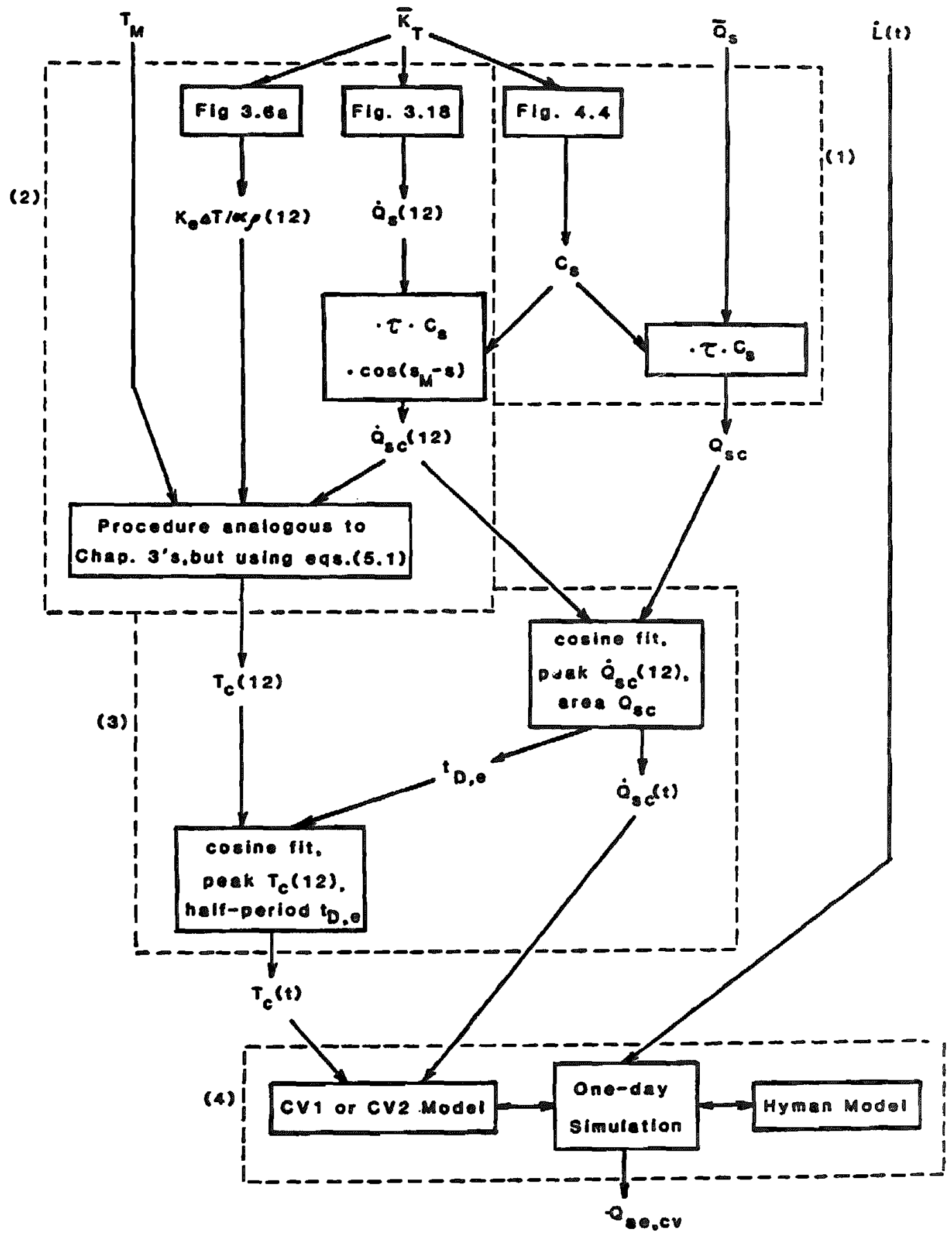

Figure 5.8 Information Flow Diagram of Average-Day Simulation Program for Clamped-Voltage Systems. 


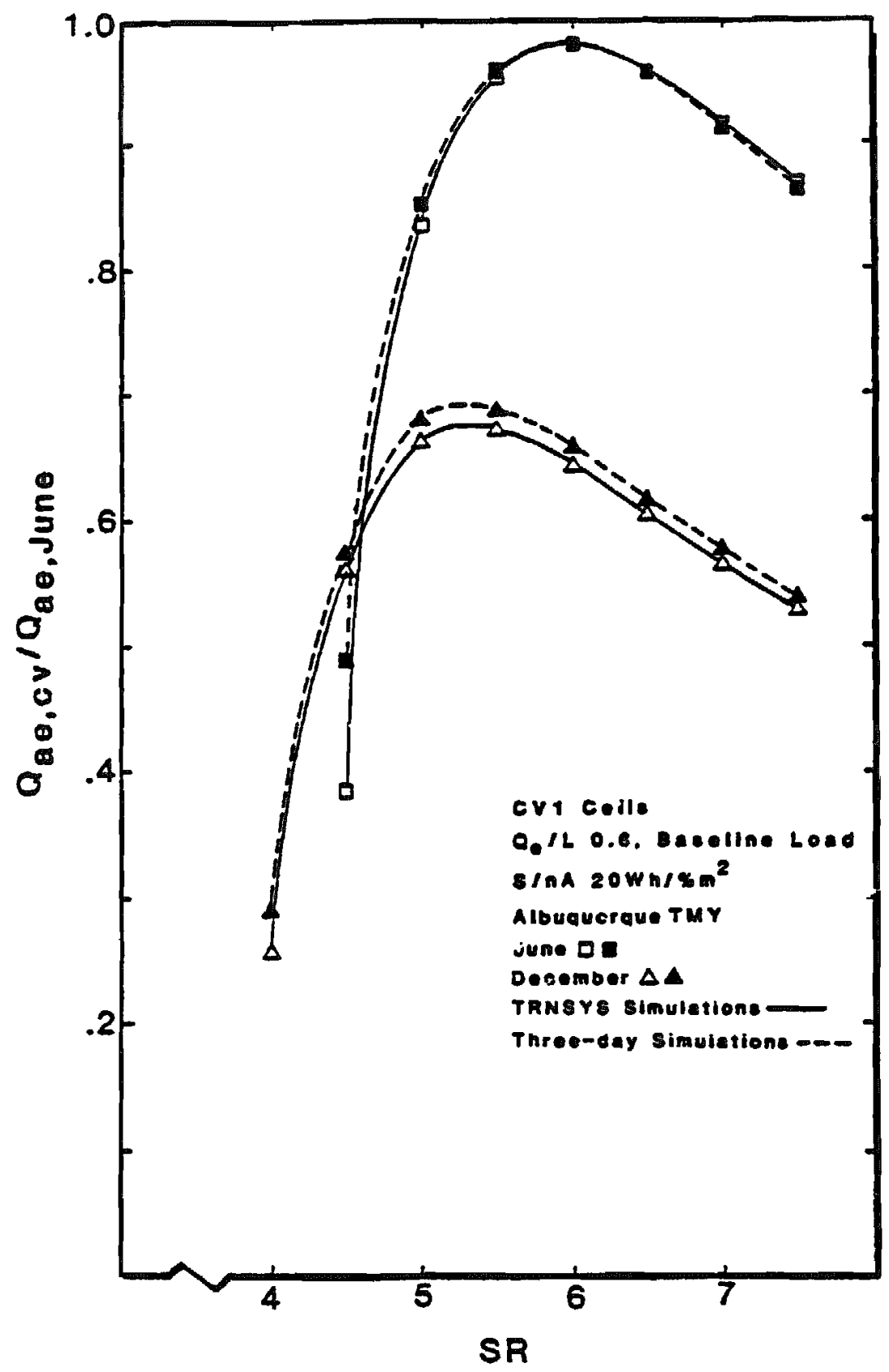

Figure 5.9 Comparison of TRNSYS and Average-Day Progran Simulation Results. 


\subsection{DISCUSSION, CONCLUSIONS AND SUMMARY}

The findings of this stady are reviewed and discassed in the first four sections of this chapter. The last section inciudes an example of array and battery sizing for a PV system in two locations.

\subsection{Simu1ation Results}

The simulation results discussed in Chapter 2 have been found to correlate well using the parameter $\bar{Q}_{e} / \bar{L}$ along with either $\bar{s} \bar{\eta} A$ or $S / \overline{\eta A Q}_{s} \cdot \bar{Q}_{e} / \bar{L}$ is the ratio of monthly average daily array output (multiplied by the power conversion efficiency) to the monthly average daily electrical load. $S / \bar{\eta} A$ is the ratio of storage capacity to effective array area while $S / \bar{\eta} \bar{Q}_{S}$ is the ratio of storage capacity to array output. For a given location, S/AiAQ is a better parameter than S/ nA when array tilt is used to vary the insolation on the array. The parameter $S / \overline{\eta A}$ is very useful when considering optioally tilted arrays or when comparing results for two different locations that have similarly tilted arrays (i.e., tilts that vary from optimu for each location by a fired increment).

For optima11y tilted or similarly tilted arrays, the paramete: S/nA collapses the data for many locations onto nearly single curves for equivalent $\bar{Q}_{\mathrm{e}} / \bar{L}$, a given load shape and equal daylengths. The result is analogons to an f-Chart (Ref. 6.1) and yields the fraction of the electrical load supplied by the PV system as a function of array size and battery size, for a given diurnal load shape and time of year (daylength).

Such an $f_{\text {-Chart shows that storage sizes grater than that }}$ determined from $\mathrm{S} / \pi \mathrm{A} \sim 50 \mathrm{~W}-\mathrm{hrs} /\left(\mathrm{F}^{\circ} \cdot \mathrm{m}^{2}\right)$ do not improve system performance. For example, for $100 \mathrm{~m}^{2}$ of $10 \%$ efficienct array, battery sizes in excess of 50 klthrs world never be warranted, regardless of daylength, geographical location, or, within reason,

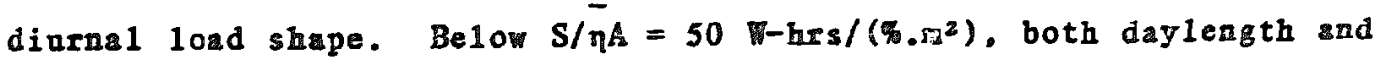
load shape becone inureasingly important in determining $\mathfrak{f}_{e^{*}}$ The knees 
of the $f_{e}$ versus storage curves depend on both $\bar{Q}_{e} / \bar{L}$ and load shape. But, they typically occur in the range of 20 to 30 $W-h r s /\left(\mathscr{F}^{2} \cdot \mathrm{m}^{2}\right)$. These two criteria are nseful design "rules of thumb'" with regard to storage capacity.

The load shape referred to above is the monthly average diurnal shape. Obviously, the better the match between the load and the array output, the higher the solar fraction. However, this study has found that random fluctuations on this load shape have little effect on system performance even for the case of no storage. This information should make simplified design techniques more useful.

Three different battery models were considered in the simulations, but were found to have little effect on overall system performance. Temperature effects were not included in this study, because little data exist on the temperature dependence of battery performance. Available data suggest that batteries which operate in cold environments would have significant decreases in performance.

Although the simulations conducted here (or any finite number of simulations) provide useful insight into system operation and sensitivity and a fer useful "rules of thumb," they do not provide a useful tool to the designer for specific applications. For that purpose one needs a fairly general simplified design technique that can accommodate arbitrary load shapes and daylengths. Such techniques were discussed in Chapters 3,4 and 5 of this report, and are reviewed in the following sections.

\subsection{Simplified Procednre for Predicting Array Outpnt}

A simplified procedure for predicting array monthly electrical output was developed in Chapter 3. It works for flat arrays and 2-D tracked systems which are passively cooled and max-power tracked. The procedure, estimates a monthly average array efficiency which can be multiplied by the monthly array insolation to gield monthly electrical production. 
Input information needed by a designer consists of mean onthy temperature, monthly $\bar{K}_{T}$ values and wind speed data for the intended location of the array, monthly collector tilts (for a flat array) and some reference information on the arrays. This reference information includes a reference efficiency at a reference teaperature and either the thermal conductance between the cells and the ambient or the array NOCT.

The procedare is extremely accurate and easy to use. Although it can be carried out by hand, it can also be programed on a hand-held calcalator for improved ease of use.

Procedures for calculating insolation on the array were not studied bere since both calculation schenes and tabular data are available in the solar field.

\subsection{Max-Power Tracked System Results}

In Chepter 4, a simplified design procedure was developed which estimates monthly overall performance of a PV syster having a passively cooled flat PV array. The procedure considers the effects of limitations in storage capacity (including no storage) and oquivalent "round trip" battery storage efficiencies as they reduce the portion of the array output which eventually reaches the load.

The procedure uses long term distributions of daily insolation of the type first introduced by Lin and Jordan (Ref. 6.2) to obtain an expected distribution of daily array energy production. This distribution, which accounts for the effect of day to day variations on system performance, is used to characterize array performance on three separate days: a good day, a mediocre day and a poor oy. The instantaneous power output of the array is reconstructed through the use of a cosine fit based on daylength and the total array output on each of the three days. 
The daily interaction between the array output and the load can be calculated from knowledge of only a few monthly mean values. The method requires specification of a daily electrical load profile, battery storage capacity and efficiency along with mean monthly daylength, mean monthly array output (from Chapter 3 ), and the $\bar{K}_{T}$ value for the month and location under consideration. It is not restricted to specific load shapes, avoids the need for extensive weather data, and does not require use of a digital computer. It has potential for adoption to hand-held calculators.

Based on comparisons with detailed computer simulation results, the simplified method yields estimates to within a standard deviation of $2.6 \%$ (absolute).

\subsection{Battery or Vo1tage-Clamped System Results}

Photovoltaic array output from a clamped-voltage system can be considerably less than that from a max-power tracked system with an arrey of equal area. Redaced output for the bettery-clamped case results mainly from improper choce of $S R$, the number of solar cells in a series per battery cell in series. However, a clamped-voltage system with optimum series ratio, SR*, can prodnce approximately $98 \%$ of the power output by the same size system operated in the max-power mode. Since the value of SR* varies from month to month, the main thrust of this work was to predict $S^{*}$.

Estimation of $S^{*}$ by means of a simplified design procedure akin to those developed for max-power tracked array and system outputs does not appear to be feasible, because a very simple method cannot reliably predict array-battery interactions. Instead, a computer program has been developed which essentially simuiates the operation of the system daring three representative days in the given month. A value of monthly energy production is obtained for each SR used in the progran. 
The resulting plots of monthly energy production versus $S R$ compare favorably with TRNSYS simulation results in terms of estimates of $\bar{Q}$ ae,c and SR, on the basis of a preliminary validation study. Further testing and development of the program shoold lead to a simple, inexpensive, and accurate method of clamped-voltage system design.

\subsection{A Sizing Example in Phoeniz and Madison}

A comercially available silicon flat array is considered here as an example of using avilable data and selecting system sizes. A sumary of the specifications available in the manufacturer's data is given in Table 6.1.

From items 1 and 2 in Table 6.1 and eq. (3.5), it can be determined that

$$
\beta=0.0039 C^{-1}
$$

Itews 1 and 3 in Table 6.1 and eq. (3.5), along with $\beta$ from above, can be ased to show

$$
\gamma=0.117
$$

Items 1 and 4 in Table 6.1 and eq. (3.5), along with $\beta$ from above, gield

$$
\gamma=0.092
$$

This discrepancy in $\gamma$ results in an extremely small ancertainty in any $\bar{\eta}$ that might be desired. Although $\gamma$ conld be neglected in eq. (3.5) without sigaificant loss of accusacy, the value of 0.117 will be used inere. 
Consider placing these arrays in Phoenix, AZ, and Madison, WI, in order to satisfy $50 \%$ of a September average daily load of 35 kW-hrs/day distributed diurnally much like the beseline load discussed in Section 2.1.7. The arrays are south-facing and tilted at the local latitude (33.40 in Phoenix and $41.9^{\circ}$ in Madison).

There are several combinations of array size and battery capacity which will gield an $f_{e}$ of 0.5 but $\bar{Q}_{e} / \bar{L}=0.6$ and $s / \bar{n}=20$ W-hrs/(\%· $\left.\mathrm{m}^{2}\right)$ will be used here for demonstration (see Fig. 2.7). A straight-through power conversion efficiency $\left(\eta_{p c}\right)$ of $90 \%$ will be considered. The array areas and battery sizes that are necessary in the two chosen locations will be determined.

Phoenix: For September, SOLWET data give a long term $\overline{\mathrm{K}}_{\mathrm{T}}=$ 0.709. Then from Fig. 3.21

$$
\begin{aligned}
\overline{\left(T_{c}-T_{a}\right)}=\left[0.274+1.04 \bar{R}_{T}\right]\left(T_{\text {NOCT }}-T_{a, N O C T}\right) \\
=[0.274+1.04(0.709)](45-20) \\
=25 \mathrm{c} .
\end{aligned}
$$

This value neods no tilt correction since the tilt is nearly optimum for the month and $c_{f} \approx 1.0$.

Also, Fig. 3.8 gives

$$
\overline{\log _{10} Q_{s}}=0.12
$$

For September and Phoenix

$$
T_{M}=31 \mathrm{c} .
$$

Equation (3.23a) now yields 


$$
\begin{aligned}
& \bar{\eta}=\eta_{I}\left\{1-\beta\left[\overline{\left(T_{c}-T_{a}\right)}\right.\right.\left.-\overline{\left(T_{a}-T_{M}\right)}-\left(T_{m}-T_{T}\right)\right] \\
&\left.+\gamma \overline{\log _{20} Q_{s}}\right\} \\
&=0.0992[1-0.0039[(25)-(3)-(31-28)] \\
&+0.117(0.12)]\} \\
&=0.086=8.6 \%
\end{aligned}
$$

SOLMET data also show for a latitude tilt in September

$$
\begin{aligned}
\bar{Q}_{s} & =25.7 \mathrm{HJ} /\left(\mathrm{dag} \cdot \mathrm{m}^{2}\right) \\
& =7.14 \mathrm{~kW}-\mathrm{hrs} /\left(\mathrm{day} \cdot \mathrm{m}^{2}\right) .
\end{aligned}
$$

Thus, to produce a $\bar{Q}_{e} / \vec{L}=0.6$, an array area of

$$
\begin{aligned}
A & =0.6 \bar{L} /\left[\eta_{\mathrm{pc}} \overline{\eta Q_{s}}\right] \\
& =0.6(35) /[0.9(0.086) 7.14] \mathrm{m}^{2} \\
& =38 \mathrm{~m}^{2}
\end{aligned}
$$

would be required. To obtain an $\mathrm{s} / \bar{\eta} \hat{A}=20 \mathrm{~W}-\mathrm{hrs} /\left(\% \cdot \mathrm{m}^{2}\right)$, a storage capacity of

$$
\begin{aligned}
\mathrm{s} & =20 \overline{\eta A} \\
& =\left[20 \mathrm{~W}-\mathrm{hrs} /\left(\overline{\mathrm{m}} \cdot \mathrm{m}^{2}\right)\right](8.58 \%)\left(38 \mathrm{~m}^{2}\right) \\
& =6500 \mathrm{~W}-\mathrm{hrs}
\end{aligned}
$$

would be required. 
Madison: In Madison, for September, $\overline{\mathrm{K}}_{T}=0.509$ and $\mathrm{T}_{M}=15 \mathrm{C}$.

Then

$$
\begin{aligned}
& \overline{\left(T_{c}-T_{a}\right)}=20 \mathrm{c} \\
& \overline{\log _{10} Q_{s}}=0.27 \\
& \bar{\eta}=0.092=9.2 \%
\end{aligned}
$$

Also for a latitude tilt

$$
\begin{aligned}
\bar{Q}_{s} & =17.1 \mathrm{MJ} /\left(\mathrm{day} \cdot \mathrm{m}^{2}\right) \\
& =4.75 \mathrm{~kW}-\mathrm{hrs} /\left(\mathrm{day} \cdot \mathrm{m}^{2}\right)
\end{aligned}
$$

Therefore

$$
A=(0.6)(35) /[0.9(0.092) 4.75] /(0.9)(0.092)(4.75)=53 \mathrm{~m}^{2}
$$

and

$$
\begin{aligned}
S & =20(9.2) \quad(53) \mathbb{W} \text {-hrs } \\
& =9750 \mathrm{~W} \text {-hrs }
\end{aligned}
$$

Norice that, for the same $\bar{Q}_{e} / \bar{L}$, the array area scales inversely with the prodnct of monthly average efficiency and array insolation, since

$$
\bar{\eta}_{\mathrm{Phx}} A_{\mathrm{Phx}} \bar{Q}_{s, \mathrm{Phx}}=\bar{\eta}_{\mathrm{Mad}} A_{\mathrm{Mad}} \bar{Q}_{s, \mathrm{Mad}}
$$

Also note that, for a given S/ $\bar{A} A$, the storage capacity scales with the product of the monthly efficiency and the array area or inversely with the array insolation, since 
or

$$
\mathrm{s}_{\mathrm{Phx}} /\left[\bar{\pi}_{\mathrm{Phx}} A_{\mathrm{Phx}}\right]=\mathrm{s}_{\mathrm{Mad}} /\left[\bar{\eta}_{\mathrm{Mad}} \mathbb{A}_{\mathrm{Mad}}\right]
$$

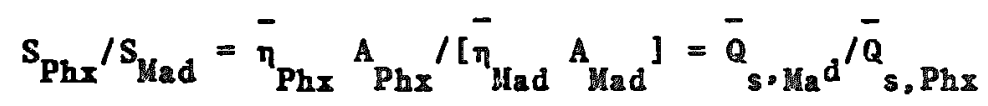

The results of Chapter 2 have been used here to conveniently predict system performance, but the simplified procedure outlined in Chapter 4 coula be used if other months or other load shapes were to be considered. 


\section{CHAPTER 6 REFERENCES}

6.1 W.A. Beckman, S.A. Klein, and J.A. Duffie, Solar Heating Design, Wiley Interscience, New York, NY (1977).

6.2 B.Y.H. Lin and R.C. Jordan, 'The Long-Term Average Performance of Flat-P1ate Solar-Energy Collectors," Solar Energy 2, 53 (1963). 
Table 6.1

Example of Manufacturer's Data

Array Size* $0.403 \mathrm{~m}^{2}$

NOCT (at $\left.0.8 \mathrm{~kW} / \mathrm{m}^{2}\right) * 45^{\circ} \mathrm{C}$

\begin{tabular}{|c|c|c|c|c|}
\hline $\begin{array}{c}\text { Reference } \\
\text { Condition }\end{array}$ & $\begin{array}{c}\text { Cell* } \\
\text { Temp. } \\
{ }^{\circ} \mathrm{C}\end{array}$ & $\begin{array}{c}\text { Insolation* } \\
\mathrm{kW/ \textrm {m } ^ { 2 }}\end{array}$ & $\begin{array}{c}\text { Max-Power* } \\
\text { W } \\
\text { (typical) }\end{array}$ & $\begin{array}{c}\eta^{\dagger} \\
(\%)\end{array}$ \\
\hline 1 & 28 & 1.0 & 40 & 9.92 \\
2 & 50 & 1.0 & 36.6 & 9.08 \\
3 & 45 & 0.8 & 29.9 & 9.15 \\
4 & 65 & 0.8 & 27.4 & 8.40 \\
\hline
\end{tabular}

* Taken from manufacturer's data

+ Calculated from manufacturer's data 


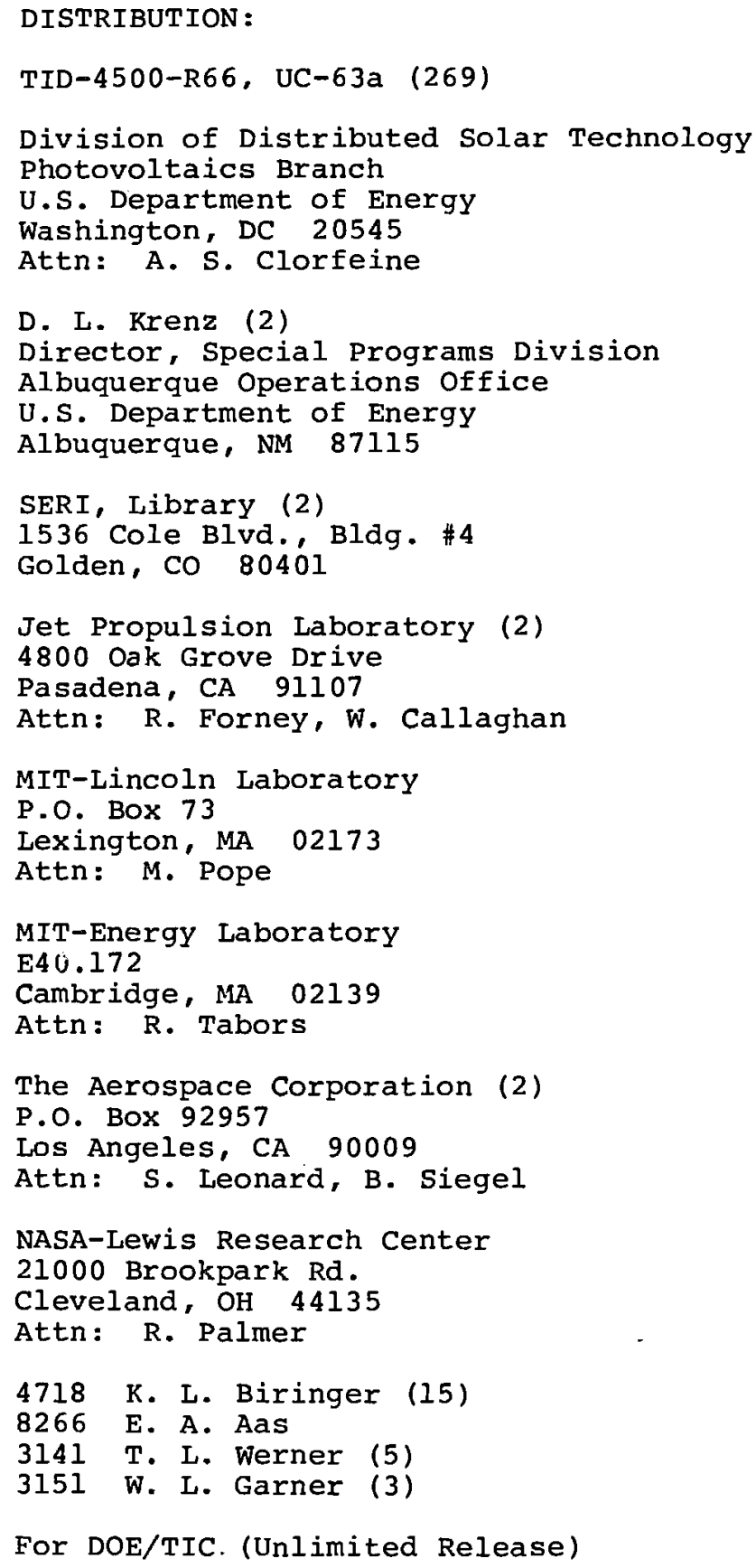

